\title{
Individual lifestyle advice: development, implementation, and evaluation within the Hartslag Limburg cardiovascular prevention project
}

Citation for published version (APA):

Harting, J. (2005). Individual lifestyle advice: development, implementation, and evaluation within the Hartslag Limburg cardiovascular prevention project. [Doctoral Thesis, Maastricht University]. Maastricht University. https://doi.org/10.26481/dis.20050303jh

Document status and date:

Published: 01/01/2005

DOI:

10.26481/dis.20050303jh

Document Version:

Publisher's PDF, also known as Version of record

Please check the document version of this publication:

- A submitted manuscript is the version of the article upon submission and before peer-review. There can be important differences between the submitted version and the official published version of record.

People interested in the research are advised to contact the author for the final version of the publication, or visit the DOI to the publisher's website.

- The final author version and the galley proof are versions of the publication after peer review.

- The final published version features the final layout of the paper including the volume, issue and page numbers.

Link to publication

\footnotetext{
General rights rights.

- You may freely distribute the URL identifying the publication in the public portal. please follow below link for the End User Agreement:

www.umlib.nl/taverne-license

Take down policy

If you believe that this document breaches copyright please contact us at:

repository@maastrichtuniversity.nl

providing details and we will investigate your claim.
}

Copyright and moral rights for the publications made accessible in the public portal are retained by the authors and/or other copyright owners and it is a condition of accessing publications that users recognise and abide by the legal requirements associated with these

- Users may download and print one copy of any publication from the public portal for the purpose of private study or research.

- You may not further distribute the material or use it for any profit-making activity or commercial gain

If the publication is distributed under the terms of Article 25fa of the Dutch Copyright Act, indicated by the "Taverne" license above, 


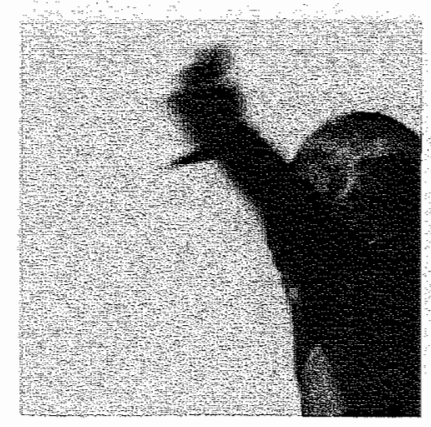

Individual lifestyle advice:

development, implementation, and evaluation within the Hartslag Limburg cardiovascular prevention project 



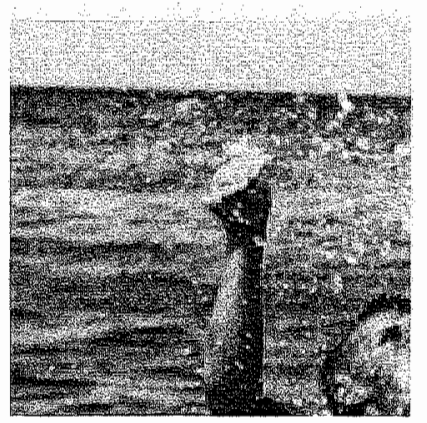

Individual lifestyle advice:

development, implementation, and evaluation

within the Hartslag Limburg cardiovascular prevention project

PROEFSCHRIFT

ter verkrijging van de graad van doctor aan de Universiteit Maastricht; op gezag van de Rector Magnificus, Prof. mr. G.P.M.F. Mols volgens het besluit van het College van Decanen in het openboar te verdedigen op donderdag 3 maart 2005 om 14:00 uur

door

Janneke Harting 
Promotor

Prof. dr. N.K. de Vries

Co-promotor

Dr. P. van Assema

\author{
Beoordelingscommissie \\ Prof. dr. H.W. van den Borne (voorzitter) \\ Prof. dr. J.M. Bensing (Universiteit Utrecht) \\ Prof. dr. H.J.G.M. Crijns \\ Prof, dr. G.J. Kok \\ Prof. dr. C. Spreeuwenberg
}

\title{
Colofon \\ Foto omslag: Hanneke Roeper \\ Lay-out: Nora Oosting en Leo Zander, Maastricht \\ Druk: PrintPartners Ipskamp
}

ISBN $90-808752-2-8$

The studies presented in this dissertation were conducted under the auspices of the Care and Public Health Research Institute (Caphri) in the Faculty of Health Sciences of Maastricht University. Caphri is part of the Netherlands School of Primary Care Research ( $\mathrm{CaRe}$ ) which has been acknowledged since 1995 by The Royal Netherlands Academy of Art and Science (KNAW).

The lifestyle advice intervention and evaluation studies described in this thesis were supported by a grant of the Netherlands Heart Foundation. Financial support by the Netherlands Heart Foundation for the publication of this thesis is gratefully acknowledged. 

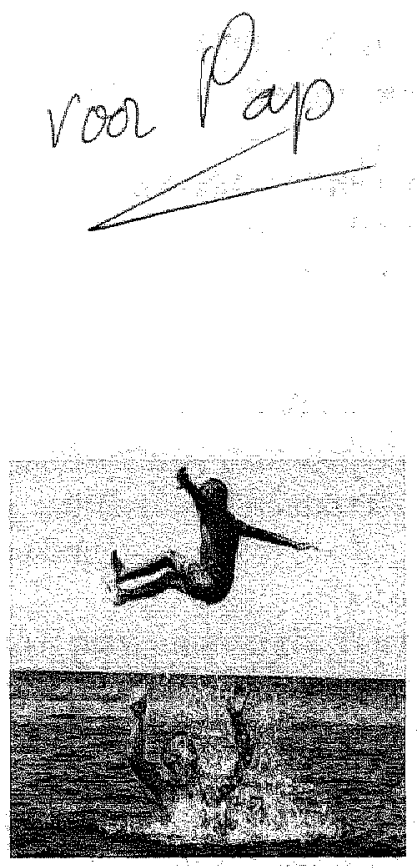
$\therefore$

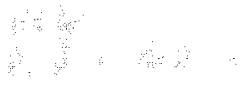

$\because$

$+\quad \therefore \quad$

$\therefore \quad \therefore \quad \therefore \quad \cdots$
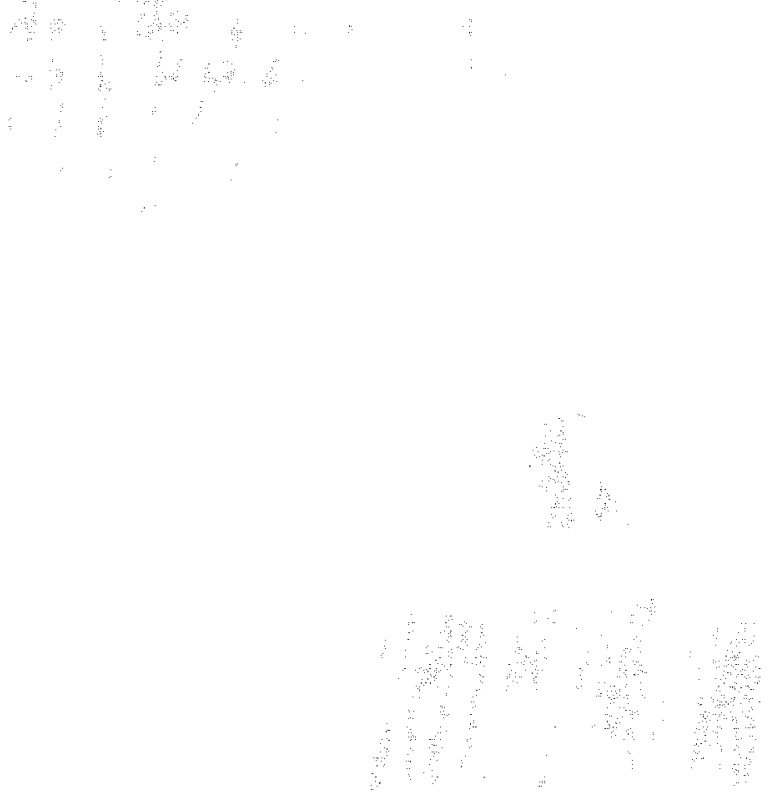


\section{CONTENTS}

Chapter 1 General introduction

Chapter 2 The stage-matched health counseling model of

Hartslag Limburg: a six-step approach

Chapter 3 Quality assessment of health counseling: performance

of health advisors in cardiovascular prevention

Chapter 4 Patients' opinions on health counseling in the

Hartslag Limburg cardiovascular prevention project:

perceived quality, satisfaction, normative concerns, and behavior related outcomes

Chapter 5 Health advisors: the more professional, the more effective? An exploratory path analysis of factors determining satisfaction with and effectiveness of health counseling

Chapter 6 Cardiovascular prevention in the Hartslag Limburg project: effects of health counseling on behavioral risk factors in a cardiology outpatient population

Chapter 7 Cardiovascular prevention in the Hartslag Limburg project: effects of a high-risk approach on behavioral risk factors in a general practice population

Chapter 8 Post-trial implementation of the health counseling component of the Hartslag Limburg cardiovascular prevention project

Chapter 9 General discussion

References

Summary

Samenvatting

Mijn dank 
$\because \quad \because \quad \because$

:

$\therefore$

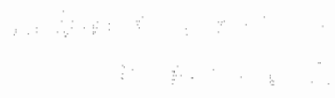

$\therefore \quad \therefore \quad$

..

$\therefore$

$\because$

$\therefore$

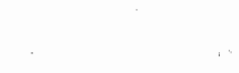

‥

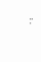

$\therefore$

$\therefore$ 
CHAPTER I

General introduction 
This thesis concerns the development, implementation, and evaluation of an individual lifestyle advice intervention that formed part of the Hartslag. Limburg cardiovascular prevention project. Although much of the Hartslag Limburg project is still continuing, the present report focuses on the first few years after implementation. By way of introduction, this chapter briefly describes the overall Hartslag Limburg project, the individual lifestyle advice, and the design for the evaluation study that accompanied the intervention. The chapter concludes with a brief ontline of the thesis.

\section{HARTSLAG LIMBURG: BRIEF OVERVIEW}

Hartslag Limburg, Dutch for Heartbeat Limburg, was (and still is) a regional project aimed at the prevention of cardiovascular disease (CVD) in the southern part of the Dutch province of Limburg (Ruland et al., 1999). The Hartslag Limburg project consisted of a community project and a high-risk project. The community project was targeted at all 180,000 inhabitants of the town of Maastricht and four of its neighboring municipalities: Meerssen, Margraten, Valkenburg, and Eijsder. This community part was aimed at providing health promoting facilities in the local setting, with and for the population, at encouraging citizens to make use of these opportunities, and at sustaining the supply of such facilities by propagating a health-promoting policy. The high-risk approach of Hartslag Limburg focused on individuals who were at elevated risk of developing CVD. These high-risk individuals were invited to participate in the project in two health care settings: (1) the cardiology outpatient clinic of the University Hospital Mastricht and (2) several general practices from the city of Maastricht and its region. After giving their informed consent, the highrisk patients underwent either a routine or an incidental health check by their general practitioner (GP) or cardiologist. Based on the patient's cardiovascular risk profile, medical treatment could be optimized and health counseling was offered to discuss cardiovascular risk behaviors and possible lifestyle changes leading to a healthier life.

The Hartslag Limburg project started in 1998. It was the result of a joint approach by several collaborating partners. The main funding organization was the Netherlands Heart Foundation (NHS). The project management and project coordination were handled by the Regional Public Health Institute Maastricht (GGD-zzl). In the community project, the other partners were the five municipal authorities, community social work organizations, community health care organizations, local organizations and community representatives, which collaborated in several health committees. In the high-risk proj- 
ect, the other participants were severd cardiologists of the University Hospital Maastricht (azM), several regional GPs, and four so-called health advisors, occupying a newly created position in the Dutch health care system. In the overall Hartslag Limburg project, five departments of Maastricht University were also inwolved.

Hartslag Limburg has been subjected to several evaluation studies, namely, a process and effect evaluation of the community project (Ronda, 2003), a process evaluation of the high-risk project, three effect evaluations of the high-risk project (relating to the behavioral level, the biomedical, morbidity and mortality level, and the quality of life and consumption of care level), and a nomative as well as a managerial evaluation of the complete prevention project. Because of its comprehensive and thorough approach, in 2001, Hartslag Limburg as a whole was selected as one of the twelve WHO "Towards Unity for Health" demonstration projects (Boelen, 2001).

The focus of this thesis is on the high-risk project of Hartslag Limburg, more specifically, on the process evaluation of this approach, as well as on the evaluation of its effects on cardiowascular risk behaviors and the determinants of these behaviors.

\section{RATIONALE BEHIND HARTSLAG LIMBURG}

Cardiovascular discases (CVD) are among the main global public health problems (Pyöräa, De Backer, Graham, Poole-Wilson, \& Wood, 1994; Rose, 1992). In the Netherlands, CVD caused $34.7 \%$ of all deaths between 1999 and 2001 , making them the leading cause of mortality and premature dear 1 s (RIVM, 2002, 2003). At the start of the project, CVD prevalenee and nortality were relatively high in the southern part of the province of Limburg, and behavior related cardiovascular risk factors, such as obesiry and smoking, were over-represented among its residents compared to other parts of rhe Netherlands (GGD, 1999). "These epidemiological data formed the starting point for Hartslag Limburg (Ruland et al., 1999).

As recommended (Rose, 1992), Hartslag Limburg combined a community-based intervention with an individual approach. An indridual strategy is expected to produce substantial risk reductions in a relatively small number of people, whereas a community strategy is expected to produce small benefits. for the individual, but, as a great many people are involved, to have a substantial impact on the total burden of disease at population level. Both strategies are interactive and mutually supportive, and should be seen as two components of a single preventive approach. A combined approach is further legitimated by the fact that CVD are common even among people with low risk scores (Rose, 1992). 
In individual cardiovascular prevention strategies, priority should be given to patients with established CVD or healthy individuals who are at high risk of developing CVD, as these patient categories are assumed to profit most (Rose, 1992; D. Wood et al.s 1998). Reducing biomedical risk factors, such as high blood pressure and cholesterol level, as well as behavioral risk factors, such as high fat consumption, low fruit and vegetables intake, smoking, and physical inactivity, offers the potential of generating substantial health gains (CDC \& National Center for Chronic Disease Prevention and Health Promotion, 1998; RIVM, 2002). Some examples: a reduction of 5-6 mm Hg in diastolic blood pressure has been found to lead to a $14 \%$ reduction in the risk of CVD (Pyöräla et al., 1994); each $1 \%$ fall in the average serum cholesterol level may lead to a $3 \%$ fall in the incidence of CVD (Rose, 1992); half of the CVD mortality in the Netherlands can be attributed to smoking; an increase of the average Dutch fruit and vegetable intake from $250 \mathrm{gram}$ a day to $400 \mathrm{gram}$ a day has been estimated to prevent 3,000 deaths from CVD each year; and insufficient physical activity causes approximately $5.7 \%$ of all cause mortality (RIVM, 2002). As CVD have a multifactorial etiology and the diverse cardiovascular risk factors have a multiplicative effect, modest reductions in multiple risk factors are likely to reduce risk more than aggressive reduction of a single risk factor while ignoring others (Pyörälä et al., 1994). Therefore, a multiple factor prevention approach is expected to be most effective (Rose, 1992).

CVD prevention also requires multiple components. An individual-oriented high-risk strategy requires first of all a complete registration of risk factors (Rose, 1992), and secondly, sufficient treatment of biomedical risk factors (Pyörälä et al., 1994). For a complete prevention approach, health counseling as a third ingredient has been strongly recommended (CDC \& National Center for Chronic Disease Prevention and Health Promotion, 1998). In the Netherlands, cardiovascular risk factor management has been found to be sub-optimal. For instance, CVD patients discharged from the hospital have been found to show a high prevalence of modifrable risk factors, due to ineffective management of blood pressture; lipids and glucose (EUROASPIRE Study Group, 1997). Moreover, cardiologists rarely discuss issues such as diet and physical activity with their patients, and although they advise most smokers to quit, they lack the time to offer them additional help and seldom refer them to specialized cessation programs (Van Berkel, Boersma, De Baquer, Deckers, \& Wood, 1999). In general practices, it has also been demonstrated that risk factor recording, biomedical treatment, and health counseling were inadequate and open to improvement (Van Drenth, Hulscher, Van der Wouden, Mokkink et al., 1998; Drenthen, 1997; Hulscher et al., 1998; Kromhout, 1999).

All in all, it was decided to include all three recommended prevention elements in the high-risk approach of the Hartslag Limburg project in both the cardiology outpatient clinic and the general practices. Because of their high prevalence and high impact on health (RIVM, 2002), high fat consumption, smoking behavior, and physical inactivity were chosen as the behavioral risk factors of primary interest. 


\section{HIGH-RISK APPROACH}

The high-risk intervention was aimed at patients who had a greater than $20 \%$ risk of incurring a cardiovascular event within 10 years (Pyörälä et al., 1994; D. Wood et al., 1998), and who were incidentally or routinely seen by either their GP or their cardiologist. For the general practice population, a pre-selection procedure was initially carried out by guesstimating the cardiowascular risk from information available from the patients' records, using a risk model based on the Framingham study (Anderson, Odell, Wilson, \& Kannel, 1991). For the patients of the cardiology outpatient clinic of the University Hospital Maastricht (azM), this high-risk criterion meant any manifestation of a cardiovascular disorder.

The intervention method was threefold. First, a complete computerized cardiovascular risk profile had to be made up for all patients, to more accurately estimate the absolute multifactorial risk of CVD, as this should be the guide to further interventions (D. Wood et al., 1998). Second, the risk profile could serve as a means for the GPs or cardiologists to evaluate and, if necessary, optimize the treatment of biomedical risk factors in accordance with the national practice guidelines or treatment consensuses. Third, patients were invited to visit one of the four health advisors for an inventory of their behavioral risk factors and for counseling on healthy lifestyle changes and adherence to medical treatment. In accordance with evidence-based international recommendations (WHO, 2003; D. Wood et al., 1998) and with national guidelines (Kemper, Ooijendijk, \& Stiggelbout, 2000; Voedingsraad, 1991), the health advisors applied the following "healthy rules of life": the patients' fat consumption should preferably consist of unsaturated fat and not exceed $35 \%$ of the total energy intake, patients should not smoke, and they should be moderately active for at least 30 minutes a day on five to seven days a week.

Each of the three approaches was expected to reduce the patient's total cardiovascular risk. Furthermore, the simultaneous and collaborative prevention efforts from both the physicians and the health advisors were anticipated to reinforce their individual effectiveness. An overview of the complete intervention model (Rimer, Glanz, \& Rasband, 2001) is presented in Figure 1.1. Such a conceptual model of proposed causal linkages among a set of concepts believed to be related to a specific health problem is thought to be useful in narrowing both research questions and the targets of interventions (Earp \& Ennett, 1991).

The three main elements of the high-risk approach were accompanied by several tasks to be executed by five different groups of actors: members of the research team, practice assistants, health advisors, GPs, and cardiologists. Table 1.1 shows a matrix of the diverse tasks and the division of roles as intended at the start of the high-risk project. The research team, sometimes assisted by the GPs, was responsible for the pre-selection of high-risk patients, who were to be invited to participate in the study by the GPs or the cardiologists. The research team also had to initially record the biomedical risk factors and to offer, for each patient, a computerized risk profille. The practice assistants and the health advisors were in a position to complete the risk profile, while the health advisors, 


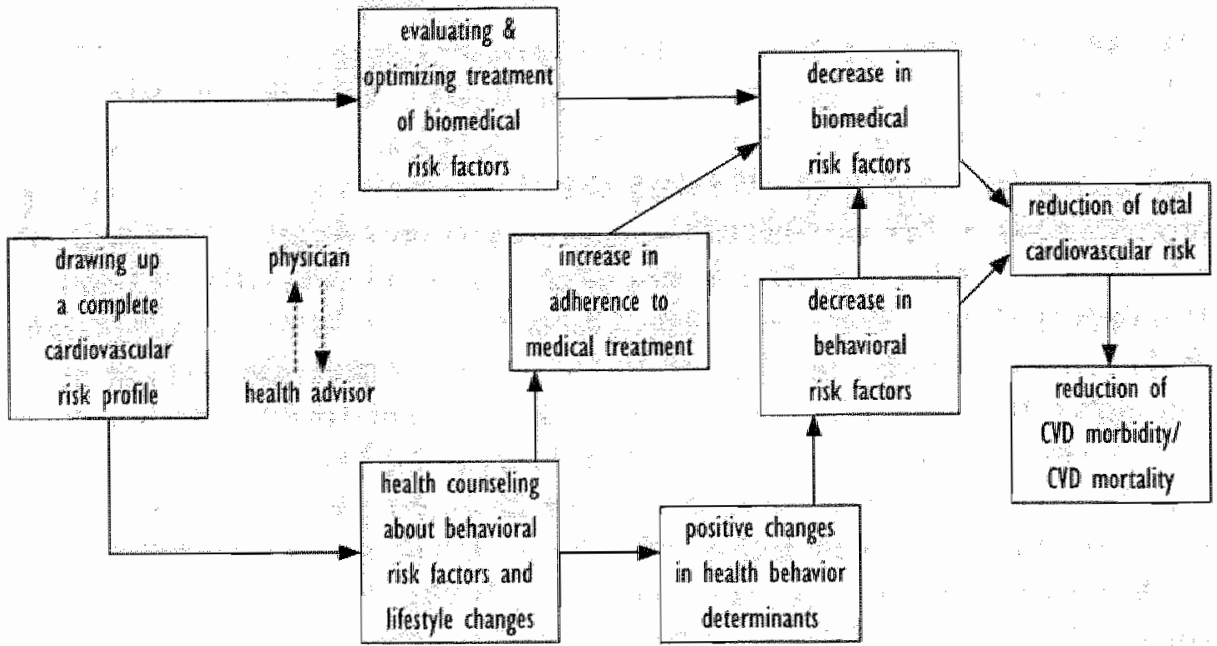

Figure 1.1 Causal intervention model for the high-risk project

$\mathrm{GPs}$ and cardiologists were required to evaluate and discuss the profile in relation to the national treatment guidelines, consensuses, and "healthy rules of life". Next, the GPs and cardiologist were expected to, if necessary, optimize medical treatment, and the health advisors had to discuss with the patients their treatment adherence and to counsel them on their risk behaviors and possible healthy lifestyle changes. After the patient contacts had been completed, the health advisors were to prepare a report and discuss this with the physicians, after which these were asked to reinforce the health advisors' efforts wherever posisible.

\section{COUNSELING COMPONENT}

Hartslag Limburg opted for the new function of health advisor to provide the counseling. This was based on several reports showing that physicians themselves would be neither sufficiently motivated nor equipped to execute this task. For instance, in a Dutch panel study, GPs had rejected draft guidelines that proposed a systematic collection of information on and recording of behavioral risk factors such as stress, dietary habits, and physical exercise, because they considered this too difficult and too time consuming (Van Drenth, Hulscher, Van der Wouden, Van Weel, \& Grol, 1998). Besides, in general practices, behavior related risk fac- 


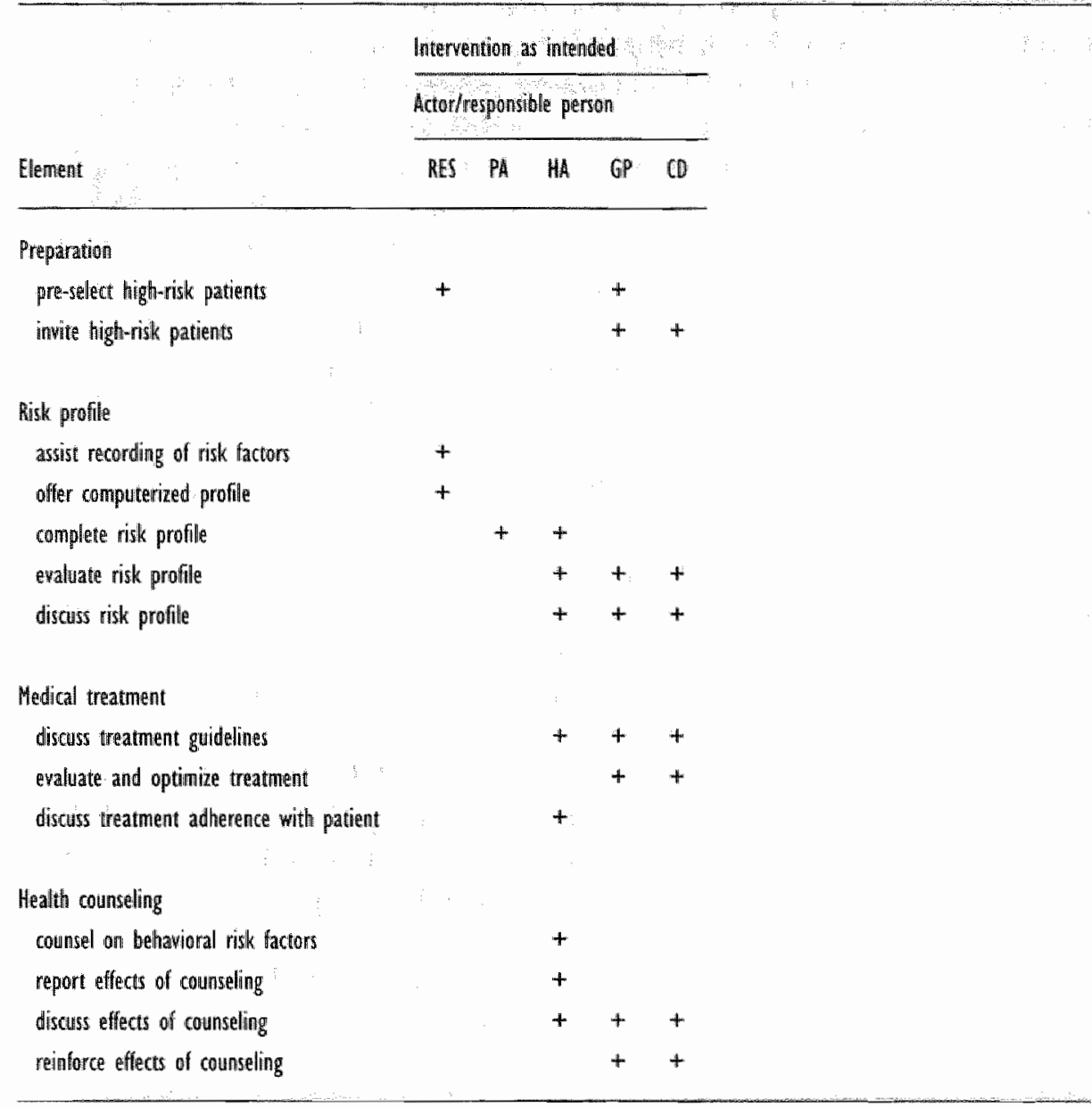

RES $=$ research team, $P$ H $=$ practice assistant, HA $=$ health advisor

$G P=$ general praciitioner, $C D=$ cardiologist; intended: 4 planned

tors, such as weight and smoking status, have been found to be recorded in an average of only $10 \%$ of the parients' medical records (Van Drenth, Hulscher, Van der Wouden, Van Weel et al., 1998). Furthermore, although the national clinical guidelines recommend optimal management of behavioral risk factors (Frijling et al, 2002), and plysicians in general have a positive attitude towards giving their patients unsolicited lifestyle advice ( $\mathrm{KNMG}, 2000$ ), it has been found that little lifestyle advice is actually being given (Frijling et al, 2002). Although GPs show a good level of knowledge about what a healthy lifestyle is, they report a lack of training in lifestyle counseling, and express doubts about the effectiveness of lifestyle advice (summarized by Frijling et al., 2002). 
In the Netherlands, the idea of delegating health counseling fits in with a trend towards delegating physician tasks that are not strictly medical to other health care workers. This redistribution in primary care is in any case justified by two reviews. The first found greater compliance with treatment prescribed by nurse practitioners than by physicians, and, somewhat less clearly, greater patient satisfaction and resolution of pathological conditions among patients consulting nurse practitioners ( $S$. A. Brown \& Grimes, 1995), The second found that nurse practitioners provided care that led to increased levels of patient satisfaction and similar health related outcomes when compared with care by a doctor (Horrocks, Anderson, \& Salisbury, 2002). Besides, nurse practitioners seem to provide a quality of care that is at least as good, and in some ways better than, that of doctors (Horrocks et al., 2002). They have been found to make more complete records, provide more information, be better communicators, and offer more advice on self-care and management (summarized by Horrocks et al., 2002).

The four health advisors in Hartslag Limburg were all female and aged between 30 and 40 years. Two specialized cardiac nurses were recruited for the cardiology outpatient clinic, while a dietician and a well-trained practice assistant were appointed for the general practices. Before the intervention started, all four were specifically trained in behavior change and counseling techniques (Harting, Van Assema, Van der Molen, Ambergen, \& De Vries, 2004). To facilitate effective lifestyle counseling, a theory-based and empirically guided stage-matched health counseling model was developed, consisting of an opening section, a middle section, and a closing section (see Figure 1.2, Harting \& Van Assema, In preparation).

Briefly, the opening section of the model instructs the health advisors to establish rapport and collaboration. The middle section first coaches the health advisors in drawing up a full inventory of the patients' health behaviors and of the determinants impeding healthy changes. By analogy to stage theories of behavior change, the health advisors classify each patient as being in one of six consecutive motivational steps, which guide them in selecting one or more appropriate intervention strategies. For the patients in the receptiveness step, these strategies should lead to greater attention for and interest in a healthy lifestyle. Patients in the awareness step need to obtain more knowledge of and insight into health risks and health behaviors. For those in the willingmess step, the counseling should focus on achieving a more positive attitude, more perceived social support and more self-confidence with respect to a healthy lifestyle. Patients in the ability step have to be helped to overcome possible barriers and to achieve the skills needed to effect healthy changes. The implewentation step should result in conciete plans to make healthy changes as well as in the actual realization of these plans. Lastly, for patients in the maintenance step, the health advisor should promote the continuation of their healthy habits. The closing section of the model instructs the health advisor to draw up an action contract before terminating the meeting in a careful way. 
1 OPENHG SECTON

II MIDDLE SECTIOH

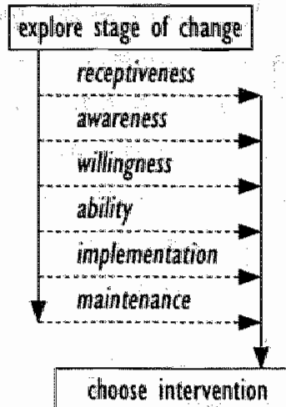

III CLOSING SECTION

Figure 1.2 Schematic counseling model

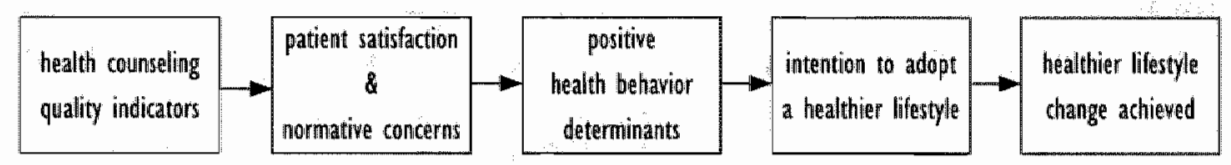

Figure 1.3 Causol model of the counseling component

In general, the health advisors were expected to adopt an empathic attitude, to use a respectfull approach, and to act in a professional way. They were also required to establish adequate information exchange, and to focus on providing patients with greater insight. Finally, they had to ensure that the aims of the counseling were clear, and to reach agreement on concrete action plans that tied in closely with the patients ${ }^{x}$ personal expectations, situation, motivation, and capabilities.

The counseling component of the high-risk approach has its own causal intervention model (Figure 1.3), encompassing the quality of the counseling, the patients' satisfaction as well as their normative concerns, their opinions on health behavior determinants, their intention to change their behavior, and the behavioral changes they actually make. Although reciprocal relations may exist and empirical findings on the relations have been inconsistent, it is theoretically plausible that counseling quality precedes the patients' satisfaction and normative evaluation, and that satisfaction and normative concerns in turn precede 
health behavior related outcomes (Aharony \& Strasser, 1993; Pascoe, 1983). As regards quality, communication and interaction theories are rather clear about the various requirements for health counseling (e.g. Charles, Gafni, \& Whelan, 1997; Lang, Van der Molen, Trower, \& Look, 1990; Mead \& Bower, 2000 ; W. R. Miller \& Rollinick, 1991; Silverman, Kurtz, \& Draper, 1998). However, the empirical findings regarding the specific surplus value of the different aspects toward satisfaction with care and the outcomes of care have been rather inconsistent (e.g. J. B. Brown; Stewart, \& Ryan, 2003; Hall \& Dornan, 1988a; Mead \& Bower, 2002; Stewart, 1995a). Patient satisfaction is considered to be an impact effect, that is, an attitude resulting from the combined cognitive and affective or emotional responses to the distinct aspects of a health service (Linder-Pelz, 1982; Pascoe, 1983). In the case of health comnnunication, a second impact domain that deserves attention is that of moral responses, such as responsibility or even over-responsibility, life restraints and a guilty conscience (Martin, 2001; Minkler, 1999). Both satisfaction and normative concerns may function as mediating variables berween counseling quality and behavior related outcomes. These clinical outcome variables may include compliance, behavioral intentions, health behavior, and health care utilization (Pascoe, 1983; Strasser, Alharony, \& Greenberger, 1993). For the present study, the most important outcomes were assumed to be the health behavior related outcomes that may ultimately result in clinical changes in health (Aharony \& Strasser, 1993; Pascoe, 1983).

\section{DESIGN OF THE EVALUATION STUDY}

The present evaluation study of the high-risk approach consisted of two main parts: an effect evaluation of its result at the behavioral level, and a process evaluation mainly focusing on the health counseling component of the approach.

The effect evaluation (see also Table 1.2) was based on the design with the fewest threats to internal as well as external validity, that is, a randomized controlled trial (RCT, Green \& Lewis, 1986). The RCT consisted of one pre-test at baseline $(\mathrm{T}=0)$ and two post-tests, at four months $(\mathrm{T}=4)$ and 18 months $(\mathrm{T}=18)$ post inclusion, respectively. Patients were included between April 1999 and October 2001: The level of randomization for the general practice setting was the practice, and that for the cardiology outpatient clinic the patient. Patients' self-reports of fat intake, smoking habits, and physical activity level were assessed with validated questionnaires. For the three health related behaviors, the effect questionnaires also assessed changes in intention to change and behavioral determinants. Because of differences in study population, randomization level, and actual implementation of the intended intervention, the effects of the high-risk approach were evaluated separately for the two research 
settings. Power calculations (Lipsey, 1990) were based on an assumed baseline smoking rate of $35 \%$, an expected decline of smokers in the control group (partly due to the community intervention) of $7 \%$, and the ability to detect an ultimate difference in smoking cessation of $8 \%$ between the intervention and control groups (Editorial Committee of the Regional Project ZZL, 1997). In both settings, this required a sample size of 486 patients at the second post-test in each experimental group. Assuming an attrition rate of $10 \%$ at all three mea surement moments, it was calculated that a total of 1,350 patients per setting had to be included in the study $(\alpha=.05$, one-sided, power $=.90)$.

The main question a process evaluation aims to answer is to what extent an intervention program is faithfully delivered as planned (Green \& Lewis, 1986). Important aspects are the reach of the program (e.g., who were exposed and how much of the program was received by them), and the fidelity of its implementation (e.g., to what extent was the intervention protocol followed, (Bartholomew, Parcel, Kok, \& Gottlieb, 2000). At the same time, a process evaluator should continuously search for the reasons that hamper a faithful delivery of the intervention. This process information is essential for the interpretation of the outcomes of an effect evaluation (Bartholomew et al., 2000). If a particular program fails to show an intervention effect, process data can help to determine the cause, that is, whether the lack of effect was due to the program's theoretical methods and practical strategies (impact path ways) or because of the program's implementation failures (process pathways, Bartholomew et al., 2000). Conversely, if a certain effect evaluation does find intervention effects, process data can be used to determine the probability that these effects can really be attributed to the program (Bartholomew et al., 2000 ). Without a process evaluation, effect evaluations are "black box" evaluations (Bartholomew et al, 2000).

Besides investigating program implementation, a process evaluation may have four other objectives (Green \& Lewis, 1986), namely to examine (1) the responses of people at the implementation site (consumer or professional groups, community agencies, private parties), (2) the recipients response (the participants' actual movement through the program, the quality of their progression, and their level of satisfaction with the program), (3) the practitioners' response (experiences of people implementing the program), and (4) the competencies of personnel ( $k$ nowledge, skills, attitude, and actual performance). All but the site response have been formally addressed by the present process evaluation. As is typical of process evaluations, the various process studies used nonexperimental designs (Windsor, Baranowski, Clark, \& Cutter, 1994). To increase their inferential strength, the principle of triangulation was applied, using different methods and different sources to answer the various process questions. This made the design of the process evaluation more complex than that of the effect evaluation (see Table 1.2). 
Table 12 Overview of study topics ond moin research methods

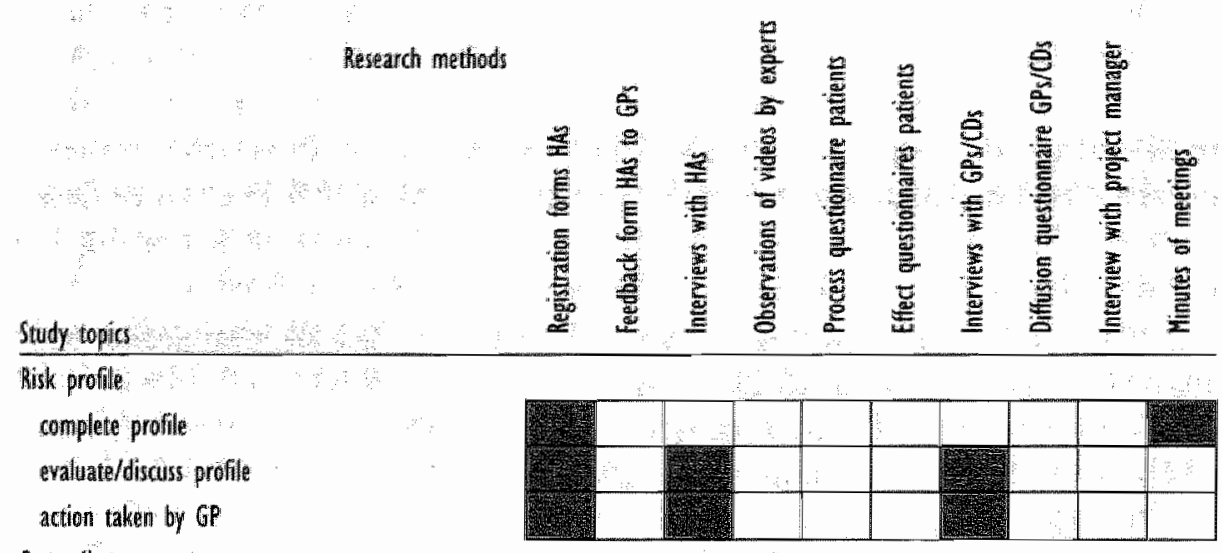

Counseling:

counseling model

quality

quantity

topics

referrals

sutcess.

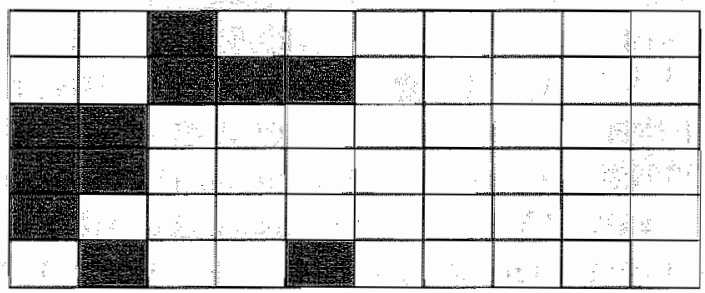

Reiliforcement

conference $H A$ and $G P$

report HA to GP/CD

support to patient by GP/CD

Impact patients

sarisfaction

normative concerns

implement action/comply with advice

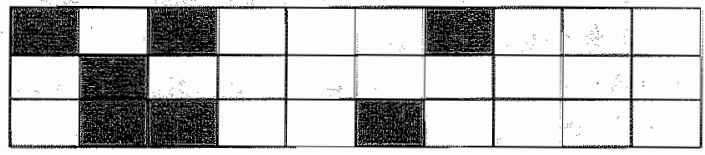

Eflect patients.

changes in determinants

changes in intention

clianges in behavior

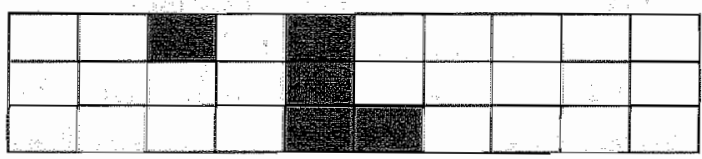

Implementation

pre-trial

in:trial

past-trial
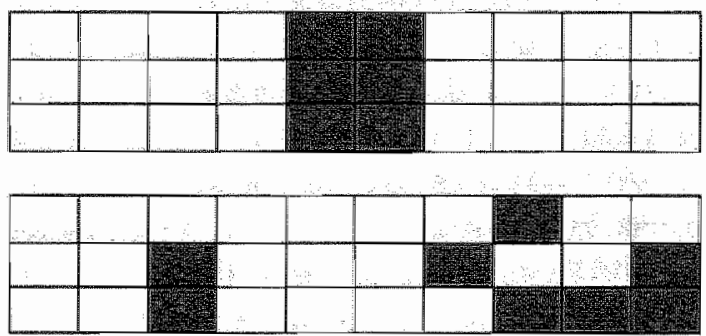

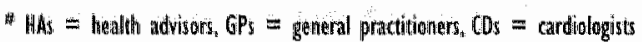


The main process topics were derived from the causal model of the counseing component (Figure 1.3). The first topic related to the applicability of the counseling model in practice. A second process issue concerned the guality of the health counseling, several quantitative aspects of the counseling service (e.g. number of patients, time required per consultation, total time spent per patient), and the content of the counseling sessions. A third process topic was the impact of the health counseling service on the patients and their initially reported changes as regards the global concept of a "healthy lifestyle". Less central process questions addressed some of the components of the causal intervention model (Figure 1.1), namely, the completion and use of the risk profile and the reinforcement expected from the mutual approach of both physician and health advisor. The former process evaluation components all cover the in-trial implementation of the intervention. In addition, its perceived pre-trial implementation and its actual post-trial implementation were also studied.

The main research methods used for the process evaluation were the registration by the health advisors, observations of video-recordings of the counseling by experts, a post-counseling questionnaire for the intervention patients, interviews with health advisors, GPs and the project manager, a diffusion/implementation questionnaire for the GPs and cardiologists, and minutes of several kinds of project meetings.

\section{OUTLINE OF THE THESIS}

The outline of this thesis is as follows. Chapter 2 describes the health counseling model that had been developed, as well as the experience the health advisors gained with its practical use. Chapter 3 is dedicated to the quality of the health counseling according to the counseling and behavior change experts. Chapter 4 reports on the opinions of the patients about the health counseling service, that is, the perceived quality, satisfaction, normative concerns, and injtial changes towards a "healthy lifestyle". Chapter 5 further explores the associations between perceived quality and the impact and outcome effects of the health counseling with the aim of generating hypotheses about their causal relation. The behavioral effects of the counseling component in the cardiology outpatient setting are described in Chapter 6 , and those of the high-risk approach in the general practice setting in Chapter 7 . Chapter 8 presents a description of the post-trial implementation of the intervention in the two settings. Finally, the overall discussion in Chapter 9 further elaborates on the findings presented in the preceding chapters and concludes with some societal implications. 
The stage-matched health counseling model of Hartslag Limburg: a six-step approach

A manuscript based on this chapter will be submitted for publication as:

Harting, J., \& Van Assema, P. (2004). The stage-matched health counseling madel of Hartslag Limburg: a six-step approach 


\section{ABSTRACT}

This article presents the stage-matched health counseling model of Hartslag Limburg, a cardiovascular prevention project in the Netherlands. The model is based on a combination of stage theories and notivational theories of behavior change. Methods of facilitating stage transition for behavior change are described for each of the six motivational stages of the model Empirical evidence of effectiveness has been found for most of the approaches suggested. 24 This stage-matched approach is supposed to result in more tailored health communication, better targeted strategies for change, and thus more effective thealth counseling interventions. The implementation of the counseling model is described from three different perspectives, namely those of health counselors, patients and health counseling experts. Although the patients were satisfied, both health counselors and counseling experts felt counseling in accordance with the model to be rather difficult. 


\section{INTRODUCTION}

Health counseling interventions have been found to generate small (Ashenden, Silagy, \& Weller, 1997) to quite substantial (Kok, Van den Bome, \& Mullen, 1997) changes in risk behaviors in the short term. In the long term however, these effects seem to decay (Simons-Morton, Calfas, Oldenburg, \& Burton, 1998). Although measurable impacts on clinical outcomes have been found (Mullen, Mains, \& Velez, 1992), these were only modest in multiple risk factor interventions, and did not result in reduced mortality (Ebrahim \& Smith, 1997). Interpreting these findings is problematic, because most reports lack a detailed description of the intervention, particularly of the counseling model; its theoretical backgrounds, strategies, and actual implementation (Ashenden et al., 1997; Ebrahim \& Smith, 1997; Kok et al., 1997; Mullen et al., 1992; Simons-Morton et al., 1998). On the other hand, several theoretically and. empirically based health counseling models thave been published (e.g. Doherty, James, \& Roberts, 2000; Elford, Yeo, Jennett, \& Sawa, 1994; Laitakari \& Miilunpalo, 1998), although their effectiveness in practical applications has not been reported. These counseling models vary considerably in terms of theoretical foundation, comprehensiveness, prescribed interview structure, and relevant topics to address. This situation makes it hard to formulate specific requirements for effective health counseling interventions and to make a well-motivated choice among the counseling models available.

In search of a suitable health counseling model for the multiple risk factor intervention called Hartslag Limburg (Heartbeat Limburg, Ruland et al., 1999), a regional cardiovascular prevention project in the Netherlands, we opted for a Dutch version (Van der Burgt \& Verhulst, 1996). This model was based on stage theories as well as on other theories and principles of behavior change. However, as the quality of an intervention, that is, the systematic and combined application of principles and techniques from the behavional sciences, have been found to be an important determinant of its effectiveness (Mullen et al, 1992; Mullen et al., 1997), we felt that the counseling model needed to be further extended and elaborated. Meanwhile, we attempted to ensure practical applicability.

Because of the extensive evaluation studies that accompanied the Hartslag Limburg project, this article is able to describe not just the theoretically and empirically based health counseling model as such, but also its implementation from three different perspectives, those of health counselors, patients and health counseling experts. Future publications will also be able to relate the model and the practical experiences to the intervention's effectiveness in changing cardiovascular risk behaviors. This may lead to the formulation of more specific requirements concerning health counseling interventions in general and health counseling models in particular. 


\section{BACKGROUND}

The Hartslag Limburg project integrates a population strategy, aimed at the whole regional population, with a high-risk approach, targeted at individuals already having an elevated risk of a cardiovascular event. Both sub-projects focus on the reduction of three behavioral risk factors, for which, in accordance with evidence-based national guidelines, Hartslag Limburg formulated the following tecommendations (Ruland et al., 1999): patients fats consumption 26 should preferably consist of unsaturated fats and not exceed $35 \%$ of the total energy intake, patients should not smoke, and be moderate-intense physically active for at least 30 minutes a day on five to seven days a week.

For the high-risk patients, a complete cardiovascular risk profile was made, after which the cardiologist or general practitioner involved was requested to review and, if necessary, optimize medical treatment. Additionally, the high-risk patients were invited to visit a "health advisor", a newly created profession in the Dutch health care system. Four health advisors were trained to make a thorough inventory of behavioral risk factors, and to counsel patients about their behavioral risks and possible lifestyle changes (see Box 2.1). It was for this purpose that the present health counseling model was developed.

Health education and counseling interventions that are effective on the short term have been found to be relatively time-consuming (Ashenden et al,, 1997; Mullen et al., 1992). Although no differences in effects were found for the number of contacts, total contact hours, or length of follow-up (Mullen et al., 1992), more than one contact may be needed (Ashenden et al., 1997; Mullen et al., 1997), and long-term effects seem to be more likely if continuing interventions are used (Simons-Morton et al., 1998). As a result, it was decided that a full counseling course in Hartslag Limburg would be of flexible length, but should not exceed six consultations, with the first meeting allowed to last a maximum of 45 minutes, and the follow-up interviews lasting 30 minutes each. In addition, after completing the counseling course the patients were given the opportunity of a telephonic booster session as means of reinforcement (Burke, Dunbar-Jacob, \& Hill, 1997). Because compliance may be improved by spousal support (Burke et al., 1997), patients could bring any company they liked, at their own initiative or at the health advisor's instigation. Furthermore, in order to enthance effectiveness (Mullen et al., 1997), the health advisors were encouraged to boost their counseling with written health education materials. Finally, the health advisors were able to refer patients to activities that could further support a healthy lifestyle, as they had been provided with a list of all regional health promoting facilities.

The effects of the high-risk strategy were evaluated by means of structured questions in a randomized controlled trial that started in April 1999. 
Bax 2.1 - Becoming a health advisor

\section{BASIC REQUIIREMENTS}

D A higher vocational training for the health care sector

¿ An aptitude for counseling patients about their lifestyle

- Affinity with people from the lawer socio-econamic classes

口 Understanding and (preferably) speaking the local dialect

FURTHER TRAINIING AND SUPPORT

a theoretical introduction to risk behaviors and behavior change with further theoretical self-wition, a theory refresher day, and occasional consultations with experts on health counseling or on behavior thange

D A two-day practicall course in counseling skitls, a wwo-day training on the use of the counseling protocol, and a minimum of five simulation contacts

- Two external courses on smaking cessation

- Bi-monthly feedbacks sessions using video-recorded patient contacts

$\square$ Monthly intervision meetings and twelve individual meetings with a supervisior

\section{BASIC FRAMEWORK}

Hartslag Limburg was founded upon the biopsychosocial model of disease (Engel, 1977), which assumes that in addition to biological factors, psychological as well as social factors affect someone's health status. This opens up opportunities for health promotion and disease prevention, and stresses the importance of patient participation and patient empowerment in achieving and maintaining optimal health (Mead \& Bower, 2000).

As a consequence, a patient-centered approach (Mead \& Bower, 2000) and shared decision-making (Charles et al., 1997) were adopted as the basic counseling principles, and mutuality as the preferred patient-provider relationship (D. L. Roter \& Hall, 1997). These starting-points encouraged the health advisors to take into account the patient's perspective and to share, in some way, power and control. Both aspects may increase patient satisfaction and adherence, while the last, as an activating approach, also may increase physical health (Michie, Miles, \& Weinman, 2003). Mutuality also provides opportunities for a more deliberative patient-provider interaction (Emanuel \& Emanuel, 1992), permitting the persuasive communication that is seen as essential for effective health education and promotion (McGuire, 1985). To allow these principles to be integrated, a general, tripartite counseling model was used (e.g. Lang er al., 1990), involving an opening, a middle, and a closing section (see Figure 2.1). Guided by general accepted ideas from the counseling literature (e.g. Kanfer \& Schefft, 1988; Lang et al., 1990; Silverman et al.; 1998), the opening and the closing section of the model were defined in more detail, as were the required counseling skills. 
1 Writhe whIn

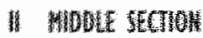

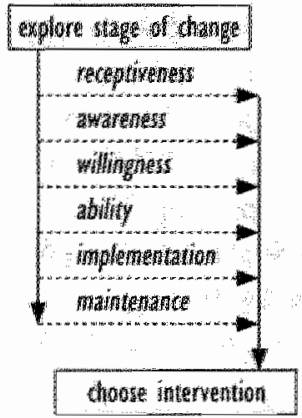

H: cosing stonow

Figure 2. Schematic counseling model

In the opening section it is essential to find an opportunity for health counseling. Important tasks are establishing rapport and defining the roles of both participants. This may elminate ambiguties and misunderstandings, and result in mutual agreement about the counseling agenda and goals. Further cooperation should be created by incorporating the patients' experiential world, that is, their situation, perceptions, and motives. This promotes further information exchange and contributes to shared power and responsibility. After an inventory of a parient's risk behaviors and global motivational stage, agreement should be reached about how to continue. This usually involves a trade-off between the necessity of change, i.e. the existing cardiovascular risk and possible health advantages, and the motivation for such change. In the closing section, the counseling session was to be summarized, clarifying which goals have been reached and which topics still need further elaboration. This should preferably lead to a mutually agreed action contract, specifying exactly what kinds of actions the patient is going to take (see Box 2.2). Such a contract is meant to facilitate self-monitoring, seeking information, or engaging in new behavior. Furthermore, the counseling sessions should be evaluated, repeating the main points, and exploring and taking into account the patient's experiences so far. In the end, the parties should reach a clear agreement about follow-up:

The fundamental principles of this basic framework demand a positive regard and a non-normative, yet motivating approach from the health advisor. Generall interview skills, such as attending behavior and exploratory competencies, will help the health advisor to acknowledge patients as persons, to incorporate their perspective, and thus to establish rapport and collaboration. Intensifying the 
Bax 2.2 - Making an action contrad

Hrs. A. is a hard-working woman, living alone, with an active social life, Recently, her general practitioner bas diagnosed her as a diabetic. This trightens Mrs. A. because she has seen the possible serious conrsequences among her close relatives, which makes her highty notivated to adopt a healthy diet. However, the first time Mrs. A visits the health advisor, it turms out that her lifestyle, and thus her eating pattern, is very iorregular. Mis makes it difficult to make an accurate dietary assessment as well as to provide a tallored advice: The health adwisor explains this to her and suggests that sthe should keep a diary for a while. After Mrs. A agrees, an action contract is drawn up which specifies that, over the next week, Mrs. A. is to keep a lood diary to (I) evaluate her fat, fruit, and vegetable consumption (to enable adequate dietary advice) and (2) map out her irregular food pattern (to enable a discussion about a more regular eating pattern).

counseling, especially in the middle part of the model (as described below) requires more advanced interview skills, like risk communication, proposing interpretations, and tentatively creating confrontations. This may, for example, help patients to gain further insight and to stimulate central information processing which increases the likelihood of attitude change (Parrott, 1995). Finally, specific regulating skills, for instance asking agreement, summarizing, and evaluating, are needed to adequately structure the counseling. (For specific counseling skills, see references above and the Appendix of Harting et al., 2004.)

\section{THE SIX-STEP APPROACH - FACILITATING STAGE TRANSITION}

The middle part of the counseling model is build upon a phased communication model (McGuire, 1985) and two stage theories: the Transtheoretical Model (TTM, Prochaska \& DiClemente; 1984) and the Precaution Adoption Process Model (PAPM, Weinstein, 1988). Both stage theorjes predict that behavioral change is an accumulative process during which people successively move through a series of motivational stages. They also assume that each stage is associated with specific determinants, for which some evidence has indeed been found (Weinstein, Rothman, \& Sutton, 1998). This means that different theories and concepts of behavior change can be applied at each stage in order to adequately address and change the corresponding determinants (Armitage $\&$ Conner, 2000; Maibach \& Cotton, 1995), and that the various dimensions of communication should be adapted accordingly (McGuire, 1985).

This stage-matched approach with its conjunction of theories may result in more tailored health communication (McGuire, 1985), and better targeted strategies of behavior change (Armitage \& Conner, 2000), leading to more 
effective interventions (Armitage \& Conner, 2000). In addition, it allows for the application of multiple methods and strategies, which has also been found to increase effectiveness (D. Roter, 1989; Simons-Morton et al, 1998).

In the present health counseling model, this integration of theories resulted in six motivational steps: receptiveness, awareness, willingness, ability, implementation, and maintenance (Van der Burgt \& Verlhulst, 1996). For each ind ividual risk behavior or sub-behavior, the health advisor is invited to draw up a thorough inventory of determinants impeding healthy changes. On the basis of her findings, she classifies the patient in one of the six motivational steps of behavior change. This will guide her in adapting her communication and selecting one or more appropriate intervention strategies, in order to adequately enhance motivation, and thus facilitate stage transition toward sustained behavior change. Mismatching will mainly incite resistance (W. R. Miller \& Rollnick, 1991), and may produce undesirable effects (Prochaska \& Velicer, 1997).

\section{Receptiveness}

First, the health advisor has to address to what extent the patient is receptive to counseling about behavior change in general: the patient has to be "tuned in" (McGuire; 1985). Although adequate exposure may seem self-evident in individual health counseling, personal and situational variables are potential interfering determinants (McGuire, 1985). Unexpressed whishes, needs, questions, expectations and emotions may seriously reduce the patient's receptiveness (Kanfer $\&$ Schefft, 1988). Therefore, it is important that the health advisor elaborately explores this "patient's agenda" (Barry, Bradley, Britten, Stevenson, $\&$ Barber, 2000), and pays special attention to the patient's interest when initiating new topics or steps. In addition, patients may become distracted by feelings of dissatisfaction, uncertainty, annoyance, fatigue or anxiety. This stresses the need to identify verbal and non-verbal signals that may indicate lack of involvement (Kanfer \& Schefft; 1988).

Next, the health advisor will look for further opportunities to discuss specific risk or health behaviors. In this respect, selective attention and misconceptions may hamper progression (McGuire, 1985; Weinstein, 1988). Patients who wrongfully believe that they do not engage in certain risk behaviors or believe that such behaviors are not harmful; will be more receptive to information that confirms these belief, than to information contradicting them (Weinstein, 1988). Investigating the notions behind these, mostly protective, mechanisms may open up a sensible dialogue. Besides, assessing their actual behavior and presenting them with objective information, may provide patients with more realistic perceptions and create room for further discussion (see also awareness).

Other aspects that can impede receptiveness are "competing needs". The "need for a healthy lifestyle" may not be the patient's only, or even his most prominent or urgent need (Barry et al., 2000). Patients can deal with many needs at the same time, including other health needs, but also financial, social 
and emotional needs, interfering with the need for prevention. If not acknowledged, these competing needs may seriously frustrate the counseling. Finally, patients may refuse counseling as such or counseling about a particular topic. The health advisor should then try to discover what makes someone maccessible. Respectfully addressing the patient's initial resistance, probably based on negative experiences or on feelings of helplessness, may bring about some relief and confidence, which in turn may enhance receptiveness. However, if patients persist in their refusal, this ought to be respected.

\section{Awareness}

Based on the Health Belief Model (Janz \& Becker, 1984) and the Protection Motivation Theory (R. W. Rogers \& Prentice-Dunn, 1997), full awareness concerns personal susceptibility, hazard severity and precaution effectiveness (Weinstein, 1988). All three beliefs evolve in three phases: acknowledgement in general, significance for others, and significance for oneself (Weinstein, 1988). For cardiovascular risk behaviors, this means for instance that patients should realize that smoking is harmful, that the damage caused by smoking is severe, and that smoking cessation is an effective protection - and that all this is personally relevant.

The health advisor can induce awareness by giving information (Weinstein, 1988). This may include general information about fat intake, smoking and physical inactivity in relation to cardiovascular diseases, and about the health benefits to be expected from behavioral change. However, patients tend for instance to underestimate their fat consumption (Brug, Van Assema, Kok, Lenderink, \& Glanz, 1994) and to overestimate their physical activity level (Ronda, Van Assema, \& Brug, 2001). Hence, discouraging this kind of unrealistic optimism and encouraging an adequate risk perception, may require more personalized information (Weinstein, 1988). This means giving feedback about the extent to which patients themselves engage in certain risk behaviors, and rectifying incorrect beliefs about the risk status of others and the precautions others take (Weinstein, 1988). Both informativeness in general (Stewart, 1995a) and individualization of information (Mullen et al., 1992) can increase intervention effects.

Because people have difficulties interpreting objective risk estimates (Weinstein, 1988), the health advisor should, if possible, carefully use analogies, metaphors and anecdotal examples (McGuire, 1985, see Box.2.3). Also, she may emphasize that individual (small) risks accumulate by multiplication (Anderson et al., 1991), so that even small behavioral changes can substantially decrease the total cardiovascular risk. Too threatening information however, may evoke unwanted reactions, such as avoidance and denial (Hale \& Dillard, 1995). In general, the information should be clear and comprehensible, and adapted to the patient's frame of reference, information needs, and processing capacitics, as this "relevance" has been found to generate better outcomes (Mullen et al., 1992). 
Box 2.3 - Firing squad

"But take my granddad, Mr. B a heayy smoker, argues, "He smoked all his llfe and yet he lived to be 93 years old!' I should say he was a lucky nan, a very lucky man', the health adviyor answers. 'Let me illustrate this with a short story I once heard froim a cardialogist, but be prepared lor a shock, because it's rather cruel Imagine a group of one hundred preople in front of a firing squad. The machine guns start to fire. After the smoke has lifted; only one man is still standing and aliwe. Well, thiat man was your granddad. You see how lucky he must have been?

Mr. B. is quiet for a moment, then rods hesitantly. "Is it really that bad? "Well", the health advisor puts things in perspective, "Leet's say, at least it gives you an idea of the odds."

\section{Willingness}

Willingness inwolves patients having to acquire the intention to act (Prochaska \& DiClemente, 1984; Weinstein, 1988). The Theory of Planned Behavior (Ajzen, 1991), the Social Learning Theory (Bandura, 1986), and the ASEmodel (H. De Vries, Dijkstra, \& Kuhlman, 1988) indicate three important categories of determinants in motivation building. These are attitude, which is especially relevant in the first phase of this motivational step, social influence, which acquires a steadily increasing weight, and perceived control or selfefficacy, which is mainly of concern in the last phase of this step, as well as in the motivational steps which are discussed below (Prochaska \& Velicer, 1997; $H$. De Vries et al., 1988). Interwentions addressing these constructs have been found to be potentially effective in changing intentions and behaviors (Burke et al., 1997; Hardeman et al, 2002).

An attitude is the result of weighing pros and cons (Ajzen, 1991) and therefore closely connected to expectancy-value models (Weinstein, 1988) and the idea of decisional balance (Prochaska \& Velicer, 1997). It has been found for several health behaviors that an increase in pros precedes and exceeds the decrease in cons (Prochaska \& Velicer, 1997). Hence, to create a positive attitude, the health advisor has to confirm and strengthen the pros, especially in the short term, and challenge the cons of healthy behaviors, and do the opposite for unhealthy ones. In doing so, she should keep in mind that salient beliefs may vary substantially among patients (Hardeman et al, 2002). A decision matrix may help patients to list all their positive and negative beliefs regarding certain healthy and unhealthy behaviors and to subsequently weigh both alternatives (W. R. Miller \& Rollnick, 1991). Such a matrix may be filled in during the meeting or at home.

Social influence covers the perceived social norm and the motivation to comply, the perceived behavior of others, and social pressure and support (Bandura, 1986; H. De Vries et al., 1988, see Box 2.4). This means that the health advisor has to find out to what extent patients feel supported or thwarted by others. Together with the patient, she can discuss the perceived social norm, reconsider 
Mrs. C., obese, has been slinming for years. Howewer, after each period of strict dieting, she completely relapses. After talking this ower with the health advisor, she decides to adopt a different strategy, inwolving no more rigorous diets, but just trying to eat as healthy a diet as possible. This seems to work quit well, although her energy intake remains rather high: One problem are her numerous brothers, sisters and in-laws and the regional habit of eating at least two big pieces of fruit lan at birthdays and other parties. Although this traditional pastry is rather low-lat. two large pieces are a real energy bomb. Mrs. $C$. tells it is very thard to refuse the second piece, because she will get cynical comments from all family members. Together with the health advisor, she devises the following solution. At each party, Hrs. C. will contact the hostess beforehand to shortly explain her new healthy eating strategy and to ask for two small pieces of flan to be serwed. Although this also caused some hilarity among the other family members, as expected, most hostesses turned out to be really supportive.

arguments to conform to it, discuss the perceived behavior of others, and think of positive role models. In case of social pressure, the health advisor must search for strategies to resist, and if social support is insufficient or lacking, she should look for and mobilize potential supporters. Of course the health advisor herself should express a highly supportive attitude.

In lay terms, perceived control and self-efficacy (Ajzen, 1991; Bandura, 1986) can be translated into self-confidence. If self-confidence is low because the patient has failed on prior efforts to change, the health advisor has to explore the underlying reasons. If the strategy is inadequate, more adequate strategies should be considered, for instance applying the principle of small steps, that is, changing behavior bit by bit (Bandura, 1986). If patients attribute prior failures solely to themselves (internal) and definitely believe they will fail again (stable), reattribution can be sought in situational aspects and modifiable qualities (external and unstable, Weiner, 1985). Again, acceptable role models may be useful (Bandura, 1986). Because patients are at high risk of cardiac events, physical symptoms deserve special attention (Bandura, 1986) to see to what degree they correctly (e.g. angina pectoris) or incorrectly (e.g. aching muscles) discourage physical activity.

\section{Ability}

Once they have formed the intention to act, patients should start with planning activities (Weinstein, 1988) to prepare themselves properly for the change to come (Prochaska \& DiClemente, 1984). Preparation implies paying attention to enabling factors, such as existing skills and barriers (Bandura, 1986; Green \& Lewis, 1991, see Box 2.5.a and 2.5.b), which have to be distinguished from the perceived self-confidence from the previous step. 
Box 2.5.a-How to read food labels

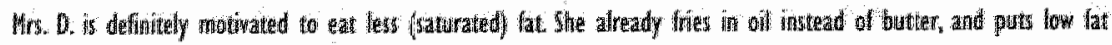

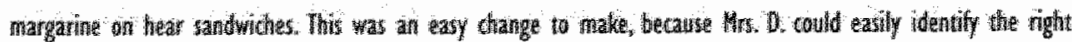

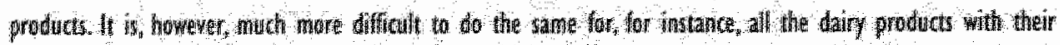

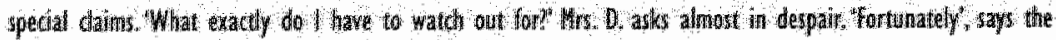

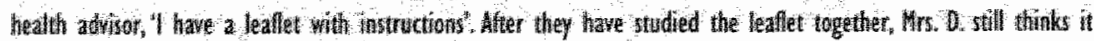

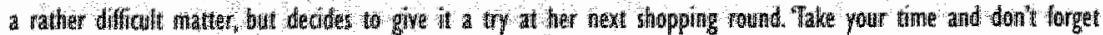

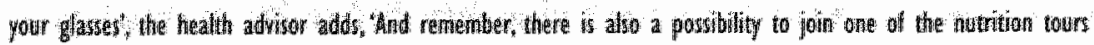
at the supermanket:

Box 2.5.b-5wimming to expensive

For Fr. and Firs. E. it turns out that swimening is the most lavorite and most suttable way to change their sedentary lifestyle. Swinming mobilizes the whole body, puts no extra burden on the joints, and has an addritonal velaxing effect. Besides, the swimming pool is just around the corrier. Regretably however, because they liwe off a small social security bendit, they can not afford to swim more than once a month, despite the discount that is offered by the local authorities. Of course they are rather disappointed, but decide to have a look at other local adivities.

Converting intentions into practice may require, for instance, physical skills (ability to implement plysical action), cognitive skills (ability to process information), social skills (ability to organize support), or emotional skills (ability to resist pressure). As the acquirement of skills has been found to be effective (Burke et al., 1997; Mullen et al., 1992), the health advisor may offer guided learning or refer patients to additional health or social services in the community. Well-known barriers include a lack of time, lack of money, inadequate equipment, insufficient or non-existing facilities, and having too many options (Armitage \& Conner, 2000). In these cases priorities and alternatives should be discussed. If possible, providing supplies and materials can be helpfiul (Mullen et al., 1997; Simons-Morton et al., 1998).

\section{Implementation}

Once able to act, patients should actually implement the intended action (Prochaska \& DiClemente, 1984; Weinstein, 1988). The formulation of implementation intentions (Gollwitzer \& Brandstätter, 1997) has been found to enhance actual achievement of single acts as well as regular performance (Orbell \& Sheeran, 2002, see Box 2.6). This means phrasing a concrete plan, specifying exactly when, where, how, and what will be done. Such an implementation intention links specific situational cues with goal-fulfilling responses, which in 


\section{Box 2.6 - Implementotion plan}

\begin{tabular}{|c|c|}
\hline Goall & Feeling less tense, steeping better, feeling fitter \\
\hline What: & Take an hours walk, two times a week \\
\hline When & Tuestay and Friday after dinner, say $7.30 \mathrm{pm}$ \\
\hline Where & Front home to St. Pietersberg hill and back \\
\hline How & Woderate tempo, short rest uphill \\
\hline Note 1 & Take a bottle of water : \\
\hline te 2 & Ask friends to join at least once a week \\
\hline
\end{tabular}

turn acquire some degree of automatism by being under the control of relevant situational cues. Besides, it may enhance commitment (Armitage \& Conner, 2000). The goals chosen should be challenging but feasible (Strecher et al., 1995), complexity should be low, the required time limited, and the costs fair (Weinstein, 1988). A selection of means may be helpful (Strecher et al., 1995). Explicitly expressing commitment, preferably in a written implementation plan, makes implementation even more likely (Burke et al., 1997).

Further help can be found in the principle of stimulus control (Elder, 1987), saying that removing stimuli that trigger undesirable behavior (e.g. availability of cigarettes, ashtrays, chocolates, snacks) will prevent patients from engaging in it. Other help may come from external cognitive aids (Burke et al., 1997), such as reminders (e.g. marking sports appointments in ones diary, setting an alarm) and prompts, which are small signs put up in places where patients are supposed to take action (e.g. fridge magnets).

\section{Maintenance}

Once they have changed their beliavior, patients have to continue their newly obtained health behaviors (Prochaska \& DiClemente, 1984; Weinstein, 1988). According to contingency management (Burke et all, 1997), this means first of all that any successes must be reinforced through positive feedback, for example by means of compliments or rewards (Mullen et al., 1992; SimonsMorton et al., 1998). Addressing existing or anticipated problems, looking for solutions (Simons-Morton et al, 1998), and making necessary reattributions (Weiner, 1985) seem equally important. Also, self-management techniques (Meichenbaum \& Turk, 1987) can be helpful in maintaining the changes achieved (Mullen et al., 1997). This implies offering suitable methods of selfmonitoring, evaluation, readjustment, and self-reinforcement, which may help patients to stay in control of the target behavior. 
Box 2.7 - Stress as a pitfoll

Mrs. E. siopped smoking a few weeks ago Today it is the last wime she visits the health advisor, who arks whether

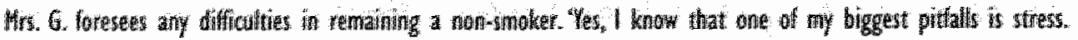

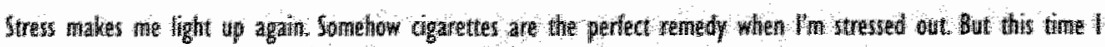

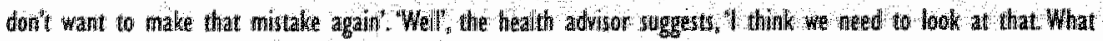

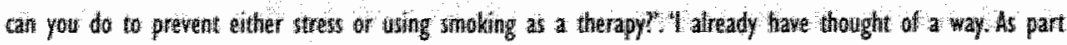

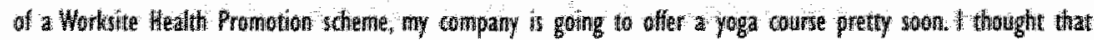

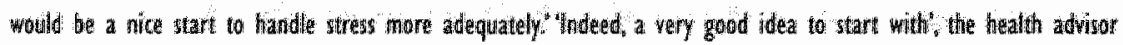

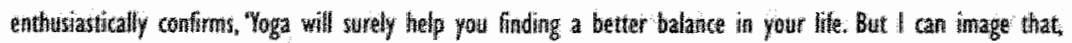

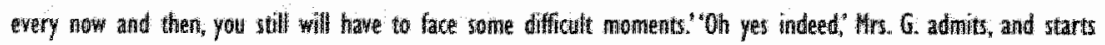
listing the challenget she thas had to face last week.

The Relapse Prevention Theory (RPT, Marlatt \& Gordon, 1985) provides three other potentially effective interventions (Irvin, Bowers, Dunn, \& Wang, 1999). First, it emphasizes the importance of anticipating lapses and relapses after change (see Box 2.7). By asking patients to think of situations in which they run a high risk of occasional mistakes or permanent regression, the health advisor creates the opportunity to impart effective coping strategies (Brownell \& Cohen, 1995). This means either avoiding these situations or adequately dealing with them. Second, the RPT proposes that a single Japse does not inevitably lead to a complete relapse. If the health advisor succeds in convincing patients that a lapse is a single failure from which they can learn how to avoid it in the future, full relapses may be prevented. Finally, the RPT involves the idea of lifestyle imbalance, meaning that the "shoulds", that is, things that one feels obliged to do, exceed the "wants", that is, things that one likes to do. The health advisor may inform the patient that an imbalanced lifestyle can cause additional cardiovascular risk. In addition, she may propose that less stress may also make it easier to maintain a healthy lifestyle. To achieve a balanced way of life however, patients might need to consult other health care or social workers.

\section{PRACTICAL EXPERIENCES}

Data about the implementation of the counseling model were gathered from three sources. First, the health advisors were interviewed about their practical experiences after 12 and 24 months. Second, all 1,301 patients received a questionnaire covering several quality, impact and outcome measures directily after completing their counseling course (Harting, Van Assema, \& De Vries, 
Submitted). Responses were received from 1,056 parricipants $(81.2 \%)$. Third, three independent experts evaluated the application of the model in 64 videorecorded counseling sessions during the first 18 month of the intervention, using an observation list (Harting et al, 2004).

\section{The health advisors}

The health advisors generally considered the basic framework of the model to be a good guide for health counseling, that is, it helped to keep the meetings focused and structured, 'keeping the overall perspective in mind'. In the begin. ning, however, they also felt the model to be too constrictive, seeing 'many" good reasons for not achieving the "ideal interview"'. Based on patients' reactions, some issues were found to be superfluous, inconvenient, or patronizing. As their experience increased, they were better able to use the model in a flexible way, to switch between the various topics, and to adapt their style to the patient they were confronted with.

At first the health advisors found it difficult to apply the principles of patientcenteredness and shared decision-making, partly because they believed that this kind of patient involvement is still unusual in the Netherlands. Therefore, the health advisors, although experienced in communication with patients, had to go through a considerable shift in their approach. This was also the case for numerous patients, who also differed in their appreciation of and contribution. to the participation and empowerment frame. As their level of experience grew, the health advisors were better able to work within and appreciate this paradigm. In doing so, they noticed several advantages and reported that it 'really invites patients to participate', 'stimulates self-reflection', 'helps them to develop their ideas', and 'leads to solutions that fit into their lives'.

For several reasons, the health advisors had problems with the six-step approach. First, they were originally focused on properly structuring the interview and applying the various counseling skills. This made it hard to simultaneously integrate and apply the various theoretical concepts for each moti* vational step. Instead, the health advisors mainly used the steps as a guide to write patient reports and prepare follow-up interviews. In time, however, they were better able to apply the six-step approach during the actual sessions. Second, the health advisors initially expected too many behavioral effects, making them focus too much on behavior change rather than on stage transition. Occasionally, this yielded unnecessary resistance. Later on, they lowered their expectations, became better able to recognize and handle resistance, and more easily allowed themselves to "shift back" to previous motivational steps. As a result, they were able to find opportunities for counseling in nearly all patients. However, the willingness step in particular still tended to cause problems, mainly because patients refused to discuss their ambivalent personal values in more detail. Third, the health advisors typified the six-step approach as a 'simplification of reality', since 'reality was much more complex'. 
Finally, it was unclear what extent of behavioral change or stage transition the health advisors should be satisfied with. They indicated that even after two years they still struggled with this question, arguing this was partly instigated by contradictory aims. Where the Hartslag Limburg project in general aimed for the national norms regarding fat intake, smoking, and physical activity (meeting the norm being what counts), the six-step approach of the health counseling model primarily aimed at stage transition (in which any change counts). This made them wonder whether to continue counseling patients who made substantial behavioral changes, but who still failed to meet the norms. The health advisors suggested allowing occasional breaks, after which patients night be ready for further change, but the experimental design of the study did not permit this flexibility.

\section{The patients}

Preliminary findings (Harting et al., Submitted) indicate that the parients greatly appreciated the health counseling, with a score of 8.2 on a ten-point scale. The new service was seen as a good addition to existing health care facilities by $87.6 \%$ of the patients. Also, $85.8 \%$ of the patients preferred the personal method of health education to mass-medial approaches. In their view, however; the counseling did not necessarily have to be offered by the new professionals: only $17.6 \%$ of the patients favored the health advisor, while $7.6 \%$ preferred their general practitioner or cardiologist. To the other $77.4 \%$ the counselor's identity did not matter.

The goal of the counseling was reported by $93.3 \%$ of the patients to be clear. Of the action plans, $69.4 \%$ had been drawn up jointly and $20.5 \%$ had been mainly formulated by the patients themselves. Moreover, $86.3 \%$ of the patients fully agreed with its content. In spite of this, $71.2 \%$ of the patients reported that it was not easy to put the action plans into practice. Nonerheless, $84.4 \%$ of them reported a positive stage transirion, that is, a positive alteration in one or more determinants of behavior change.

\section{The experts}

Bases on sessions during the first 18 months of the project, the health counseling experts were less positive than the patients (Harting et al., 2004). On a four-point scale ( 1 = unsatisfactory, $2=$ doubtful, $3=$ satisfactory, $4=$ good), they assessed the basic counseling attitude as satisfactory (3.15), the interview skills narrowly failing to be satisfactory (2.85), and the regulating skills as somewhat more doubtful (2.65). The way the health advisors explored the motivational steps and chose and applied their interventions, was only seen as satisfactory for one of them (3.05), while the others were observed as not fully meeting that standard $(2.37-2.78)$. It was concluded that health counseling is a very difficult skill, but that, all things considered, the overall quality of the health counseling could nevertheless be evaluated as rather encouraging. 


\section{DISCUSSION}

\section{Considerations regarding the model}

Although the health counseling model used in the Hartslag Limburg project was experienced as a good guide, integral implementation appeared to be a difficult task. On average, it took the health advisors more than six months before they conld adequately apply the principles of patient-centeredness and shared decision-making, and more than 18 months before they could flexibly use the basic framework and effectively employ the integrated stage-matched approach. Up to that moment, although the patients were satisfied, the health counseling experts did not find the quality of the counseling completely satisfactory. This gives rise to a critical reconsideration of the counseling model.

Stage theories are a simplification of reality, because few people will match the prototype that can be defined for each stage (Weinstein et al., 1998).

Furthermore, to what extent each motivational variable plays a role in subsequent stages seems unclear (Armitage \& Conner, 2000), and the specific strategies that cause stage transition have so far not been accurately specified (Weinstein et al., 1998): This may indicate that the composition of the present health counseling model was too arbitrary after all, which may at least partly explain why the health advisors found it difficult to classify patients in one of the motivational steps and to choose an appropriate intervention. Implementation of the model may be further complicated because human behavior is flexible (Weinstein et al., 1998) and because it is unclear whether individuals must move through the stages sequentially (Armitage \& Conner, 2000). Besides, patients" experiences indicate that behavioral changes seem in any case difficult to accomplish. Perhaps both the model and its implementation could be improved by emphasizing that the choice of a specific process of change should be guided particularly by the self-change efforts a patient is already engaged in (Prochaska \& Velicer, 1997).

Although the present health counseling model may be too complex, compared to other stage-matched approaches (e.g. Doherty et al., 2000; Elford et al., 1994; Laitakari \& Miilunpalo, 1998), it seems at least as straightforward, transparent, and applicable. On the one hand, the practical experiences gained in the Hartslag Limburg project, might mean that a stripped counseling model, which guides health counselors more closely through a series of well-defined actions, should be reflected upon. On the other hand, in view of the complexity of behavior and behavior change in real life, the present model should perhaps even be extended, and efforts to achieve its appropriate implementation should even be intensified. These additional efforts might, for instance, address the willingness step, in which attitudinal ambivalence is probably at a maximum (Armitage, Povey, \& Arden, 2003). However, the ultimate choice of an effective counseling model will only be possible after more models have been fully described and seriously examined for their practical applicability and effectiveness.

Finally, it remains unclear at what moment the health advisor should be satisfied and the counseling could be terminated. Apart from the ambiguity of the 
goals to be reached which was described above, the problem of termination may also have been generated by a shorrcoming of the counseling model itself. In composing the model, an early version of the PAPM was used, ignoring its later extension with an additional stage for people who have consciously decided not to adopt any (further) new behavior (Weinstein et al., 1998). Explicitly integrating this seventh stage into the present model would probably make it easier for both partic to discuss this issue and to find an appropriate moment to end the counseling course. This decision may also be encouraged by allowing occasional breaks.

\section{Practice implications}

It can be concluded from the experience of the health advisor, that the practical implementation of the present counseling model requires a great deal of time, theoretical and practical training, as well as much assistance and support (see also Harting et al., 2004). Furthermore, users of the present model should be prepared for the problem that patients ${ }^{3}$ reactions may depend on their previous experiences with, and current appreciation of and contribution to, the participation and empowerment frame (Harting et al., 2004; Mead \& Bower, 2000). This problem might possibly be solved by adapting the counseling even more closely to the patient concerned, but it might also require additional supervised practical training (Harting et al, 2004).

Furthermore, users should be thoroughly aware that health counseling generally will bring about only small behavioral results (e.g. Ashenden et al., 1997). Expecting substantial behavior changes may interfere with an adequate application of the present model. Stressing that stage transitions are the primary aim of the stage-matched approach, may help the health counselors to focus on explo-

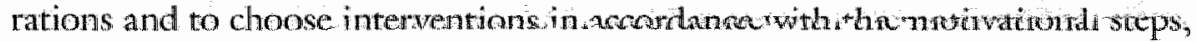
as well as to observe and reinforce changes at the level of behavioral determinants. To this end, being able to notice and deal with resistance may be a key counseling skill (W. R. Miller \& Rollnick, 1991).

\section{ACKNOWLEDGEMENT}

The health counseling model was composed as part of the Hartslag Limburg project, which is coordinated by the Maastricht Regional Public Health Institute (GGD-zzl), and funded by the Netherlands Heart Foundation (NHS). A debt of gratitude is owed to Els van Mechelen and Marieke van der Burgt for their helpful suggestions, the latter also for her comments on the interview fragments, and to the four health advisors for implementing the model and for frankly sharing their experiences. 


\section{CHAPTER 3}

Quality assessment of health counseling:

performance of health advisors

in cardiovascular prevention

This chapter has been published as:

Harting, J., Van Assema, P., Van der Molen, H.T., Ambergen, T., \& De Vries, N.K. (2004).

Quality assessment of health counseling: performance of health advisors in cardiovascular prevention.

Patient Education and Counseling 2004; 54: 107-118 


\section{ABSTRACT}

Quality assessments of interventions are seen as essential in optimizing their implementation, interpreting their effectiveness, and illuminating their underlying processes. In Hartslag Limburg, a cardiovascular prevention project, the quality of a health counseling intervention was assessed as part of the process evaluation. Four health advisors each video-taped 16 counseling sessions, all of which were assessed by three independent observers. Health counseling was found to be a very difficult skill, but, all things considered, the overall quality was evaluated as rather encouraging. No indication was found of quality improvement over time. The interpretation of the findings was complicated by limited absolute interobserver agreement, but reliable rellative distinctions could be made between the health advisors' performance and their application of various counseling skills. Future quality investigators are advised to carefully match study goals with study methods, and practitioners planning a health counselling project should take the complexity of the task into account. 


\section{INTRODUCTION}

Studies reporting the results of health counseling interventions mostly lack a thorough quality assessment (Ebrahim \& Smith; 1997). Effects, or the lack of effects, can therefore not be adequately interpreted (Green \& Lewis, 1986). A quality assessment is also needed to optimize an intervention during the study period, to trace changes in intervention delivery over time, and to obtain insight into the relation between distinct intervention aspects and specific impact or outcome effects (Green \& Lewis, 1986). Because of these potential benefits, a quality assessment study was set up for the health counseling intervention in Hartslag Limburg.

Hartslag Limburg (Dutch for Heartbeat Limburg) is a regional prevention project aiming at the reduction of cardiovascular diseases (CVD, Ruland et al., 1999). The project started in 1998 and includes a community project, targeting all 180,000 inhabitants of the area, and a high-risk project, concentraring on individuals already running a high risk of CVD. Both sub-projects focus on the reduction of three behavioral cardiovascular risk factors: high fat consumption, smoking and physical inactivity. In 2001, Hartslag Limburg was selected as one of the twelve WHO "Towards Unity for Health" demonstration projects.

The high-risk intervention uses a multiple risk factor approach, consisting of two complementary strategies. First, a complete biomedical risk profile is made for each patient, and the cardiologist or general practitioner involved are requested to reconsider and, if necessary, optimize medical treatment. Second, patients are invited to visit a health advisor, a newly created profession in the Dutch health care system. After an inventory of behavioral risk factors, she counsels patients about their behavioral risks and possible lifestyle changes, using a practical counseling protocol.

The protocol is based on general counseling models (e.g. Kanfer \& Schefft, 1988; Lang et al., 1990), health counseling models (e.g. W. R. Miller \& Rollnick, 1991; Russell, 1986); and various theories of behavior and behavior change (Conner \& Norman, 1995). The core section of the protocol invites the health advisor to explore the specific factors hampering change and to apply adequate intervention strategies. General principles are patient-centeredness (Mead \& Bower, 2000; C. R. Rogers, 1973) and shared decision-making (Charles et al., 1997; Elwyn et al., 2001), requiring a positive regard and a nonnormative, yet motivating approach. In addition, effective communication skills are specified to structure, direct and intensify the counseling (e.g. Lang et al., 1990; Silverman etc al., 1998).

The biomedical and behavioral effects of the high-risk project were evaluated in a randomized controlled trial (RCT) that started in April 1999. A prominent component of the simultaneous process evaluation, and the subject of the present study, was a quality assessment of the intervention by the health advisors. For this purpose video-recorded health counseling sessions were evaluated by three independent observers using an observation list. The main research question was whether the health advisors performed in accordance with common 
counseling standards, that is, whether they sufficiently structured, directed and intensified the interviews, whether their behavioral explorations and interventions were consistent with the protocol, and whether they satisfactorily took into account the principles of patient-centeredness and shared decision-making. Additional research questions concerned differences in counseling quality between health advisors and the development of health counseling quality in time. Furthermore, differences in quality were studied between initial and follow-up meetings, between male and female patients, and between sessions with single patients and patients accompanied by their partners.

This article illustrates the complexity of an adequate quality assessmemt, but may also encourage others to undertake and report quality assessments as part of their evaluation studies.

\section{METHODS}

\section{Outline of trial and intervention}

During the RCT, 10 cardiologists of the University Hospital Maastricht, and 35 general practitioners of 25 practice units spread throughout the region, included 2,743 high-risk patients. The intervention patients were counseled in the setting of their inclusion. The length of a full counseling course was flexible, but did not exceed six consultations, with the first meeting allowed to last a maximum of 45 minutes, and the follow-up interviews 30 minutes each. Patients could bring any company they liked, at their own initiative or at the health advisor's instigation.

The four health advisors in Hartslag Limburg were female and aged between 30 and 40 years. Basic requirements were a higher vocational education in the health care sector, an aptitude for counseling patients about their lifestyle, and affinity with people from the lower socio-economic classes. Speaking the local dialect was seen as an advantage. Two specialized cardiological nurses were rectuited for the hospital setting. For the general practices, a dietician and a practice assistant with a fairly high level of education were selected. Before the start of the intervention period, the health advisors received further training, combining commonly used methods (Kruijver, Kerkstra, Francke, Bensing, \& Van de Wiel, 2000). The main components were an introduction to theoretical topics, such as risk behaviors and models of behavior change, a two-day practical course in counseling skills, a two-day training on the use of the counseling protocol, and several simulation contacts. Training was continued during the intervention with a theoretical refresher day, two external courses on smoking cessation, and further theoretical self-tuition. However, the most intensive training tools were the two-monthly feedback sessions using video-recorded consultations during the first eighteen months of the trial. 
I OPENIRG SECTIOM

II MDDLE SECTIOH

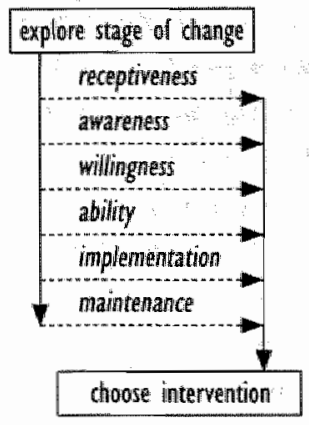

III CLOSHE SECTION

Figure 3.1 Schemotic counseling model

The health advisors used a counseling protocol consisting of three sections: an opening, a middle and a closing section (see Figure 3.1). Briefly, the opening section instructs the health advisors to establish rapport and collaboration (Kanfer \& Gealick-Buys; 1991). The six-step approach in the middle section first coaches the health advisors to make a thorough inventory of the patients' health behaviors, and of the determinants impeding healthy changes. Next, by analogy with stage theories of behavior change (Prochaska \& DiClemente, 1984; Weinstein, 1988), the health advisors have to classify each patient as being in one of the six consecutive motivational steps: receptiveness, awareness, willingness, ability, implementation and maintenance (Van der Burgt \& Verhulst, 1996; Laitakari, 1998). Subsequently, the middle section guides the health advisors in selecting one or more appropriate intervention strategies (e.g. Grueninger, Goldstein, \& Duffy, 1990). The closing section tells the health advisors to make an action contract before carefully terminating the meeting (Russell, 1986). Depending to its aim, each protocol section requires distinct skills and strategies, all of which were integrated in the observation list.

\section{Study procedure}

During the first eighteen months of the intervention, each of the four health advisors video-taped 16 interviews, including 8 initial consultations and 8 follow-up sessions, yielding a total of 64 video recordings. The health advisors did not start recording until they had practiced for an initial period of three 
months. During the next year, a bimonthly recording interval was chosen to guarantee sufficient time for feedback and improvement. The last video was recorded fifteen months after the first.

The health advisors recorded the videos themselves, and asked patients to participate in the quality assessment study immediately prior to the consultation. No specific requirements had to be met, other than that all 64 video recordings should concern different patients. In their short explanation, the health advisors emphasized that the purpose was a quality assessment of their own performance, not that of the patients. Absolute confidentiality was guaranteed. The health advisors asked patients for their verbal informed consent, while making clear that they could always refuse. For practical reasons, the patients were not randomly selected and no systematic record of refusals was kept. To obtain a representative sample, the recordings were made on previously defined days, and the health advisors were unfamiliar with the patients who had their initial consultation. This selection procedure has generally been found to result in low refusal rates (Coleman, 2000).

All 64 recorded consultations were assessed by three independent observers, who were experts on counseling techniques and on theories of behavior and behavior change, willing to assess a minimum of 16 videos, available during the recording period, and familiar with the local dialect. The observers had to have at least passed an examination in behavioral theories and completed two university counseling courses on interview and consultation skills. In total, ten observers were recruited: four PhD students and six final-year MPH-students of the Health Science Faculty of Maastricht University. They were between 25 and 35 years old and four of them were male. They were divided into four groups of three observers each, with two observers joining two different groups.

To facilitate uniformity of observations, observers received a detailed description of the evaluation criteria for the counseling skills to be judged. Moreover, to activate existing knowledge, they had to familiarize themselves with the counseling protocol and the accompanying background information. Lastly, they received written and verbal instructions about the observation list, so all of them would handle counseling situations and the observation list in a similar way.

Finally, additional qualitative information was gathered. First, observers were invited to write down comments on their assessments, especially on the unsatisfactory ones: These comments were used as feedback to the health advisors to facilitate their learning process. Second, at three points of time in the research period, the health advisors were interviewed about their experiences and opinions. Both sources of qualitative information were used to interpret some of the assessmient outcomes.

\section{Observation list}

To obtain an accurate quality picture, based on the counseling protocol, a fivepart observation list was constructed (see Appendix 3.1). Part I covers regulat- 
ing skills that are necessary to structure the consultation (Lang et al, 1990 ; Silverman et al., 1998), but also to form a working relationship (Kanfer \& Schefft, 1988, Russell, 1986). Such a therapeutic alliance is part of a patientcentered approach (Mead \& Bower, 2000) and enables shared decision-making (Charles et al., 1997). Important issues are opening the interview, creating further collaboration, using regulating summaries, drawing up an action contract, closing the interview, and agreeing about prolongation. Part II pays attention to general interview skills that are useful to direct and intensify the counseling (Lang et al., 1990; W. R. Miller \& Rollnick, 1991; Silverman et al., 1998). Relevant skills are attending behawior, asking questions, selection and insight giving skills and differentiating skills. Part III addresses the exploration of aspects of behavior change and part IV the intervention relating to these aspects (Conner \& Norman, 1995). Each of the six motivational steps, that is, receptiveness, awareness, willingness, ability, implementation and maintenance, requires specific behavioral strategies, all in order to facilitate stage transitions toward sustained behavior change. Part V concerns the brsic counseling attitude, which is essential in establishing a parient-centered approach (Mead \& Bower, 2000) and ensuring shared decision making (Elwyn et al., 2001). Important issues are a positive regard, non-normative behavior, and a stimulating approach. A further operationalization of the observation list can be found in Appendix 3.1.

Each of the five parts of the observation list consists of several subscales, measured by one or more items, and asks for a concluding overall mark. The items and overall marks had to be scored on one of two four-point rating scales: "unsatisfactory, doubtful, satisfactory, good" and "not at all or hardly, slightly, considerably, strongly". Most items also had an answering option "not applicable", meaning that the health advisor rightly made no use of this particular element, as it was not necessary or not useful in the consultation. Counseling skills that were not used in situations where they evidently had to be applied, had to be marked as unsatisfactory or doubtful.

\section{Analysis}

Originally, the study had a balanced between-within-subjects design, with video recordings as subjects, health advisors as between subjects factor and observers as within-subjects factor. This design became unbalanced however, because not all health advisors started at the same point in time, whereas quality assessment was nonetheless to serve as immediate feedback. Hence, the first and last groups of observers did not assess an equal number of consultations per health advisor. Two statistical packages were used: Stata 6.0 (weighted Kappas) and SPSS 9.01 (all other analyses), both for Windows.

\section{Data preparation, data reduction and patient characteristics}

The missing value (MV) analysis demonstrated that no items had to be eliminated, but that some further analyses required replacement of MVs. According 
to the observation instructions, "not applicable" (NA) meant that a particular counseling aspect was righty omitted, indicating that $\mathrm{NA}$ was conceptually identical with satisfactory. Therefore, NAs were recoded correspondingly.

The data were reduced using reliability analyses. To ensure the independence of observations, the four groups of observers with related observations (i.e. who had seen the same videos) were split into three different sets of four independent observers (1.e. who had seen different videos). The 77 single items of the observation list could be clustered into 19 theorctically meaningful subscalles with sufficient internal consistency (see Appendix 3.1; for reasons of readability, "subscale" also is used for single items). Principal component analyses (PCA) confirmed these findings.

Frequencies were run for patient characteristics: Crosstabs with $x^{2}$ tests determined the distribution of patients among health advisors, and among initial and follow-up counseling sessions. Because of their theoretical rellevance, patient characteristics were taken into account in some of the following analyses.

\section{Interabserver agreement}

Interobserver agreement for the dependent observers was assessed in three consecutive steps, of decreasing rigor. The first step determined the absolute agreement between the three raters, resulting in a multirater Kappa for each group of dependent observers as a whole (Nichols, 1997; Siegel \& Castellan, 1988). As agreement was found to be poor; the second step assessed the weighted absolute agreement by including a correction factor for varying distances between raters. This resulted in a calculated mean weighted Kappa (Siegel \& Castellan, 1988). Because agreement still appeared to be at most fair, the third step established the relative agreement between raters. The resulting Kendall's coefficient $W$ undicates whether observers followed a similar score pattern and thus agreed about rank orders (Siegel \& Castellan, 1988). A further clarification of the three interobserver agreement methods can be found in Table 3.1.

\section{Quality of health counseling}

The scores of the dependent observers were combined with an aggregate file procedure, using the interview number as breaking variable $(\mathrm{N}=64)$. Because dependence of observers was associated with subsequent time intervals, this aggregation procedure created observation periods. To assess the overall quality of health counseling, mean scores were calculated for each subscale and each overall mark. Differences between subscales and between owerall marks were tested in a repeated meastures procedure (GLM). Because the questionnaire asked no final opinion on the whole interview, a representative total score was computed using the mean of the overall marks and the weighted mean of the scores on the subscales.

Differences in counseling quality between health advisors, between observation periods (i.e. changes over time), between initial and follow-up interviews, between male and female patients, and between sessions with one or more participants, were evaluated in an univariate ANOVA procedure (GLM). The ini- 
tial model, with total score as dependent variable, encompassed all of the above mentioned independent variables, Because of a shortage of observations, interaction terms were ignored (Tabachnick \& Fidell, 2001). This model was reduced in a top-down procedure with stepwise deletion of most non-significant terms. The remaining model was subsequently applied to the scores on subscales and the overall marks.

\section{RESULTS}

\section{Patient characteristics}

As agreed, 32 initial and 32 follow-up consultations were recorded on video. The patient was male in 43 sessions $(67.2 \%)$ and the average age of the participants was 60.6 years (range $36-75$ ). Fifty-five sessions involved only one person (85.9\%), while others involved patients and their partners. Gender and number of participants were equally distributed across health advisors $\left(\chi^{2}=4.59, \mathrm{df}=3, \mathrm{p}=0.20\right.$ and $\chi^{2}=4.26, \mathrm{df}=3, \mathrm{p}=0.2 \mathrm{l}$, respectively) and across initial and follow-up meetings $\left(\chi^{2}=0.83, \mathrm{df}=1, \mathrm{p}=0.36\right.$ and $\chi^{2}=0.13$, $\mathrm{df}=1, \mathrm{p}=0.72$, respectively). Further, gender and age distribution largely corresponded with that of the study population as a whole $(67.9 \%$ male, mean age 61.6), indicating a representative sample.

\section{Interobserver agreement}

The multirater Kappas and the weighted Kappas both indicated poor to fair agreement about the absolute quality of the counseling (Table 3.1). Kendall's coefficient however, showed that observers agreed to a considerable extent about the quality ranking of individual counseling skills and of the consultations as a whole, with the highest level of concordance for the subscales and the lowest for the overall marks. The relatively poor agreement within the third observation group was mainly caused by one observer. Hence, the absolute scores presented here should be interpreted with caution, but may nevertheless serve as fairly reliable indications of comparative differences between the performances of the health advisors and their application of the various counseling skills. 


\section{Quality of health counseling}

As can be seen in Table 3.2, the overall quality of the health counseling (2.85) narrowly failed to be assessed as sufficient (i.e. 3.00 or $66 \%$ of the maximum possible score). Nevertheless, observers considered the health advisors' basic counseling attitude (3.15) to be satisfactory, and of higher quality than their interview skills (2.85) and their exploration of the steps of behavior change (2.79). The interview skills, in turn, were evaluated more favorably than the intervening strategies (2.66). These interventions, as well as the regulation skills (2.65), were regarded as open to serious doubt.

As for the regulation skills, the closing of the interview was assessed as rather unsatisfactory, and ranked as inferior to the other structuring aspects. The observers were more pleased with the opening of the interview and the settling of action contracts, than with the rather doubtful use of regulating summaries, but ranked the former at the same level as creating collaboration and making clear arrangements about the prolongation of the counseling. Of the interview skills, attending behavior was given the highest quality score. Making inquiries and asking for further explanation were seen as more satisfactory than the way health advisors practiced selection and insight giving skills and differentiating skills. No great differences were found in the way the health advisors addressed the individual motivational steps of behavior change, although awareness was seen as more adequately dealt with than receptiveness and willingness. Finally, as for the basic counseling attitude, the observers evaluated the health advisors' non-normative behavior more favorably than their positive regard, and regarded both aspects as slightly superior to their stimulating behavior.

\section{Differences in quality}

The top-down ANOVA procedure revealed no differences in scores for gender and for single versus joint consultations. This resulted in a rather simple model, with score as dependent variable, and health advisor, observation period and initial versus follow-up consultation as significant independent factors.

Only the overall performance of the third health advisor was regarded as sufficient (3.05), although even she did not have a satisfactory score on all individual counseling skills (Table 3.2). According to the observers, she performed significantly better than the second (2.78) and fourth health advisor (2.65). On the whole, the first health advisor was seen as the second best (2.91), and as performing significantly better than the fourth. Although not always significant, this pattern $(3>1>2>4)$ was recognizable in nearly all parts and subscales of the observation list. Remarkable exceptions were non-normative behavior, where the fourth health advisor scored better than the others, and the arrangement of action contracts, which was handled satisfactorilly onlly by the second health advisor. Further, the previously established pattern of increasing marks in the order regulating skills, behavioral exploration and intervention, interview 


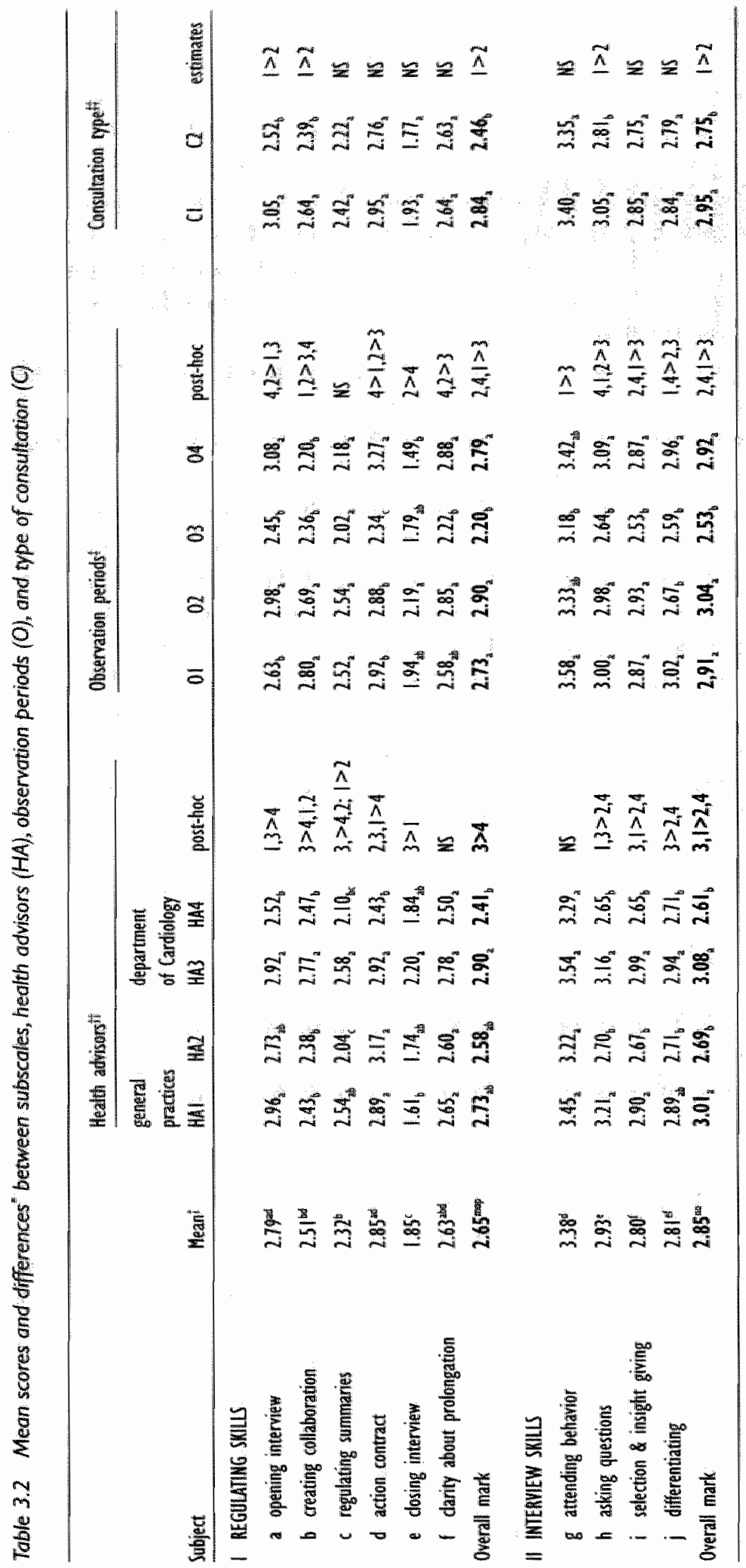




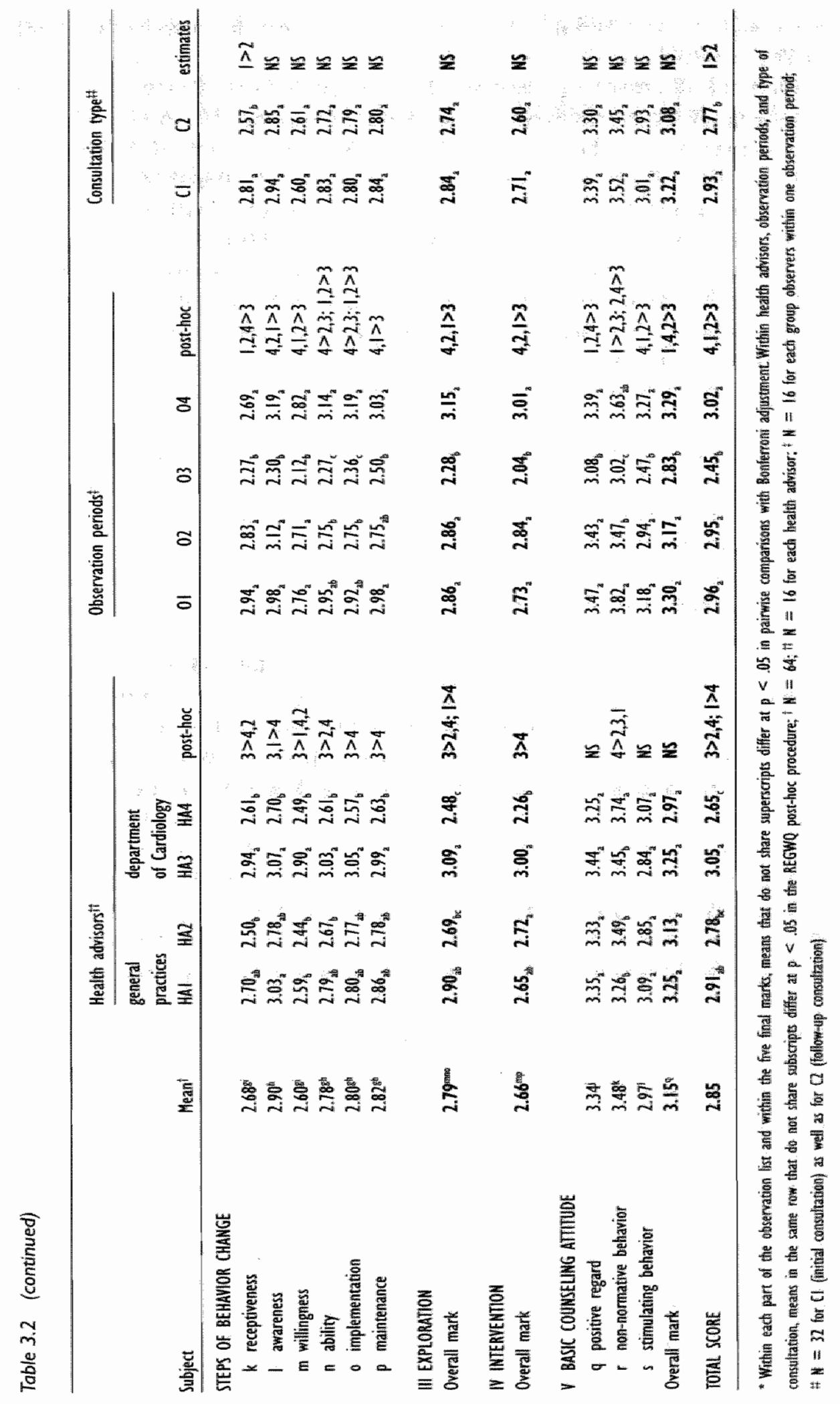


skills, and basic counseling attirude appeared to be identical for each of the four health advisors.

Table 3.2 also shows a poorer overall assessment in the third period. Although not always significant, the same pattern was found for health advisors ${ }^{3}$ performance on the subscales. No differences in total scores were found between the first, second, and fourth observation periods. Together, this indicates that counseling skills did not improve over time. Additional analyses within observation periods did not show a time effect either.

On the whole, health advisors appeared to manage initial consultations better than follow-up meetings. This difference was mainly caused by the opening of the session, the way health advisors made inquiries, and their attention to the parient's receptiveness.

\section{DISCUSSION AND CONCLUSION}

\section{Quality of heal th counseling}

On the whole, the health advisors' performance in the high-risk part of the Hartslag Limburg prevention project was evaluated as not entirely sufficient. This is a somewhat disappointing result, since the theoretical and practical introduction they had received, as well as the continuous feedback during the intervention period, were rather extensive in comparison with other communication training programs (Kruijver et al., 2000). This may indicate that health counseling is a rather complex and difficult task which is hard to train. That is supported by a review of communication training programs, which found only limited effects on nurses skills and behaviors (Kruijver et al., 2000). The review also revealed barriers to improving consultation practice, such as prior experience, teachers being unfamiliar with practice, insufficient practical and emotional support, a negative attitude among colleagues, pressure of time, and feedback given in an unsafe environment. In the present study, the health advisors, while still unaware of the overall assessment, acknowledged that these process variables may indeed have inhibited their development, perhaps because of the pioneering situation.

Compared to two other evaluations of counseling quality, the present results may be seen as hopeful. In the only analogues quality assessment study found, midwives used motivational interviewing to help pregnant wonen stop smoking (Tappin et al, 2000). A minimum of $75 \%$ of their audio-recorded interviews were evaluated as consistent with this counseling technique, in the sense that they were given at least $66.6 \%$ of the maximum score. Using the same cutoff point in the present study would mean that $45.3 \%$ of the interviews reached this quality level. Although a second study was originally designed for other 
purposes, the data provided allowed a corresponding overall score for counseling quality to be derived (Ram et al., 1999). This study used video observations of general practitioners, whose general communication performance was rated at $41.7 \%$ of the maximum possible score. Translated into a compatible percentage, the health advisors in the present study obtained $61.6 \%$ of the highest possible score. Because these comparisons presumably are negatively biased by the complexity of the present task, it may be concluded that the health advisors performed considerably better than the general practitioners, though somewhat poorer than the midwives. Other quality assessments did not report an actual quality score, made use of simulation contacts, assessed only specific counseling aspects, or made no use of rating scales.

Despite the marginally insufficient overall score, the health advisors' attending behavior and basic counseling attitudes in particular were evaluated as fairly positive. These aspects can be classified as care-oriented or socio-emotional behaviors (Ong, De Haes, Hoos, \& Lammes, 1995), that may be characteristical of patient-centeredness. This style of caregiver-patient relationship is found to contribute to compliance with medical recommendations and quality of life, while socio-emotional behaviors as such have mostly been associated with patients' satisfaction, understanding of information, and physical health (e.g. Bensing, 1991; Ong, Visser, Lammes, \& De Haes, 2000). Thus, the high quality of attending behavior and basic counseling attitude in the present study may be an important factor in achieving the intended behavior change and health improvement.

In their evaluation, the observers may have overlooked the fact that counseling in practice should always be adapted to the individual patient, which may have led to an underestimation of the health advisors' actual counseling performance. This personal adaptation is necessitated by the great differences in patient preferences for consultation styles (Van den Brink-Muinen et al., 2000; Mead \& Bower, 2000), patient communication styles (Kettunen, Poskiparta, \& Liimatainen, 2000), and patient participation frames (Kettunen, Poskiparta, Liimatainen, Sjögren, \& Karhila, 2001). It has also been suggested that clini cians' flexibility and responsiveness to patient preferences may be the key to patient-centered counseling (Long, 1995 cited in Mead \& Bower, 2000). In the present study, the observers were theoretical rather than practical counseling experts, who saw only one session in a whole counseling process, and used an observation list with rather stringent criteria that lacked an overall score for counseling quality. Therefore, they may have overestimated the importance of theoretical criteria, and at the same time have underestimated their practical applicability. The health advisors did indeed report that they had difficulties acting according to the pre-set guidelines, mainly because of discouraging patient attitudes and reactions. 


\section{Differences in quality}

Significant differences in quality were found between the health advisors, with a fairly consistent pattern during the whole intervention period, as well as on nearly all individual counseling aspects: Apart from true quality differences and the so called halo effect, meaning that assessments are influenced by the observers' overall impression (Scott, Fuqua, \& Newman, 1986), this pattern might be a reflection of individual counseling styles or personal characteristics (Pope \& Kline, 1999). However, the fact that the fourth health advisor was rather consistently evaluated as less competent than the other three may also be caused by her lack of active command of the local dialect. In reaction, most patients switched to standard Dutch, which was less familiar to them. This may have limited the intensity of the counseling, generally leading to poorer evaluations, but also to higher scores on non-normativity. By contrast, the less normative approach of the fourth health advisor may have been inspired by her finding the counseling protocol too normative, making her a less intensive counselor than the orher three.

Significant differences were also found between the performance on individual counseling skills, relating to differences between the initial and follow-up consultations. While rating scales measuring patient-centeredness have been found to be relatively insensitive to the complexiry of medical interactions (Mead \& Bower, 2000), the present instrument was able to detect quality differences for the individual aspects of health counseling interactions. Apart from the different situations, this may have been due to the comprehensiveness of the observation list. As a resul.t, the present quality assessment method appeared to be a useful tool for personal feedback and for general recommendations on further education and training of the health advisors. The discriminating power of the observation list also contrasts with earlier conclusions that various quality measures, because of their high correlations, only represent one unidimensional counseling factor (Scott et al., 1986).

No indication was found for improvement of counseling quality over time. One possible explanation involves the same factors that probably interfered with health advisors' overall performance, which would mean that there was in fact no improvement. This is, however, contradicted by the health advisors' own opinion that they did indeed became more skillful and competent, but that this improvement was slow to evolve, exceeding the quality assessment period of eighteen months. It is known that the integration of acquired or modified communicative behaviors into daily routine may take some time (Hulsman, 1998 cited in Kruijver et al., 2000). To be able to observe such quality improvement, the present study might have needed both longer intervals between the video recordings and a longer study period. On the other hand, it would have been advisable to speed up development, for instance by supervised practical training.

A second explanation for the absence of quality improvement over time would inwolve shortcomings of the study design. A crossed, balanced design (Tabachnick \& Fidell, 2001), in which varying groups of observers would 
have judged video recordings from different intervention periods, would have resulted in clearer findings about possible developments. In that case however; observers might have been more vulnerable to instrumentation (1.e. changes in their characteristics, Green \& Lewis, 1986), again threatening the internal validity of the study.

\section{Reliability and validity}

The internal consistency of the observation list was acceptable, but a serious limitation of the present study was the rather poor absolute interobserver agreement. Although regrettable, this may be not very surprising after all. To begin with, interobserver agreement may have been reduced by the complexity of the situation observed (Wakefield, 1985). This complexity increases the amount of subjective judgment, making it more difficult for observers to agree about quality thresholds for specific behavioral manifestations (Mead \& Bower, 2000). The consultations in the present study were of considerable length, the performance assessed was rather comprehensive, and the rating codes used were quite exhaustive and complex. Assessments of communication skills that have reported better interobserver agreement usually have used less complex instruments in less complex circumstances (e.g. Smit \& Van der Molen, 1996). Thus, agreement probably could have been improved by a more concise observation list, less complicated rating codes, and briefer video recordings, but it may be questioned whether this would still have done enough justice to the complexity of the profession involved:

A second factor that may have impeded interobserver agreement is the rather limited observational instruction in combination with the absence of an extensive observation training (Mead \& Bower, 2000). Both aspects should have been more actively addressed in the present study, but this could not be achieved because of financial and time restrictions. However, interobserver agreement could have been strengthened by offering the observers a further specification of scoring criteria.

Poor reliability results in poor validity and limits validation opportunities (Streiner \& Norman, 1995). Validation is also problematic because of the lack of a "gold standard" for health counseling quality (Elwyn et al., 2001). However, apart from face validity, several experts in the domain of health counseling and behavior change were consulted in the preparation of the present instrument to ensure expert validity. Besides, both the extensive theoretical underpinning of the score list and the high internal consistency of its subscales indicate at least content validity. Also, most correlations suggest that the different subscales measured different counseling aspects. Finally, since the expert opinions on counseling quality are to be linked with patient opinions as well as other process, impact and outcome data, more information will be obtained about concurrent and predictive validity, respectively. In fact, a comparison with preliminary data of the simultaneous quality assessment by patients indicates 
that they at least agree with the experts about the superior quality of the third health advisor:

Validity was possibly affected because video recordings are, for ethical reasons, a quite obtrusive research method and therefore likely to change practice. Although other firdings suggest that in primary care this "audience effect" (Wakefield, 1985) is rather limited (Coleman, 2000; Ram et al, 1999), the four health advisors reported that the video camera had made them nervous and uncertain, and that patients behaved either more exuberant or more reserved than in the absence of the video. Therefore, the quality of the video-recorded consultations may have been inferior to the health advisors' normal practice. The alternative of audio recordings are experienced as threatening only initially (Tappin et al., 2000), and found to overlook just little communicative information (Weingarten, Yaphe, Blumenthal, Oren, \& Margalit, 2001). Nevertheless, the present study opted for the additional observation of non-verbal behavior, because this has been said to be at least as important as verbal performance (Argyle, 1983).

In sum, in view of the complexity of the task, the results of the few other qualicy assessments available, the favorable evaluations of some critical counseling aspects, and the additional need for individual adaptation, the health advisors" performance in our study can be evaluated as rather encouraging. Due to limited interobserver agreement and the absence of an external standard however, the absolure quality scores remain difficult to interpret. Shortcomings in the study design as well as validity problems also precluded a thorough evaluation of quality improvement over time. Thus, solid conclusions about the implementation of the current intervention remain problematic.

\section{Practice implications}

Qualiry assessments of health counseling interventions within an RCT are rare and difficult to conduct, but are also worthwhile because they can yield valuable process information. Before starting a quality assessment, researchers should carefully select a methodology that is appropriate for the primary aim of the study. The complex instrument used in the present study was found to be useful for personal feedback and general recommendations on further education and training, thus helping to optimize the intervention. For this purpose however, a more sober and less expensive study design would probably have been sufficient. Although the relative interobserver agreement enables the present results to be linked to other process, impact and outcome data, their value for the interpretation of the results of the RCT may be limited. For this purpose, a simpler and more pragmatic quality assessment, generating more valid results, might have been more adequate, but the study design should probably have been even more rigorous and costly. The present methodology seems fairly effective in elucidating processes underlying an intervention in an RCT. Nevertheless, a better focus on the nature of the processes to be elucidated could have reduced the 
observation list, and a less rigorous design could have been considered, allowing the gathering of longer-term and qualitative information.

Finally, practitioners intending to start a health counseling project should take into account that counseling is a complex and difficult task that requires great skills. Also, they should anticipate slow quality progress. Hence, they should carefully watch the process factors that may inhibit health counselors' performance and improvement, and, besides offering adequate preparatory training, consider additional supervised practical training.

\section{ACKNOWLEDGMENT}

Data were collected as part of the Hartslag Limburg project, which is coordinated by the Maastricht Regional Public Health Institute (GGD-zzl), and funded by the Netherlands Heart Foundation (NHS). Thanks are due to the four health advisors, and to all participating patients and observers. 


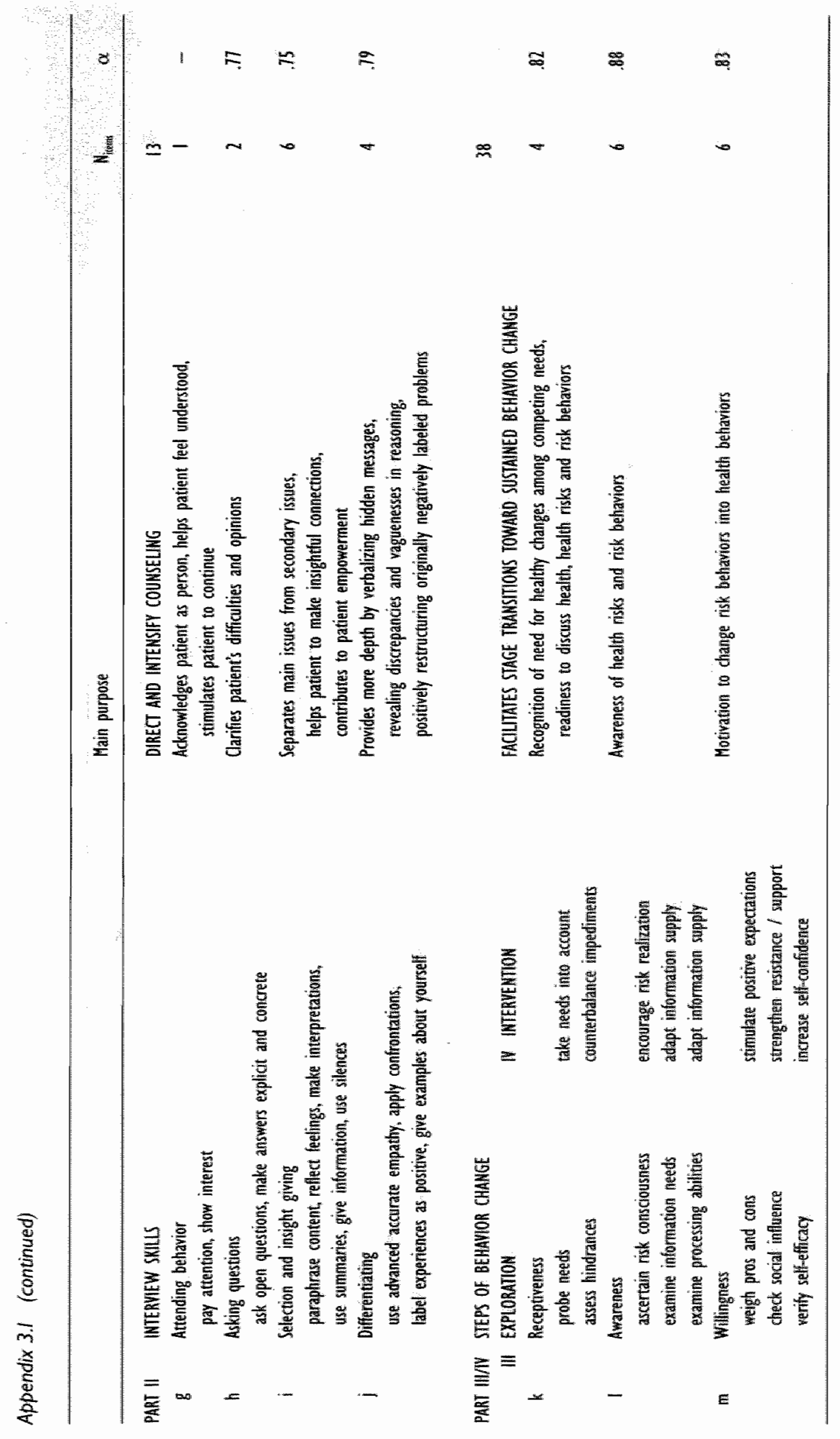




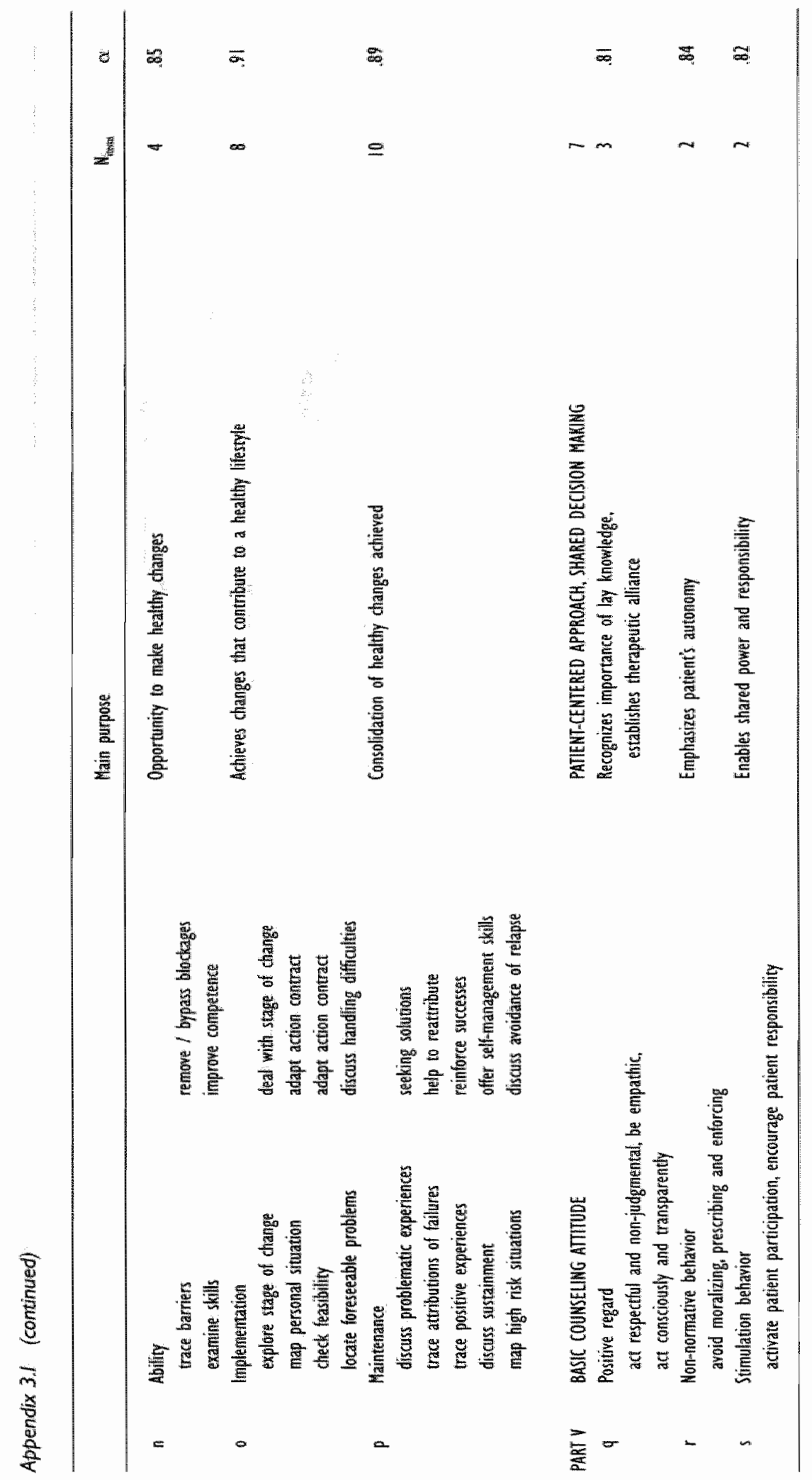




\section{CHAPTER 4}

Patients' opinions on health counseling in the Hartslag Limburg cardiovascular prevention project: perceived quality, satisfaction, normative concerns, and behavior related outcomes

This chapter has been submitted for publication and is under revision as: Harting, J., Van Assema, P., \& De Vries, N.K. (2004). Patients' opinions on health counseling in the Hartslag Limburg cardiovascular prevention project: perceived quality, satisfaction, normative concerns, and behavior related outcomes. 


\section{ABSTRACT}

This survey assessed patients' opinions on a new service in the Dutch health care system, viz, health counseling about behavioral risks and possible lifestyle changes. This was introduced within the framework of the Hartslag Limburg prevention project and was offered to patients at high risk of cardiovascular diseases. A questionnaire was developed to measure quality, satisfaction, normative concerns, and behavior related outcomes. It was distributed among 1,301 64 patients after they had completed the counseling, and returned by 1,056 of them (response rate $81.2 \%$ ). Patients generally reported high levels of quality and satisfaction. They also indicated that the service generated changes in health behavior related outcomes, but the accompanying effect studies will have to provide more solid evidence for its effectiveness. It was concluded that the service was highly acceptable to patients, but that the health advisors should be careful not to induce less favorable normative concerns. 


\section{INTRODUCTION}

Health counseling by a health advisor about behavioral risks and possible lifestyle changes is a new, additional service in the Dutch health care system. It was introduced within the framework of Hartslag Limburg (Dutch for Heartbeat Limburg), a regional project for the prevention of cardiovascular diseases (CVD) in the Dutch province of Limburg (Ruland et al, 1999). Because of the novelty of the service (Green \& Lewis, 1986), an extensive process evaluation was carried out, including the present inventory of patients ${ }^{2}$ opinions.

As certain quality aspects of health communication have been found to be a precondition for its effectiveness (J. B. Brown et al., 2003; Mullen et al., 1992 ; D. Roter, 1989; Stewart, 1995b), the first aim of the present study was to assess how patients evaluated the quality of the counseling. The second aim was to measure the patients' level of satisfaction with the new service, as satisfaction has been found to increase the intention to comply (Pascoe, 1983) and to enhance the actual adherence to health advice (Aharony \& Strasser, 1993; D. Roter, 1989). The third aim was to assess patients' moral concerns, which have been claimed to be evoked by health communication (Martin, 2001; Minkler, 1999) and to positively or negatively affect health behavior related outcomes (Brownell, 1991). The fourth aim was to get some initial indications of the new service's effectiveness by addressing the perceived changes in behavioral determinants, intention, health behavior, and health itself. Finally, we assessed whether the patients' opinions varied with different health advisors, patient characteristics, the moment at which they entered the study, and the total number of consultations.

The health counseling sessions focused on the reduction of three behavioral risk factors, viz., high fat consumption, smoking, and physical inactivity, and proceeded in accordance with a practical counseling model (Harting \& Van Assema, In preparation). The new service was a prominent component of the high-risk project within the Hartslag Limburg program, which was aimed at individuals with an elevated cardiovascular risk. Between April 1999 and October 2001, health counseling was offered to the intervention patients in a randomized controlled trial ( $\mathrm{RCT}$ ) to evaluate the behavioral and biomedical effects of the high-risk approach. In 2001, Hartslag Limburg as a whole, i.e. the high-risk project, a community project, and the accompanying evaluation studies, was selected as one of the twelve WHO "Towards Unity for Health" projects (Boelen, 2001). 


\section{DEFINING QUALITY, SATISFACTION, NORMATIVE CONCERNS, AND BEHAVIORAL OUTCOMES}

Although patient satisfaction has become increasingly important in evaluating the quality of thealth care services, consensus is still lacking on the mechanisn that produces satisfaction and on the concept of satisfaction itself (Aharony \& Strasser, 1993; B. Willuans, Coyle, \& Healy, 1998). Another debate concerns the distinctions and causal relationships between perceived quality, sarisfaction, and outcomes of care (e.g. Aharony \& Strasser, 1993; Pascoe, 1983). This lack of consensus makes it necessary to define the perspectives that were adopted for the present study.

Perceived quality is seen as a cognitive evahuation of the structure, process, and immediate outcome of a health service (as opposed to behavional or clinical outcomes); which in turn may serve as independent determinants of satisfaction (Aharony \& Strasser, 1993; Donabedian, 1980; Linder-Pelz, 1982; Pascoe, 1983). Structural components relate to the way in which care is organized and financed, and the accessibility, avalability, continutity, and convenience of care (Aharony \& Strasser, 1993; Pascoe, 1983). For instance, satisfaction has been found to be influenced by length of visit, service location, waiting time, travel time, and costs (Pascoe, 1983). Regarding the process of care (Aharony \& Strasser, 1993; Pascoe, 1983), Findings suggest taking into account the patientprovider interaction, technical competence, interpersonal skills, and continuity of care (e.g. J. B. Brown et al., 2003; Hall \& Dornan, 1988a; Stewart, 1995a; S. Williams, Weinman, \& Dale, 1998). The immediate outcome characteristics, or "procedural end points" (Donabedian, 1980), are assumed to include comfort experienced and commitment.

Patient satisfaction is regarded as an impact effect, i.e., as an artitude resulting from the combined cognitive and affective or emotional responses to the distinct aspects of a health service (Linder-Pelz, 1982; Pascoe, 1983). For instance, patients may experience higher or lower levels of satisfaction with the specific structural, procedural and immediate outcome dimensions of care discussed above ( $\mathbb{P a s c o e}, 1983$ ). In addition, patients' contentment with care can be assessed on a more global level (Dabholkar, Shepherd, \& Thorpe, 2000; Pascoc, 1983; Zastowny, Stratmann, Adams, \& Fox; 1995). In the case of health counseling, moral responses deserve attention as a second impact domain (Martin, 2001; Minkler, 1999). These feelings in turn may positively or negatively affect belavioral intentions, health behavior, and health itself (Brownell, 1991). This moral dimension may be related to "patient convenience" (Zastowny et al., 1995).

Outcome variables of a health service include compliance, behavioral intentions, health behavior, health, and health care utilization (Pascoe, 1983; Strasser et al., 1993). For the present study, the perceived health behavior related outcomes, which may ultimately result in clinical changes in health (Aharony \& Strasser, 1993; Pascoe, 1983), were assumed to be the most interesting outcome variables. 
On the whole, perceptions of quality, satisfaction, normative concerns, and outcomes may vary as a function of patients' socio-demographic characteristics (Pascoe, 1983) and their preexisting attitudes, expectations, and prior experiences (Strasser et al., 1993), as well as their physiological and psychological health (Aharony \& Strasser, 1993).

\section{METHODS}

\section{Population, intervention, and study procedure}

During the RCT, 10 cardiologists of the University Hospital Maastricht, and 35 general practitioners of 25 practice units throughout the region, included 2,743 high-risk patients. High risk was defined as $\geq 20 \%$ chance of incurring a cardiovascular event within the coming 10 years. The 1,398 patients in the intervention group were invited for health connseling. The length of a full counseling course was flexible, but was not intended to exceed six consultations, with the first meeting allowed to last a maximum of 45 minutes; and the follow-up sessions 30 minutes each.

The four health advisors in Hartslag Limburg, all female and aged between 30 and 40 years, used a theoretically and empirically underpinned model consisting of an opening, a middle, and a closing section (see Figure 4.1, Harting \& Van Assema, In preparation).

Briefly, the opening section of the model instructs the health advisors to establish rapport and collaboration. The middle section first coaches the health advisors in drawing up a full inventory of the patients" health behaviors and of the determinants impeding healthy changes. By analogy to stage theories of behavior change, the health advisors classify each patient as being in one of six consecutive motivational steps. After having identified the factors hampering change, the model guides the health advisors in selecting one or more appropriate intervention strategies. For the patients in the receptiveness step, these strategies should lead to greater attention for and interest in a healthy lifestyle. Patients in the awaveness step need to obtain more knowledge of and insight into health risks and health behaviors. As for those in the willingness step, the counseling should focus on a more positive attitude, more perceived social support and more self-confidence with respect to a healthy lifestyle. Patients in the ability step have to be helped to overcome possible barriers and to achieve the skills needed to effect healthy changes. The implewentation step should result in concrete plans to make healthy changes as well as in the actual implementation of these plans. Lastly, the health advisor should promote that patients in the maintenance step continue their healthy habits. The closing section of the model 
1 OPENHE SECIOH

II MIDOLE SECTION

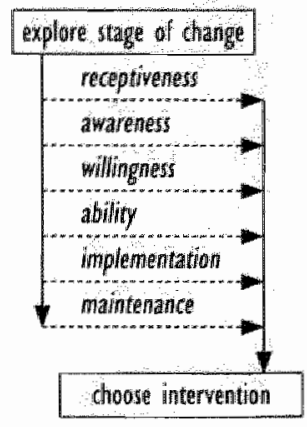

III CLOSING SECTION

Figure 4:I Schematic counseling model

tel]s the health advisor to draw up an action contract before terminating the meeting in a careful way.

In general, the health advisors are expected to adopt an empathic attitude, use a respectful approach, and act in a professional way. They are also required to establish adequate information exchange, and focus on increasing the patients' insight into their own situation. Finally, they have to ensure that the aims of the counseling are clear, and reach agreement on concrete action plans that tie in closely with the patients' personal expectations, situation, motivation, and capabilities.

Immediately after ending the counseling course, the health advisors handed out a patient opinions questionnaire, which had to be answered by the patients at home and returned to the researcher's address at the university. The health advisors explained that the main purpose of the questionnaire was to evaluate the new health service. To minimize the influence of social desirability, patients were assured that their opinions were strictly confidential and not accessible to the health advisors themselves. In order to increase the patients' response rate, a written reminder was sent in case the questionnaire had not been returned to the university within two weeks.

\section{Questionnaire}

The precise wording of the items in the patient opinions questionnaire (see Appendix 4.1) was guided by the definitions of the individual concepts dis- 
cussed above, as well as by the specifications given in the counseling model. It was decided, where possible, to ask for evaluarions instead of reports (e.g. the perceiwed adequateness instead of the amount of information exchange), in order to best capture the responsiveness of the provider to the patients' needs and expectations (J. B. Brown et al., 2003), which may represents the key element in the interaction (Stiles, 1989).

Regarding the quality of the new service, patients were asked to appraise the structural aspects, the process components (the health advisors' counseling attitude, their interview skills, and the suitability of their recommendations), and the immediate outcomes. In addition, they were asked to assign an overall quality mark to the health advisor. To avoid overlap with the quality aspects and in line with tradition in marketing research, satisfaction was composed of severad. evaluative statements on the service as a whole. Moral concerns were specified as feeling more responsible for one's health, experiencing more life restraints, and being troubled more severely by a guilty conscience as a result of the health counseling. In addition, patients were asked how intrusive they found the new service. The outcome effects were all assessed on a global content level, viz., healthy living, since it was not known beforehand which specific heaith behavior would be the topic of the counseling. The patients were asked to report any changes in health behavior related determinants, behavioral intentions, actual health behaviors, and continuation of healthy habits as a result of the counseling, as well as to indicate whether they had felt healthier after or before the counseling. Finally, they were asked whether they favored personal counseling over mass media approaches, and which health care provider would be the most suitable to provide it.

Some steps were taken to minimize common methodological flaws in quality and satisfaction research (Aharony \& Strasser, 1993; Perneger, Kossovsky, Cathieni, Di Florio, \& Burnand, 2003). To increase response variance and to avoid ceiling effects, ratings were preferred above reports where possible, and five-point Likert scales or bipolar adjectival scales were used. Where fusible, positively and negatively worded items were balanced, and, if required, both sides of a concept were measured with two separate items. To prevent neutral responses, the aspects relating to the health advisors' counseling attitude were measured on four-point umpolar adjectival scales. Besides, patients were invited to write additional comments on a separate blank page.

Additional information about socio-demographic patient characteristics, such as age, gender, and educational level, and indicators of patients' earlier health behaviors, such as body mass index (BMI) and smoking status, were derived from both the inclusion list and the baseline effect questionnaire. The registration forms that the health advisors kept for each patient supplied the health advisor's number and the total number of consultations. 


\section{Analysis}

Descriptive statistics revealed the population characteristics, number of consultations, and means and standard deviations for all patient opinions. To examine whether the research population was representative of all patients who actually visited a health advisor, a logistic regression analysis was performed with response as dependent variable, and age, gender, educational level, $\mathrm{BMI}_{\mathrm{y}}$ and smoking status as independent variables.

Repeated measures procedures (GLM) tested differences in patients' opinions on the individual aspects of guality, normative concerns, and health behavior related outcomes. Whether differences in opinions were associated with different service or patient characteristics was examined in linear regression analyses. For each opinion as dependent variable, health advisor, age, gender, educational level, BMI, smoking status, inclusion week, and total number of consultations were entered as independent variables. Interactions between age and gender, and the other independent variables were also included in the regression equations. All regression models were subsequently reduced by stepwise deletion of non-significant interaction terms $(p \geq .01)$, which resulted in the elimination of all interaction effects. This was followed by a stepwise deletion of non-significant main effects $(p \geq 05)$.

\section{RESULTS}

\section{General information}

Of the entire intervention group of 1,398 patients, 1,301 actually visited the health advisor, and 1,091 returned the patient opinion questionnaire. Thirtyfive guestionnaires ( $3.2 \%$ ) with more than $25 \%$ missing values were labeled as non-response, resulting in an effective response of 1,056 (81.2\% of actual visitors; $\mathrm{N}_{\text {thospitit }}=519, \mathrm{~N}_{\mathrm{GP}}=537$ ). Smokers were found to be twice as likely to non-respond than non-smokers ( $O R=.42, x^{2}=25.59$, $\mathrm{df}=1, \mathrm{p}<.0001$ ).

At baseline, respondents had an average age of 61.9 years, and two thirds of them were male (see Table 4.1). Half of the parients had a low educational level, while over one third had an intermediate level and the remaining one eightlh a high level. The mean BMI of the respondents was 27.4 , with nearly half of the patients being overweight and nearly a quarter being obese. Less than a quarter of the patients smoked.

The mean number of consultations per person was 2.62. Nutrition had usually been the main topic of the counseling, followed by physical activity, and smoking. 


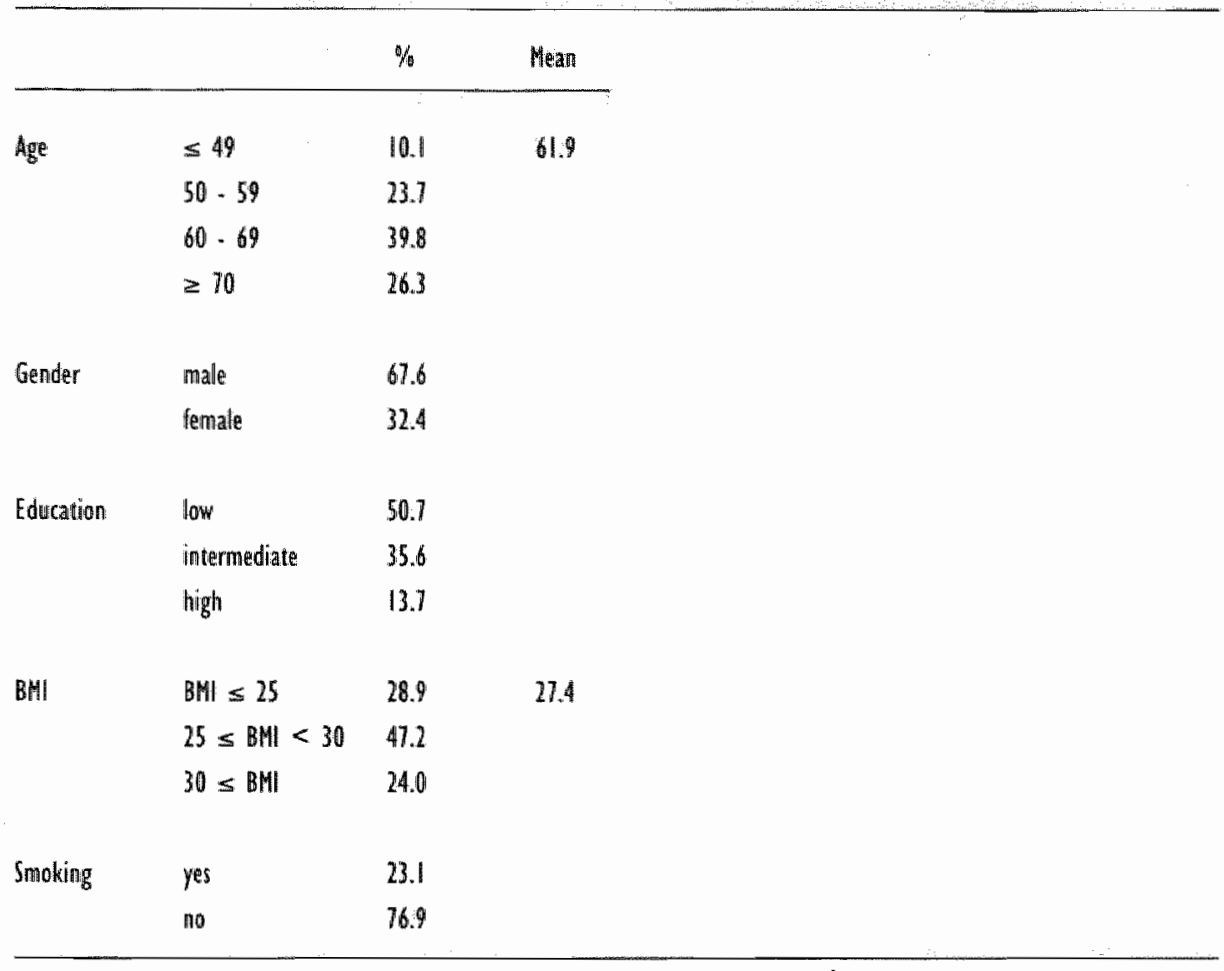

Perceived quality, satisfaction, normative concerns, and behavioral outcomes

The structural aspects of the service were generally regarded as satisfactory (Table 4.2), but the waiting time, and the time and money patients had to invest were seen as somewhat less acceptable. As for the process aspects, patients greatly appreciated the health advisors' counseling attitude, with respectfulness rated highest, followed by empathy, and professional attitude. Patients were also content with the health advisors' interview skills, with somewhat higher scores for their information exchange abilities than for their capacity to provide insight. In addition, patients felt that the health advisors succeeded in adapting their recommendations to the patients' personal beliefs and circumstances. However, implementation of the action plans that the health advisors and the patients had agreed on was still perceived as rather difficult. Both of the immediate outcome aspects, i.e., clarity about the aims and actions and agreement reached, were perceived as satisfactory. Most patients felt that their own contribution to drawing up the action contracts had been at least equal to that of the health advisor. The overall quality mark of 8.2 could be verbalized as "good". 
Toble 4.2 Patients' opinions about quality, satisfoction, nomative concerns, and autcomes of heafth counseling

\begin{tabular}{|c|c|c|c|c|c|}
\hline & Mean & 50 & $\%$ & opinion & \\
\hline \multicolumn{6}{|l|}{ QHALTY AfPeTS } \\
\hline \multicolumn{6}{|l|}{ Structure } \\
\hline good structural aspects & 1.30 & .39 & 99.4 & agreed & $p 0 p$ \\
\hline \multicolumn{6}{|l|}{ Process } \\
\hline \multicolumn{6}{|l|}{ Counseling attituds } \\
\hline enpathic attitude & 3.37 & .45 & 89.4 & considered applicable & $(\geq 3)^{*}$ \\
\hline respectrul attitude & $3.43_{\mathrm{i}}$ & .46 & 88.5 & considered appificable & $(z 3)^{p}$ \\
\hline protessiontal attitude & $3.28_{2}$ & .48 & 82.5 & considered applicable & $(\geq 3)^{+}$ \\
\hline \multicolumn{6}{|l|}{ Interview skifls } \\
\hline grood information exchange & $1.26^{\mathrm{a}}$ & .51 & 97.8 & agreed & $(>0)^{t}$ \\
\hline good insight giving & $1.17^{\mathrm{b}}$ & .70 & 91.0 & agreed & $(>0)^{s}$ \\
\hline \multicolumn{6}{|l|}{ Adaptation } \\
\hline personal fit of advice & $1.14_{\text {ala }}$ & .46 & 979 & were positive & $(>0)$ \\
\hline ease of actions & $-0.02_{\text {sat }}$ & .97 & 28.8 & were positive & $(>0)^{t+}$ \\
\hline \multicolumn{6}{|l|}{ Outcame } \\
\hline darity of aims/actions: & $1.27^{23}$ & .56 & 96.1 & were positive & $(>0)^{\text {it }}$ \\
\hline agreement reached & $1.18^{\mathrm{kb}}$ & .70 & 86.3 & were positive & $(>0)^{n}$ \\
\hline Overall mark & 8.17 & 1.01 & 99.1 & were positive & $(\geq 6)^{\prime}$ \\
\hline
\end{tabular}

\section{IMPACT EEFECTS}

Satissaction

satisfaction scale

1.07 xa

52

95.7 were positive

$1>0,1$

supplement to usual care

$1.10_{0.653}$

60

87.6 were positive

$(>0)^{k}$

Normative concerns

nuore responsilule:

$0.93^{\text {man }} \quad .73$

78.1 agreed

$p 0)^{\mathrm{i}}$

more life restraints

$.0 .50^{\text {the }}$

15.4 agreed

$(>0)^{4}$

more guilty conscience

-0.1 \&

32.8 agreed

$(>0)^{2}$

intrusiventess

-1.32 dite

2.1 agreed

$(>0)^{\dagger}$

\section{QuTCONE EFFECTS}

positive treatth determinants

\begin{tabular}{|c|c|c|c|c|}
\hline $0.59_{\text {zan }}$ & .45 & 84.8 & were positive & $(>0)^{\text {H }}$ \\
\hline $0.88_{665 t}$ & .53 & 79.2 & were positive & $p 0]^{i f}$ \\
\hline $0.73_{\text {caxe }}$ & .58 & 66.5 & were positive & $(>0)^{+t s}$ \\
\hline $0.66_{\text {dd d d }}$ & .60 & 59.9 & were positive & $(>0)^{13}$ \\
\hline $0.39_{\text {etert }}$ & .55 & 36.6 & were positive & $(>0)^{\mathrm{th}}$ \\
\hline $.1 .03_{\text {角 }}$ & .90 & 5.0 & agreed & $(>0)$ \\
\hline
\end{tabular}

intending a healthy lifestyle

practicing a bealdiy lifestivle

maintaining healthy lifestyle

.77

realing healthier after

feeling healthier before

5.0 agreed

$>0$ )

* nominal variables are fiot included in the table

secores in the same questionnaire paris that do not share the same subscripts/superscripts differ at $p<.05$ ir painwise comparisons with Bonferroni adjustrinent 
1. five-point Likert scate: $-2=$ strongly disagree, $+1=$ desagra, $0=$ newtral, $1=$ agree, $2=$ strongly agree

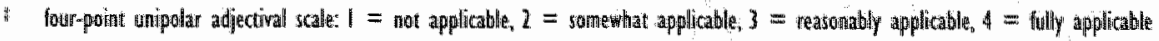

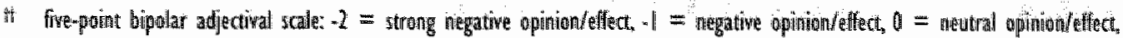

$1=$ positive opinion/effect, 1 = stromg positive apinion/effect

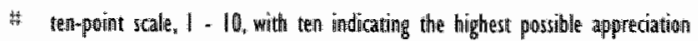

Patients were positive about most satisfaction topics. They particularly endorsed. that the new service was recommendable to others, while giving their lowest endorsement to the statement that it warranted repeated participation. They were positive about the added value of the health counseling service in addition to usual care. Regarding the normative concerns, patients found themselves much more responsible for their health than before they had visited the health advisor, but this leaves unclear whether they experienced this as a positive or negative effect. On average, patients did not experience an increase in life restraints nor an increased guilty conscience. Nevertheless, $15.4 \%$ and $32.8 \%$, respectively, reported an intensification of these moral concerns. Patients did not regard the health counseling as intrusive.

The patients reported quite positive changes in health behavior related outcomes, viz. (in order of the magnitude of the change): intention to change behavior, behavior change achieved, maintenance of behavior change, and determinants of behavior change. Besides, patients on average felt somewhat more healthy after they had visited the health advisor, and mostly denied that they had felt healthier before these visits.

\section{Differences with regard to opinions}

The patients who had been counseled at the hospital were less pleased with the structural aspects, but more satisfied with the health advisors" counseling attitude (Table 4.3). For most other quality aspects, patients who had visited the third health advisor were consistently more positive than other patients. They also gave a higher overall mark, were more sarisfied, perceived a greater added. value, reported less increase in moral concerns, and greater changes in behavior related outcomes.

Older patients evaluated three out of ten quality aspects higher and gave higher overall marks than did younger ones. Older patients experienced more moral concerns and reported more changes in health behavior determinants, and less often reported feeling healthier after the counseling. Wonnen perceived three process variables as having higher quality, and gave higher overall marks than men. On the other hand, women suffered more from a guilty conscience. In general, patients with a low educational level were more positive about the quality 


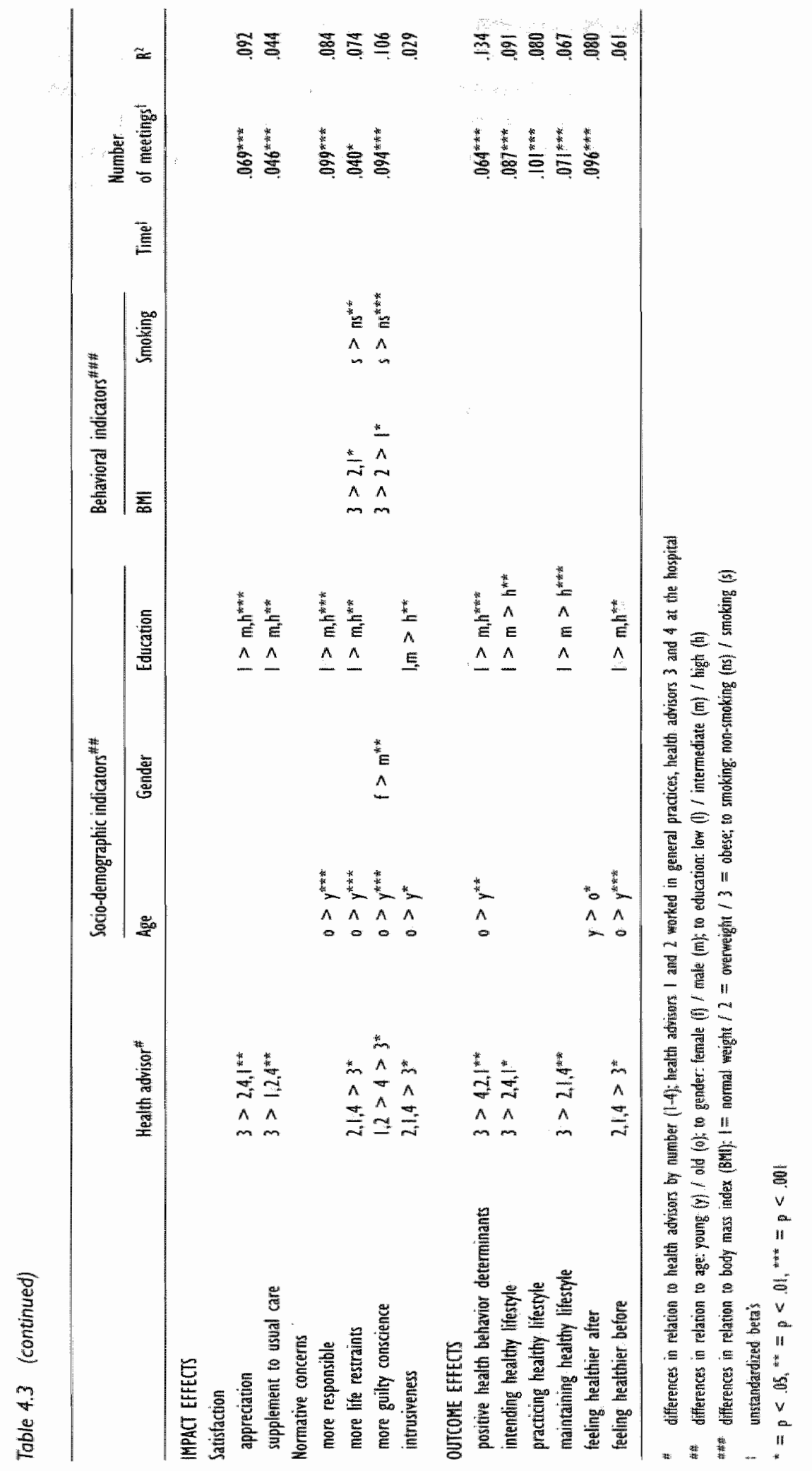


of the counseling, were more satisfied, perceived more normative concerns, and reported greater changes in outcome level than did respondents with an intermediate or high educational level. By contrast, highly educated patients were more positive about the structural aspects and the health advisors' respectfulness.

Obese patients were less positive about six of the ten quality aspects, and reported a greater increase in life restraints and to be more troubled by a guilty conscience than did patients who were overweight or had a normal weight. Smokers perceived the health advisors as less empathic, the recommendations as less suitable, and the actions they agreed upon (which were fewer) as more difficult than did non-smokers. Smokers also experienced more life restraints and were more troubled by a guilty conscience.

Patients who had entered the study at a later moment were more positive about the structural aspects of the service. A larger number of consultations was positively related to five of the quality aspects, both satisfaction measures, three normative concerns and five outcome variables. Additional analyses revealed that the number of consultations about nutrition had the greatest influence, followed by physical activity and smoking. Attending more consultations was also associated with perceiving the action plans as more difficult to implement. Here, the number of consultations about smoking appeared to have the greatest influence.

All these characteristics contributed little to the differences in patients' opinions, as most of the explained variances did not exceed $10 \%\left(.017 \leq \mathrm{R}^{2} \leq .193\right)$.

\section{DISCUSSION}

\section{Patients' opinions}

In general, the patients perceived the quality of the health counseling service within the Hartslag Limburg project as rather good and as bringing about high levels of satisfaction. However, it must be remembered that most satisfaction studies report high satisfaction scores (Pascoe, 1983). Average scores for satisfaction with care have been found to range from .76 to .84 on a $0.00-1.00$ scale (Hall \& Dornan, 1988a). A recent Swiss RCT of four patient satisfaction questionnaires found scores between .62 and .87 (Perneger et al., 2003), and a recent Dutch study among discharged inpatients revealed scores between .62 and .83 (Hendriks, Vrielink, Smets, Van Es, \& De Haes, 2001). Transformed to comparable scale formats, the present study found an overall quality score of .80 and a satisfaction score of .77 . Although this is indeed rather high, the present scores are not extreme compared to other findings.

High levels of perceived quality and satisfaction in quantitative studies do not necessarily imply that patients did not have any negative experiences 
(B. Williams et al., 1998; Zastowny et al, 1995). In the present study, of the $22 \%$ of the patients who provided additional written comments, around $35 \%$ did indeed report some negative experiences, in spite of their being rather satisfied on the whole. Comments included that the counseling sessions had been superfluous, too superficial, too manipulative, or too "nitpicking". Also, some of the patients had been confronted with their inability to change and had subsequently experienced feelings of helplessness.

The findings of two previous qualitative studies may explain the apparent contradiction. First, patients tend to express dissatisfaction only in case a service is viewed as responsible ("culpable") for negative events which were expected to be solved ("duty", B. Williams et al, 1998). Being satisfied may reflect opinions such as "they are doing their job" or "they are doing the best they can" (B. Williams et al., 1998). For the present study, these reactions seems the more plausible because of the novelty of the intervention. Second, patients are likely to discriminate between being satisfied and being very satisfied (Collins \& $O^{\prime}$ Cathain, 2003). Being satisfied means that they evaluate a service as problem solving, adequate, and acceptable, but also as leaving some room for improvement (Collins \& O'Cathain, 2003). Being very satisfied is associated with unexpected extra services (B. Williams et al., 1998), additional efforts beyond what was expected, and being better than average or outstanding (Collins \& $O^{\prime}$ Cathain, 2003). The absence of a ceiling effect for most measures in the present study may indicate that patients were indeed satisfied rather than very satisfied. This finding stresses the importance of additional qualitative investigations in satisfaction research (Avis, Bond, \& Arthur, 1997). Moreover, the combined qualitative and quantitative opinions in the present study appeared useful in providing feedback.

A substantial number of patients reported that they experienced greater responsibility (78.1\%), more life restraints (15.4\%), and an increased guilty conscience $(32.8 \%)$ as a result of the counseling. It is debatable how desirable these side-effects are in instigating changes in behavior related outcomes (Brownell, 1991). Perhaps the best evidence exists for the concept of responsibility, for which an association has been found with subsequent adherence to a treatment regimen (J. B. Brown et al., 2003). Responsibility can be regarded as equivalent to the concept of personal norm (Ajzen, 1991), which some have suggested should be integrated in theories of health behavior and health behavior change (Conner \& Armitage, 1998; Parker, Manstead, \& Stradling, 1995). Whether increased life restraints and an intensified guilty conscience are desirable or otherwise seems however open to more doubt.

The changes reported in the health behavior related outcomes are surprisingly high in view of the modest results of comparable interventions (e.g. Ashenden et al., 1997). This may be partly explained by the general measurement level, i.e. "healthy living", as opposed to specific risk behaviors, and by the fact that perceived changes give no indication of their magnitude, which is usually of greater importance in effect studies (e.g. smoking reduction vs. smoking cessation). 
The relations found between the quality and satisfaction scores and the socioconomic variables correspond with previous findings: increased satisfaction has been associated with being older, being female, and being less highly educated (Allarony \& Strasser, 1993; Pascoe, 1983; Sitzia \& Wood, 1997). The same holds for the small amount of variance in perceived quality and satisfaction that is accounted for by these patient characteristics (Pascoe, 1983).

More important seems that obese patients and smokers perceived the counseling as having poorer quality and as causing more moral concerns, while they, at least objectively, would need the health counseling service most. Though this may reflect stigmatizing effects of health education messages in general (Martin, 2001), it may also indicate that health advisors in particular should be careful about their approach when facing these patient categories, as exactly they might be confronted with difficult changes to be made. The present results suggest that the healrh advisors may better be able to motivate obese patients and smokers by adapting their recommendations even more precisely, by applying the principle of small steps in even more detail (i.e. changing little by little Bandura, 1986), and by trying to achieve even greater agreement about action contracts (t.e. shared decision making, Charles ct all, 1997).

The more counseling sessions the patients had attended, the greater the satisfaction and the more changes in behavior related outcomes they reported. This corresponds with the findings of two reviews, which concluded that interventions that were effective in the short term appeared to be relatively time-intensive (Ashenden et al., 1997; Mullen et al., 1992). Although one of them did not find differences in effects for the number of contacts, total contact hours, or duration of follow-up (Mullen et al., 1992), a third review indicated that longterm effects seem to be mote likely with continuing interventions (SimonsMorton er al., 1998). Interpreting the present association is difficult, as these cross-sectional data do not allow causal inferences to be made, but the longterm results of the concomitant effect studics might give further insight into this matter.

\section{Limitations}

The response to the present satisfaction survey was $81.2 \%$. The Swiss RCT of four satisfaction questionnaires reported response rates between $69.9 \%$ and $72.8 \%$ (Perneger et al., 2003), and the recent Dutch study among discharged inpatients an overall tesponse of $63 \%$ (Hendriks, Oort, Vriclink, \& Smets, 2002). The relatively high, and therefore satisfactory response we found may have been caused by the fact that the questionnaires had been handed out personally, as well as by the fact that the study involved an out-patient population.

Somewhat inconvenient is the selective response, with smokers twice as likely to non-respond than non-smokers. Though smokers who remained in the study were not less satisfied than non-smokers, they were less positive about 
several quality aspects and experienced more normative concerns: Smokers who dropped out may have had poorer opinions or more moral concerns, and may thus have positively biased the present findings. However, considering the small percentage of smokers in our study, as well as the results of an earlier evaluation of the impact of non-response on satisfaction scores (Lasek, Barkley, Harper, \& Rosenthal, 1997), the present bias can be assumed to be small.

Despite the steps taken to minimize methodological flaws, the high levels of perceived quality and satisfaction may be due to a number of "social-psychological artefacts", such as social desirability bias (reporting what one thinks is appropriate), and the Hawthorne effect (being satisfied just because of the extra attention received, Sitzia \& Wood, 1997). Additionally, there could have been a novelty effect in the present study (being positive just because of the newness of the service, Green \& Lewis, 1986). These biases are the more likely since the current questionnaire was only partly validated (see below).

Recommendations regarding measurement instruments for quality and satisfaction have been somewhat incongruent. It has been highly recommended to use a well-validated instrument, but it has also been widely acknowledged that context-specific, relevant and salient questions may be required (e.g. Sitzia, 1999; Zastowny et al., 1995). As for the present study, since most existing satisfaction instruments were regarded as too general and not addressing the quality topics that were our main interest, it was decided to compose a context-specific questionnaire. Some indications of its validity can however be presented.

The internal consistency of the subscales of the present questionnaire appeared to be reasonably good. No information is available about its reproducibility.

As for the content validity (Sitzia ${ }_{n} 1999$ ), the present instrument can be said to be wel]-documented with existing literature and to contain items relating to most factors that are important for the issues under study. The comprehensiveness of the questionnaire, resulting from the exhaustive sampling of aspects, may also speak in favor of its content validity (Ware, Snyder, Wright, \& Davies, 1983).

By way of appraisal for criterion validity (Sitzia, 1999), we were able to compare the quality the patients had perceived with the more objective quality assessment that experts had made of 64 video-fecorded counseling sessions (Harting et al., 2004). Although not all measures were completely comparable, the experts agreed with the patients, for instance, about the generally superior performance of the third health advisor, on the relatively positive scores on issues reflecting a patient-centered approach, and on the relatively high opinion about information exchange. The value of this triangulation is endorsed by several findings showing that patient satisfaction ratings correlate positively with expert-developed indices of technical quality (Hall \& Dornan, 1988b). That the experts' evaluations were systematically lower than those of the patients is consistent with the findings of a previous Dutch satisfaction study (Hendriks et al., 2002).

The construct validity of the questionnaire was not examined separately, and such an examination would be difficult because a well-specified theory of satisfaction is lacking (Ware et al, 1983). However, the fact that the present instru- 
ment appeared to encompass clearly distinguishable subscales (maximum correlation .66), and that the differences in quality and satisfaction scores across the various socio-demographic variables were found to be similar to those in previous studies, may indicate at least some discriminant validity.

\section{Practice implications}

Health counseling by a health advisor as a supplement to the Dutch health care system is highly acceptable for patients at high risk of cardiovascular diseases. In the present process evaltiation study, patients indicated that the service was likely to generate changes in health behavior related outcomes, but results of the accompanying effect studies will have to provide more solid evidence about the health counseling's effectiveness. If such counseling is to be implemented, counselors must be careful not to engender less favorable normative concerns, especially in counseling obese and smoking patients, who seem to be most vulnerable in terms of victim blaming.

A quality and satisfaction survey is a useful tool in evaluating and optimizing care. Its interpretation can be facilitated by using well-validated instruments, which should be supplemented with context-specific items. The addition of qualitative measures is strongly recommended, as they appear to offer the best means of identifying negative experiences and reasons for dissatisfaction, that is, exactly those aspects of care that are amenable to improvement.

\section{ACKNOWLEDGEMENT}

Data were collected as part of the Hartslag Limburg project, which is coordinated by the Maastricht Regional Public. Health Institute (GGD-zzl), and funded by the Netherlands Heart Foundation (NHS). 
Nitess $\alpha \quad$ item specification

\section{QUALLTY INDICATORS}

\section{Structure}

structural aspects

Process

Counselling attitude empathic attitude

respectful attitude

professional attitude

Interview skills

information exchange

insight giving

Adaptation

personal fit of advice

ease of actions

Outcome

darity of aims and actions agreement reached

cooperation achieved

Owerall mark

\section{IMPAT EFFECTS}

\section{Satisfaction}

satisfaction scale

supplement to usual care

Normatrve concerns

more responsible

more life restraints

stronger guilly conscience

intrusiweness

6.57 duration of individual meetiags and entire counseling course, location waiting time, time and money invested

5.82 was the health advisor friendly and a good listener, did she sympathize, and show interest and consideration

4.60 did you feel at ease, accepted and equal to the health advisor, were you able to behave spontaneously

4.17 was the health advisor credible, competent, motivating, and influential

7.82 the health advisor's listening skills, questions she asked, information she supplied (3), and the opportunities you were given to express yourself (2)

2.67 the health advisor"s help in verbalizing your own thoughts and assessing your own lifestyle

6.82 fitting in with existing health behaviors, everyday life, own ideas, opinions and meanings, previous recommendations 
Appendix 4.1 (continued)

Heratitem specification

\section{OUTCOME EFECTS}

positive health determination

10. .88 attention, interest, awareness, knowledge, atritude "social suppori and

interuding a healthier lifestyle

practicing a healthy lifestyle

maintaining thesthy lifesty

feeling healthier after

leeling healthier before

$$
\text { pressune, self-conffidence, barriers, and skils }
$$

AOOITIONAL QUESTIONS

Lavor personal/mass media

which care prowider

$\begin{array}{ll}1 & \cdots \\ 1 & \cdots \\ 1 & \cdots \\ \| & \cdots \\ 1 & \cdots\end{array}$




\section{CHAPTER 5}

Health advisors: the more professional, the more effective? An exploratory path analysis of factors determining satisfaction with and effectiveness of health counseling

A manuscript based on this chapter has been submitted for publication as:

Harting, J., Van Assema, P., Van der Molen, H.T., Van Breukelen, G., \& De Vries, N.K. (2004). Health advisors: the more professional, the more effective? An exploratory path analysis of factors determining satisfaction with and effectiveness of health counseling. 


\section{ABSTRACT}

Patient opinions survey data $(\mathrm{N}=1,056)$ regarding lifestyle counseling were used to build an exploratory causal framework: perceptions of quality as independent variables, perceived satisfaction and normative concerns as mediating variables, and self-reported changes in health behavior determinants and in the intention to change lifestyle as outcome variables. Perceived quality seems highly important for the effectiveness of health counseling. Effectiveness may be 84 improved by making a professional impression and by optimizing insight giving skills. Patient satisfaction seems to be a vital mediator. High levels of information exchange, a respectful attitude, and agreeing on actions that patients can easily perform may prevent the occurrence of normative concerns. These do not seem to contribute to the desired lifestyle changes. 


\section{INTRODUCTION}

In health care in general, an interesting debate is going on about the causal relat tionships between perceived quality, patient satisfaction, and outcomes of care (e.g. Aharony \& Strasser, 1993; Pascoe, 1983). This discussion on the "causality factor" is also going on within the field of patient-provider communication research (Hall, 2003). Communication and interaction theories are fairly clear about the elements that contribute to effective health counseling (e.g. Charles et al., 1997; Lang et al., 1990; Mead \& Bower, 2000; W. R. Miller \& Rollnick, 1991; Silverman et al., 1998), but empirical findings on the importance of the quality of these different counseling aspects in determining satisfaction with care and outcomes of care have been rather mixed (e.g. J. B. Brown et al., 2003; Hall \& Dornan, 1988a; Mead \& Bower, 2002; Stewart, 1995a).

This article provides an exploratory path analysis, taking into account patients' opinions on several quality aspects of health counseling, their level of satisfaction, the perceived normative concerns, and the self-reported changes in health behavior determinants and in the intention to adopt a healthier lifestyle. The resulting causal framework may be used as input for the theoretical debate about the mechanisms of health counseling, for longitudinal confirmatory research, and for suggestions to improve the effectiveness of health counseling in practice.

\section{THE PATH MODEL}

As several conceptualizations exist of the path model's elements and various causal relations between these elements have been proposed, it is necessary to define the perspectives that have been adopted for the present study.

\section{Defining the path model's concepts}

Perceived quality is seen as a cognitive evaluation of the structure, process, and immediate outcomes of a health service (as opposed to behavioral or clinical outcomes, Aharony \& Strasser, 1993; Donabedian, 1980; Linder-1Pelz, 1982; Pascoe, 1983). Structural components include the way in which care is organized and funded, and the accessibility, availability, continuity and convenience. of care (Aharony \& Strasser, 1993; Pascoe, 1983). As regards the process of care (Aharony \& Strasser, 1993; Pascoe, 1983), findings suggest taking into account the patient-provider interaction, technical competence, interpersonal skills, and continuity of care (e.g. J. B. Brown et al., 2003; Hall \& Dornan, 1988a; Stewart, 1995a; S. Williams et al., 1998). The immediate outcome char- 
acteristics, or "procedural end points" of care, are assumed to include felt comfort and commitment (Donabedian, 1980).

Althougly patient satisfaction has become increasingly important in evaluat" ing the quality of health care services, consensus on its concept is still lacking (Ahatony \& Strasser, 1993; B. Williams et al., 1998). Here, patient satisfaction is regarded as an impact effect, that is, as an attitude resulting from the com* bined cognitive and affective or emotiona responses to the distinct aspects of a health service (Linder Pelz, 1982; Pascoe, 1983). In the case of health communication, other impact effects that deserve attention are moral responses, such as responsibility (or ower-responsibility), life restraints and a guily conscience (Martin, 2001; Minkler, 1999). These moral impacts may, as "patient convenience", be related to patient satisfaction (Zastowny et al., 1995).

Clinical outcome variables of a health service include compliance, behavioral intentions, health behavior, health, and health care utilization (Pascoe, 1983; Strasser et all., 1993). For the present study, health behavior related outcomes, which may ultimately result in clinical changes in health (Aharony \& Strasser, 1993, Pascoe, 1983), were assumed to be most important.

\section{Rationale for the path model}

Due to the cross-sectional nature of the present data, the construction of the basic causal model for the exploratory path analysis was based on theoretical notions and the limited empirical findings available.

Although recursive and reciprocal relations may exist, it is theoretically plausible that perceived quality precedes satisfaction and that satisfaction in turn precedes health behavior related outcomes (Aharony \& Strasser, 1993; Pascoe, 1983). This causal sequence can be corroborated by some empirical findings. For instance, influence on satisfaction has been found for length of visit, service location, waiting time, travel time, and costs (Pascoe, 1983), and several quality aspects of health communication have been found to derermine its effectiveness (J. B. Brown et al., 2003; Mullen et al., 1992; D. Roter, 1989; Stewart, 1995b). In turn, satisfaction has been found to increase the intention to comply (Pascoe, 1983) and to enhance the actual adherence to health advice (Aharony \&. Strasser, 1993; D. Roter, 1989).

The resulting provisional causal framework, with satisfaction as mediating variable between service quality and service outcomes, is consistent with the evaluation response coping framework (Bagozzi, 1992), and with some empirical findings in the health care sector (Gotlieb, Grewal, \& Brown, 1994; Sinclair, Fleming, Radwinsky, Clupper, \& Clupper, 2002) and the field of marketing (Brady \& Robertson, 2001; Cronin, Brady, Hult, \& Tomas, 2000; Dabholkar et al., 20009. Apart from sarisfaction, moral concerns may also function as mediators (Brownell, 1991). For instance, responsibility for a treatment decision has been established as a mediator between finding common ground, meaning that both parient and provider endorse the treatment choice, and the 


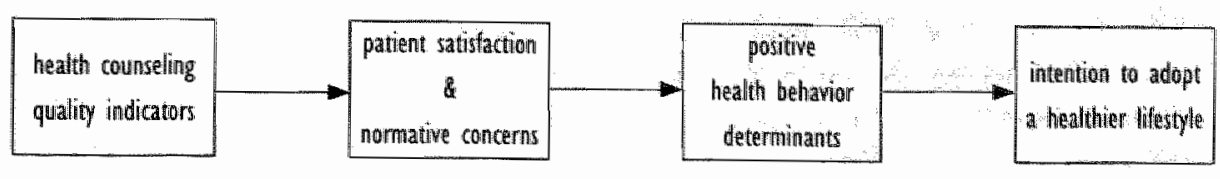

Figure 5.1 Basic path model

subsequent adherence by the patient to the treatment regimen (J. B. Brown et al., 2003). As regards the two behavior related outcomes in the present model, it has repeatedly been shown that changes in behavioral determinants predict changes in the intention to behavior change (for an overview, see Armitage \& Conner, 2000).

The above considerations were used to construct the basic causal framework for the present study (Figure 5.1). The elements of this basic path model are referred to below as endogenous variables. In view of the selective response and to correct for possible confounders, we also included health advisor, age, gender, educational level, smoking, and body mass index (BMI) in the path model. These provider and patient characteristics are referred to below as exogenous variables.

\section{METHODS}

Study, intervention, and sample characteristics

The data for the parh model analysis were originally collected to monitor the implementation of a new health counseling service in the Dutch health care system (see Harting et al., Submitted). The health counseling formed a prominent part of the high-risk intervention of the Hartslag Limburg cardiovascular prevention project (Dutch for Heartbeat Limburg, see Ruland et al., 1999), whose effects were evaluated in a randomized controlled trial (RCT, see Harting et al., In preparation-a; Harting et al., In preparation-b). Between April 1999 and October 2001, 10 cardiologist at the University Hospital Maastricht and 35 general practitioners (GPs) of 25 practice units throughout the region included 2,743 patients with an elevated cardiovascular risk. The randomization procedure resulted in an intervention group of 1,398 patients, of whom 1,301 actually visited one of the four health advisors who were responsible for the counseling (the requirements for and training of the health advisors are listed in Box 5.1). The main topics of the counseling were three important cardiovascullar risk 
Box 5.1 - Becoming a health advisor

\section{BASIC MEQUULEHENTS}

D A higher vocational training for the health care sector

- An aptitude for counseling patients about their lifestyle

a Affinity with peoplle from the lower socio-economic classes

- Understanding and (preferably) speaking the local dialect

\section{FURTAER THANING ALD SUPPORT}

D theoretical hatroduction to rish behaviors and behavior change with further theoretical sell-tuition, a theory refresher day, and occasional consultations with experds on health counseling or on behavior change

a A two-day practical course in counseling skills, a pro-day iraiming on the use of the counseling protoco, and a minimum of fire simulation contacts

- Two external courses on smoking cessation

¿ Birmorithly ledback sessions using video fecorded patient contacts

$1 \mathrm{H}$ Monthly intervision meetings and twelve individwal metings with a supervisor

behaviors: high fat consumption, smoking, and physical inactivity. Directly after the counseling the intervention patients received a questionnaire to assess their experiences with the new health counseling service (see below).

A special health counseling model had been developed for the intervention (Harting \& Van Assema, In preparation). In general, the health advisors were expected to adopt an empathic attitude, use a respectful approach, and act in a professional way. They were also required to establish adequate information exchange, and focus on improving patients' insight. They had to ensure that the aims of the counseling were clear, and to reach agreement on concrete action plans that tied in closely with the patients ${ }^{x}$ personal expectations, situation, motivation, and capabilities.

Furthermore, the health counseling model consisted of three more specific sections. The opening section instructed the health advisors to establish rapport and collaboration. The middle section first coached them in drawing up a full inventory of the patients' health behaviors and of the factors impeding healthy changes. By analogy to stage theories of behavior change, the health advisors classified each patient as being in one of six consecutive motivational steps, which guided them in selecting one or more appropriate intervention strategies. For the patients in the receptiveness step, these strategies should lead to greater attention for and interest in a healthy lifestyle. Patients in the awareness step needed to obtain more knowledge of and insight into health risks and health behaviors. For those in the willingness step, the counseling should focus on a more positive atritude, more perceived social support and more self-confidence as regards a healthy lifestyle. Patients in the ability step had to be helped to overcome possible barriers and to achieve the skills needed to effect healthy changes. 
The implementation step should result in concrete plans to make healthy changes as well as in the actual realization of these plans. Lastly, for patients in the waintenance step, the health advisor should promote continuation of their healthy habits. The closing section of the model told the health advisor to draw up an action contract before terminating the meeting in a careful way.

The baseline measures for the RCT revealed the following sample characteristics. The respondents had an average age of 61.9 years, and $67.6 \%$ of them were male. The educational level was low for $50.7 \%$ of them, intermediate for $35.6 \%$ and high for $13.7 \%$. The BMI was 27.4 , with $47.2 \%$ of the patients being overweight and $28.9 \%$ being obese. Fewer than a quarter of the respon. dents smoked $(23.1 \%)$. The registration that the health advisors kept during the trial showed that the mean number of consultations per patient had been 2.6 (range $1 \cdot 6)$, totaling on average $87 \mathrm{~min}(S D=48 \mathrm{~min}$ ).

\section{Questionnaire}

The patient opinions questionnaire was based on the above definitions as well as on specifications of the health counseling model. The following selection was made for the path model. Nine quality aspects were taken into account (eight sum scores, one single item). These were the structural aspects of the service, the health advisors' empathic, respectful, and professional attitude, two important interview skills, namely, information exchange and giving insight, the personal suitability of the recommendations received, the ease with which the intended actions could be implemented, and the clarity of the aims and actions the patients agreed on. As impact, and therefore mediating variables, the path model included a sum score for satisfaction, and three normative concern measures, namely, feeling responsible for one's health (single item), experiencing life restraints, and feeling troubled by a guilty conscience (both sum scores). As outcomes of care, the path model comprised a sum score combining the changes in nine health behavior determinants, and a single item measuring the intention to change health related behaviors. The operationalizations of the incorporated endogenous elements, their measurement scales, and the results of the reliability analyses are provided in Appendix 5.1.

\section{Analysis procedure}

Due to the small number of missing values (maximum $3 \%$ ), these were replaced with the mean score for the endogenous variable in question. For most endogenous variables, skewness and kurtosis tests were significant due to the large $\mathrm{N}(=1,056)$, but the absolute values were not extreme $(\leq 1.2$ and $\leq 3.2$, respectively). Inspection of the histograms suggested that data transformations were not necessary and that the maximum likelihood method of estimation was appropriate (Kline, 1998). 
Deseriptive statistics were used to examine the means, standard deviations, correlations, variances, and covariances of the endogenous variables (SPSS 11). In view of the nested design (patients nested within general practices or cardiologists), mixed linear regression of each endogenous variable was done (using SPSS) to check for the presence of intraclass correlation, that is, of GP and cardiologist effect (Goldstein, 1995). Because no such effects were found (all intraclass correlations $<.01$, all $p>.22$ ), patients wete taken as the units of analysis. in the path analyses with Lisrel 8.30 , ignoring the nesting within practices and physicians.

The just identified path model, including all exogenous and endogenous variables, included 300 paths and had 0 degrees of freedom (Holbert \& Stephenson, 2002; Kline, 1998). The prior empirical evidence regarding specific relations between most of the exogenous and endogenous variables as well as berween most of the endogenous variables themselves was regarded insufficient to constrain the path model beforehand. To avoid complex Lisrel models with very many parhs, two preparatory explorative analyses were done with SPSS. First, the linear mixed model analyses mentioned above were used to limit the number of paths from the exogenous variables to the endogenous variables by only including the significant relationships in the initial path model. Second, an additional mediation analysis was performed (Kenny, Kashy, \& Bolger, 1998; MacKinnon, Krull, \& Lockwood, 2000). This consisted of a series of linear regression analyses with the nine quality aspects as independent variables, satisfaction and the three normative concerns as mediators, and health behavior determinants as dependent variable. The significant relations found were used to limit the paths between the endogenous variables in the initial path model.

The further path model analysis was guided by structural equation modeling literature (e.g. Holbert \& Stephenson, ; Kline, 1998). As it is particularly the validity of reciprocal paths in cross-sectional data which should be questioned, it was decided to refrain from feedback loops and to keep the path model recursive. The covariance matrix was used as input for the analysis, and maximum likelihood (MLE) as the method of estimation. Modification indices were used for further model building, resulting in several additional paths from exogenous to endogenous variables, from quality aspects to mediators and behavior related outcomes, and between the mediating variables themselves. This led to an acceptable fit. Next, to increase parsimony, the model was trimmed by constraining those paths to zero that were non-significant at .01 level $(t<2.57)$. Although the chi-square test for the final model remained significant, it was concluded on the basis of the other fit indices that this could be attributed to the large study population. Thus, the final model was regarded as the best compromise between optimal fit and relevant paths and the best possible model to formulate hypotheses about the mechanism of health counseling. 


\section{RESULTS}

A usable response was received from 1,056 patients (81.2\%), with smokers twice as likely to non-respond as non-smokers. Means, standard deviations, correlations, variances, and covariances of the endogenous variables included in the path model are presented in Table 5.I. In summary, the patients regarded the quality of the counseling as satisfactory to good and reported a considerable degree of satisfaction. A large majority feit more responsible for their health as a result of the counseling and a minority indicated an increase in life restraints and guilty conscience. A substantial proportion of the patients mentioned changes in behavior related outcomes, and most of them considered the new service a good addition to existing health care facilities. For a complete description of the survey results, including the influences of the exogenous on the endogenous variables, readers are referred to Harting et al. (Submitted).

The final path model had the following statistics: $x^{2}=268.05$ (df $=135$, $\mathrm{p}=.00), \mathrm{RMSEA}=.031(90 \% \mathrm{CI}=.025-.036), \mathrm{NFI}=.97$, and $\mathrm{NNEI}=.96$. The standardized residuals of the covariance matrix varied from -4.74 to 5.24 . Table 5.2 presents the regression equations of the path model, the explained variances of the endogenous variables as well as the significant paths between them. Table 5.3 presents the total, direct, and indirect (mediated) effects. Betas with an absolute value below. 10 were considered small, those from .10 to .20 modest, those from .20 to .30 moderate, and those above .30 considerable (adapted from Cohen, 1988). The complete model with all significant paths was found to be too complex to be displayed in its entirety. Instead, two separate figures present the most salient relations found, thereby selecting paths with moderate, modest, and almost modest betas ( $z .07$ ).

The path model explained $44 \%$ of the variance of intention toward a healthier lifestyle (Figure 5.2.a). The greatest influence was exerted by the modest indirect positive effect of a professional atticude. An empathic attitude had a modest negative direct effect, but this was partly compensated by its posirive indirect effects. Both giving insight and clarity of aims and actions had small positive indirect effects, and information exchange had a small positive direct effect. Most of the effects on intention were preceded by changes in health determinants, and mediated through satisfaction alone or, to a lesser extent, through responsibility as well.

As regards the health behavior determinants, the path model explained $55 \%$ of the variance (Figure 5.2.a). A professional attitude, giving insight, and clarity of aims and actions each had a modest positive effect. Small effects of some importance were found for an empathic attitude (positive) and the ease with which intended actions could be implemented (negative). No direct effects were found. The indirect effects were mainly mediated via satisfaction and to a lesser extent via responsibility. The mediating function of a guilty conscience was negligible. 


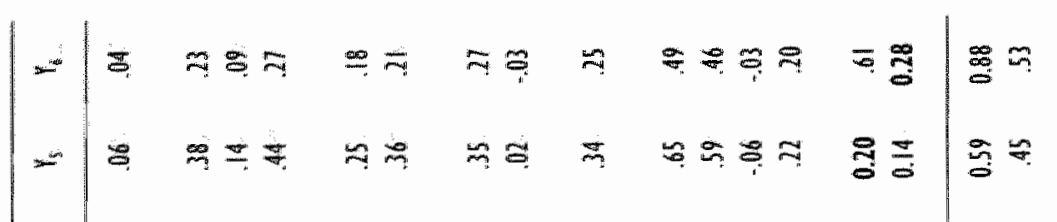

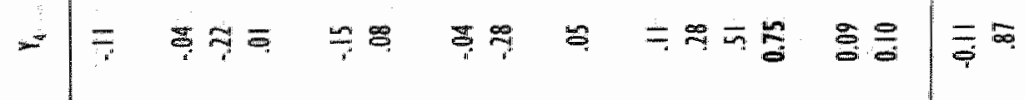

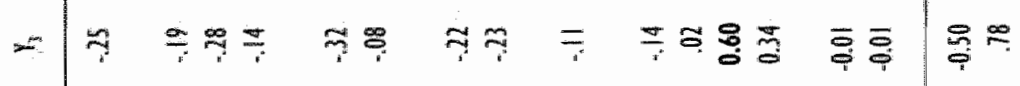

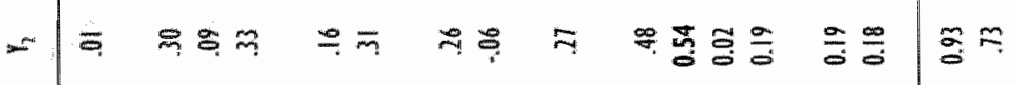

- 해

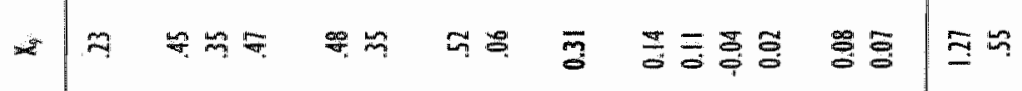

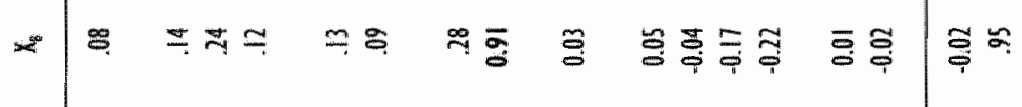

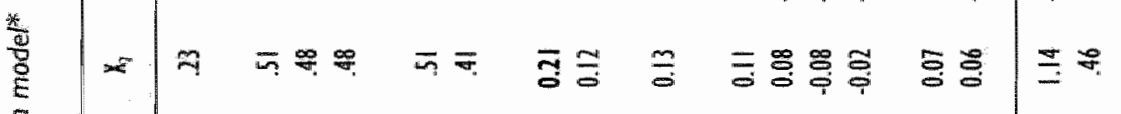

点

喜

毫 ×

㟧

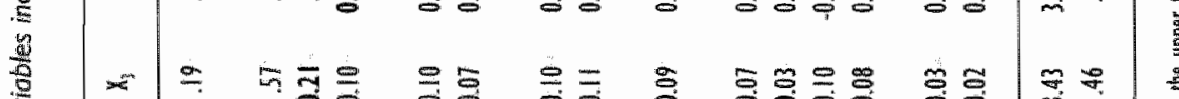

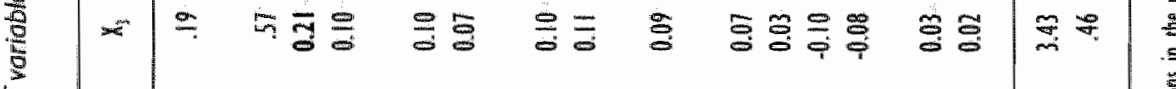

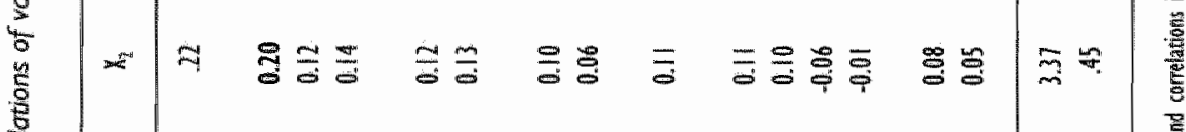

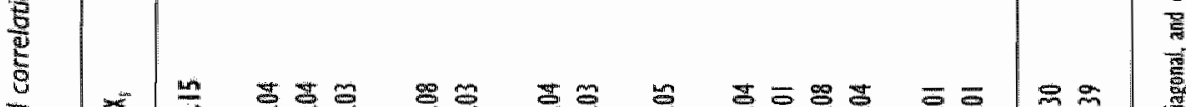

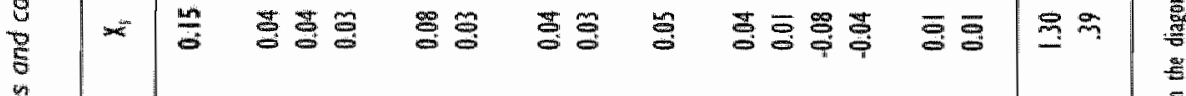

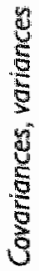

$\overline{1}$

$\frac{\pi}{8}$

(1)

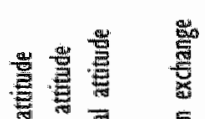

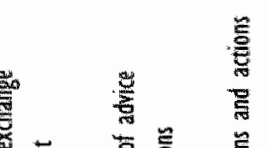

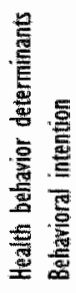

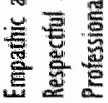

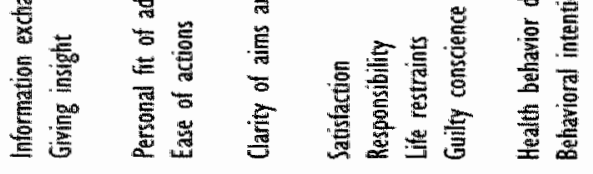

$\times x$

$x$ 


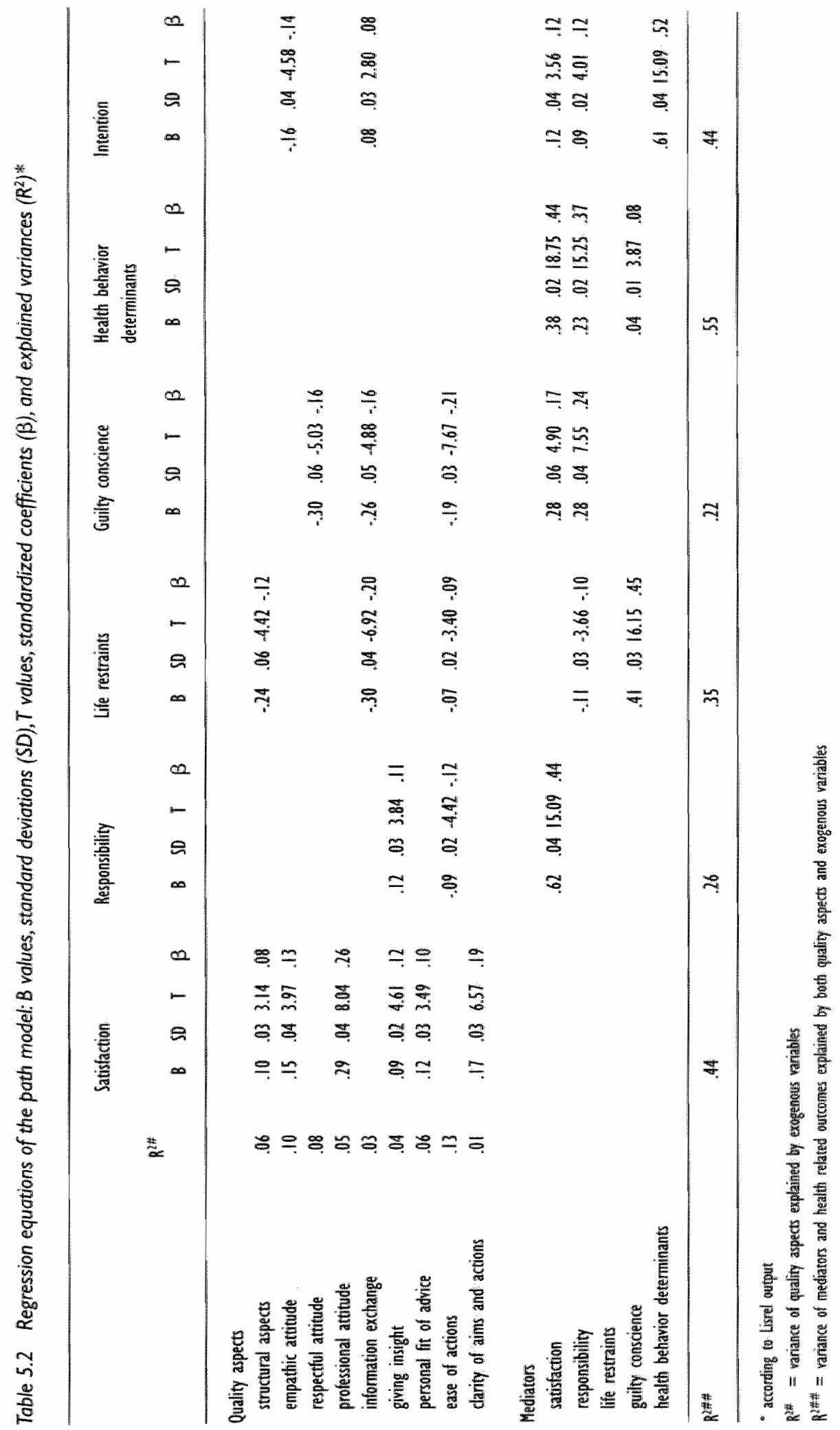




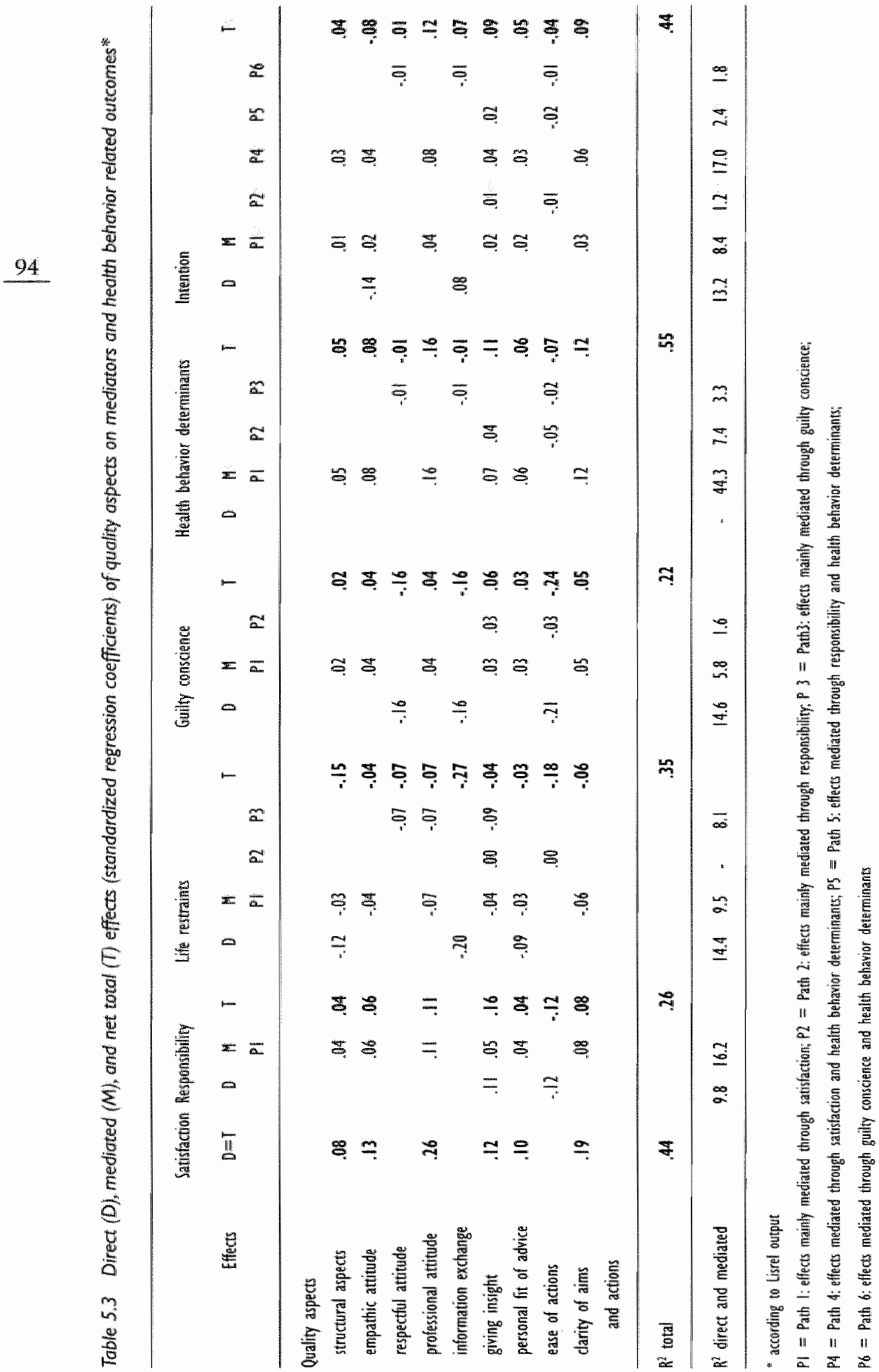




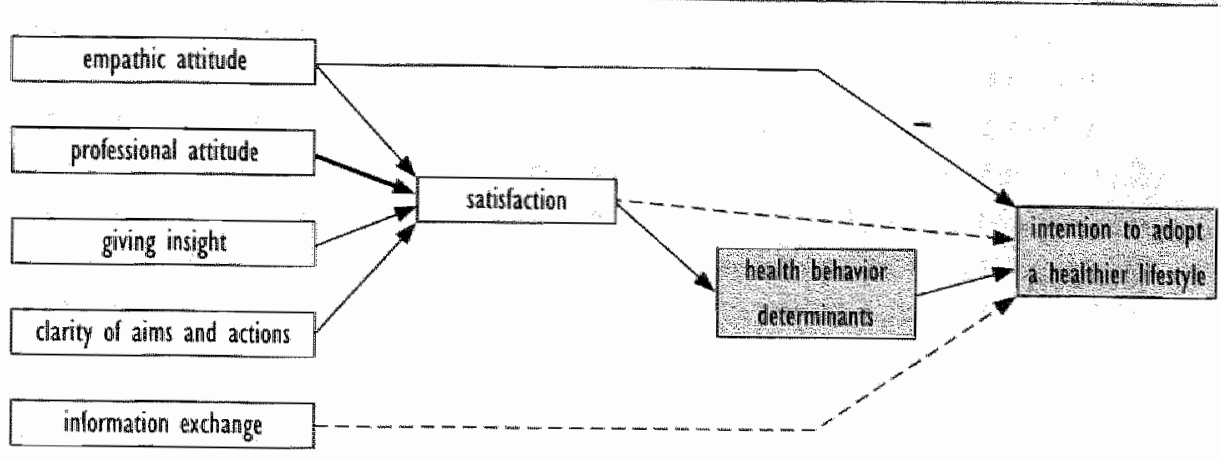

Figure 5.2.a Main influences on heolth behavior determinants and intention to adopt a heolthier lifestyle

Figure 5.2.b Main influences on normative cancerns and their mediating effect on health behovior related outcomes

The parh model explained $26 \%, 35 \%$ and $22 \%$, respectively, of the variances of responsibility, life restraints, and a guilty conscience (Figure 5.2.b). With regard to responsibility, modest positive effects were found for giving insight (direct) and a professional attitude (indirect). The ease with which intended actions could be implemented had a modest negative effect (direct). Satisfaction appeared to be an important mediator. As regards life restraints, intormation exchange had a moderate decreasing effect, and structural aspects and the ease with which intended actions could be implemented both had a modest decreasing effect. No increasing effects on life restraints were found for any of the quality aspects. Nearly half of the decreasing effects were direct, the other half were mediated through satisfaction and a guilty conscience. A guilty conscience, in turn, was moderately decreased by the ease with which intended actions could be implemented, and modestly by both a respectful attitude and infor- 


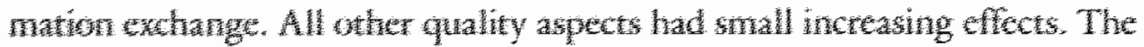

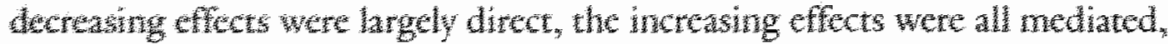

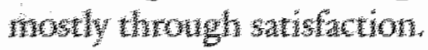

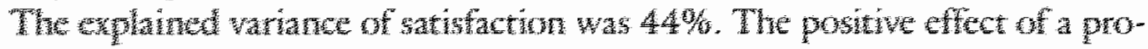

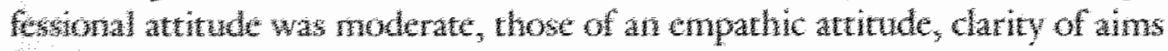

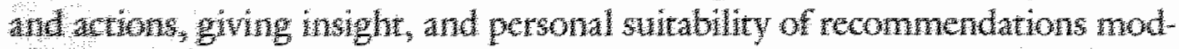

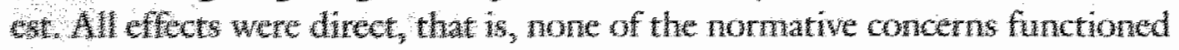
as metwors.

\section{DISCUSSION}

\section{The path model}

In the cxploratory path analysis, the perceved quality of the new heath counseling servee explaned a considerable part of the variance of the health behavior determinats and the intention to change 1 festyle behaviors. This was also the case for satisfaction, which, in addition, emerged as the man mediator berween perceived quality and the health behavior related outcomes. Comparable path nolel andyses found simiar or even greater percentages of explained variance for several types of behavional intention and an analogous importance of satisfacthon as mediating varible (Cronin et al, 2000; Dabholkar et al, 2000; Gotheb et al., 1994). Two other studies have found comparable explained variances of satisfaction, by perceved quality of service provision (i.e., instrumental cate, expressive care, and communication effectiveness), and by the degree to which a service met the desires of the patient (Like \& Zyzanski, 1987; Sinclair et al., 2002). Moreover, mecting patients' service desires has been suggested to decrease disease symptomatology (Roth \& Crane-Ross, 2002), and to increase wellness and quality of life (Roth \& Crane-Ross, 2002; Sinclair et al., 2002). Taken together, this indicates that the quality aspects that were included in the present study may indeed be of great importance for the effectiveness of health counseling, and that this effectiveness may indeed be mediated through satisfaction.

The present parh model further indicates that feeling responsible for one's health may be a second, though less important, mediator between perceived service quality and health behavior related outcomes. Limited support for such a mediating role of responsibility was found in earlier studies (e.g. J. B. Brown et al., 2003; Schwartz \& Howard, 1980). However, the concept of responsibility may be regarded as equivalent to that of personal norm (Ajzen, 1991), for which a similar mediating role has recently been demonstrated between behavior determinants and behavioral intention (Armitage \& Conner, 2001). Taken together, these findings underline earlier suggestions that the concept of personal norm should be integrated in theories of health behavior and health 
behavior change (Conner \& Armitage, 1998), and that its role might be a mediating one.

Assuming that the causal model adopted as the basic framework for the present study is correct, the exploratory path analysis offers several starting points to improve the health counseling service.

'To start with, the path model suggests that the health advisors can increase their effectiveness by strengthening the impression of professionality, operationalized in our study as being credible, capable, motivating, and authoritative. Though this specification makes it difficult to compare the present findings with those of other studies, the relative importance of a professional attitude for an increase in behavioral outcomes seems not to have been demonstrated before. A professional attitude might reduce unnecessary parient uncertainty, which is argued to be one of the major principles characterizing effective communication (Silverman et al., 1998). Credibility as such may be essential for internalizationbased persuasion, which in turn may lead to more stable changes in attitudes than identification (induced by attractiveness, liking) or compliance-based persuasion (induced by rewards, punishments, McGuire, 1985). A helpful means to increase the impression of professionality may be the application of a methodical approach, that is, working in a goal-oriented, conscious, systematic and process-oriented way (see e.g. Egan, 1990). Given the success of more protocolled approaches in the field of cognitive behavior therapy (Barlow \& Hofmann, 1997), this may also imply that the counseling model used in the present study should be altered into a more clearly structured counseling protocol.

The path model also indicates that if health advisors further improve their insight giving skills, that is, by helping patients to verbalize their thoughts and to understand the way they live, this may increase both health behavior related outcomes. A previous study found a similar positive correlation for "therapeutic listening", that is, meeting the patients' desires to explain which causes of problems they perceive and how they have handled problems previously, and a negative correlation for not meeting this desire (Like \& Zyzanski, 1986, 1987). Insight giving skills may help patients to understand their health problem as well as to fully express themselves, for which positive relations have been found with satisfaction (Frederikson, 1995) and health outcomes (Stewart, 1995b). Besides, giving insight may generate greater patient involvement, which, by encouraging central information processing, may facilitate attitude change (Petry \& Cacioppo, 1986).

Next, somewhat surprisingly, the path model shows that health advisors should beware of being too empathic, as this may have a negative effect on the intention to change lifestyle behaviors. Too much good listening, sympathizing, and showing interest and consideration seems to confirm rather than to disaffirm patients in their unhealthy habits. This finding perhaps corroborates a previous conclusion that, although an essential element of health counseling, empathy in itself is not a sufficient force to motivate people to change (Lang et al., 1990). That an empathic attitude may simultaneously increase satisfaction, positively influence health behavior determinants, and, through both of these mediators, posi- 
tively affect behavioral intention may be interpreted as an illustration of previously found contradictory influences of patient-centeredness (Mead \& Bower, 2002).

Furthermore, if health advisors optimize the level of information exchange, this may slightly increase the parients' behavioral intention, but not their level of satisfaction or their opinion on health behavior determinants. This is in line with some previous studies, which found that information provision was related to compliance (e.g. D. Roter, 1989), but apparently contradicts one of the most consistent findings that more information provision from both the provider and the patient is related to patient satisfaction (S. Williams et al., 1998). This disagreement can probably be explained by the fact that the present study assessed the perceived appropriateness of information exchange, instead of the perceived amount of information provision (J. B. Brown et al., 2003). These two measures do not necessarily correspond (Stiles, 1989). Besides, one study has observed that satisfaction was not positively correlated with meeting a patient's desire for information, but instead, showed a strong negative correlation with not meeting a patient's information needs (Like \& Zyzanski, 1986, 1987). Taken together, this might mean that beyond a certain threshold, more information exchange has no surplus value in terms of satisfaction and health related outcomes, and that this threshold level was attained in the present study.

Nevertheless, the path model suggests that high levels of perceived information exchange remain essential, specifically to prevent patients from experiencing life restraints and feelings of guilt. A guilty conscience seem similarly lessened by a respectful attitude. In the present study, increases in the two moral concerns were reported by a considerable proportion of the patients. Avoiding these troubling feelings seems even more relevant since the path model indicates that their positive influence on behavior related outcomes is negligible. Hence, increased levels of life restraints and a guilty conscience should be regarded as negative side-effects. On the one hand, the lack of a mediating role may be explained by reactance theory (Fogarty, 1997). This theory proposes that a recommended change in behavior may be perceived as athreat to an individual's freedom, which in turn may generate a motivational state aimed at recapturing the affected liberty, resulting in non-compliance. On the other hand, the insignificant influence of both feelings may reflect that expectations of personal control over health behaviors, imposed by the health counseling, exceed reality (Brownell, 1991). This means that if health advisors overestimate personal capacity or underestimate social and environmental determinants (Brownell, 1991), patients may shift from a problem-solving coping approach (i.e. behavior change) to an emotionfocused coping strategy (i.e. denial or avoidance, Cohen \& Lazarus, 1983).

Lastly, to further prevent both negative side-effects, that is, feelings of life restraint and guilt, the health advisors should limit the difficulty of the actions the patients agree to implement. Easier actions may, however, also have a more modest decreasing effect on responsibility, and hence a small negative impact on both health behavior related outcomes. On the one hand, it could be concluded that the reassuring effects outweigh the negative influences. On the other hand, this finding might mean that making actions too easy could be counterproduc- 
tive. This is in line with the goal setting theory, which states that goals should not be set too high, but should nevertheless be challenging (Locke, Shaw, Saari, \& Latham, 1981). In sum, it may be concluded that starting with fairly easy actions could be fine, but only if one does not wait too long with increasing their difficulty.

\section{Limitations}

Despite the rather convincing theoretical arguments and empirical findings, the causal framework for the present parh model can certainly be questioned. Due to the cross-sectional nature of the data, alternative models with fairly comparable statistics can be easily imagined, for instance with a reversed order of the mediating variables. Some support for the present framework has come from preliminary analyses of the accompanying effect study, in which satisfaction with the health counseling service did indeed have an effect on some of the long-term measures of the intention to change behavior (Harting et al., In preparation-a, In preparation-b). Nevertheless, the results of the present path analysis must be interpreted with caution.

Another criticism of the present path model lies it possible incompleteness. First, a "hidden confounder" may have been missed, such as a trait-like general notion of overall satisfaction (Greenley \& Young, 1983), the parients" a priori physical or psychological health (Aharony \& Strasser, 1993), and the patients' expectations and requests before visiting the health advisors, as well as their subsequent fulfillment (Like \& Zyzanski, 1987; Sitzia \& Wood, 1997). Second, several additional mediators are conceivable, for instance an overall measure of quality (Dabholkar et al., 2000) and the perceived value or utility of the counseling (Zeithaml 1988, cited in Cronin et al., 2000). These flaws can however be attributed to the fact that the present study is a secondary data analysis. Moreover, it may be assumed that the present path model at least includes the most relevant elements.

Lastly, it should be kept in mind that changes in health behavior determinants and intention to behavior change were measured in the present study on a global. level, that is, with regard to a healthy lifestyle in general. In other words, the results cannot be unconditionally translated into specific cardiovascular risk or health behaviors, although the present intention to change measure at least moderately correlates with the more specific intention to change measures of the parallel effect study.

\section{Conclusion}

Perceived quality seems highly important for the effectiveness of health counscling. The behavior related effects of counseling may in particular be increased by making a professional impression and by an optimal use of insight giving skills. 
Patient satisfaction scèns indeed to be an essential mediator between counseling quality and counseling effects. Undesirable side-effects, such as perceived life restraints or guilt, may be prevented by high levels of information exchange, a respectul atritude, and agreeing on actions that patients can easily perform. This is especially worthwhile since these side-effects seem not to contribute to the desired behavior related effects. Hence, if the causality of the present path model is correct, it offers some useful starting-points to improve the effectiveness of health counseling.

\section{ACKNOWLEDGEMENT}

Data were collected as part of the Hartslag Limburg project, which is coordinated by the Maastricht Regional Public Health Institute (GGD-zzl), and funded by the Netherlands Heart Foundation (NHS). 


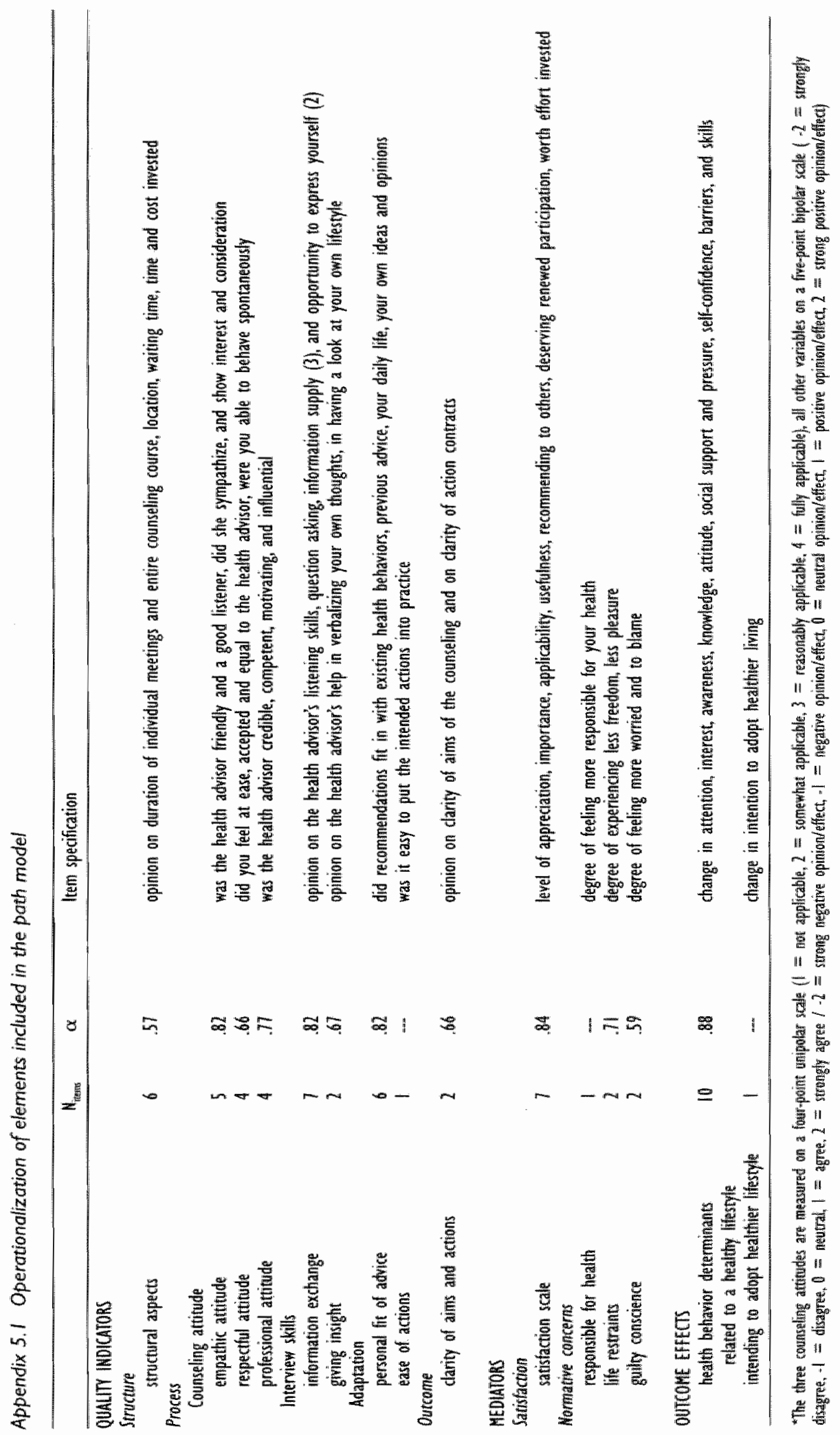





\section{CHAPTER 6}

Cardiovascular prevention in the Hartslag Limburg project: effects of health counseling on behavioral risk factors in a cardiology outpatient population

A manuscript based on this chapter has been submitted for publication as: Harting, J., Van Assema, P., Van Limpt, P., Gorgels, T., Van Ree, J., Ruland, E., Vermeer, F., \& De Vries, N.K. (2004). Cardiovascular prevention in the Hartslog Limburg project: effects of health counseling on behavioral risk factors in a cardiology outpotient population. 


\section{ABSTRACT}

The aim of this study was to evaluate an individual lifestyle advice intervention to reduce cardiovascular risk behaviors. The effects were assessed in a randomized controlled trial at the cardiology outpatient clinic of the University Hospital Maastricht. Participants had a manifested cardiovascular disorder or were at high risk of developing one. Questionnaires were completed by 1,270 patients at baseline, 1,169 after four months (92\%), and 1,032 after 18 months 104 (81,3\%). After four months, intention-to-treat analyses revealed a decrease in fat consumption $(-5,6 \%, \mathrm{p}=.000)$, a reduction in the percentage of smokers $(\mathrm{OR}=.57, \mathrm{p}=.039)$ and a trend toward an increased physical activity level $(\mathrm{OR}=1.28, \mathrm{p}=.081)$. No long-term effects were found. It was concluded that the lifestyle advice intervention was potentially effective, but should be further improved. 


\section{INTRODUCTION}

Cardiovascular diseases (CVD) are among the main global public health problems (Pyörälä et all, 1994; Rose, 1992). In the Netherlands, CVD bring about $35 \%$ of all dearhs, making them the leading cause of mortality (RVM, 2003). In the southern part of the Dutch province of Limburg, CVD prevalence and mortality are relatively high compared to other parts of the Netherlands, and belhavior related cardiovascular risk factors, such as obesity and smoking, are more common among its residents (GGD, 1999). These epidemiological data were the reason for initiating the regional cardiovascular prevention project Hartslag Limburg (Dutch for Heartbeat Limburg, Ruland et al., 1999), which combined a community-based intervention with an individual approach (Rose, 1992). The present article describes the effects of the individual lifestyle advice intervention in a cardiology ourpatient setting.

In individual cardiovascular prevention strategies, priority should be given to patients with established CVD or healthy individuals who are at high risk of developing CVD. For these groups, changing cardiovascular risk factors has the potential capacity to generate substantial health gains (RIVM, 2003; Rose, 1992; D. Wood et al., 1998). As CVD have a multifactorial etiology and the various cardiowascular risk factors have a multiplicative effect, a multiple factorial prevention approacin is expected to maximize the effect (Pyörälä et al., 1994; Rose, 1992).

As one of the essential prevention components, health counseling of behavioral risk factors has been strongly recommended (CDC \& National Center for Chronic Disease Prevention and Health Promotion, 1998). Indeed, education and counseling have been found to contribute to behavioral changes and a better health status for CVD patients (Mullen et al., 1992; Mullen et al., 1997). Nevertheless, Dutch cardiologists rarely discuss issues such as diet and physical activity with their patients, and although they do advise most smokers to quit, they have no time to offer them additional help with quitting, and seldom refer them to specialized cessation programs (Van Berkel et al., 1999). For these reasons, Hartslag Limburg started an individual lifestyle advice intervention at the cardiology outpatient clinic of the University Hospital Maastricht (azM).

The main research question was whether the individual lifestyle advice generated positive changes in fat consumption, smoking behavior, and physical acrivity level. As changes in behavioral determinants were expected to precede changes in the three cardiovascular risk behaviors, these secondary end-points were evaluated as well. The results are compared with those of other lifestyle interventions and discussed in the light of the results of the process evaluation that accompanied the effect study. 


\section{METHODS}

\section{Interwention}

Intervention patients were invited to visit a health advisor, a newly created position in the Dutch health care system. The two health advisors, who were originally specialized cardiac nurses, had been trained in behavior change and counseling technigues (Harting et al, 2004) and in the use of the specially developed, theorybased and empirically supported stage-matched health counseling model (Harting \& Van Assema, In preparation). In accordance with evidence-based international recommendations (WHO, 2003; D. Wood et al., 1998) and national guidelines (Kemper et al., 2000; Voedingsraad, 1991), three major rules for a healthy lifestyle were formulated. First, fat consumption should preferably consist of unsaturated fat and not exceed $35 \%$ of the total energy intake. Second, patients should refrain from smoking. Third, they should be moderately active for at least $30 \mathrm{~min}-$ utes a day on five to seven days a week. The specific topics of the counseling were inspired by these norms, but were decided on in consultation with the patient.

To increase the effectiveness of their personalized information and advice, the health advisors were encouraged to hand out additional leaflets and booklets (Burke et al., 1997), which had been selected beforehand on the basis of their high quality. For smokers motivated to quit, trial packages of nicotine replacement and bupropion therapy were available, as these medications have proven to be helpful (Hughes, Stead, \& Lancaster, 2004; Silagy, Lancaster, Stead, Mant, \& Fowler, 2004). Furthermore, the health advisors were provided with a complete overview of local health promoting activities, enabling them to refer patients to such events or programs in their own neighborhood. For those patients who appreciated this, the health counselors used a telephonic booster, which has been found to be a promising means to sustain behavioral effects (Van Elderen-van Kemenade, Maes, \& Van den Broek, 1994).

\section{Design and participants}

The design of the effect study was a randomized controlled trial with one pretest questionnaire ( $\mathrm{T}=0)$ and two post-test questionnaires after $4(\mathrm{~T}=4)$ and 18 months ( $\mathrm{T}=18$ ), respectively, all to be completed at home. Randomization took place at patient levell. From April 1999 to October 2001, ten cardiologists of the outpatient clinic periodically asked all eligible patients to join the study (inclusion range 17-506), while several others contributed occasionally. The eligibility criterion for the study was a greater than $20 \%$ risk of incurring a cardiovascullar event within the next 10 years (Pyörälä et al., 1994; D. Wood et al., 1998), which meant that all patients with any manifestation of a cardiovascular disorder could be included. No systematic record of refusals was kept, but verbal reports indicated that the negative response was negligible. Informed consent was obtained from 1,388 patients, after which they were told their randomization starus. 
Dietary fat intake was measured with a validated questionnaire. This covered the nineteen food products that contributed most to the consumption of saturated fat. A comparison with a seven-day diet record has shown the questionnaire's validity to be satisfactory ( $R=71$, Van Assena, Brug, Ronda, \& Steenhuis, 2001). The 35 items were combined into a total far score. Reliable fat scores could be calculated for $92 \%$ of the respondents who had less than $50 \%$ missing values. The Dutch Nutrition Intake Survey (VCP, Gezondheidsraad, 2001; RIVM, 2003) indicated that fat scores of 17 points for men and 14 points for women should be regarded as the approximate upper levels of recommended dietary fat intake.

As regards smoking, the point-prevalence was assessed by asking respondents whether they had smoked, even if it had been only one puff, during the last seven days. Smokers had to specify since when they smoked and whether they had ever tried to quit. Non-smokers were asked whether they had smoked in the past, and if so, how long ago they had quit smoking.

Physical activity level was measured with a short questionnaire, which had been validated by comparison with a seven-day physical activity record $(\mathrm{R}=.50$, Koremans, Derks, Tuinstra, Diederiks, \& Brug, 2000; Ronda et al., 2001). Its items were slightly adapted to the senior population under study. Patients had to register their performance on 11 activity categories, in minutes per day and days per week. This led to an indirect physical activity score. As an additional direct measure, patients had to indicate the number of days per week on which they were usually active for at least 30 minutes. Patients who met the direct and indirect norm of being sufficiently physically active were classified as meeting the recommended target.

For all three cardiovascular risk behaviors, several psychosocial determinants were assessed, whose selection was based on the aims of the intervention specified in the counseling model (Harting \& Van Assema, In preparation). Intention to change was included as the most proximal determinant of behavior change (Ajzen, 1991). This was assessed by asking to what extent patients were planning to eat less fat, to stop smoking, and to become more physically active. Attitude, social influence, and self-efficacy expectations were included as more distal predictors of behavior change (Ajzen, 1991; Bandura, 1986; H. De Vries, Mudde, \& Dijkstra, 2000). Their operationalizations have been reported elsewhere (Ronda et al., 2004). Bipolar five-point scales were used, as is common in studying behavioral determinants (H. De Vries et al., 2000).

Awareness of one's own behavior (Weinstein, 1988) has been found to be an important factor for changing dietary behavior as well as physical activity (Brug et al., 1994; Ronda et al., 2001). To evaluate awareness, patients" selfrated lewels of fat intake and physical activity (low-high) were compared with the more objectively assessed fat intake and physical activity levels. Patients who were realistic were characterized as "aware" and those who were unrealistic as "unaware" (for the exact procedure, see Ronda et al., 2001). 
Additional process questions asked the intervention patients at $T=4$ and $\mathrm{T}=18$ to what degree they had been able to adhere to the health advice they had received and how much support they had received from their cardiologist. All patients were asked to specify the health information they had gathered for themselves, the health promoting activities they had enrolled in, whether their cardiologist had discussed any lifestyle topics, and whether they had attended any cardiac rehabilitation program (CRP). Finally, patients had to enter their age, gender, weight and length (allowing their body mass index (BMI) to be calculated), and their educational level.

Further process data were collected from three sources. First, to monitor the implementation of the intervention, the health advisors kept a thorough registration for each patient, including number of contacts, contact time, and primary topic of the counseling sessions. Second, a separate process questionnaire was used to assess the opinion of the intervention patients about the new health counseling service (see also Harting et al., Submitted). Third, three independent experts evaluated the application of the counseling model in 64 videorecorded counseling sessions during the first 18 months of the intervention (Harting et al., 2004).

\section{Analysis}

Logistic regression analyses were used to detect any sellection biases. Response at baseline was regressed on the condition (intervention ws. usual care) and the cardiac diagnosis (from left ventricular hypertrophy to myocardial infarction). Both response rates at first and second follow-up were regressed on condition, age, gender, educational level, smoking status, and BMI, all measured at baseline. Baseline differences in population characteristics between study groups were checked in a logistic regression analysis with condition as the dependent variable. Baseline differences on the behavior related scores that could have been caused by awareness of condition were examined with cross-tabs with $\chi^{2}$ tests and one-way analyses of variance.

Differences between study groups on the three behavioral outcomes at both follow-up measures were assessed with either multiple linear or logistic regression analyses. Apart from experimental condition, the complete regression models included the patient characteristics at baseline, the baseline score on the dependent variable concerned, and the interaction terms of experimental condition with all other independent variables. Comparable regression analyses were used for the behavioral determinants, but the interaction terms were limited to those between condition and pre-scores for the behavior and the determinant in question. Nonsignificant interaction terms and main effects were subsequently removed from the model, leaving only influential covariates in the analysis. The significance level was .05 for the behavior and intention measures, and .01 for measures of the more distal determinants. The analysis of the determinants of smoking behavior included only those patients who smoked at baseline, first or second follow-up. 
Differences between two possible sub-populations, that is, patients who had attended cardiac rehabilitation and patients who had not, were examined with univariate covariance analyses (fat score) and logistic regression analyses (smoking and physical activity), using condition, having attended a CRP at baseline, and the interaction between the two as additional independent variables $(\alpha=.05)$.

We tried to gain more insight into the process and effects of the health counseling by performing two additional analyses within the intervention group alone $(\alpha=.05)$. First, after having determined the final regression model for each behavior and intention measure, three process variables were entered: the health advisor, the total number of consultations about the topic of interest, and the satisfaction scores the parients gave directly after completing the counseling. Second, because the behavioral determinants were formulated with regard to behavior change rather than the target behavior itself (e.g., intention to reduce one's fat intake rather than to adhere to a low-fat diet as such), addirional analyses were carried out for subgroups of patients who had not changed their fat intake, smoking behavior, or physical activity level.

All analyses were run with SPSS for Windows 11.0.1. For reasons of multiple testing (type I errors) and transparency, the exact p-values are provided for all significant effects found.

\section{RESULTS}

\section{Response rates}

Baseline data were received from 1,270 patients, indicating an initial response of $91.5 \%$ (see Figure 6.1). As no significant differences in response rates for condition and diagnostic category were found, it was decided to base all further analyses on this baseline group. At the first post-test, 1,169 patients responded, and at the second post-test 1,032 , representing $92.0 \%$ and $81.3 \%$ of the baseline group, respectively. At the first follow-up, intervention parients $(\mathrm{OR}=.58, \mathrm{p}=.004)$ as well as smokers ( $O R=52, p=.001$ ) were found to be nearly twice as likely to have dropped out as control patients and non-smokers. In addition, the probability of dropping out decreased slightly with age $(O R=1.02, \mathrm{p}=.025)$. At the second follow-up, the probability of dropping out was found to be more than twice as high among baseline smokers as among non-smokers $(\mathrm{OR}=.43$, $p=.000)$. In view of this selective response, it was decided to use intention-totreat procedures, with missing values to be replaced by baseline values, for all effect analyses to come. 


\begin{tabular}{|c|c|c|c|}
\hline Aumber of pastents (percentages) & \ & c & $\|$ \\
\hline \multicolumn{4}{|l|}{ linformed consent } \\
\hline$N$ at inctustion & 1388 & 688 & 700 \\
\hline Baseline & $\downarrow$ & $\downarrow$ & $\downarrow$ \\
\hline$N$ at $T=0$ & 1270 & 639 & 631 \\
\hline$\% / 6$ of inclusion & $(91.5)$ & $(92.8)$ & $(90.1)$ \\
\hline First lallow-up & $\downarrow$ & $\dagger$ & $\nabla$ \\
\hline$N$ at $T=1(4$ monthis $)$ & 1169 & 604 & 565 \\
\hline Wor indusion & $(84.2)$ & $(87.8)$ & $(80.7)$ \\
\hline$\%$ of basaline & $(92.0)$ & $(94.5)$ & $(89.5)$ \\
\hline Second follow-up & $\downarrow$ & $t$ & $\downarrow$ \\
\hline$N$ at $T=2$ (118 months) & 1032 & 537 & 495 \\
\hline$\%$ of indusion & $(74.4)$ & (78.1) & $(70.7)$ \\
\hline$\%$ of baseline & $(81.3)$ & $(84.0)$ & (78.4) \\
\hline
\end{tabular}

: $T=\operatorname{total} 6=$ control groups $1=$ intervention grous

Figure 6.1 Flow chart for the cardiology outpatient climic

\section{Baseline data}

The characteristics of the study population are presented in Table 6.l. Men had a higher probability of being assigned to the intervention group (71.3\%) than to the control condition $(66.7 \% ; \mathrm{OR}=1.31 ; \mathrm{p}=.049)$.

The patients' mean fat score was 17.5 (Table 6.2). Approximately two-thirds of the patients were aware of their actual level of fat intake. On average, the patients had positive scores on all determinants of a decrease in their fat consumption. Just over a quarter of the participants smoked (26.5\%). Smokers had been so for an average of 37.5 years. Their average score on the determinants of smoking cessation was positive, except for one of the attitude measures and for self-efficacy. Of the non-smokers, $71.9 \%$ reported to have smoked in the past, of whom $52.5 \%$ had quit smoking more than five years ago. Of the study population, $57.2 \%$ were classified as sufficiently physically active. Two-thirds of the patients were aware of their activity status. Again, the respondents had rather positive scores on the determinants of increasing their physical activity level. No differences were found between study groups as regards baseline scores. 


\begin{tabular}{|c|c|c|c|c|c|c|c|c|c|}
\hline & & \multicolumn{2}{|c|}{ Experimental condition } & \multicolumn{2}{|c|}{ Contral condition } & \multicolumn{4}{|c|}{ Total propulation } \\
\hline & & $\mathbb{N}^{*}$ & $\%$ & $\mathbb{N}^{*}$ & $y^{* * \infty}$ & $N^{*}$ & $\% / 0^{* *}$ & Mean & SD \\
\hline \multirow[t]{4}{*}{ Age } & $\leq 49$ & 91 & 14.4 & 80 & 12.5 & 171 & 13.5 & 61.1 & 9.26 \\
\hline & $50 \cdot 60$ & 175 & 27.7 & 161 & 25.2 & 336 & 26.5 & & \\
\hline & $60 \cdot 70$ & 231 & 36.6 & 260 & 40.7 & 491 & 38.7 & & \\
\hline & $\geq 70$ & 134 & 21.2 & 138 & 21.6 & $m 2$ & 21.4 & & \\
\hline \multirow[t]{2}{*}{ Gender } & male & 450 & 71.3 & 426 & 6.7 & 876 & 69.0 & & \\
\hline & femrale & 181 & 28.7 & 213 & 33.3 & 394 & 31.0 & & \\
\hline \multirow[t]{3}{*}{ Education } & loiti & 312 & 52.9 & 332 & 54.5 & 644 & 53.7 & & \\
\hline & intermediate & 199 & 33.7 & 188 & 30.9 & 387 & 32.3 & & \\
\hline & high & 79 & 13.4 & 89 & 14.6 & 168 & 14.0 & & \\
\hline \multirow[t]{2}{*}{ Smaking } & yes & 160 & 26.7 & 160 & 26.4 & 320 & 26.5 & & \\
\hline & no & 440 & 73.3 & 447 & 73.6 & 887 & 73.5 & & \\
\hline \multirow[t]{3}{*}{$B M$} & $\mathrm{BMI}<25$ & 170 & 28.0 & 186 & 29.8 & 356 & 28.9 & 27.46 & 4.32 \\
\hline & $25 \leq \mathrm{BM} \|<30$ & 287 & 47.2 & 286 & 45.8 & 573 & 46.5 & & \\
\hline & $30 \leq 8 M 1$ & $|5|$ & 24.8 & 153 & 24.5 & 304 & 24.7 & & \\
\hline
\end{tabular}

" Intals per category wary due to missing values, *" Valid percentages

\section{Implementation of the intervention}

On average, the patients attended 2.76 meetings (range $1-9 ; S D=1.73$ ), which took a total of just over 90 minutes (range $15-330 ; S D=55.3$ ) over a period of 87 days (range 1-616; $\mathrm{SD}=90.2$ ). At $\mathrm{T}=4$, a quarter of the parients still had a further counseling session planned, and one-fifth were expecting another phone call from the health advisor.

Nutrition was at least once the primary topic of the counseling for $53.5 \%$ of the patients, smoking for $19.1 \%$, and physical activity for $38.0 \%$. For $12.2 \%$ of the patients, none of these target behaviors had ever been the issue of centrall interest. Other main topics registered were the relationship between behavior and health in general (being at least once the main topic for $21.7 \%$ of the patients), stress $(9.6 \%)$, illness $(8.8 \%)$, or other $(4.4 \%)$.

A telephonic booster session, which took an average of 10 minutes, was registered for $31 \%$ of the parients, and approximately $35 \%$ of them were referred to local health promoring activities. 


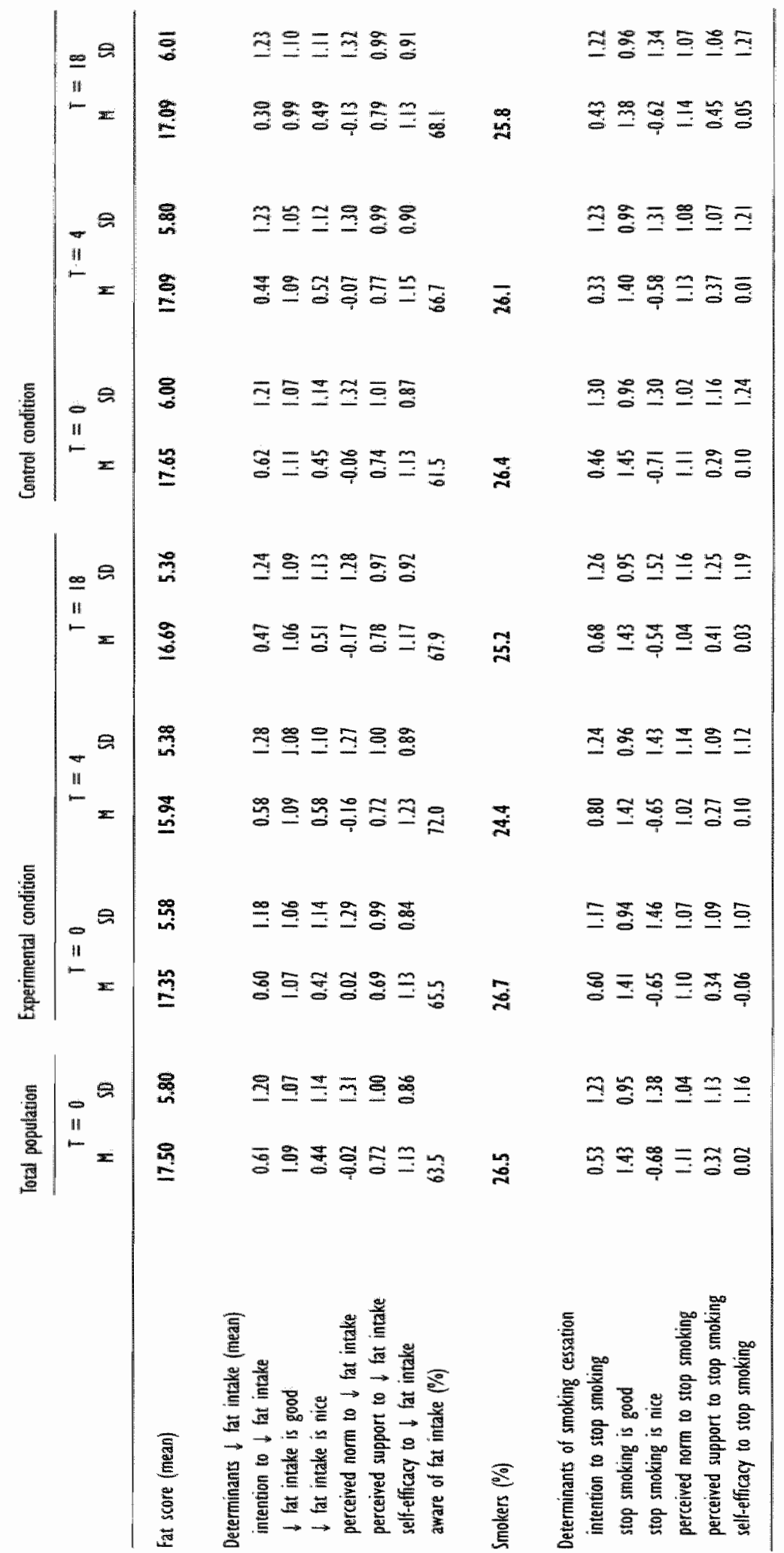




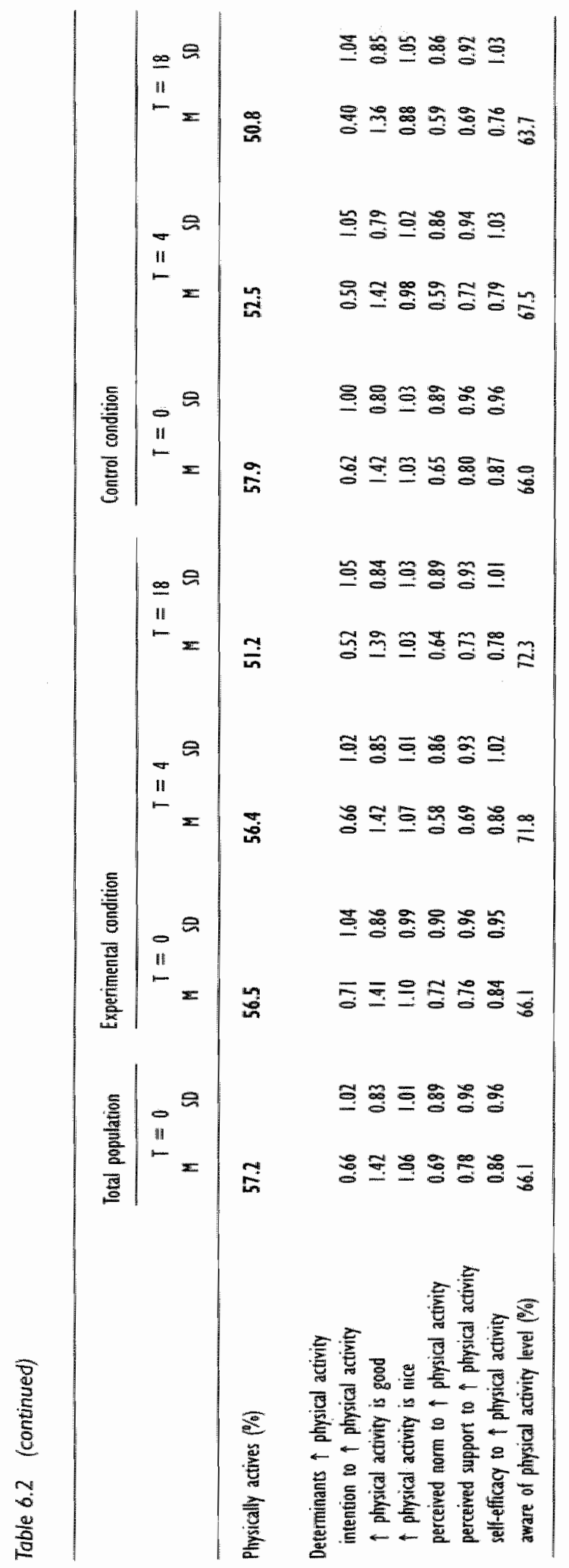


Toble 6.3 Results on primary outcomes at the cordiology outpatient clinic

\begin{tabular}{|c|c|c|c|c|c|c|}
\hline \multirow[b]{2}{*}{ Ia Heaith behawior } & \multicolumn{2}{|l|}{ Fat scare } & \multicolumn{2}{|l|}{ Smoking } & \multicolumn{2}{|c|}{ Physical activity } \\
\hline & $\mathrm{T}=\mathbf{4}$ & $\pi=18$ & $I=4$ & $I=18$ & $T=4$ & $I=18$ \\
\hline Condition & -.962 & & .564 & & .143 & \\
\hline \multirow[t]{2}{*}{$u=$ imferwention $)$} & $p=0.000$ & & $p=039$ & & $p=.081$ & \\
\hline & \multicolumn{2}{|c|}{$\downarrow$ Fat consumption } & \multicolumn{2}{|c|}{ Stap smoking } & \multicolumn{2}{|c|}{$\uparrow$ Physical activity } \\
\hline $3 \mathrm{~b}$ Intention to change & $\mathrm{I}=4$ & $I=18$ & $\mathrm{I}=4$ & $T=18$ & $T=4$ & $T=18$ \\
\hline Condition & .152 & .173 & .379 & & .004 & \\
\hline$(1=$ interventition $)$ & $p=.012$ & $p=.004$ & $p=.000$ & & $p=031$ & \\
\hline
\end{tabular}

* unstandardined linear regression coefficients and bimary logistic regression extimates

\section{Intervention effects}

At $\mathrm{T}=4$, a main effect was found for condition on fat consumption (Table 6.3). In the intervention group, the mean total fat score was nearly a full point below that of the control group. The difference in mean fat score was no longer significant at $\mathrm{T}=18$, mainly because the intervention patients had increased their fat consumption again (see Table 6.2).

At $\mathrm{T}=4$, condition had a main effect on smoking. For smokers in the intervention group, the likelihood that they were still smoking at $\mathrm{T}=4$ was nearly half of that for smokers in the control group (OR $=.57,95 \% \mathrm{CI} .33-97)$. No effect was found at $T=18$.

The effect of condition on physical activity at $T=4$ was not significant $(\mathrm{OR}=1.28,95 \% \mathrm{CI} 0.97-1.70)$, and no effect was found at $\mathrm{T}=18$.

As regards the intention to reduce the fat consumption, a main effect for condition was found at both follow-up assessments, meaning that the intervention group was more willing to change than the control group. An increased intention to stop smoking and to become more physically active was reported by the intervention patients only at $T=4$. No significant effects were found for the more distal determinants.

\section{Process information}

At $T=4$, the intervention group had considerably more often sought information about most behavioral risk factors than the control group, but not about stress, medication or health in general (Table 6.4). This difference was far less prominent at $\mathrm{T}=18$ months. The two groups differed only slightly in their rather limited enrolment in health promoting activities. 
Table 6.4 Additional process information: information seeking and participation in activities

\begin{tabular}{|c|c|c|c|c|}
\hline & \multicolumn{2}{|c|}{ Experimental condition } & \multicolumn{2}{|c|}{ Control condition } \\
\hline & $T=4$ & $T=18$ & $t=4$ & $r=18$ \\
\hline \multicolumn{5}{|l|}{ Sought information about } \\
\hline nutrition & 41.8 & 25.3 & 16.2 & 18.6 \\
\hline smoking & 11.5 & 0.5 & 5.8 & 6.9 \\
\hline physical activity & 28.2 & 13.9 & 8.9 & 9.4 \\
\hline stress, medication, \& health & 33.0 & 29.8 & 30.8 & 35.5 \\
\hline \multicolumn{5}{|l|}{ Enrolled in activity on } \\
\hline nuirition & 2.7 & 2.1 & 1.4 & 1.2 \\
\hline smoking & 2.0 & 0.8 & 0.5 & 1.3 \\
\hline activity for the elderly & 5.1 & 5.4 & 2.4 & 3.5 \\
\hline sports activity & 3.1 & 4.6 & 2.4 & 2.9 \\
\hline walking activity & 2.4 & 2.1 & 0.7 & 2.1 \\
\hline stress reduction \& other & 4.9 & 4.5 & 4.3 & 4.3 \\
\hline \multicolumn{5}{|l|}{ Ablle to comply with advice } \\
\hline fully & 14.1 & 11.0 & & \\
\hline largely & $38 . B$ & 35.8 & & \\
\hline partly & 30.3 & 33.0 & & \\
\hline hardly & 4.2 & 4.4 & & \\
\hline not at all & 1.6 & 1.6 & & \\
\hline no advice & 10.9 & 8.7 & & \\
\hline do not remember advice & - & 5.7 & & \\
\hline \multicolumn{5}{|l|}{ Support from cardiologist } \\
\hline muich & 14.7 & & & \\
\hline considerable & 14.5 & & & \\
\hline some & 14.9 & & & \\
\hline none & 9.7 & & & \\
\hline no consultation & 32.9 & & & \\
\hline \multicolumn{5}{|l|}{ Cardiologist discussed lifestyle } \\
\hline yes & & 24.5 & & 27.3 \\
\hline no & & 61.3 & & 61.1 \\
\hline
\end{tabular}


At $\mathrm{T}=4$, one-eighth of the intervention patients reported to have been fully abje to comply with the recommendations received, while a third had been able to comply largely and another third partly. Approximately $5 \%$ reported that compliance had been largely impossible. At $\mathrm{T}=18$, the ability to comply had slightly decreased.

At both $T=4$ and $T=18,60 \%$ of all patients who had consulted their cardiologist reported that no lifestyle issues had been discussed, and at $\mathrm{T}=4,45 \%$ of the intervention patients among them stated to have perceived only some or no 116 support with regard to lifestyle changes.

At baseline, more than $40 \%$ of all patients had participated in a CRP. In both experimental conditions, a further $15 \%$ of the patients had attended such a program at $\mathrm{T}=4$ and another $11 \%$ had done so at $\mathrm{T}=18$.

Intervention patients regarded the health counseling service as being of rather high quality ( 8.2 on a ten-point scale), were rather satisfied with the new service, and thought it a welcome addition to usual care (both 4.1 on five-point scales, Harting et al., Submitted). The experts considered the quality of the counseling as nearly satisfactory ( 2.85 on a four-point scale, Harting et al., 2004).

\section{Influence of process indicators}

Patients who had attended a CRP at baseline showed a tendency toward fewer health counseling sessions compared to those who had not attended a CRP. This was mainly caused by fewer consultations about diet and smoking. At baseline, CRP attenders were less likely to be smokers (23.1\%) than nonattenders (28.9\%), and this difference was sustained over 18 months. Attending a CRP or not did not influence the main intervention effects for fat consumption and smoking at $\mathrm{T}=4$, but the subgroup of non-attenders showed a sustained decrease in fat intake at $\mathrm{T}=18(\mathrm{~F}=3.872, \mathrm{p}=.049)$. Compared to control patients and non-attenders, intervention patients who had attended a CRP at baseline were somewhat more likely to maintain their activity level at $\mathrm{T}=4$ $(\mathrm{OR}=1.79,95 \% \mathrm{CI} 1.13-2.84)$ and $\mathrm{T}=18(\mathrm{OR}=1.51,95 \% \mathrm{Cl} .97-2.35)$.

Within the intervention group, the health advisors only differed in their effectiveness with regard to the patients' intention to become more physically activity at $\mathrm{T}=4$. The more consultations about nutrition, the lower the patient's fat score at $T=4$ and $T=18$ and the greater the patient's intention to decrease the fat consumption at $T=4$. As regards physical activity, the number of consultations was positively related to the intention to increase activity at $\mathrm{T}=4$. Patients who reported being more satisfied with the intervention had lower fat scores and a stronger intention to decrease their fat consumption at $T=4$ and $T=18$. In terms of physical activity, being more satisfied led to higher scores on the intention to increase this at both follow-up assessments.

No major changes in findings occurred for the effects at determinant level for the subgroups of patients who did not change their risk behavior as a result of the intervention. 


\section{DISCUSSION}

\section{Main results}

The health counseling component of the Hartslag Limburg project in the cardiology outpatient clinic led to a substantial decrease in fat consumption, a small increase in smoking cessation, and a positive trend towards an increase in physical activity after four months. After 18 month, these effects no longer existed. Positive effects were also found on the intention to change any of the three risk behaviors after four months. After 18 months, such an increased intention was still observed for a reduction of the fat intake. No intervention effects were found on any of the behavioral determinants.

Despite the favorable conclusions of two earlier review studies (Mullen et al., 1992; NHS Centre for Reviews and Dissemination University of York, 1998), the effects of the present intervention were rather small and not sustained in the longer term. Our findings are, however, in line with those reported in two more recent reviews. The first, summarizing RCTs of chronic disease patient education, concluded that the effects on self-management, including lifestyle behaviors, were usually small and only observable for six months (Cooper, Booth, Fear, \& Gill, 2001). The second, reviewing individualized multifactorial lifestyle interventions for high-risk cardiovascular patients, concluded that changes in (behavioral) CVD risk factors were often clinically modest (Ketola, Sipilä, \& Mäkelä, 2000). Our findings are also comparable with more recent lifestyle interventions after cardiac rehabilitation. For instance, the ELMI trial, which included telephone follow-up calls and two counseling sessions six and nine months after ending the cardiac rehabilitation, did not find any effects on behavioral outcomes after one year (Lear et al., 2003).

Nevertheless, the present findings permit the conclusion that brief health counseling of patients with a manifest cardiovascular disorder is potentially effective in changing multiple cardiovascular risk behaviors in the short term. However, the limited effects do not justify a large-scale implementation yet. Based on the process information of the present study as well as on empirical findings of other cardiovascular prevention studies, various explanations for the limited effects of our intervention can be proposed.

First, it may be questioned whether the lifestylle advice intervention was implemented as intended. The evaluations of experts in this discipline (Harting et al., 2004) as well as the opinions of the patients (Harting et al., Submitted), indicate that improvements may be found in structuring the counseling sessions better and in applying the specified behavior change strategies more strictly. In addition, more fully adopting the principles of motivational interviewing (W. R. Miller \& Rollnick, 1991) may enable the health advisors to more adequately handle the resistance that patients may experience (Harting et al., Submitted) when they are confronted with restrictions (Fogarty, 1997).

Next, the registration the health advisors kept, revealed that the three health behaviors that were the main endpoints of the present study had never been the 
topic of primary interest for $12 \%$ of the patients. This partial shift in focus may have weakened the intervention's effectiveness. The health advisors explained that for some patients, namely for those with a healthy lifestyle, discussing lifestyle issues had been superfluous, but that for others, especially for those recently discharged from the hospital, stress, worry, anxiety, and uncertainty had been much more important topics. Whether the health advisors were effectiwe in reducing their patients' distress was not examined.

In addition, the health advisors declared that the comprehensive theorybased and empirically guided counseling model was difficult to implement in an appropriate way (Harting \& Van Assema, In preparation). They also stated that the stage-matched approach was an oversimplification of the way their patients tended to behave in reality (Harting \& Van Assema, In preparation). This observation was supported by a recent finding that many stage transitions may occur within a rather short period of time (De Nooijer, Van Assema, De Vet, \& Brug, Accepted for publication). This suggests that even individually tailored interventions, such as the present stage-matched counseling approach, probably focus on the wrong behavioral determinants, possibly limiting their effectiveness.

Second, although the individual lifestyle advice in essence appeared to be effective, additional intervention components may be needed to maintain the lifestyle changes that were achicved. Our process findings indicate that reinforcement may be found in additionally involving the cardiologists, as secondary analyses revealed that perceiving their support seemed to contribute to smoking cessarion, and in making better use of the local health promoting facilities. Programs offering disease management, defined as "a combination of patient education, provider use of practice guidelines, appropriate consultation, and supplies of drugs and ancillary services" (Hunter \& Fairfield, 1997), have been found to have a positive impact on outcomes that are closely linked to subsequent CVD morbidiry and mortality (Haskell, 2003; McAlister, Lawson, Teo, \& Armstrong, 2001). Such a disease management approach may however be difficult to implement, as the multiple component intervention that was originaliy proposed by the Hartslag Limburg project was found to be unfeasible for both organizational and motivational reasons. Besides, the optimal mix of interventions and their cost-effectiveness are still unclear (McAlister et al., 2001).

In applying such a more comprehensive multifactorial approach, an exception should perhaps be made for smoking. A review of individual multiple factor lifestyle interventions concluded that rew of them had an effect on smoking (Ketola et al., 2000), and even the more comprehensive intervention studies mentioned above did not find any long-term effects on smoking. For smokers, an unifactorial intervention may be more adequate and the best moment to intervene may be during hospitalization, as at the hospital, smokers are more receptive to a smoking cessation intervention than in other circumstances (evidence summarized by Bolman, De Vries, \& Van Breukelen, 2002). A recent review suggests that intensive in-hospital stop-smoking interventions, including inpatient contacts plus follow-up for at least one month, are associated with increased quit rates (Rigotti, Munafo, Murphy, \& Stead, 2004). 
Third, the present findings indicate that offering a longer follow-up may be more effective. However, there is no consensus yet on the frequency and duration needed for secondary prevention programs to be effective. For instance, voluntary extended-length participation ( $>1$ year) in cardiac rehabilitation liad positive effects on several behavior related biomedical outcomes compared to standard-length participation (3 months, Brubaker et al., 1996), but a small RCT found no differences between sustained CRP, a home-based maintenance exercise program after CRP, and standard care after CRP (Brubaker et al., 2000). On the other hand, two interventions that combined a multi-component approach with regular follow-up meetings for at least four years showed promising long-term changes in both fat consumption and physical activity level (Haskell et al., 1993; Murchie, Campbell, Ritchie, Simpson, \& Thain, 2003).

Finally, our findings indicate that offering both cardiovascular rehabilitation and individual health advice may be more effective than offering either of the services alone. This view is supported by an earlier review study (NHS Centre for Reviews and Dissemination University of York, 1998). Until now, however, most cardiovascular rehabilitation programs (CRPs) are structured programs emphasizing exercise and offered only to patients who have had a myocardial infarction or have undergone cardiac surgery (Bär \& Vonken, 1990; NHS Centre for Reviews and Dissemination University of York, 1998). Opening up CRPs to cardiac patients who currently have no access may at least substantially increase the percentage of patients who stop smoking. In addition, offering additional individual lifestyle advice to patients that attended a CRP' may help them to remain their physical activity level.

\section{Validity issues}

The internal validity of this study may have been threatened by the fact that, for ethical reasons, organizational difficulties, and time constraints, the experimental condition as well as the content of the intervention had to be made known to all patients before they answered the baseline questionnaire. As their answers were going to be used by the health advisor to get a preliminary idea of their lifestyle, this familiarity with experimental condition may, for instance, have resulted in greater honesty in the intervention group and more socially desirable answers in the control group. Although the limited differences found between the intervention and control groups at baseline do not indicate such an effect, the present procedure does not allow solid conclusions about the real differences between study groups at baseline, nor adequate correction for these differences in statistical analyses.

A second problem of internal validity of the present study relates to the baseline measure itself, as well as the additional process questionnaire the intervention patients received after the intervention had been terminated. 'The baseline questionnaire may have sensitized patients in the intervention group to the approaching health counseling intervention (Green \& Lewis, 1986). This makes it impossible to determine whether lifestyle changes were a result of the inter- 
vention as such or a product of the interaction between the patients' increased receptiveness and the actual intervention. The additional process questionnaire may have worked as an intervention in and of itself or as a rcinforcement of the health counseling sessions.

These threats to the internal validity, and hence the external validity, were however regarded as acceptable in view of the benefits, viz, the opportunity to compare the two study groups at baseline, especially because of the patients" familiarity with their experimental status, and the option to gain additional insight into the causal process of the intervention.

With regard to the external vallidity, the self-selection by both the cardiologists and the patients might be problematic. Problems with recruiting sufficient cardiologists indicate that those who did participate were considerably more motivated than their non-participating colleagues. For the patients, no systematic record of refusals was kept, but verbal reports indicate that the negative response was negligible. However, it remains unclear to what extent the cardiologists pre-selected the patients they invited to participate, for instance on cardiovascular risk level or on estimated motivation. Thus, the results of the present study can presumably only be generalized to rather motivated cardiologists and a rather motivated outpatient population.

A final problem of the validity of the study is that, although a validated food frequency questionnaire was used, its lay-out may have caused more missing vallues among the present, older study population, than was desirable.

\section{Conclusion}

Despite the limitations discussed, the short-term effects on cardiovascular risk behaviors indicate that offering multifactorial counseling to patients with a manifest cardiovascular disorder is potentially effective. The rather limited effect sizes, as well as the absence of effects in the longer term, also show that the present approach should be further improved. Although improvements could be achieved by enhancing the quality of the counseling service itself, a longer-lasting and. more comprehensive approach might be more effective in secondary prevention. This may require additional program components, the active participation by cardiologists, and/or ask for a more intense utilization of existing prevention facilities.

\section{ACKNOWLEDGEMENT}

Data were collected as part of the Hartslag Limburg project, which was coordinated by the Maastricht Regional Public Health Institute (GGD-zzl), and funded by the Netherlands Heart Foundation (NHS). 


\section{CHAPTER 7}

Cardiovascular prevention in the Hartslag Limburg project: effects of a high-risk approach on behavioral risk factors in a general practice population

A manuscript based on this chapter has been submitted for publication as: Harting, J., Van Assema, P., Van Limpt, P., Gorgels, T., Van Ree, J., Ruland, E., Vermeer, F., \& De Vries, N.K. (2004). Cardiovascular prevention in the Hartslag Limburg project: effects of a high-risk approach on behavioral risk factors in a general practice population. 


\section{ABSTRACT}

The aim of this study was to evaluate a general-practices-based high-risk cardiovascular prevention approach in the Netherlands. It consisted of the complete registration of risk factors, optimizing medical treatment, and health counseling. Behavioral effects were assessed in a randomized controlled trial. Questionnaires were completed by 1,300 patients at baseline, 1,174 after four months $(90.3 \%)$, and $1,046(80.5 \%)$ after 18 months. After four months, 122 intention-to-treat analyses revealed a decrease in fat consumption $(-7,5 \%$, $\mathrm{p}=.000)$, which was partly sustained after 18 month $(-2.9 \%, \mathrm{p}=.014)$. After 18 months, obese intervention patients were nearly twice as likely found to be sufficiently physically active than their control counterparts (OR $=1.90$, $p=.023$ ). No effects were found for smoking nor for the intention to change any of the three risk behaviors. Process data showed that the registration of risk factors and the optimization of medical treatment were only partly realized, and that the health counseling could be further improved. 


\section{INTRODUCTION}

In the Netherlands, cardiovascular disease (CVD) bring about $35 \%$ of all deaths, making them the leading cause of mortality (RIVM, 2003). In the southern part of the country, prevalence of and mortality from CVD are relatively high, and behavior related cardiovascular risk factors, such as obesity and smoking, are common among its residents (GGD, 1999). These epidemiologic data were the reason for initiating the regional cardiovascular prevention project Hartslag Limburg (Dutch for Heartbeat Limburg, Ruland et al., 1999). The project combined a community-based intervention with an individual highrisk approach (Rose, 1992). The focus of the present article is on the behavioral effects of the individual approach in a general practice setting.

In individual cardiovascular prevention strategies, priority should be given to patients with established CVD or healthy individuals who are at high risk of developing CVD (Ebrahim \& Smich, 1997; Rose, 1992; D. Wood et al., 1998). Among these groups, changing cardiovascular risk factors has the potential capacity to generate substantial health gains (CDC \& National Center for Chronic Disease Prevention and Health Promotion, 1998; RIVM, 2003). Since CVD have a multifactorial etiology and cardiovascular risk factors have a multiplicative effect, a multiple factorial prevention approach is expected to be most effective (Pyörälä et al., 1994; Rose, 1992). In addition, multiple components are required for effective CVD prevention (Pyörälä et al., 1994; Rose, 1992; D. Wood et al., 1998), such as a complete registration of risk factors, optimal treatment of biomedical risk factors, and counseling of behavioral risk factors (CDC \& National Center for Chronic Disease Prevention and Health Promotion, 1998; Mullen et al., 1997). In Dutch general practices, the implementation of these components has been found to be suboptimal (Van Drenth, Hulscher, Van der Wouden, Mokkink et al., 1998; Drenthen, 1997; Hulscher et al., 1998; Kromhout, 1999).

The potential effectiveness of an individualized high-risk approach in primary care has been acknowledged before (Ashenden et al., 1997; Ebrahim \& Smith, 1997). Some intensive multiple risk factor interventions have indeed yielded a promising decline in risk factors (e.g. Cutler et al., 1991; Imperial Cancer Research Fund OXCHECK Study Group, 1995; D. A. Wood et al., 1994), though others have failed to do so (e.g. Burton et al., 1995; Lindholm, Ekbom, Dash, Isacsson, \& Scherstén, 1996; Lindhol met al., 1995). More extensive and rigorous research has therefore been recommended, before allocating substantial public funds to such general-practice-based health promotion efforts (Ashenden et al., 1997).

The main research question of the present study was whether the high-risk approach generated positive changes in fat consumption, smoking, and physical activity level. As changes in behavional determinants were expected to precede changes in the three cardiovascular risk behaviors, these secondary end-points were evaluated as well. 


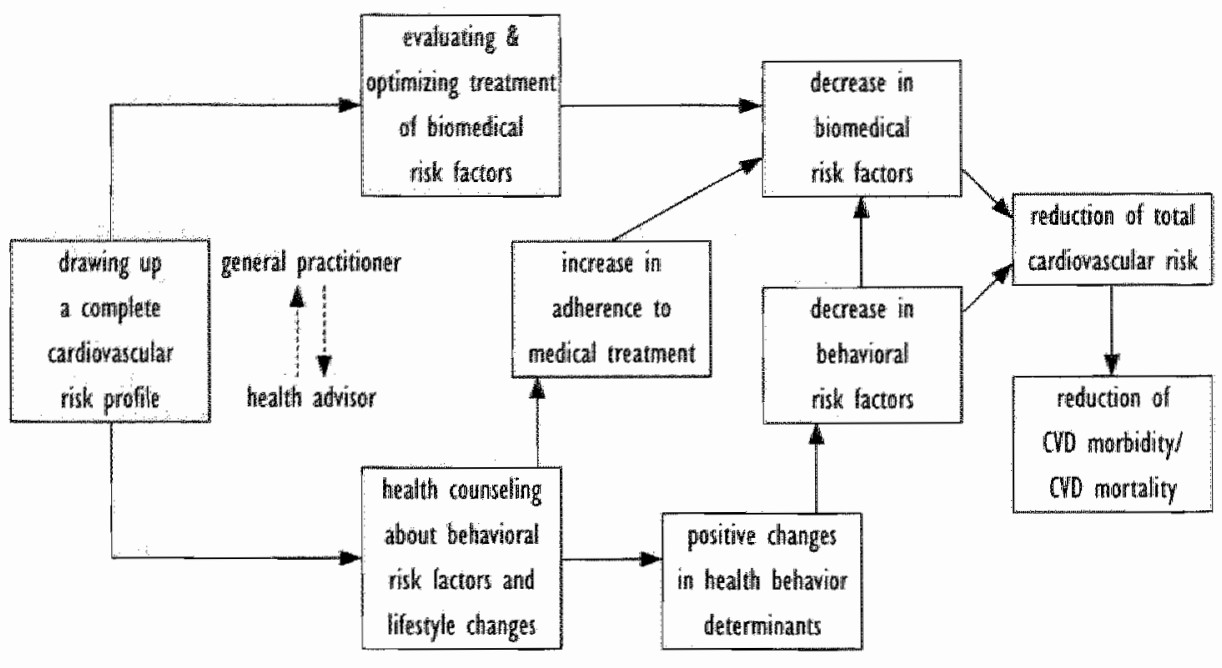

Figure 7.I Causal intervention model

\section{METHODS}

\section{Intervention}

The intervention protocol was threefold (see Figure 7.1 for the causal intervention model as this is recommended by Rimer et al., 2001). First, a complete computerized cardiovascular risk profile had to be drawn up to provide a guide for drug treatment and lifestyle interventions (D. Wood et al., 1998). Second, the general practitioners (GPs) had to evaluate and, if necessary, optimize the treatment of bionedical risk factors in accordance with the national practice guidelines. Third, patients were invited to visit a health advisor for an inventory of their behavioral risk factors and to be counseled on healthy lifestyle changes and adherence to medical treatment. This was introduced as a new service in the Dutch health care system. The simultaneous and collaborative prevention efforts from the GPs and the health advisors were anticipated to reinforce their individual preventive effects.

The two health advisors, one a specialized practice assistant and the other a dietician, had been trained in behavior change and counseling techniques (Harting et al., 2004) and in the use of a theory-based and empirically guided stage-matched health counseling model (Harting \& Van Assema, In preparation). In accordance with evidence-based international recommendations (WHO, 2003; D. Wood et al., 1998) and national guidelines (Kemper et al., 2000; Voedingsraad, 1991), they made use of the following rules of life: patients' fat consumption should preferably consist of unsaturated fat and not exceed $35 \%$ of 
the total energy intake, patients should not smoke, and they should be moderately active for at least 30 minutes a day on five to seven days a week.

The health advisors were encouraged to consolidate their personalized information and advice with leaflets and booklets (Burke et al., 1997). Trial packages of nicotine replacement and bupropion therapy were available as effective additional strategies for smoking cessation (Hughes et al., 2004; Silagy et al., 2004). For those patients who appreciated this, the health counselors used a telephonic booster, as a means to sustain behavioral effects (Van Elderen-van Kemenade et al., 1994). Furthermore, the health advisors were expected to refer patients to health promoting activities in their neighborhood, to regularly consult with the GPs about their patients, and to ensure written feedback information in the patient records.

\section{Design and participants}

The effect study had an experimental design, with one pre-test questionnaire $(T=0)$ and two post-tests questionnaires after $4(T=4)$ and 18 months $(T=18)$, respectively. After stratification for socioeconomic class of neighborhood (high vs. low) and preventive orientation of GPs (high vs. low), the 25 participating general practice units (each expected to include 45 patients) were randomized into 12 intervention and 13 control units (usual care). Participants had to have a greater than $20 \%$ risk of incurring a cardiovascular event within ten years (Pyörälä er al., 1994; D. Wood et al., 1998). As a pre-selection, an initial guesstimate of their cardiovascular risk was based on the, sometimes incomplete, information from their records, using a risk model based on the Framingham study (Anderson et al., 1991). From April 1999 to October 2001, the 35 participating GPs asked the preselected patients to take part in the study, either personally during a consultation or by sending them an invitation letter. No systematic record of refusal was kept, but approximately $45-50 \%$ of the invited patients gave their informed consent $(N=1,355)$.

\section{Data collection}

Dietary fat intake was measured with a questionnaire covering the food products that contribute most to the consumption of saturated fat. Its relative validity has been assessed by comparison with a seven-day diet record ( $R=.71$, Van Assema et al., 2001). Reliable total fat scores could be calculated for records with less than $50 \%$ missing values on the 35 items, leaving $92 \%$ of the respondents. Based on the Dutch Nutrition Consumption Survey (VCP, Gezondheidsraad, 2001; RIVM, 2003), fat scores of 17 points for men and 14 points for women should be regarded as the approximate upper levels of recommended dietary fat intake.

The point-prevalence of smoking was assessed by asking respondents whether they had smoked, even if it had been only one puff, during the last seven days. 
Smokers had to specify since when they had smoked and whether they had ever tried to quit. Non-smokers were asked whether they had smoked in the past, and if so, how long ago they had quit smoking.

Physical activity level was measured with a short questionnaire (Ronda et al., 2001), which was slightly adapted to the senior population under study. Its relative validity had been investigated by comparison with a seven-day physical activity record $(\mathrm{R}=.50$, Koremans et al., 2000; Ronda et al., 2001). The questionnaire addressed 11 activity categories, to be scored in minutes per day and days per week, allowing to calculate an indirect physical activity score. In addition, patients were asked to indicate directly the number of days per week on which they were ustually physically active for more than 30 minutes. Patients who directly as well as indirectly met the norm of being sufficiently physically active were classified as meeting the recommended target.

For all three cardiovascular risk behaviors, several psychosocial determinants were assessed. The selection of these determinants was guided by the aims of the intervention specified in the counseling model (Harting \& Van Assema, In preparation $\rangle$. As most proximal determinant of behavior change, the intention to change was included in the questionnaire by asking to what extent patients were planning to cat less fat, to stop smoking, and to become more physically active (Ajzen, 1991). More distal predictors of behavior change included attitude, social influence, and self-efficacy expectations (Ajzen, 1991; Bandura, 1986; H. De Vries er al., 2000), whose operationalizations have been reported elsewhere (Ronda et al, 2004). Bipolar five-point scales were used, as is common in studying behavioral determinants (H. De Vries et al., 2000).

Awareness of one's own behavior (Weinstein, 1988) has been found to be an important factor in changing dietary behavior as well as physical activity (Brug et al., 1994; Ronda et al., 2001). This awareness was assessed by evaluating the self-rated levels of fat intake and physical activity (low-high) against the objectively assessed fat intake and physical activiry level. Patients who were realistic were labeled "aware" and those who were unrealistic "unaware" (for the exact procedure, see Ronda et al., 2001).

Process questions asked the intervention patients to indicate their perceived overall adherence to lifestyle recommendations. All parients were asked to specify the health information they had gathered and the health promoting activities they had engaged in. Finally, the parients were questioned about their age, weight and length (allowing their body mass index (BMI) to be calculated), and their level of education.

Additional process data were gathered from three sources. First, the health advisors kept a thorough registration of their activities in order to monitor the implementation process. Second, the intervention group was asked to report their opinion about the new service on a separate process questionnaire immediately after the counseling had ended (Harting et al., Submitted). Third, three independent experts evaluated the application of the counseling model in 64 video-recorded counseling sessions during the first 18 month of the intervention (Harting et al, 2004). 


\section{Analysis}

Logistic regression analyses were used to detect any selection biases. As regards response rates at baseline, only condition (experimental vs. control) and the main reason for inclusion (biomedical risk factors or cardiovascular problems) were available as independent variables. For the response rates at first and second follow-up, the independent variables considered were condition, age, gender, educational level, smoking status, and BMI, all measured at baseline.

Condition was regressed on population characteristics to determine baseline differences between study groups. Cross-tabs with $\chi^{2}$ tests and one-way analyses of variance examined baseline differences in behavior related scores that could have been caused by awareness of condition.

Depending on their measurement level, differences between study groups on the three behavioral outcomes at both follow-ups were assessed by means of multiple linear or logistic regression analyses. The complete regression models included the following independent variables: condition, the population characteristics, the baseline score on the dependent variable concerned, and the interactions between condition and all other independent variables. Similar regression analyses were used for the behavioral determinants, except that the interaction terms were limited to those between condition and the pre-scores for the behavior and the determinant in question. Non-significant interaction terms and main effects were subsequently removed from the model in a hierarchical stepwise procedure with $\alpha=.05$ for outcomes at behavioral level and $\alpha=.01$ for outcomes at determinant level. The analysis of the determinants of smoking behavior included only those patients who smoked at baseline, first or second follow-up. If a significant main or interaction effect for condition was found, a multilevel analysis was used to correct for two possible level effects, that of general practice and that of GP.

To gain more insight into the process and effects of the health counseling two additional analyses were performed within the intervention group alone $(\alpha=.05)$. First, after having determined the final regression model for each behavior and behavioral intention measure, three process measures were entered in one step: the health advisor, the total number of consultations about: the topic of interest, and the patients' self-reported satisfaction score. Second, because the behavioral determinants had been formulated with regard to behavior change instead of the target behavior itself (e.g., intention to reduce one's fat intake instead of to comply with a low-fat diet as such), additional analyses were carried out for subgroups of patients who had not changed their level of fat intake, smoking habits, or physical activity, respectively.

The multilevel analyses were run with MLwiN 1.1, all other analyses with SPSS for Windows 11.0.1. For reasons of multi-testing (type I errors) and transparency, the exact $\mathrm{p}$-values are provided for the significant effects found. 


\section{RESULTS}

\section{Response rates}

Baseline data were received from 1,300 patients, indicating an initial response of $95.9 \%$ (see Figure 7.2). As no significant differences in response rates for condition and diagnostic category were found, it was decided to base all further analyses on this baseline group. At the first post-test, 1,174 patients responded 128 and at the second post-test 1,046 , representing $90.3 \%$ and $80.5 \%$ of the baseline group, respectively. At first follow-up, patients in the intervention condition $(\mathrm{OR}=.46, \mathrm{p}=.000)$ or who were smokers at baseline $(\mathrm{OR}=.47, \mathrm{p}=.000)$ were found to be more than twice as likely to have dropped out as patients in the control group and non-smokers. The opposite was the case for patients with an intermediate educational level compared to patients with a low or high educational level $(\mathrm{OR}=1.77, \mathrm{p}=.009)$. At second follow-up, the difference in drop-out for condition was smaller but still significant $(O R=.62, \mathrm{p}=.002)$, whille it remained the same for smoking status $(\mathrm{OR}=.44, \mathrm{p}=.000)$. In view of this selective response, it was decided to use intention-to-treat procedures, with missing values to be replaced by baseline values, for all effect analyses to come.

\begin{tabular}{|c|c|c|c|}
\hline Mumber of patients (percentages) & $\pi$ & $c$ & 1 \\
\hline \multicolumn{4}{|l|}{ Informed consent } \\
\hline N at indusion & 1355 & 657 & 698 \\
\hline Baseline & $\nabla$ & $\downarrow$ & $\downarrow$ \\
\hline$N$ at $T=0$ & 1300 & 630 & 670 \\
\hline$\%$ of indeusion & $(95.9)$ & $(95.9)$ & $(96.0)$ \\
\hline First follow up & $\downarrow$ & 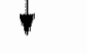 & $\downarrow$ \\
\hline$N$ at $T=4$ & 1174 & 583 & 564 \\
\hline$\%$ of indlusion & $(80.6)$ & $(88.7)$ & $(80.8)$ \\
\hline$\%$ of baseline & $(90.3)$ & $(92.5)$ & $(84.2)$ \\
\hline Second follow-up & $\downarrow$ & $\nabla$ & $\nabla$ \\
\hline$N$ at $I=18$ & 1046 & 534 & 512 \\
\hline$\%$ of inclusion & $(77.2)$ & $(81.3)$ & $(03,4)$ \\
\hline$\%$ of basetine & $(80.5)$ & $(84.8)$ & $(76.4)$ \\
\hline
\end{tabular}

: $T=$ total $_{1} \mathrm{C}=$ control group, $\mathrm{I}=$ interuention groups

Figure 7.2 Flow chart for the general proctices 


\begin{tabular}{|c|c|c|c|c|c|c|c|c|c|}
\hline & & \multicolumn{2}{|c|}{ Experimental condition } & \multicolumn{2}{|c|}{ Control condition } & \multicolumn{4}{|c|}{ Total poputation } \\
\hline & & $\mathbb{N}^{*}$ & $\%$ & $\mathbb{W}^{*}$ & $\sin ^{12 k}$ & $\mathbb{N}^{*}$ & $\%$ & Mean & 50 \\
\hline \multirow[t]{4}{*}{ Agge } & $\leq 49$ & $n$ & 11.5 & 54 & 8.6 & 131 & 0.1 & 62.25 & 0.05 \\
\hline & $50-60$ & 155 & 23.1 & 149 & 23.7 & 304 & 23.4 & & \\
\hline & $60 \cdot 70$ & 260 & 38.8 & 273 & 43.3 & 33 & 41.0 & & \\
\hline & $\geq 70$ & 178 & 26.6 & 154 & 24.4 & 332 & 25.5 & & \\
\hline \multirow[t]{2}{*}{ Gender } & male & 421 & 62.8 & 440 & 69.8 & 861 & 66.2 & & \\
\hline & female & 249 & 37.2 & 190 & 30.2 & 439 & 33.8 & & \\
\hline \multirow[t]{3}{*}{ Edducation } & low & 336 & 52.7 & 285 & 48.1 & 621 & 50.5 & & \\
\hline & intermediate & 220 & 34.5 & 217 & 36.7 & 437 & 35.6 & & \\
\hline & high & 81 & 12.7 & 90 & 15.2 & 171 & 139 & & \\
\hline \multirow[t]{2}{*}{ Smoking } & yes & 196 & 30.9 & 185 & 30.1 & 381 & 30.5 & & \\
\hline & no & 483 & 69.1 & 430 & 69.9 & 868 & 69.5 & & \\
\hline \multirow[t]{3}{*}{ BMM } & $B M H<25$ & 178 & 28.3 & 151 & 24.9 & 329 & 26.6 & 27.79 & 4.39 \\
\hline & $25 \leq 8,11<30$ & 295 & 47.8 & 295 & 48.6 & 590 & 47.8 & & \\
\hline & $30 \leq B M I$ & 155 & 24.7 & 161 & 26.5 & 316 & 25.6 & & \\
\hline
\end{tabular}

* Totals per categery vary due to missing walues, ** Yalid percentages

\section{Baseline data}

Table 7.1 shows the characteristics of the study population at baseline. No differences in patient characteristics were found between the two study groups.

The mean fat score was 17.4 (Table 7.2). Approximately two-thirds of the patients were aware of their actual level of far intake. On average, they had positive scores on all determinants of a decrease in their fat consumption, except for the perceived norm. Just over $30 \%$ of the study population were smokers, and they had been so for an average of 38.6 years. Their average score on the determinants of smoking cessation was positive, except for one of the attitude measures (pleasantness, negative) and for self-efficacy (neutral). Of the non-smokers, $73.2 \%$ reported to have smoked in the past, of which $60.3 \%$ had quit snoking more than five years ago. Just over $55 \%$ of the patients could be classified as sufficiently physically active. Nearly two-thirds of the patients were aware of their activity status. Here, the respondents had rather positive scores on all the determinants of increasing their physical activity level. 


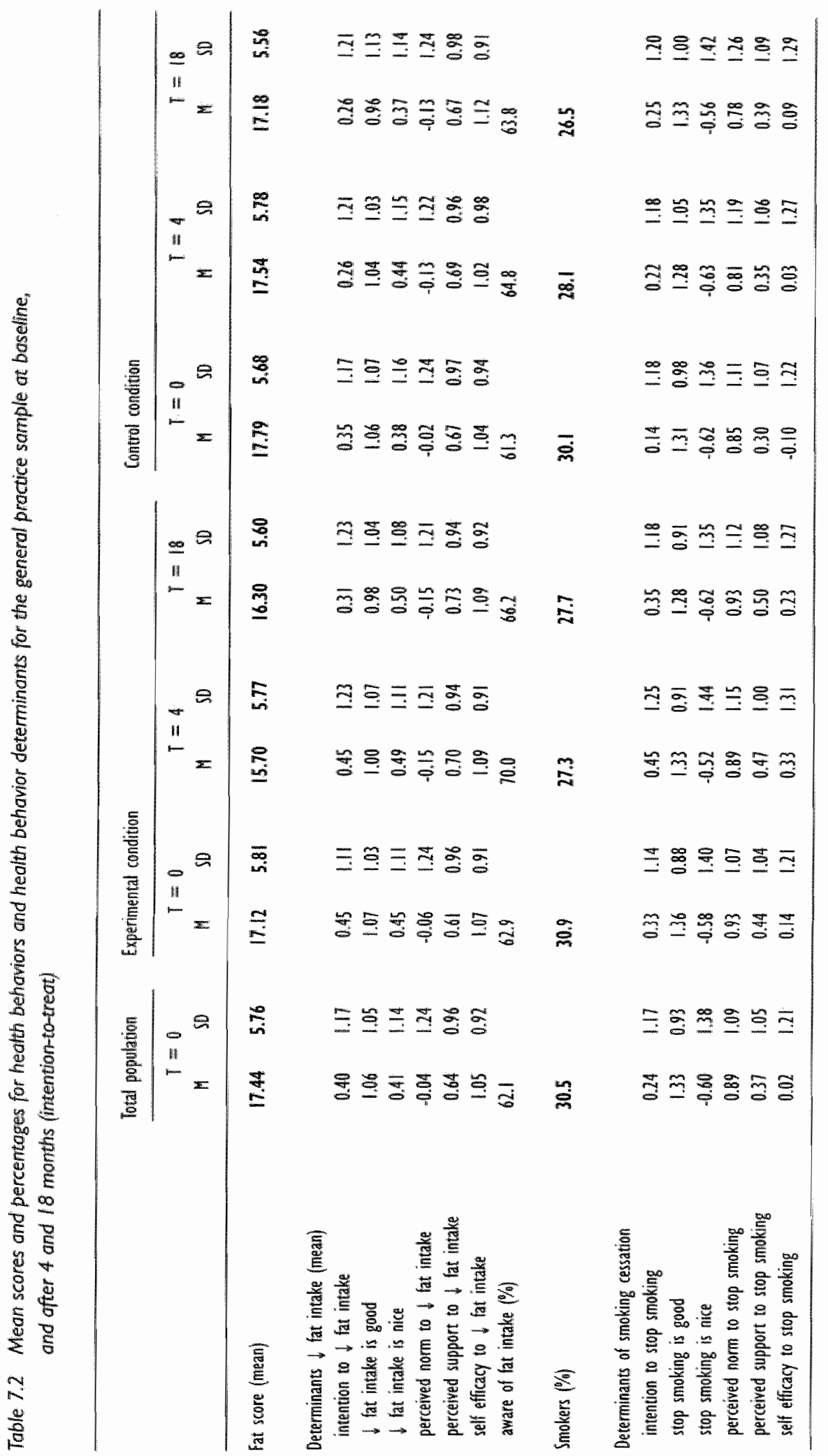




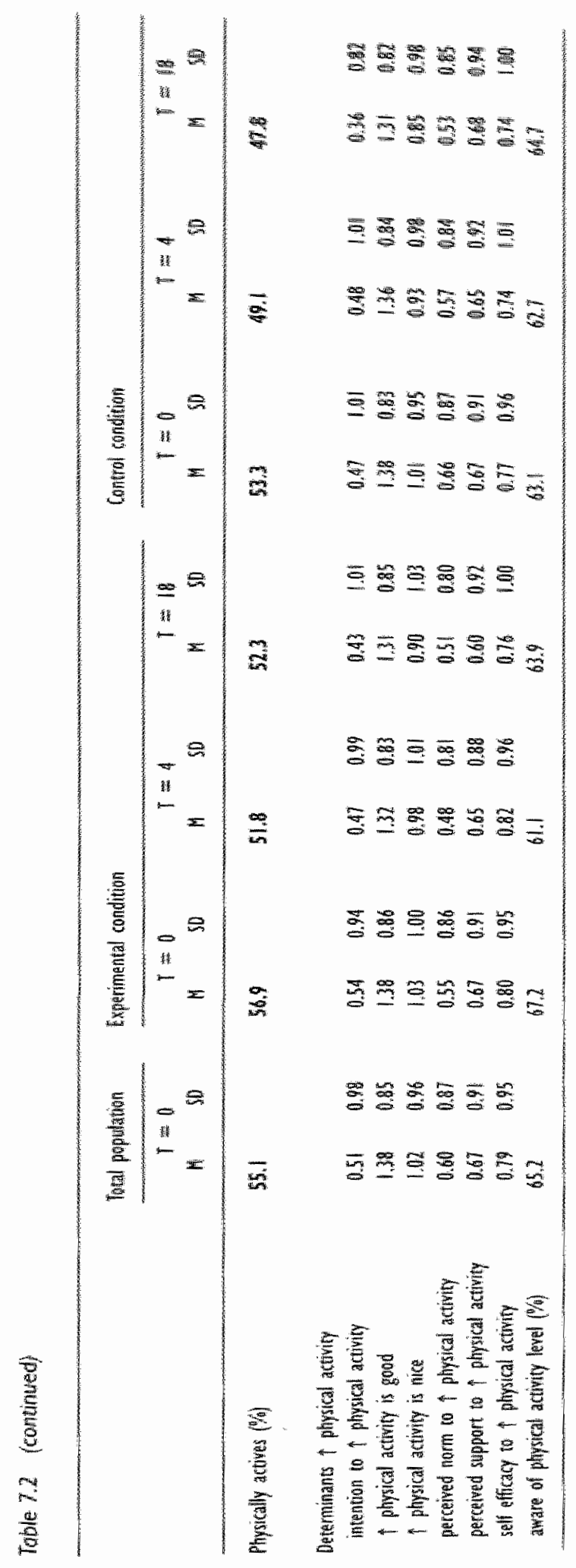


Differences at baseline between study groups were found for selfefficacy regarding smoking cessation and perceived norm to increase physical activity level.

\section{Implementation of the intervention}

None of the risk profiles could be produced in computerize form. The registration by the health advisors revealed that $70 \%$ of the risk profiles were talked through by both health advisor and GP. Of those discussed, $27 \%$ disclosed new information to the GP, $10 \%$ led to changes in medical treatment, and $4 \%$ resulted in further diagnostic action. The health advisors reported that for some risk profiles the GPs had particular reasons not to follow the national practice guidelines. Reasons for not talking through the other risk profiles were lack of time (mostly) or lack of interest (sometimes) on the part of the GPs.

On average, the parients attended 2.31 counseling sessions (range 1-9; SD 1.38), which took a total of 83 minutes (range 20-220; SD 39.90) over a period of 53 days (range 1-322; SD 59.1). After four months, $29 \%$ of the patients still had another counseling session planned, and $17 \%$ were expecting another phone call from the health advisor.

Nutrition was at least once the primary topic of the counseling for $59 \%$ of the patients, smoking for $15 \%$, and physical activity for $23 \%$. For $6 \%$ of the patients, none of these target behaviors had ever been the issue of central interest.

A telephonic booster session, which took an average of 10 minutes, was registered for $13 \%$ of the patients and $9 \%$ of the patients were referred to local health promoting activities.

\section{Intervention effects}

Ar $T=4$, a main effect was found for condition on fat consumption (Table 7.3). In the intervention group the mean total fat score was nearly 1.3 points below that of the control group. At $\mathrm{T}=18$, small interaction effects were found for condition with both age and smoking, in essence indicating that, compared to the control group, the fat consumption in the intervention group showed a greater decrease among smokers but less among smokers of older age. When omitting these interactions, a main effect for condition remained, indicating that the intervention group scored nearly 0.5 fat points lower than the control group $(\mathrm{p}=.014)$. The decline in main effect compared to $\mathrm{T}=4$ can be attributed to a renewed increase in fat intake in the intervention group as well as to a further decrease in the control group (see Table 7.2).

No effects of condition were found for smoking at $\mathrm{T}=4$ and $\mathrm{T}=18$.

No effect of condition was found for physical activity at $T=4$, but $T=18$ revealed an interaction effect of condition and BMI. Subgroup analysis for the three BMI categories pointed out that patients who were classified as obese at 
Table 7.3 Results on primory outcomes in the genterol proctices

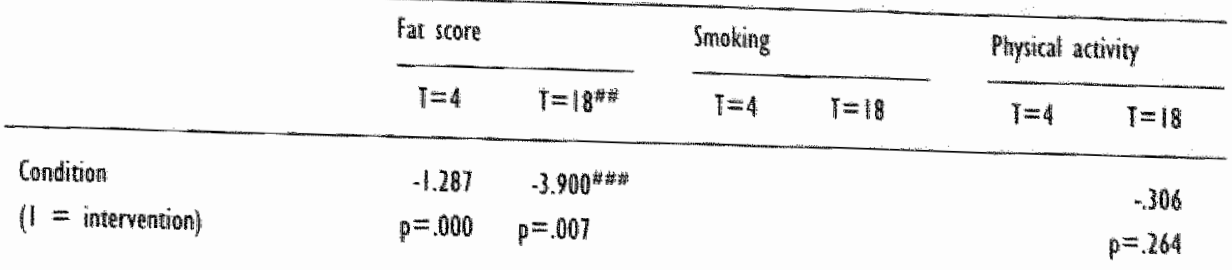

Condition * age

$p=032$

Condition"zmoking

1.040

$p=.02 \%$

Condition * B B

Age

$-.027$

$p=.067$

Smoking

$-987$

(I = smaker $)$

$p=.003$

BMI 3

$(I=B M: 3,0=B M I I, 2)$

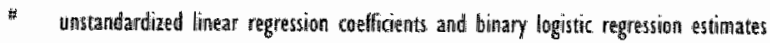

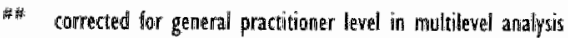

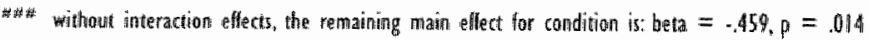

baseline $(\mathrm{N}=316$ ) were nearly twice as likely to be sufficiently physically active at $\mathrm{T}=18$ as their control counterparts $(\mathrm{OR}=1.90,95 \%$ CI $1.09-3.30)$.

No intervention effects werte found for the intentions to change any of the three risk behaviors at $T=4$ and $T=18$. For the determinants of a reduced fat consumption, three small interaction effects were found (not in Table). First, self-efficacy to reduce the fat intake at $T=18$ was increased by the intervention only for people with high self-effecy scores at baseline. Second, at both follow-ups, the intervention increased the impression that others would like them to quit for smokers initially having rather high scores on this perceived norm. Third, intervention patients who perceived low support towards increasing their activity level at $T 0$ experienced more support at $T=4$ than similar patients in the control group. 
For the subgroups of parients who did not change their risk behaviors at $T=4$ or $\mathrm{T}=18$, only minor differences were found in intervention effects at determinant level.

\section{Process information}

After four months, the intervention group had considerably more often sought information about several behavioral risk factors than the control group, but not about stress, medication, or health in general (Table 7.4). At $T=18$, the differences, although smaller, still existed for nutrition and physical activity, but were no longer present for smoking. At that time, the control group also reported to have sought substantially more information about the three other topics. The two groups differed only slightly in their limited enrolment in health promoting activities.

At $T=4,10 \%$ of the intervention patients reported to have been fully able to comply with the recommendations received, while $38 \%$ had been able to comply largely, 34\% partly, and $9 \%$ hardly or not at all. At $\mathrm{T}=18$ the ability to comply had slightly decreased.

Intervention patients regarded the health counseling service as being of fairly high quality ( 8.2 on a ten-point scale), were rather satisfied with the new service, and thought it a welcome addition to usual care (both 4.1 on five-points scales, sec Harting et al., Submitted). The experts considered the quality of the counseling as almost satisfactory ( 2.85 on a four-point scale, see Harting et al., 2004).

\section{Influence of process indicators}

Within the intervention group, no differences in effects were found between both health advisors.

The total number of consultations about nutrition was negatively related to the fat score at ' $T=4$. The same applies to the number of consultations about smoking and the probability of having quit smoking at $T=4$.

The degree of satisfaction with the counseling was positively related to higher scores for the intention to decrease the fat consumption at $\mathrm{T}=4$, and the intention to increase the level of physical activity at $T=18$. Satisfaction was not related to any of the smoking variables. 
Table 7.4 Additional process information: information seeking, porticipation in activitues, and degree of complionce (valid percentages)

\begin{tabular}{|c|c|c|c|c|}
\hline & \multicolumn{2}{|c|}{ Experimental condition } & \multicolumn{2}{|c|}{ Control candition } \\
\hline & $T=4$ & $T=18$ & $T=4$ & $T=18$ \\
\hline \multicolumn{5}{|l|}{ Soughtt information about } \\
\hline nutrition & 35.5 & 22.8 & 14.4 & 178 \\
\hline smoking & 11.4 & 4.3 & 4.5 & 5.3 \\
\hline physical actiwity & 18.4 & 12.0 & 6.1 & 8.1 \\
\hline stress, medication, \& health & 16.8 & 21.4 & 10.7 & 321 \\
\hline \multicolumn{5}{|l|}{ Enrolled in course on } \\
\hline nutrition & 0.9 & 2.4 & 1.2 & 1.9 \\
\hline smoking & 0.4 & 0.8 & 1.0 & 0.9 \\
\hline activity for the eiderly & 2.5 & 5.3 & 2.8 & 4.4 \\
\hline sports aciwity & 2.5 & 3.3 & 1.0 & 2.8 \\
\hline walking activity & 2.5 & 3.1 & 1.5 & 1.5 \\
\hline stress reduction \& other topics & 1.8 & 3.5 & 3.6 & 6.4 \\
\hline \multicolumn{5}{|l|}{ Complying with advice (\%) } \\
\hline fully & 10.0 & 7.5 & & \\
\hline largely & 38.0 & 27.9 & & \\
\hline partly & 33.5 & 39.4 & & \\
\hline hardly & 5.1 & 6.2 & & \\
\hline not at all & 4.1 & 4.3 & & \\
\hline no advice & 9.4 & 7.9 & & \\
\hline do not rementiber advice & $=$ & 6.8 & & \\
\hline
\end{tabular}

\section{DISCUSSION}

\section{Main results}

The high-risk approach of Hartslag Limburg in general practices led to a substantial decrease in fat consumption after four months. After 18 months, this decrease had declined but was still modest, and a promising increase in physical activity level was observed for patients who were obese at baseline. Intervention effects were found neither for smoking nor for the intention to change any of the three risk behaviors addressed. The few effects at determinant level were negligible. 
The results illustrate that more intensive multiple risk factor and multiple component interventions aimed at high-risk patients indeed have a potential to generate changes in behavioral risk factors (Ashenden et al., 1997; Ebrahim \& Smith, 1997). In some respects, the effects of the present approach seem to exceed that of two other practice-based interventions using a fairly similar (in terms of type and intensity) counseling component (Steptoe et al., 1999; Woollard, Burke, Beilin, Verheijden, \& Bulsara, 2003). A third study, with a comparable high-risk lifestyle intervention in primary care found posi136 tive changes in health related behaviors, but no differences with the control group (Ketola, Mäkelä, \& Klockars, 2001). As in our study, most of the analogous lifestyle interventions did not reveal any effects on smoking (Burton et al., 1995; Cupples \& KcKnight, 1994; Cupples \& McKnight, 1999; Imperial Cancer Research Fund OXCHECK Study Group, 1995; Lindholm et al., 1995; Wood, 1994, see also review by Ketola et al., 2000).

That the present intervention was mainly effective in changing the patients ${ }^{3}$ fat consumption, is a modest result given the multiple factor and multiple component approach that was used. Hence, our intervention should not be widely implemented in its present form. Based on the causal intervention model (see Figure 7.1), the main reasons for the limited effects are to be found in shortcomings with regard to the quality and focus of the counseling component, drawing up and using the cardiovascular risk profile, and the reinforcing effect that was expected from the mutual dedication from both the health advisor and the GP. In addition, it may be questioned whether health counseling alone is the best way to induce people to change their behavior.

First, it is questionable whether the health counseling component was completely implemented as intended. Although it was attempted to ensure the practical applicability of the counseling model, the health advisors experienced difficulties in working from the comprehensive theoretical framework and found it hard to adequately handle the multinude of different methods and strategies (Harting \& Van Assema, In preparation). Their experiences were in line with the evaluations of the experts as well as of the patients, indicating that the quality of the counseling left room for further improvement (Harting et all, 2004; Harting et al., Submitted). Improvements may be found in using a less complex counseling model, in structuring the counseling sessions more strictly, and in applying the behavior change strategies more specifically. In addition, more fully adopting the principles of motivational interviewing (W. R. Miller \& Rollnick, 1991) may enable the health advisors to more adequately handle the resistance that patients may experience (Harting et al., Submitted) when they ate confronted with restrictions (Fogarty, 1997).

Second, doubts may persist as to whether the mulriple risk factor focus of our counseling service was the most adequate. Findings of others indicate that educational and counseling interventions solely aimed at either dietary fat intake (Hooper et al., 2001; Tang et al., 1998) or physical activity (SimonsMorton et al, 1998) or smoking (Law \& Tang, 1995) show at least moderate results, which, for diet and smoking, outweigh the effects of interventions aim- 
ing at multiple lifestyle changes (Rigotti et al, 2004; Roe, Hunt, Bradshaw, \& Rayner, 1997). This suggests that a multiple (i.e. a triple) risk factor focus in health counseling should not be preferred, and that it is specincally smoking, as an addictive behavior, which deserves an alternative approach:

In a systematic revicw, behavior modificarion techniques were not found to be more effective than a (cost-effective) simple stop smoking advice given by a physician during a single consultation ( $2 \%$ additional quitters, Law \& Tang, 1995). Given the effectiveness of a minimal contact smoking cessation program for Dutch GPs, resalting in $6.1 \%$ addirional quitters after 12 months (Pieterse, Seydel, De Vries, Mudde, \& Kok, 2001), a large-scale implementation of this minimal intervention strategy should be considered. Smokers who decide to stop should be offered auxiliary medical therapy as well as follow-up interventions (Law \& Tang, 1995). Further counseling of smokers who are not motivated to stop in an initial consultation seems not to be effective. They probably should be approached again on a later occasion, as they may then be found in a more readily stage of change.

A combined approach still seems to be adequate to effectuate changes in fat consumption and physical activity, as both behaviors are directly related to the patient's energy balance, but it may be questioned whether counseling alone is a sufficient strategy. In the context of the present study, more referrals to health promoting activities in the community could have been useful. The effectiveness of future combined dietary and activity approaches may also benefit from additional strategies, for instance the provision of diets or nutritional supple-. ments (Hooper et al., 2001) or of exercise equipment and/or supervised exercise (Simons-Morton et al., 1998). An example of such a more comprehensive and combined dietary and activity intervention has shown promising results (Anderssen, Hjermann, Urdal, Torjessen, \& Holme, 1996).

Third, a rather consistent finding is that health education and counseling interventions with a longer follow-up generate better results (Hooper et al., 2001; Simons-Morton et al., 1998), although it is not always clear whether it is the duration of the intervention or of the follow-up that determines whether the intervention is effective (Hooper et al., 2001). In the present study, the number of consultations, which the health advisor and the patient decided on together, was, to a certain degree, associated with positive results, but the causality of the relationship remained unclear. Instead of more consultations at once, the health advisors indicated that it could be worthwhile to call up patients after a substantial break for follow-up visits in some kind of regular schedule. This may allow a new window of opportunity to be found, as patients may be more open to behavioral change.

Finally, during the trial, it was found to be infeasible to develop and implement a computerized risk profile. Only some of the general practices had a completely automated registration system, different practices used incompatible software, and a planned national practice registration system had not yet been chosen. As GPs should always use absolute CVD risk when making clinical judgments about using drugs to modify biomedical risk factors, rather than just 
considering the level of any one risk factor alone (D. Wood et al., 1998), the absence of a computerized profule may have discouraged them from a thorough re-evaluation and optimization of medical treatment. Besides, the behavioral risk factors in particular may have remained beyond the GPS view. Moreover, the intended collaboration between the health advisors and GPs could only partly be accomplished. Together, this may have hampered the intended mutual reinforcment of preventive effects.

\section{Validity issues}

The (limited) effects found should also be interpreted in light of the probable methodological shortcomings of the study.

The internal validity may have been threatened by the fact that, due to ethical and logistic reasons, the experimental condition as well as the content of the intervention were known to all patients before they answered the baseline questionnaire. As their answers were going to be used by the health advisor to get a initial idea of the patients' lifestyle, this familiarity with experimental condition may, for instance, have resulted in more honesty in the intervention group and more socially desirable answers in the control group. Although the limited differences that were found at baseline do not indicate such an effect, the present procedure allows neither solid conclusions about the real differences between study groups at baseline, nor adequate statistical correction for such differences. Randomization at patient level, however, was not possible, because of the substantial risk of contamination due to the intended involvement of the GPs in the intervention.

A second problem relating to the internal validity is that of the baseline measure itself, as well as the additional process questionnaire the intervention patients received after the intervention had been terminated. The baseline questionnaire may have sensitized patients in the intervention group to the approaching health counseling intervention (Green \& Lewis, 1986). This makes it impossible to distinguish whether the lifestyle changes found are a result of the intervention as such or a product of the interaction between the patients' increased receptiveness and the actual intervention. The additional process questionnaire might have worked as an intervention in and of itself or have functioned as reinforcement of the health counseling that had just been completed. This means that part of the effects should probably be attributed to the process questionnaire. These internal validity threats, however, were regarded as acceptable in view of the benefits, viz., the possibility to compare the two study groups at baseline, especially because of the patients' familiarity with their experimental status, and the option to gain additional insight into the "black box" of the intervention and thus into the causal intervention model.

A third validity issue is the risk of having missed the optimum of intervention effects. Before the intervention started, it was assumed that a complete 
counseling course would take no more than four months. The finding that nearly $30 \%$ of the courses exceeded this time span probably means that maximum short-term effects could have been found at, for instance, six months postinclusion. Since that was when the biomedical follow-up measures were scheduled, and their results were presumed to influence the behavioral self-reports, it was neverthelless decided to stick to the original study design.

Forth, the way the intention to change as well as the determinants of change were operationalized, precluded a thorough interpretation of the absence of intervention effects on these variables. All predictors were measured with regard to changing the current behavior instead of with regard the target behavior as such. Hence, the lack of effects on these variables in the present study means that patients were not positive about changing their lifestyle any further. It remains however possible that they changed their opinions about and intention to perform the health related behaviors as such. This operationalization diffculty also limits further inferences regarding the causal intervention model.

In terms of external validity, the main problem is the self-selection of the general practices and the study population. The problems encountered with recruiting sufficient practices indicate that only those practices with rather motivated GPs entered the study. Efforts to compose a random sample of eligible preselected and labeled high-risk patients, by asking the GP to include the first three high-risk patients visiting the practice on a randomly assigned day each month, failed because this usually slipped the physician's mind and caused organizational difficulties.

To examine the reasons for non-response, a small study was carried out in two intervention practices and one control practice (Eymael, Van Limpt, \& Van Ree, 2001). Of the 55 non-responders, $29(53 \%)$ answered a questionnaire with a modest inventory of their reasons not to participate. Those diagnosed with hypercholesterolemia had been more inclined to participate than patients without this diagnosis. The main reasons for refusal were perceiving the study as too lengthy $(38 \%)$, anxiety about being engaged with health in the way the intervention proposed $(38 \%)$, being under treatment by a medical specialist $(24 \%)$, and being reluctant to undergo the medical examinations that accompanied the study $(21 \%)$. Other reasons were not seeing the study as useful, not thinking to be able to comply with lifestyle advices, and being disabled (cach reason 14\%), For the most part, these findings are in line with differences between attenders and non-attenders in a study that invited parients for a health check in their general practice (Pill, French, Harding, \& Stott, 1988; Pill \& Stott, 1988).

Thus, the present results can presumably be generalized only to rather motivated GPs and rather motivated patients. However, the efforts needed to follow up original non-responders may not outweigh their low level of success and can therefore be seen as not very beneficial (Davies, Pyke, Kinmonth, \& on behalf of the Family Heart Study Group, 1994). A repeated personal invitation by the GPs themselves at the next practice visit would perhaps have greater motivating power. 


\section{Conclusion}

Despite its limitations, the study results may be regarded as rather valid. Of the three-fold approach of the high-risk intervention of Hartslag Limburg, only the health counseling component could be mostly implemented as intended. "This component was mainly effective in reducing the patients' fat consumption. Hence, it may be questioned whether the multiple risk factor focus of the counseling service was the most adequate. Improvernents of the interventions may 140 be found in enhancing the quality of the counseling component itself, simplifying the counseling model, addressing smoking separately, adding additional strategies, and offering a longer follow-up. Moreover, strengthening the input of other two intervention components, viz, the risk profile and the GP, may be required to increase their own preventive contribution as well as to achieve the mutual reinforcement desired. Studying such an improved cardiovascular prevention effort again should be worthwhile.

\section{ACKNOWLEDGEMENT}

Data were collected as part of the Hartslag Limburg project, which is coordinated by the Maastricht Regional Public Health Institute (GGD-zZl), and funded by the Netherlands Heart Foundation (NHS). 


\section{CHAPTER 8}

Post-trial implementation of the health counseling component of the Hartslag Limburg cardiovascular prevention project

A manuscript based on this chapter has been submitted as: Harting. .., Van Assema, P., Ruland, E., Van Limpt, P., Gargels, T.,

Van Ree, J., Vermeer, F., \& De Vries, N.K. (2004). Post-trial implementation of the health counseling component of the Hartslag Limburg cardiovascular prevention project. 


\section{ABSTRACT}

Within the Hartslag Limburg cardiovascular prevention project, lifestyle counseling by a health advisor was introduced as a new service in the Dutch health care system. It was initially offered in the context of an experimental trial, to evaluate its effectiveness. Based on a positive process evaluation, funding was obtained to explore the opportunities for a post-trial implementation of the service. Using Rogers' diffusion of innovations theory, post-trial implementa142 tion efforts are described for the cardiology outpatient clinic of a universiry hospital (successful) and for four general practices (unsuccessful). Qualitative information was collected from minutes of meetings and in informal conversations with the health advisors and the Hartslag project manager. In addition, short questionnaires were completed by the cardiologists and general practitioners involved. It was found that the implementation of an innovative service may be facilitated by avoiding any post-trial interruption and by allocating the responsibility to one single "change agent". In addition, an innovarive health care service that is perceived as not very complex and as compatible with current practice routines may be relatively easy to implement. The same holds for innovations that can be "re-invented" without much difficulty. The implementation process may be further supported by changes in the organization of care that create opportunities for, instead of competition with, an innovative health care service. It can be concluded that studies of post-trial implementations may reveal valuable information about factors that are decisive to the success of such processes. 


\section{INTRODUCTION}

Although real-world diffusion studies are needed to learn about the exportability and effectiveness of interventions in less controlled conditions than those accompanied with trials, it is the dissemination step in intervention development which has received the smallest share of attention and resources (Rimer et al., 2001). Diffusion studies constitute less than $1 \%$ of all public health and health promotion research (B. F. Oldenburg, Sallis, Ffrench, \& Owen, 1999), and the continuation of programs for health behavior change has hardly ever been reported at setting level (Glasgow, Bull, Gillette, Klesges, \&: Dzewaltowski, 2002). Not surprisingly, it has been claimed that there are no established pathways to diffusion (B. F. Oldenburg et al., 1999). Therefore, as a start, we felt it would be worthwhile to describe the post-trial implementation process of an innovative preventive service in two different health care settings.

Health counseling by a health advisor about behavioral risks and possible lifestyle changes is a new, additional service in the Dutch health care system. It was introduced as part of the high-risk project of Hartslag Limburg (Heartbeat Limburg), which intended to reduce the cardiovascular risk for patients with an elevated risk of developing cardiovascular disease (CVD) in the Dutch province of Limburg (Ruland et al., 1999). The high-risk patients were recruited from the cardiology outpatient clinic of the University Hospital Maastricht and from nine general practices distributed throughout Maastricht and its surrounding region.

To assess its effectiveness, the new service was offered in a randomized controlled trial (RCT) from April 1999 to October 2001 (see Harting et al., In preparation-a; Harting et al., In preparation-b). As the trial period progressed, the question arose whether the health counseling service could be continued afterwards, which had always been the intention of the project team. Based on encouraging outcomes of the process evaluation (see Harting et al., Submitted), a major Dutch health insurance company decided to provide funding to explore opportunities for further implementation for another three years. The subsidy comprised payment for the health advisors, indirect costs (accommodation, traveling expenses, materials, and training), and a small research grant. The three-year post-trial implementation phase led to quite different results for the two treatment settings, i.e. the cardiology ourpatient clinic and the general practices.

The course of events put us in a rather unique position to study the diffusion of the innovation "on its way" and to conduct a comparative analysis (E. M. Rogers, 1995). After a concise description of the high-risk intervention, both as intended before the trial and as implemented during the trial, this article therefore uses Rogers' diffusion of innovations theory (E. M. Rogers, 1983,1995 ) to briefly describe the post-trial developments in both settings. In addition, the results of a short questionnaire that was administered to the physicians involved are used to examine the divergent outcomes of the post-trial implementation process more closely. A further article will analyze the same implementation process from an organizational and management perspective (Ruland, Van Raak, Spreeuwenberg, \& Van Ree, In preparation). 


\section{THE INTERVENTION AS INTENDED BEFORE THE TRIAL AND AS IMPLEMENTED DURING THE TRIAL}

The health counseling service was originally part of a comprehensive high-risk approach. The method was three-fold: composing a complete cardiovascular risk profile for each patient, reviewing and optimizing the treatment of biomedical risk factors, and counseling on behavioral risk factors (such as high fat consumption, smoking, and physical inactivity). Each of these three elements was

144 associated with several tasks to be carried out by either the research team, the practice assistant, the health advisor, the general practitioner (GP), or the cardiologist, individually or jointly.

The function of a health advisor was introduced to perform the counseling, because, among other things, research findings show that it is difficult to change the clinical roles of experienced physicians when implementing preventive services (e.g. Belcher, 1990). Since "health advisor" was at the time not a common profession in the Dutch health care system, the four health advisors who worked for Hartsiag Limburg had received pre-trial training on theories of behavior and behavior change, practical counseling techniques, and the use of a specially composed counseling protocol (Harting \& Van Assema, In preparation). In the cardiology outpatient clinic, the two health advisors were specialized cardiologic nurses, who, after initial housing problems, were provided with a desk at the outpatient clinic in one of the cardiologists' consulting rooms. In the general practices, the two health advisors were a dietician, and a practice assistant with a fairly high level of training. In most of the general practices, it proved possible (though with some difficulty) to find a part-time workspace for them, but at one practice, they had to set up at an adjoining health care facility. For both settings, the length of a full counseling course was flexible, but was not intended to exceed six consultations, with the first meeting allowed to last a maximum of 45 minutes, and the follow-up sessions 30 minutes each.

Table 8.1 presents the main tasks associated with the three elements of the high-risk approach, as well as their allocation as intended before the trial and as implemented during the trial. In addition, it provides the main reasons for discrepancies between the pre-trial intentions and in-trial implementation. Briefly, the tasks carried out in a way that most closely reflected the original intentions were those of completing the risk profile (necessary as a baseline measure for the effect evaluation) and implementing the health counseling component (as a fairly independent intervention element). All other tasks faced a diversity of difficulties and barriers, and were not implemented, partly implemented, or implemented by someone else than the intended person. Due to motivational and organizational barriers before the trial, it was not known whom of the cardiologists was going to participate during the trial. Consequently, randomization took place at patient level, precluding the cardiologists' active involvement in the intervention. 


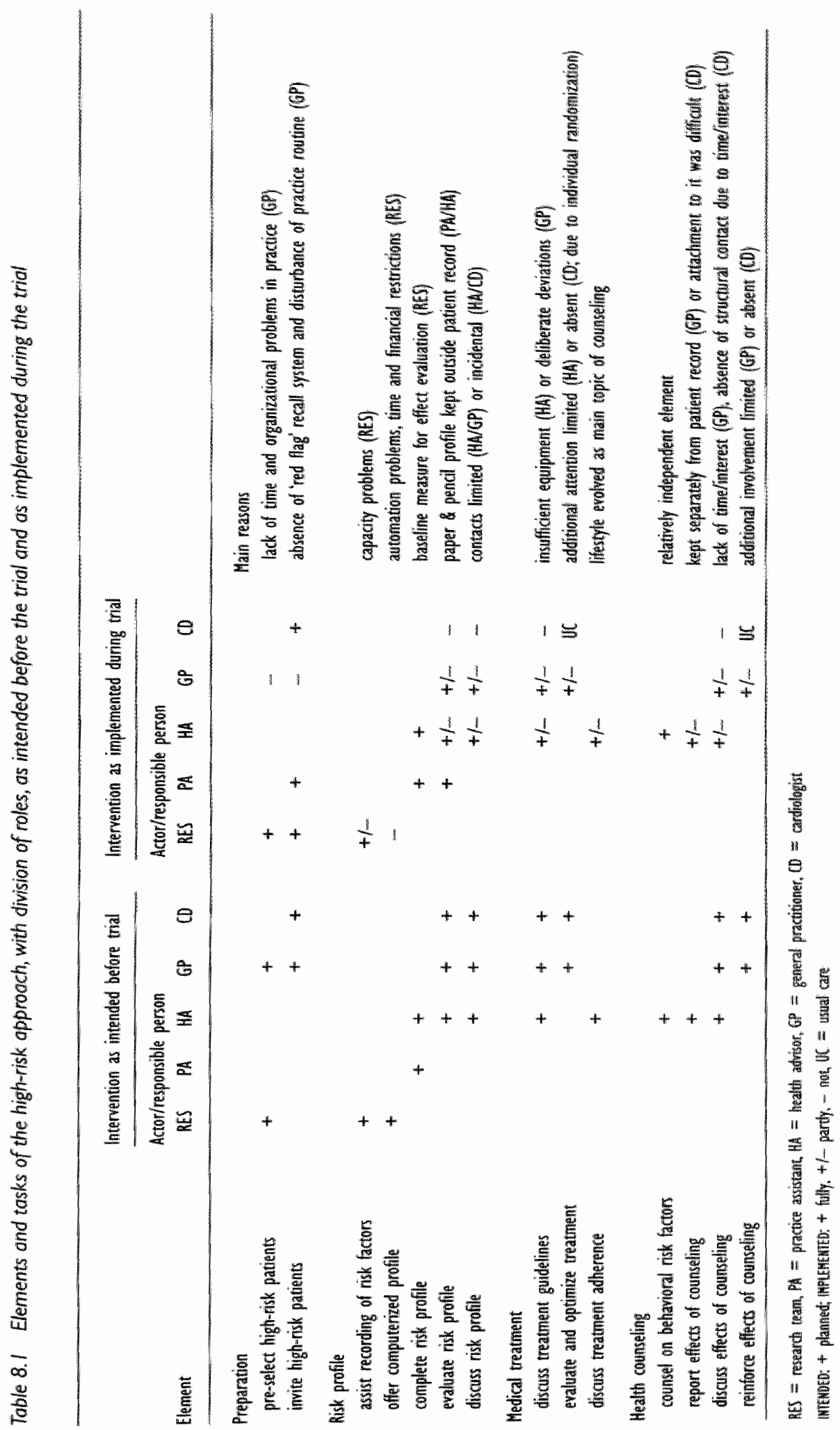




\section{DIFFUSION OF INNOVATIONS THEORY}

In terms of Rogers" diffusion of innovations theory, the introduction of health counseling by health advisors in the Dutch healith care system can be labeled as an innovarion (E. M. Rogers, 1995). Briefly, Rogers' theory predicts that the diffusion of an innovation is a stepwise process (E. M. Rogers, 1995). First of all, dissemination requires that the potential users of an innovation have to become acquainted with the innovation and develop an adequate understand146 ing of it. Important aspects in this "knowledge stage are the characteristics of the decision-making unit. In the subsequent "persuasion" stage, the potential adopters have to develop a positive attitude towards the innovation. At this stage, it is the perceived characteristics of the innovation that are decisive, such as its relative advantage, compatibility, complexity, trialability, and observability (E. M. Rogers, 1983). Other characteristics that may be influential are flexibility (Parcell, Perry, \& Taylor, 1990) and the costs or risks attributed to the innovation (B. Oldenburg, Hardcastle, \& Kok, 1997). In the next stage, the decision has to be made to adopt or reject the innovation. Activities in this "adoption" stage include gathering further information and trying out the innovation to a limited degree. During the subsequent "implementation" stage, the diffusion process can be facilitated by positive experiences gained previously and by positive social influences. At the "confirmation"stage, the innovation becomes part of the work routine. This long-term continuation requires that users of the innovation receive positive feedback and reinforcement.

Besides these variables of the diffusion process, Rogers specifies five adopter categories, viz. innovators (adventurous), early adopters (respectable), early majority (deliberate), late majority (skeptical), and laggards (traditional), each with individual characteristics that may promote or inhibit the diffusion of an innovation. In addition, several organizational characteristics may be influential. Apart from the fact that larger organizations are rather consistently found to be more innovative, the specific influence of other organizational characteristics varies considerably.

Rogers ${ }^{3}$ theory serves as theoretical background from which the post-triall implementation of the high-risk intervention will be described and analyzed.

\section{METHODS}

The present description of the post-trial implementation process of the health counseling service is based on minutes of meetings, informal conversations with the health advisors, and personal information from the Hartslag Limburg project manager. To enable us to better understand and explain the actual diffusion process, we developed a short questionnaire before the trial started. That 
focused on the perceived characteristics of the innovation itself, for three reasons: (1) before and during the trial the diffusion process was expected to be in its persuasion phase, implying that attitude development was the most important element; (2) after the trial, the diffusion process was predicted to be in its adoption phase, in which creating a positive attitude is an essential prerequisite; (3) it was assumed that the characteristics of the innovation (and the physicians' perceptions of these characteristics) would be easiest to modify.

The questionnaire consisted of 20 propositions about the introduction of the health advisor, all with 5-point Likert scales ranging from fully agree $(+2)$ to fully disagree $(-2)$. The hypothesized relative advantages were that health advices would reach more people and be more effective, that the physicians' workload and time pressure would decrease, and that the registration of cardiovascular risk factors and risk patients would be improved. Compatibility was assumed to be high if the innovation was perceived as a useful addition to medical prevention and as consistent with existing preventive regimens, the reallocation of physician tasks, and practice working routines. Complexity was verbalized as whether the innovation would cause organizational problems, uncertainty for the physician, and extra managerial tasks, such as conferring and coordination. Trialability was covered by two items asking whether the innovation was seen as bringing about irreversible changes in practice and whether the introduction of the innovation would be easy manageable in practical terms. Observability was operationalized as the degree to which the innovation was expected to yield visible results and provide an opportunity to create a distinctive profile for the physician or the practice. Costs were operationalized as the perceived financial risk for the physician or the practice, and risks as the degrec of satisfaction or dissatisfaction among patients. Additional items measured the perceived necessity of the innovation as well as the overall attitude of the physician regarding the introduction of the health advisor.

The questionnaire was sent to all participaring GPs shortly before (pre-trial) and directly after the trial period (post-trial). Only those GPs for whom pretrial as well as post-trial results were available were included in the analysis. At the cardiology outpatient clinic, only those cardiologists who had been most closely involved in the trial (i.e. those who had included the majority of the patients) were approached, and only after the trial, because it was not known beforehand which of them was going to participate during the trial.

\section{RESULTS}

Of the 16 GPs and 16 cardiologists who received the post-trial questionnaire, $75 \%$ responded, leaving two groups of 12 physicians in the study. Reliability analyses of the pre-trial scores confirmed the internal consistency of the individ- 
wal innovation characteristics (.69 $\leq \alpha \leq .80$; see also Table 8.2). For the posttrial scores however, trialability no longer proved to be a reliable scale ( $\alpha$ being negative). Therefore, its two items are described separately below.

\section{Post-trial implementation}

At the cardiology outpatient clinic, one of the senior cardiologists, who was just recovering from a heart attack himself, expressed his willingness to be in charge of and to supervise the post-trial implementation of the health counseling. As the infrastructure that was created during the trial remained practically unaltered after the trial, the health advisors working at the hospital were able to include new ligh-risk patients from time to time, and thus to continue their counseling work. In the meantime, the Hartslag Limburg project manager, in close collaboration with the superwising cardiologist and the health advisors, was expected to write a policy plan to specify the health advisors" tasks and operating procedures during the post-trial extension. This led to some major changes in the health advisors" job description, which can be regarded as a "reinvention" of the original innowation (E.M. Rogers, 1983). As the health advisors had learned during the trial that a substantial proportion of their patients experienced difficulties with aftercare and uncertainties in their home situation, the health counseling tasks were supplemented with tasks relating to the coordination of care for cardiologic patients discharged from hospital.

At first, this new combined service was intended to be implemented by a recently established unit for transmural care, but this was cancelled, mainly for financial reasons. Instead, the modified health advisors service was adopted by a newly developed "cardio-and-vascular center", that already accommodated several other preventive nursing positions. The re-invented innovation was expected to lend addirional status to the center, which was one of the main reasons why the department of Cardiology made additional funding available for the further consolidation of the new position. This decision was further encouraged by the careful registration the health advisors had kept up after the trial, enabling them to provide positive feedback about the reach and effectiveness of their post-trial efforts. In addition, it is now under consideration to also offer the new combined counseling and coordination service to other than cardiovascular high-risk patients visiting the center.

At the general practice setting the implementation of health advisors proved to be much more complicated. First of all, in most practices, the health advisors had to interrupt their work after the trial period, mostly for organizational reasons, i.e., the withdrawal of the trials infrastructure. Another problem was that the position of health advisor as such could not be easily implemented in the current practice regimes. In addition, uncertainties had been created by several developments in the Dutch general practice system, such as the planned introduction of practice nurses to perform delegated general practitioner tasks. Further competition was experienced from other recently developed specialized 
nursing services. Nevertheless, four of the originally nine intervention practices were interested in a continuation of the health counseling service after the trial. However, all but one of these practices indicated that certain, more medically oriented, adjustments to the health advisors ${ }^{3}$ tasks or routines would be advisable or necessary.

The re-invention desired was, however, impeded by ambiguities regarding the competencies and official qualifications of the health advisors, as well as by several events occurring at the practices involved (c.g. staff turnovers and even an arson attack). Furthermore, the Hartslag Limburg project manager was less involved in the post-rrial implementation process in this setting, mostly because of its decentralized nature, with no single person formally in charge. Nevertheless, the re-introduction of the health advisor proceeded quite successfully ar the practice where the least competition was encountered. In principle, the control practices from the trial were also available for post-trial implementation, but apart from the above mentioned problems, the ongoing effect evaluation precluded an immediate start.

After eighteen months of diffusion efforts, the overall decision was made that, for the time being, the post-trial implementation of health advisors in general practices was deemed impracticable. Nevertheless, the Hartslag Limburg project team is still considering whether health counseling as such could become an additional task for the prospective practice nurses.

\section{Physicians' attitudes towards the innovation}

Before the trial, the GPs mostly anticipated little relative advantage of the introduction of the health advisor (Table 8.2 ). The greatest benefit was expected from an improved registration of risk factors and of patients who were at high risk for $\mathrm{CVD}$. To some extent, the GPs saw the new health counseling service as compatible with their current work routine, but especially thought it would be a useful addition to medical prevention. Furthermore, the innovation was expected to be somewhat complex, mainly because it would involve additional managerial tasks. On average, the GPs were rather undecided about the trialability and observability of the innovation, while entertaining slightly definite views on the absence of financial risks and the level of appreciation among their patients. On the whole, the GPs' attitude towards the introduction of the health advisor was slightly positive.

After the trial, the GPs had considerably changed five of their opinions $(\delta \geq .50)$. They had tempered their expectations of the improved risk registration and they now felt that there were no clearly visible results. In addition, they expected more difficulties regarding the implementation of the innovation in the existing practice routine, but no longer feared for additional conferring and coordinating tasks. Furthermore, they had strengthened their view that the innovation would not lead to irreversible changes in practice. 


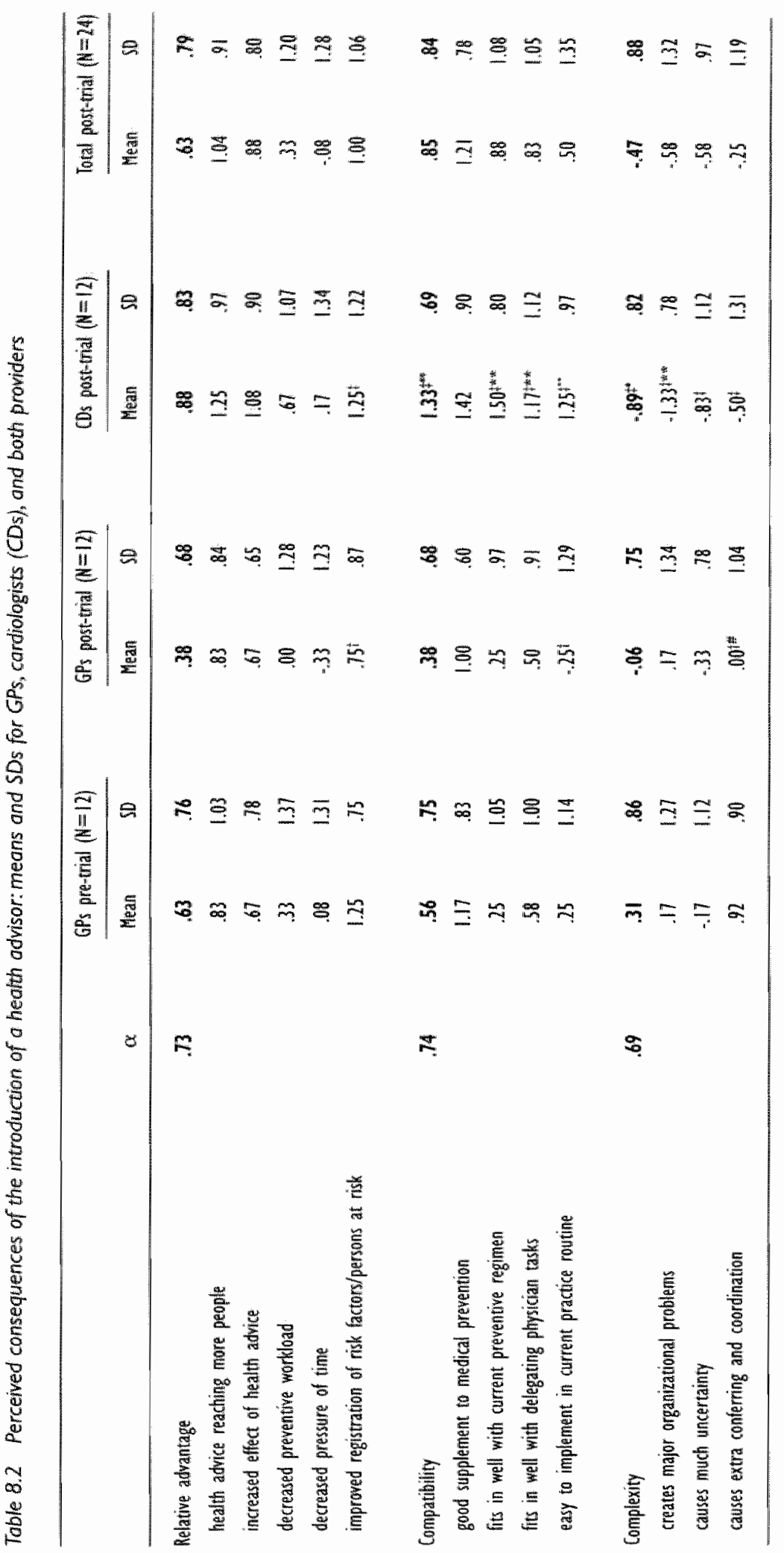




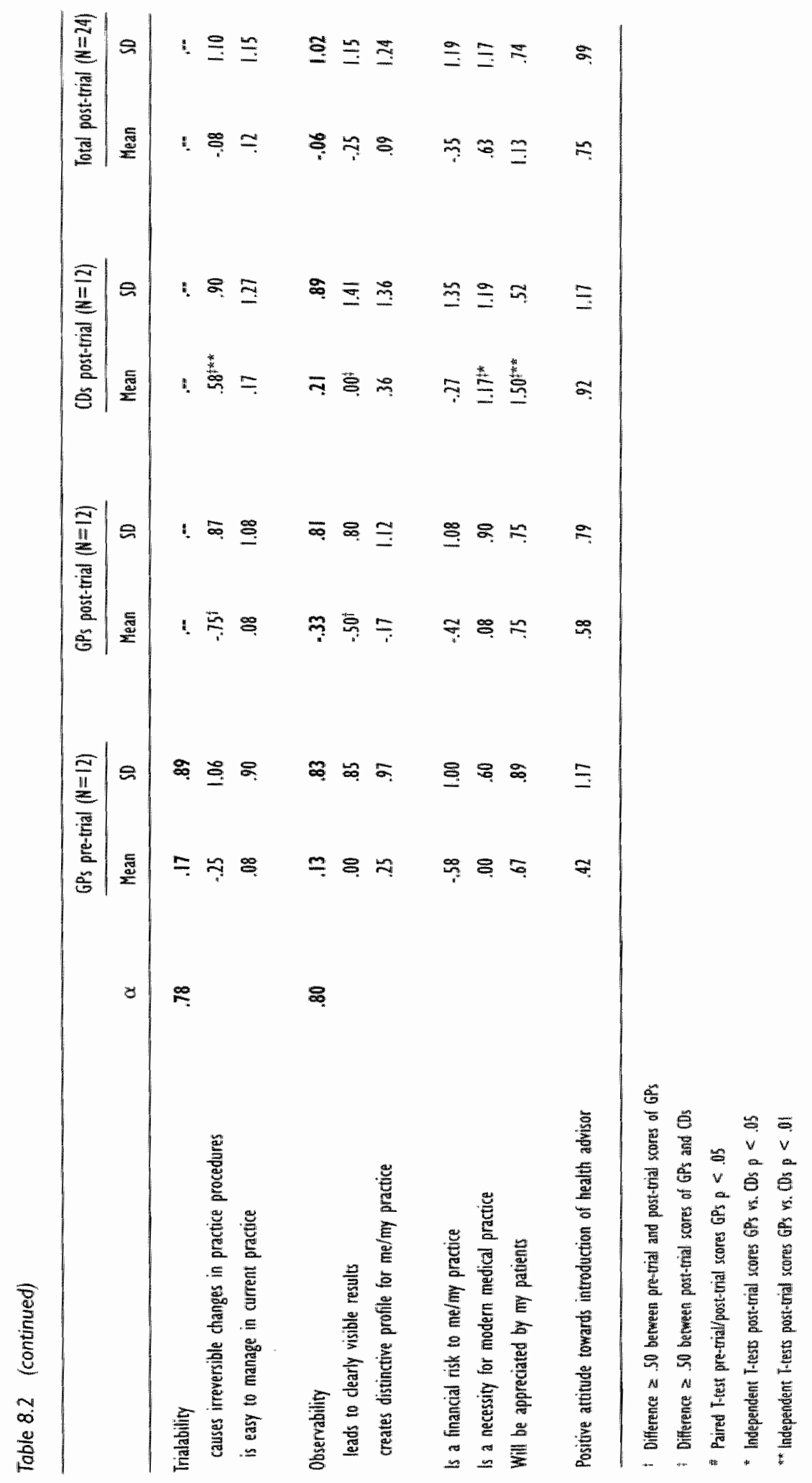


Toble 8.3 Correllations between perceived consequences of the introduction of the health advisor and the overall attitude of $G P_{5}$, cordialogists $(C D s)_{1}$ and both providers

Overall attitude $G P_{5}$ pretrial $(N=12) \quad G P_{s}$ post-trial $(N=12) \quad C D$ sost-trial $(M=12)$ Total post-trial (M=24) Perceived contequences

\begin{tabular}{|c|c|c|c|c|}
\hline helative adrantage & $.58^{\circ}$ & $62^{*}$ & $.8 g^{m}$ & $.74^{ \pm+\pi \cdot 56}$ \\
\hline Compatibility & $.72^{\text {k }}$ & $64^{*}$ & $.77^{n-i x}$ & $.66^{* \# * * *}$ \\
\hline Complexity &. $.72^{2 * x}$ & -.35 & -37 & -39 \\
\hline Causpes irreversible changige & $.3 \|$ & $.70^{*+}$ & $.66^{*}$ & $.62^{+* x}$ \\
\hline Easy to manage & 31 & 47 & -30 & .01 \\
\hline Observability & .37 & $.69^{\circ}$ & $.81^{* * *}$ & $.78^{*}$ \\
\hline Financial risk & .09 & .20 & $.75^{\text {t***}}$ & .38 \\
\hline Hecessity & $.65^{\circ}$ & .56 & .14 & .33 \\
\hline Appreciated by patients & $.59^{*}$ & $.72^{\mathbf{2 *}}$ & .07 & .40 \\
\hline
\end{tabular}

${ }^{*} p<.05, * * 0<010 * 0<0.001$

Although not resulting in a more positive overall opinion about the introduction of the health advisor, the cardiologists had a much more favorable post-trial opinion about most of the innovation characteristics than the GPs. In particular, they regarded the innovation as more compatible, less complex, and of greater value to modern medical practice. Moreover, they perceived their patients as being more satisfied with the health counseling service and they were more convinced that the innovation would lead to irreversible changes in practice procedures.

Before the trial, the GPs' overall attitude towards the innovation was mainly associated with its perceived relative advantage, compatibility, complexity (negatively), necessity, and expected appreciation by the patients (Table 8.3). After the trial, the association with perceived complexity had disappeared, and those with both compatibility and necessity had become less strong. New positive correlations were found with expected irreversible changes and the observability of results, while the association with expected appreciation by the patients had become stronger. After the trial, the cardiologists' views corresponded with those of the GPs regarding most of the positive associations, with an even stronger correlation between overall attitude and perceived relative advantage. However, no relation was found with the perceived satisfaction among the patients. Instead, there was a negative correlation with the expected level of financial risk. 


\section{DISCUSSION}

\section{Main results}

At the cardiology outpatient clinic, the post-trial implementation of the health counseling service was successful, whereas at the general practices it was not. The main "diffusion question" is whether it is possible to specify the decisive factors for this difference.

A first striking dissimilarity is the relative incompleteness of the implementation of the innovation in the outpatient clinic during the trial, leaving the cardiologists uninvolved in the intervention. "This implies that in their setting, the post-trial implementation only comprised the counseling component, whereas in the general practices it still encompassed the threefold high-risk approach, including the active involvement of the GPs.

Second, the description of the post-trial implementation shows four remarkable differences between the settings. In the outpatient clinic, the health advisors could continue their work, only one cardiologist was in charge of the further implementation, the desired re-invention did not require additional competencies or qualifications of the health advisors, and changes in the organization of care provided additional opportunities for the health counseling component to be implemented post-trial. In the general practices, there were infrastructural reasons why the health advisors could not continue their work. In addition, the responsibility for further implementation was decentralized, the desired reinvention raised doubts about the competencies and qualifications of the health advisors, and changes in the organization of care induced competition with other innovative nursing positions. This resulted in less involvement by the Hartslag Limburg project manager in this setting. Beside these differences in diffusion variables, the importance of coincidental events for the implementation process cannot be ruled out.

Third, the results of the questionnaires indicate that it was not the physicians' overall attitude, but several perceived individual characteristics of the innovation that may have influenced the post-trial implementation. After the trial period, the cardiologists evaluated the innovation as more compatible and less complex than did the GPs. They also thought the health counseling would be more appreciared by their patients. These differences in perceived characteristics may be due to the lack of involvement of the cardiologist in the intervention during the trial: either the innovation had actually been more compatible and less complex in their setting, or they had been insufficiently able to verify their pre-trial perceptions on the basis of actual experiences. As a matter of fact, the GPs did indeed seem disappointed about several characteristics after the trial compared to their neutral or optimistic perceptions before the trial.

Although its post-trial implementation in the "cardio-and-vascular center" may be regarded as a success, it may be questioned to what extent the re-invented innovation is still able to contribute to the goal, that is, reducing cardiovascular risk by optimizing the treatment of biomedical risk factors 
and reducing cardiovascular risk behaviors. To begin with, an element that was assumed to be rather crucial for the effectiveness of the original intervenrion was the active involvement of the physicians as well as the reinforcement expected from their collaboration with the health advisor. This mutual prevention approach will still not be achieved by the re-invented innovation. In addition, the health advisors now attached to the "cardio-and-vascular center" may find that their new coordinating tasks in the care for cardiologic patients after discharge may lead to a reduced priority and a declined intensity of their health counseling efforts. A recently started observational post-trial study may shed some further light on the job delineation and the effectiveness of the "new" health advisors.

Although not immediately related to the post-trial implementation, the relation between perceived consequences of the innovation and the overall attitude toward the innovation shows a remarkable difference between GPs and cardiologists. Though the cardiologists assumed their patients to appreciate the health counseling service more than the GPs thought their patients did, the cardiologists' opinion was not related to their overall attitude, while a strong positive correlation was found for the GPs. By contrast, a perception of the innovation as carrying financial risks was strongly negatively rellated to the overall attitude of the cardiologists, while no such a relationship was found for the GPs. Apparently, the relevance of perceived consequences for attitude formation differs between these two types of physicians.

Finally, Rogers' diffusion of innovations theory predicts that innovations that are perceived as causing more "irreversible changes" will be less easily adopted. For the present study, an opposite relation was found. Causing "irreversible changes" was associated with an overall positive attitude toward the innovation for borh GPs and cardiologists. Additional analyses revealed similar unexpected positive correlations with perceived relative advantage and perceived compatibility. Moreover, the perception that the innovation was a necessity for modern medical practice had its strongest positive correlation with perceived "irreversible changes". This indicates that, in the present study, the physicians interpreted "irreversible changes" not as a threat to current practice routines, as was meant by Rogers, but as an inevitable and welcome development in thealth care in general.

\section{Considerations}

The samples of both general practitioners and cardiologists were very small. In addition, the physicians in our study may have been innovators or early adopters, because of their willingness to try out the innovation during the trial. This may have positively influenced their attinde scores. It is also regrettable that pre-trial scores for the cardiologists were lacking. Their initial reluctance to participate in the study suggests that they may have been less positive than the GPs before the rrial. In addition, the cardiologists represent one outpatient clinic of one university hospital, and can therefore be seen as one single unit $(\mathrm{N}=1$ study). 
Furthermore, as no preliminary qualitative study was done to elicit the physicians' perceptions of the innovation beforehand, the quantitative part of the present study may have overlooked other influential characteristics of the innovation. For the above reasons, the present study remains mainly descriptive, is of limited generalizability, and only allows tentative causal inferences to be made.

One of the more serious shortcomings of diffusion studies is "pro-innovation bias" (E. M. Rogers, 1995), which means that researchers tend to focus mainly on successful diffusion processes. The present study however, made use of two of the strategies recommended to overcome this bias: studying innovations "On their way" and conducting a comparative analysis (E. M. Rogers, 1995). Furthermore, Rogers' theory can be criticized for not providing an adequate means of analyzing the potential contribution of the efforts on the part of the resource system or the user system to influence the diffusion process (Orlandi, Landers, Weston, \& Haley, 1990). Indeed, the present study paid relatively litthe attention to system indicators of failure or success, such as the organizational climate (Steckler, Goodman, McLeroy, Davis, \& Koch, 1992), and may therefore be affected by an "individual-blame bias" (E. M. Rogers, 1995). Moreover, our observational design neither allows firm conclusions regarding the relative importance of the potential influential diffusion variables noticed. A final criticism relates to the fact that Rogers' theory overemphasizes the adoption decision, although that is only one step in the multi-step diffusion process (Orlandi et al, 1990). The quantitative part of the present study can be criticized for having the same limitation, as we chose to measure only the perceived characteristics of the innovation. However, this seems acceptably compensated by the study's qualitative part, covering at least part of the implementation and confirmation stages of the diffusion process.

\section{Conclusion}

In spite of the above considerations, Rogers' diffusion of innovations theory appeared to be a useful tool to describe the post-trial implementation of the health counseling component of the Hartslag Limburg project. The present study showed that the implementation of an innovative health care service may be facilitated by avoiding post-trial interruptions of service delivery and by having only one single person in charge, that is, only one "change agent" (name adopted from Orlandi et al., 1990). As predicted by Rogers, the implementation of an innovarive health care service that is perceived as not very complex and as compatible with current pracrice routines may be relatively easy. The same holds for innovations that can be "re-invented" without much difficulty. Further support for the implementation process may come from changes in the organization of care that create opportunities for, instead of competition with, an innovative health care service. It can be concluded that examining post-trial implementations of interventions may reveal valuable information about factors influencing the success of such processes. 


\section{ACKNOWLEDGEMENTS}

The implementation of the Hartslag Limburg project during the trial was funded by the Netherlands Heart Foundation (NHS), while the post-trial implementation was funded by the Dutch health insurance company VGZ. Both in-trial and post-trial implementation were coordinated by the Maastricht Regional Public Health Institute (GGD-zz). Thanks are due to the four health advisors for their implementation efforts and for frankly sharing their experi-

156 ences, and to Geert Rutten, Steven Rutten, and Stef Kremers for their stimulating collaboration, which greatly motivated and inspired the first author in writing the present article. 


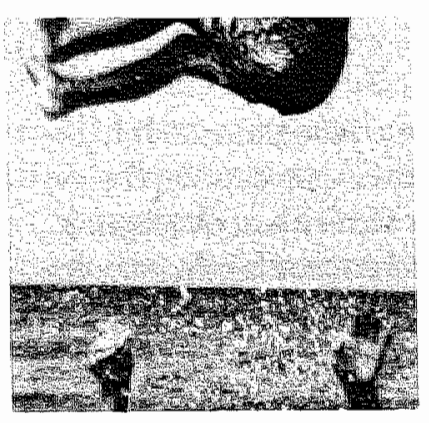

CHAPTER 9

General discussion 


\section{INTRODUCTION}

This thesis reports on the effect and process evalluation of the individual highrisk approach within the Hartslag Limburg cardiovascular prevention project. The intervention was aimed at individuals with an elevated risk of developing cardiovascular disease (CVD). The method was three-fold: composing a complete cardiovascular risk profile for each patient, reviewing and optimizing the treatment of biomedical risk factors, and counseling on behavioral risk factors. This multiple factor and multiple component intervention strategy was assumed to be most effective in reducing cardiovascular risk.

The main aim of the effect study, a randomized controlled trial, was to evaluate the effectiveness of the high-risk intervention on three behavioral risk factors: high fat consumption, smoking, and physical inactivity. The process evaluation monitored whether the intervention as a whole was implemented as intended. With regard to one of the intervention components, i.e., the individual lifestyle advice by a health advisor, the process evaluation also examined the applicability of the stage-matched counseling model developed for this specific purpose, the quality of the counseling, the opinions of the patients, and the experiences of the health care providers involved. In addition, the process evaluation monitored the post-trial implementation of the health counseling component.

The first section of this general discussion summarizes the major findings of the study as a whole. The second part briefly explores the differences in results between the two research settings, i.e., a cardiology outpatient clinic and general practices. The next section deals with the main strengths and limitations of the different study parts, and intends to present a concise reflection on the combined effect and process evaluation as a whole. The final part of this chapter provides a brief elaboration on the societal implications of the conclusions of the present study.

\section{MAIN RESULTS}

The implementation of a multi-factorial and multi-component cardiovascular risk factor intervention for high-risk patients in general practices and a cardiology outpatient clinic proved to be rather difficult. It was found to be impossible to provide the physicians with a computerized cardiovascular risk profile of their patients, which, as the first component, was assumed to be a necessary starting point of the intervention. This in turn impeded the implementation of the second intervention component, the physicians" evaluation and optimizarion of the treatment of biomedical risk factors. This component was further hampered because, for several reasons, it turned out to be difficult to actively involve 
the general practitioners and impossible to mobilize the cardiologists. The third component, the individual life style advice, was mostly implemented according to plan, but as newcomers to the Dutch health care system, the health advisors had difficulties proving their value.

Among the patients from the cardiology outpatient clinic with a manifest cardiovascular disorder, the individual lifestyle advice brought about short-term effects on fat consumption (substantial), smoking (small), and physical activity (marginal), that may contribute to the secondary prevention of CVD. Positive effects were also found on the intention to make healthy lifestyle changes. No long-term effects were found. Both the magnitude and the duration of the intervention effects may be further increased by additionally involving the cardiologists and by a more intense utilization of existing prevention facilities, such as cardiac rehabilitation programs and health behavior promoting services in the community. Among the patients from general practices who were at high risk of $\mathrm{CVD}$, the health counseling service caused favorable short-term and long-term effects on fat consumption, but hardly any changes with regard to smoking, physical activity, and the intention to make healthy lifestyle changes. Instead of further implementing the present multi-factorial health counseling, it is proposed that smokers should be regularly approached by the general practitioner with help of a minimal intervention strategy, and that nutrition and physical activity should be simultaneously addressed in a more intense and more comprehensive program that combines several prevention strategies.

The individual lifestyle advice itself can be said to leave some room for improvement as well. Although the patients reported that the new service was highly acceptable to them, that the quality had been rather good, and that they were fairly satisfied, their evaluations nevertheless imply some criticism of the health counselors' performance. Patients' opinions suggest, for instance, that the health advisors could adapt their recommendations more accurately to each patient's own ideas and personal situation. Smokers and obese patients in particular indicated that the counseling had made them feel less free and more worried and to blame. As the positive contribution of these moral concerns to changes in behavior related outcomes was found to be negligible, it would be better to prevent these feelings. The health advisors could achieve this by maximizing the information exchange and by minimizing the difficulty of actions the patients are meant to implement.

A similar criticism emerged from the quality assessment of the new service by experts in the fields of health counseling and behavior change as well as from the experiences of the health advisors themselves. On the whole, the experts evaluated the health counseling as "rather promising". The basic counseling attitude of the health advisors was appraised as more than satisfactory, but the quality of several other counseling aspects was judged to be somewhat more doubtful. This applied, for instance, to the way the health advisors structured the counseling sessions, and the way they explored the stage-related behavioral determinants and intervened on them. The health advisots agreed that they had found it difficult to combine the various counseling skills with the diverse 
behavior change strategies, that they had initially been aiming too much at changes in behavior rather than behavioral determinants, and that their competence had only gradually increased. Improvements can be found in simplifying and more strictly structuring the counseling model, and in offering the health advisors additional supervised practical training and a safe and supportive environment. This may help them to strengthen their professional attitude, which itself was found to be a probable key element for the effectiveness of individual life style advice.

Compared to other prevention programs, the funding obtained for the development, implementation, and evaluation of the Hartslag Limburg project as a whole was substantial, but not entirely sufficient to realize all project and study elements that initially had been proposed. Based on positive process information of the present study, additional funding was obtained to continue the health counseling component of the high-risk approach for another three years after the initial study period. This further implementation was not successful in the general practice setting. The service was experienced as too complex, insufficiently compatible, and too inflexible. Besides, competition was encountered from other new developments in the general practice system. The further implementation was a success, however, in the cardiology outpatient clinic. In this setting, the service could be rather easily "re-invented" (by incorporating additional tasks) and fairly simply integrated with other developments in hospital care. However, the effectiveness of the transformed service in terms of cardiovascular prevention should be assessed again.

\section{DIFFERENCES BETWEEN SETTINGS}

In the short term, the multi-factorial health counseling service appeared to be more effective in changing multiple risk behaviors and the intention to adopt a healthier lifestyle in the cardiology outpatient clinic than in the general practices. In the long term however, the multiple effect in the first setting was no longer present, while the effect on fat consumption in the latter setting was largely preserved. Apart from the different attitudes we found for cardiologists and general practitioners, several baseline and process data may explain some of the differences in intervention effects. For instance, at baseline, the average intention to change health related behaviors was consistently slightly higher among the cardiology outpatient sample. The cardiology outpatients also attended more consultations. They more often sought information about health promoting activities, and although their actual enrollment was nearly as low, they were much more frequently referred to community health promoting services. This may account for the multiple short-term effects among the cardiology outpatients. On the other hand, in the general practices smoking and 
physical activity had received relatively little attention, whereas in the cardiology outpatient clinic topics other than behavioral risk factors repeatedly had been subject of the counseling. This may account for the long-term effect on fat consumption in the general practice sample and the absence of long-term effects among the cardiology outpatients.

It may, however, be questioned whether the differences above as such explain the differences in outcomes or whether they are associated with other patient characteristics. The most plausible underlying factor is the primary diagnosis that was the reason for the patient's inclusion in the study. For two-thirds of the cardiology outpatient sample, this had been a cardiac event (myocardial infarction or cardiac surgery), while the remaining third had at least been confronted with symptoms of a cardiovascular disorder. In the general practice sample, less than a quarter had gone through a cardiac event, and more than half had no manifest cardiovascular disorder. This difference in actual health status may have meant that the two samples differed in their perceptions of cardiovascular risk as well as in their degree of reactance in response to the health counseling. Both issues will be briefly discussed.

First, according to several theories, perceived risk is a central element in motivating people to change (Janz \& Becker, 1984; R. W. Rogers \& Prentice-Dunn, 1997; Weinstein, 1988). With regard to the difference in diagnoses between the two study settings, it is important to realize that only risks that are perceived as personally relevant will motivate people to change (Weinstein, 1988). In addition, it is known that people are affected by a general sense of invulnerability, but that they tend to overestimate the severity of risks with which they have more personal experience or about which they are better informed (Denscombe, 1993). It is therefore possible that the patients from the cardiology outpatient clinic perceived higher levels of cardiovascular risk, were more motivated to change, and hence effected more changes than those from the general practices. The relative ignorance of the latter sample is supported by a recent study, which found that most general practice patients with hypertension or diabetes were unable to accurately estimate their cardiovascular risk (Frijling et al., 2004). Moreover, the inability to estimate risks and the inaccuracy of risks estimates were both associated with less personal and more physician control, suggesting that both underestimation (false reassurance) and overestimation (false fatalism) may lead to a low motivation to adopt a healthier lifestyle (Frijling et al., 2004).

In our study, the actual levels of cardiovascular risk the patients perceived was not measured and the way the health advisors discussed both actual and perceived cardiovascular risk was not specifically investigated. Nevertheless, the above findings suggest that it is worthwhile to reconsider the roles of risk perception and risk communication in the present intervention. Introducing "health risk appraisal" as an additional intervention tool might be helpful (Kreuter \& Strecher, 1996). In doing so, it should be kept in mind that, to produce behavior change, risk communication should always include high-efficacy messages as well, to enable people to effectively cope with the perceived threat (Witte \& Allan, 2000). 
Second, the theory of psychological reactance proposes that people who feel restricted in their freedom to act will react by attempting to recapture the frecdom affected (Brehm \& Cole, 1966, referred to by Jones \& Gerard, 1967). The intensity of this reactance state may be a direct function of the extent of the restriction, the number of freedoms endangered, and the value placed on them by the individual (Fogarty, 1997). Since the behavioral changes necessary for cardiovascular prevention may impact on a considerable number of freedoms, they may discourage patients from adopting a healthier lifestyle. In the present study, the mechanism proposed by reactance theory was supported by at least three findings. First, the health advisors mentioned encountering resistance in a substantial number of their patients. Second, obese patients and smokers, who presumably face the most drastic behawioral changes, reported the greatest increase in perceived life restraints. Third, an increase in life restraints appeared not to contribute to an increase in the intention to make healthy lifestyle changes. Hence, psychological reactance may indeed have played a part in the present intervention. Moreover, some evidence was found that the patients in the general practices perceived somewhat more life restraints as a result of the counseling than those in the cardiology outpatient clinic.

The probable difference in reactance may be clarified by the findings of another study, which concluded that cardiac patients were inclined to view their heart attack as an acute event, and lifestyle changes as a means to recover from that event (Wiles, 1998). Patients who had fully recovered did not see reasons to maintain their healthy habits. The same held for patients who did not recover, as they no longer saw lifestyle changes as an effective means to get better. Only those who were hoping for further recovery were still motivated to adopt or continue a healthy lifestyle. Applied to our study, these findings may mean that the patients from the cardiology outpatient clinic did not perceive the recommended lifestyle changes as a threat, but as a means to regain freedoms that they had lost because of their disease. This may explain why, in the short term, patient from this setting may have been more ready to adope several behavioral changes at once, but, in the long run, these changes were not maintained. "This again highlights the important role of risk communication in cardiovascular prevention, but also indicates that an intervention's effectiveness may be increased by taking the mechanism of psychological reactance more seriously. The present study suggests that reactance might be avoided by high levels of information exchange, and by keeping the changes in behavior the patient is supposed to carry out, at least initially, as simple as possible. Further improvement may be found in accurately applying the principle of "rolling with resistance" which is used in motivational interviewing (W. R. Miller \& Rollnick, 1991). 


\section{STRENGTHS AND LIMITATIONS}

A strong point of the present study is the combined effect evaluation and process evaluation. On the one hand, the randomized, controlled design that was applied in the effect studies can be considered as optimal to provide evidence of the program's effectiveness (Windsor et all, 1994). On the other hand, the extensive process evaluation yielded important information, especially with regard to the implementation of the intervention, and therefore considerably contributed to the interpretation of the study results (Green \& Lewis, 1986). Although for the separate process studies an observational design was used, the application of the principle of triangulation (Polit \& Hungler, 1995) increased the inferential strength of the process evaluation as a whole. Furthermore, the results of the individual process evaluation studies appeared very useful in providing feedback to the project team in general and to the health advisors in particular.

As regards the effect evaluation, a first threat to the internal validity of the RCT is that, for logistical and ethical reasons, the experimental condition as well as the content of the intervention were known to all patients before they answered the baseline questionnaire (creating a risk of sernsitization to the intervention and socially desirable answers, Green $\&$ Lewis, 1986). A second threat is that (only) the intervention patients had to complete a process questionnaire to assess their opinions about the new health counseling service (probably creating an additional intervention component). The present design, however, did not allow the influence of both threats to be discovered, implying that the internal validity of the effect study cannot be fully guaranteed. A more flexible design, for instance one that left out the baseline and process measures for part of the study sample, could have been a sensible alternative (Chen, 1990).

A third internal validity issue to be addressed, is the limited ability of the effect study to yield conclusive evidence regarding the causal intervention model. Some important mediating variables, viz, behavioral determinants and intention to change, were indeed measured. However, the way they were opera" tionalized, that is, with regard to changing the risk behavior rather than with regard to the target behavior as such, precluded any causal inferences. A final point of criticism with regard to the internal validity is the selective drop-out during the trial, but this was adequately compensated for by using intention-totreat analyses.

The most important threat to the external validity of the effect study was the self-selection of physicians and patients (Green \& Lewis, 1986). This means that the present results can only be generalized to well-motivated physicians and rather motivated high-risk patients. Another aspect that limits the generalizability of the present intervention is that of the additional infrastructural help that was offered to the general practices by the research team during the trial period. The fact that the withdrawal of this assistance was associated with the failure of post-trial implementation of the intervention in this setting, illustrates that manipulations of the "research system" complicate the inferences to the "generalizing system" (Chen, 1990). 
Despite the essential information provided by the process evaluation, the various process studies also had some essential limitations, especially in terms of their purpose to produce insight into the causal intervention and counseling models. The first problem was the observational nature of all process investigations, sometimes combined with imperfect study designs. For instance, the design of the quality assessment of the counseling by experts precluded sound conclusions about the development of the health advisors' competencies over time. Another example is that it turned out to be impossible to sensibly link the experts' opinions with the patients' opinions about the quality of the health counseling service. More precisely, a priori formulated research questions for each of the process studies could have further increased their usefulness. However, most of the problems observed were either unavoidable because of practical constraints, or induced by conflicting study aims, i.e. providing more insight and generating feedback.

A second problem with the process studies was that we were confronted with the absence of valid, pre-set qualiry standards for health counseling as described in our counseling model. The formulation and use of such a priori standards in evaluation research has been strongly recommended (Green \& Lewis, 1986; Windsor et al., 1994). Their absence in the present study made it more difficult, for instance, to interpret the experts' evaluations of the quality of the health counseling and to adequately value the parients' opinions about the counseling service. Our efforts to measure quality resulted for the experts in a theoretical comparison with a certain ideal conception, and for the patients in a normative comparison with comparable activities elsewhere in health care system (Green \& Lewis, 1986). This may be viewed as an acceptable solution, although the addition of short, well-validated instruments to assess counseling quality and patients satisfaction in general, would have had additional benefits for the interpretation of the present findings.

A last, strong aspect of the present process evaluation is that it not only assessed the intended outcomes of the intervention, but also explicitly addressed some unintended effects. Our study thereby took into account both dimensions of impact evaluations (Chen, 1990). The first, the desirability dimension, reflects the anticipated advantages of the intervention. The second, the plausibility dimension, concerns the broader, more realistic questions of the potential impacts of the program. In combining these dimensions, the study was made more sensitive to what actually happened as a result of the intervention. Moreover, our study enabled us to formulate some suggestions for the prevention of unwelcome effects.

Norwithstanding its shortcomings, it may be concluded that the present combination of effect and process studies can be regarded as a satisfactory example of a theory-driven evaluation that applied the perspective of "critical multiplism" by using multiple methodologies, investigating multiple issues, and considering the views of multiple stakeholders (Chen, 1990). 


\section{SOCIETAL IMPLICATIONS}

The present study concludes that more intense and more comprehensive programs may be needed to generate long-lasting healthy changes in multiple behavioral cardiovascular risk factors. Assuming that such programs indeed are effective in reducing cardiovascular risk, with regard to the socieral implications of the studies conclusion, three questions should be asked. First, is such an approach justifiable from an ethical point of view? Second, if justifiable, who is going to pay for it? Third, if justifiable and financed, how should such programs be implemented? All three question are briefly discussed below.

Ethical issues with regard to health promotion and disease prevention have been widely discussed (e.g. Doxiadis, 1987; Guttman \& Ressler, 2001; Minkler, 1999). In terms of the four classical moral principles, i.e., beneficence (doing good), nonmaleficence (doing no harm), autonomy, and justice, prevention is problematic and difficult to justify. For instance, in electing "good health" and "a long life" as the primary values that should be aimed for, it neglects that for most people other values, such as pleasure, unconcern and happiness, count as much or even more. In addition, it may be questioned to what extent changes in behavior contribute to a longer and healthier life for the individual, as other aspects, such as living conditions or environmental factors, may be equally important or even have greater influence. Furthermore, preventive interventions have been criticized because of their overemphasis on the responsibility of the individual, resulting in "victim blaming". Until now, the negative psychological impacts of health risk appraisals and screening for cardiovascular risk factors have been found to be small and of short duration (Glanz \& Gilboy, 1995; Shaw, Abrams, \& Marteau, 1999; Strecher \& Kreuter, 1995), and the results of our intervention indicate that some negative impacts might even be avoided altogether. However, it may be seriously questioned whether the plausibility dimension, and therefore the possible negative side-effects, have been conclusively studied at present.

It seems somewhat easier to justify prevention from a different ethical perspective, the theory of citizenship (Horstman, 2000). This gives us an opportunity to look for the way preventive practices stimulate learning processes that result in strengthening three important virtues: people's autonomy in dealing with health risks, their competencies in judging these risks, and their skills to handle the uncertainties of living in a society with an increasing risk culture. The idea of citizenship is linked to the notion of empowerment, but goes beyond it, as not only the individual who is at risk, bur also scientists, policy makers and prevention workers themselves should learn and profit from this different approach.

In conclusion, our suggestion would be to carefully try out more intensive and therefore potentially more effective preventions programs in a high-risk population, but not without inciuding a normative perspective in their development, implementation, and evaluation, to ensure that the programs answer the patients' needs and are acceptable to them. 
If, as our study concluded, cardiovascular prevention programs should indeed be of longer duration and include more strategies and components, we should ask ourselves who is going to fund their development, implementation, and evaluation. At present, less than $0.5 \%$ of the total Dutch health care budget is spent on disease prevention and health promotion (Peeperkorn, 2004), of which only part of it is meant to promote a healthier lifestyle (N. K. De Vries, 2004). Even less promising is that the resources that health promotion funding organizations have at their disposal has decreased in recent years. (Krosse, 2001). Together with the current economic decline, there does not seem to be much chance of finding the funding needed. Perhaps scientists, policy makers, and politicians should abandon the idea that low-budget prevention efforts will result in considerable health gains. Taking into account all influences people are exposed to, health promoting interventions may be regarded as a kind of homeopathy (Schnabel, 2004), in the sense of being so diluted that they cannot be reasonably expected to be effective. In our opinion, the resources that are at present available for prevention should be increased. At the same time, it seems worthwhile to look for other than governmental organizations as possible partners in prevention.

A final important issue is the practical implementation of the proposed more comprehensive prevention approaches. The difficulties we encountered in implementing the various intervention components seem to be rather common, in view of the statement that implementation of research findings goes beyond the sound of one hand clapping (Lomas, 1998). Effectively decreasing the burden of cardiovascular disease should be seen as a "multilevel compliance challenge" that requires commitment by patients, health care providers, and health care organizations as well (N. H. Miller, Hill, Kottke, \& Ockene, 1997). Interventions that intend to implement multi-component programs should therefore be aimed at optimal compliance at all three levels. A useful tool to

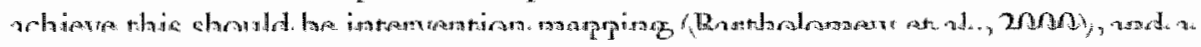
pilot study will be an essential preparatory action. Finally, although the collaboration between practice and research that was achieved in Hartslag Limburg may be regarded as impressive, even a more intensive collaboration may be needed. This in turn may require what within the Hartslag Limburg project was called "further demolishing the barriers between the health care echelons".

\section{CONCLUSION}

Offering individual lifestyle advice to patients at high risk of cardiovascular disease may cause promising changes in behavioral cardiovascular risk factors. However, a more comprehensive prevention approach, involving supplemental components and including additional health promoting strategies, may be 
needed to generate the more substantial and longer lasting behavioral changes necessary for effecrive cardiovascular prevention. Such an approach, however, requires more funding than is at present available, may be difficult to implement, and should include a nomative perspective in its development, implementation, and evaluation, to ensure that it answers the patients needs and is acceptable to them. Finally, to get such comprehensive cardiovascular prevention programs going, a more intensive collaboration between the various health care echelons is a prerequisite. 



\section{REFERENCES}

Aharony, L, \& Strasser, S. (1993). Patient satisfaction: What we know about and what we still need to explore. Medical Core Review, 50, 49-79.

Ajzen, I. (1991). The theory of planned behavior. Organizotional Behavior and Human Decision Processes, 50, 179-211.

Anderson, K. M., Odell, P. M., Wilson, P.W., \& Kannel, W. B. (1991). Cardiovascular disease risk profiles. American Heart Journal, 121, 293-298.

Anderssen, S.A., Hjermann, I., Urdal, P., Torjessen, P.A., \& Holme, 1. (1996). Improved carbohydrate metabolism after physical training and dietary intervention in Individuals with the "atherothrombogenic syndrome". Oslo Diet and Exercise Study (OBIS). A randomized trial. Journal of Internal Medicine, 240, 203-209.

Argyle, M. (1983). Doctor-patient skills. In D. Pendleton \& J. Hasler (Eds.), Doctor-patient communication (pp. 57-74). London: Academic Press.

Armitage, C. J., \& Conner, M. (2000). Social cognition models and health behaviour:A Structured review. Psychology and Health, 15, 173-189.

Armitage, C. I. \& Conner, M. (2001). Social cognitive determinants of blood donation. Journal of Applied Social Psychology, 31, 1431-1457.

Armitage, C. .. Povey, R., \& Arden, M.A. (2003). Evidence for discontinuity patterns across the stages of change: A role for attitudinal ambivalence. Psychology and Heaith, 18, 373-386.

Asthenden, R., Silagy, C.. \& Weller, D. (1997). A systematic review of the effectiveness of promoting lifestyle change in general practice. Family Proctice, 14, 160-175.

Avis, M., Bond, M., \& Arthur, A. (1997). Questioning patient satisfaction: an empirical investigation in two outpatient dinics. Social Science and Medicine, 44, 85-92.

Bagozzi, R. P. (1992). The self-regulation of attitudes, intentions, and behavior. Social Psychology Quarterly, 55, 178-204.

Bandura, A. (1986). Social foundations of thought and action. A social cognitive theory. Englewood Cliffs, N!: Prentice Hall.

Bär, F.W., \& Vonken, H. J. M. (1990). Wat is thet nut van hartrevalidatie? (What is the benefit of cardiac rehabilitation?). Nederlands Tijdschrift voor Geneeskunde, 124, 107-112.

Barlow, D. H., \& Hofmann, S. G. (1997). Efficacy and dissemination of psychological treatiment. In D. M. Clark \& C. G. Fairburn (Eds.), Science and practice of cognitive behoviour therapy (pp. 96-117). Oxford: Oxford University Press.

Barry, C. A., Bradley, C. P., Britten, N., Stevenson, F.A., \& Barber, N. (2000). Patients' unvoiced agendas in general practice consultations: qualitative study. British Medical Journal, 320 , 1246-1250.

Bartholomew, L. K., Parcel, G. S., Kok, G. \& Gottlieb. N. H. (2000). Intervention mapping. Designing theory- and evidence-based heath promotion programs. Boston: MCGraw-Hill.

Belcher, D.W. (1990). Implementing preventive services. Success and failure in an outpatient. trial. Archives of Internal Medicine, 150, 2533-2541.

Bensing. $).(1991)$. Dactor-patient communication and the quality of care. Social Science and Medicine, 32, $1301-1310$.

Boelen, C. (2001). "Towards Unity for Health": Status report. Towards Unity for Heofth Newsletter(April 2001), 5-6. 
Bolman, C.. De Vries, H., \& Van Breukelen, G. (2002). Evaluation of a nurse-managed minimalcontact smoking cessation interwention for cardiac inpatients. Heaith Educotion Research, 17. 99-116.

Brady, M. K., Robertson, C.J. (2001). Searching for a consensus on the antecedent role of service quality and satisfaction: An exploratory cross-national study. Journal of Business. Research, 51, 53-60.

Brown, J. B., Stewart, M. A., \& Ryan, B. L. (2003). Outcomes of patient-provider interaction. In T. L. Thompson \& A. M. Dorsey (Eds.), Handbook of communication research (pp. $|4|-16 \mid$ ). Mahwah: Lawrence Eribaum Associates.

Brown, S. A.; \& Grimes, D. E. (1995). A meta-analysis of nurse practitioners and nurse midwives in primary care. Nursing Research, 44,332-339.

Brownell, K.D. (1991). Personal responsibility and control over our bodies: When expectation exceeds reality. Health Psychology, 10, 303-310.

Brownell, K. D. \& Cohen, L. R. (1995). Adherence to dietary regimens 2: Components of effective interventions. Behavioral Medicine, 20, 155-164.

Brubaker, P. H., Rejeski, W. J., Smith, M. J., Sevensky, K. H., Lamb, K.A., Sotile, W. M., \& Miller, H.S. (2000). A home-based maintenance exercise program after center-based cardiac rehabilitation: effects on blood lipids, body composition, and functional capacity. Journal of Cardiopulmonary Rehabilitation, 20.50-56.

Brubaker, P. H., Warner, J. G., Rejeski, W. J., Edwards, D. G., Matrazzo, B.A., Ribisl, P. M., Miller, H. S., 8. Herrington, D. M. (1996). Comparison of standard- and extended-length participation in cardiac rehabilitation on body composition, functional capacity, and blood lipids. Americon Journal of Cardiology, 78, 769-773.

Brug. J., Van Assema, P., Kok * G., Lenderink, T., \& Glanz, K. (1994). Self-rated dietary fat intake: association with objective assessment of fat, psychosocial factors, and intention to change. Journal of Nutrition Education, 26, 218-223.

Burke, L. E." Dunbar-Jacob, J. M., \& Hill, M. N. (1997). Compliance with cardiovascular disease prevention strategies: A review of the research. Annals of Behovioral Medicine, 19, 239-263.

Burton, L. C."Paglia, M. J., German, P. S., Shapiro, S., Damiano, A. M., \& The Medicare Preventive Services Research Team. (1995). The effect among older persons of a general preventive visit on three health behaviors: smoking, excessive alcohol drinking, and sedentary lifestyle. Preventive Medicine, 24, 492-497.

CDC \& National Center for Chronic Disease Prevention and Health Promotion. (1998). From the Centers for Disease Control and Prevention. Missed opportunities in preventive counseling for cardiovascular disease - United States, 1995. Joumal of the American Medical Association, 279, 741-742.

Charles, C., Gafni, A., \& Whelan, T. (1997). Shared decision-making in the medical encounter: What does it mean? (or it takes at least two to tango). Social Science ond Medicine, 44, 681.692 .

Chen, H.-T. (1990). Theory-driven evoluations. London: Sage.

Cohen, F., \& Lazarus, R. S. (1983). Coping and adaptation in health and illiness. In D. Mechanic (Ed.). Handbook of health, health care, and the health professions (pp. 608-635). New York: Free Press.

Coleman, T. (2000). Using video-recorded consultations for research in primary care:Advantages and limitations. Fomily Proctice, 17, 422-427. 
Collins, K.. \& $O^{\circ}$ Cathain, A. (2003). The continuum of patient satisfaction - from satisfied to very satisfied. Social Science and Medicine, 57, 2465-2470.

Conner, M., \& Armitage, C. 1. (1998). Extending the Theory of Planned Behawior: A review and avenues for further research. Journal of Applied Social Psycholog\%, 28, 1429-1464.

Conmer, M., \& Norman, P. (Eds.). (1995). Predicting health behoviour. Buckingham: Open University Press.

Cooper, H., Booth, K. Fear, S., \& Gill, G. (2001). Chronic disease patient education: Lessons from meta-analyses. Patient Education and Counseling, 44, 107-117.

Cronin $\rrbracket$. J., Brady, M. K., Hult, G., \& Tomas, M. (2000). Assessing the effects of quality, value, and customer satisfaction on consumer behavioral intentions in service environments. Journal of Retailing, 76, 193-218.

Cupples, M. E., \& KcKnight, A. (1994). Randomised controlled trial of health promotion in general practice for patients at high cardiovascular risk. Generol Practice $309_{n}$ 993-996.

Cupples, M. E., \& Mcknight, A. (1999). Five year follow up of patients at high cardiowascular risk who took part in randomised controlled trial of health promotion. British Medical Journal, 319,687-688.

Cutler, J.A., Grandits, G. A., Grimm, R. H., Thomas, H. E., Billings, J. H., \& Wright, N. H., For the MRFIT Research Group (1991). Risk factor changes after cessation of intervention in the Multiple Risk Factor Intervention Trial. Prewentive Medicine, 20, 183-196.

Dabholkar, P.A. Shepherd. C. D. \& Thorpe, D. I. (2000). A comprehensive framework for service quality: An investigation of critical conceptual and measurement issues through a longitudinal study. Journal of Retailing, 76, 139-173.

Davies, G., Pyke, S., \& Kinmonth, A. L., On behalf of the Family Heart Study Group. (1994) Effect of non-attenders on the potential of a primary care programme to reduce cardiovascular risk in the population. British Medical Journal, 309, 1553-1556.

De Nooijer, J. Van Assema, P., De Vet, E., \& Brug, J. (Accepted for publication). How stable are stages of change for nutrition behaviors. Health Promotion International.

Denscombe, M. (1993). Personal health and the social psychollogy of risk taking. Health Education Reseanch, 8, 505-517.

De Vries, H., Dijkstra, M. \& Kuhiman, P. (1988). The third factor besides attitude and subjective norm as a predictor of behavioral intentions. Health Education Research, 3, 273-282.

De Vries, H., Mudde, A. N., \& Dijkstra , A. (2000). The Attitude-Social influence-Efficacy Model applied to the prediction of motixational transitions in the process of smoking cessation. In P. Norman, C. Abraham \& M. Conner (Eds.). Understanding ond chonging health behowiour: From heolth beliefs to self-regulation (pp. 165-187). Amsterdam: Harwood Academic Publishers.

De Vries, N. K. (2004). Gezond leven moet (weer) norm worden (Living healthy should be the norm (again)). TSG / Tijdschrift woor Gezondheidswetenschappen, 82, 75-76.

Doherty, Y, James, P., \& Roberts, S. (2000). Stage of change counselling. In F. J. Snoek \& T C. Skinner (Eds.), Psychology in diabetes care (Pp. 99.139). Chichester: John Wiley \& Sons.

Donabedian, A. (1980). The definition of quality and approoches to its assessment. Ann Arbor: Health Administration Press.

Doxiadis, S. (1987). Ethical ditemmas in health pramotion. Chichester: John Wiley \& Sons.

Drenthen, $T_{0}(1997)$. Challenges to prevention in Dutch general practice. Americon Journal for Clinical Nutrition, 65, 1943S-1945S. 
Earp. J.A., \& Ennett, S.T. (1991). Conceptual models for health education research and practice. Health Educotion Research, 6, 163-171.

Ebrahim, S., \& Smith, G. D. (1997). Systematic review of randomised controlled trials of multiple risk factor interventions for preventing coronary heart disease. British Medical Journal, 314, 1666-1674.

Editorial Committee of the Regional Project ZZL. (1997). Hartslog Limburg operationeel scenorio (Hortslog Limburg project scenario). Masstricht: Regional Public Health Institute Maastricht GGD-zzl.

Egan, G. (1990). The skilled helper: a systematic approach to effective helping. Pacific Grove: Brooks/Cole.

Elder. J. P. (1987). Applications of behavior modification to health promotion in the developing world. Social Science and Medicine, 24, 335-349.

Elford, R.W., Yeo, M., Jennett, P., \& Sawa, R. J. (1994). A practical approach to lifestyle change counselling in primary care. Patient Education and Counseling, 24, 175-183.

Elwyn, G., Edwards, A., Mowle, S., Wensing, M., Wilkinson, C., Kinnersley, P., \& Grol, R. (2001). Measuring the involvement of patients in shared decision-making: a systematic review of instruments. Patient Education and Counseling, 43, 5-22.

Emanuel, E. J., \& Emanuel, L. L. (1992). Four models of the physician-patient relationship. Journal of the American Medical Associotion, $111,51-57$.

Engel, G. L. ( 1977$)$. The need for a new medical model:A challenge for biomedicine. Science, 196, $1129-136$.

EUROASPIRE Study Group. (1997). A European Society of Cardiology survey of secondary prevention of coronary heart disease: principal results. European Heart journal, 18, 1569-1582.

Eymael, N., Van Limpt, P., \& Van Ree, J. (2001). Implementation of a high risk strategy: choracteristics of non-participants. Anxiety a decisive factor? (Unpublished manuscript). Maastricht: Department of General Practice, Faculty of Medicine, Maastricht University.

Fogarty, J. S. (1997). Reactance theory and patient noncompliance. Sacial Science and Medicine, 45, 1277-1288.

Frederikson, L. G. (1995). Explaring information-exchange in consultations: The patients' view of performance and outcomes. Patient Education and Counseling, 25, 237-246.

Frifling, B. D." Lobo "C. M. "Hulsether, M. E. J. L., Van Drenth, B. B., Braspenning, J. C. C.. Prins, A.,

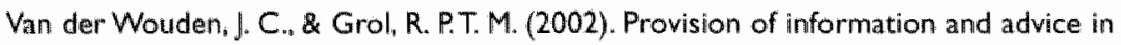
cardlovascular care: clinical performance of general practitioners. Potient Educotion and Counseling, 48, $131-137$.

Frijling, B. D., Lobo, C. M., Keus, I. M., Jenks, K. M., Akkermans, R. P., Hulscher, M. E. J. L., Prins, A.,

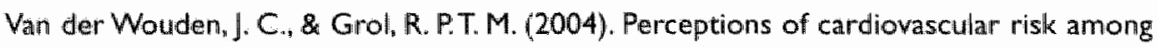
patients with hypertension or diabetes. Patient Education and Counseling, 52, 47-53.

Gezondheidsraad. (2001). Voedingsnarmen: energie, eiwitten, vetten en verteerbare koolhydraten (Dietory norms: energy, proteins, fats, and digestible carbohydrates) (No. 2001/19). Den Haag: Gezondheidsraad.

GGD. (1999). Limburgse gezondheidsenquête 1998 (Health Survey Limburg 1998). Maastrïcht: Regional Public Health Institute Maastricht GGD-zzl.

Glanz, K., \& Gilboy, M. B. (1995). Psychosocial impact of cholesterol screening and management. In R.T. Croyle (Ed.), Psychosocial effects of screening for disease prevention and detection (pp. 39-64). New York: Oxford University Press. 
Glasgow, R. E., Bull, S. S., Gillette, C., Klesges, L. M., \& Dzewaltowski, D.A. (2002), Behavior change intervention researcin in healtheare settings. A review of recent reports with emphasis on external validity. American joumal of Preventive Medicine, 23,62-69.

Goldstein, H. (1995). Multilevel statistical models (2nd ed.). London: Arnold.

Golwwitzer, P. M., \& Brandstätter, V. (1997). Implementation intentions and effective goal purm suit. Journal of Personality and Social Psychology, $73,186-199$.

Gotlieb, J. B., Grewal, D., \& Brown, S.W. (1994). Consumer satisfaction and perceived quality: Complementary or divergent constructs. Journal of Applied Psychology, 79, 875-885.

Green, L.W." \& Lewis, F. M. (1986). Measurement and evaluation in health education and health promotion. Palo Alto: Mayfield.

Green, L.W., \& Lewis, M.W. (1991). Heatth promotion plonning: an educational and environmental opproach. Mountain View: Mayfield.

Greenley, J. R., \& Young, T. B. (1983). Psychological distress and patient satisfaction. Medicol Care, 20, 373.

Grueninger, U. J., Goldstein, M. G., \& Duffy, F. D. (1990). A conceptual framework for interactive patient education in practice and clinic settings. Joumal of Human Hypertension, 4 (Suppl. 1), 2 |- 31 .

Guttman, N., \& Ressler,W. H. (2001). On being responsible: Ethical issues in appeals to personal responsibility in health campaigns. Journal of Health Communication 6 , 1117-136.

Hale, J. L. \& Dillard, J. P. (1995). Fear appeals in health promotion campaigins: Too much, too little, or just right. In E. Maibach \& R. L. Parrott (Eds.), Designing health messages:

Approaches from communication theory and public health practice (Pp. 65-80). Thousand Oaks: Sage.

Hall, J.A. (2003). Some abservations on provider-patient communication research. Patient. Education and Counseling, 50,9-12.

Hall . A., \& Dornan, M. C. (1988a). Meta-analysis of satisfaction with medical care: Description of research domain and analysis of owerall satisfaction levels. Sacial Science and Medicine, 27, 637-644.

Hall, I.A., \& Dornan, M. C. (1988b). What patients like about their medical care and how often they are asked:A meta-analysis of the satisfaction literature. Social Science and Mtedcine, $27,935-939$.

Hardeman, W., Johnston, M., Johnston, D. W., Bonetti, D. Wareham, N. I, \& Kinmonth, A. L. (2002). Application of the theory of planned behawiour in behaviour change interventions: A systematic review. Psychology and Heolth, 17, 123in158.

Harting J., \& Van Assema, P. (In preparation). The stage-matched health counseling model of Hartslag Limburg: A six-step approach.

Harting, J." Van Assema, P., Van Limpt, P, Gorgets, T, Van Ree, J., Ruland, E, Vermeer, F. \& De Vries, N. K. (In preparation-a). Cardiovascular prevention in Hartslag Limburg: Effects of a high-risk approach on behaviorall risk factors in a general practice population.

Harting, J., Van Assema, P., Van Limpt, $P_{n}$ Gorgels, T, Van Ree, J., Rularyd, E., Vermeer, Fin \& De Vries, N.K. (In preparation-b). Cardiovascular prevention in Hartslag Limburg" Effects of health counseling on behavioral risk factors in a cardiology out-patient population.

Harting, J, Van Assema, P., Van der Molen, H.T., Ambergen, T. \& De Vries, N. K. (2004). Quality assessment of health counseling: performance of health advisors in cardiovascular prevention. Patient Education and Counseling, 54, 107-118. 
Harting, I. Van Assema, P. \& De Vries, N. K. (Submitted). Patients' opinions on health counseling in the Hartslag Limburg cardiovascular prevention project: perceived quality, satisfaction, normative concerns, and behavior related outcomes.

Haskell, W. L. (2003). Cardiovascular disease prevention and lifestyle interventions. The fournal of Cardiovosicular Nursing, 18, 245-255.

Haskell, W. L., Alderman, E. L., Fair, J. M., Maron, D. J. Mackey, S. F. Superko, H. R., Williams, P.T., Johnstone, I. M., Champagne, M.A., Krauss, R. M., \& Farquhar, J.W. (1993). Effects of intensive mulliple risk factor reduction on coronary atherosclerosis and clinical cardiac events in men and women with coronary artery disease. The Stanford Coronary Risk Intervention Project (SCRIP). Circulation, 89, 975-990.

Hendriks, A. A. J, Oort, F. J., Vrielink, M. R., \& Smets, E. M.A. (2002). Reliability and validity of the Satisfaction with Hospital Care Questionnaire. Internotional Journal for Quality in Health Care, $14,471-482$.

Hendriks, A. A. J" Vrielink, M. R., Smets, E. M.A.,Van Es, S. Q. \& De Haes, J. C. J. M. (2001). Improving the assessment of (in)patients' satisfaction with hospital care. Medical Care, 39. 270-283.

Holbert, R. L., \& Stephenson, M.T. (2002). Structural equation modeling in the communication sciences, 1995-2000. Human Communication Research, 28, 531-551.

Hooper, L., Summerbell, C. D., Higgins, J. P.T., Thompson, R. L., Capps, N. E., Smith, G. D., Riemersma, R.A. \& Ebrahim, S. (2001). Dietary fat intake and prevention of cardiovascullar disease: systematic review. British Medical Journal, 322, 757-763.

Horrocks, S., Anderson, E., \& Salisbury, C. (2002). Systematic review of whether nurse practitioners working in primary care can provide equivalent care to doctors. British Medical Journal, 324, 819-823.

Horstman, K. (2000). Preventie na. 2000: Tussen wetenschap en het goede leven (Prevention after 2000: Between science and the good life). TSG / Tijdschrift voor Gezondheidswetenschappen, 78, 108-113.

Hughes, J. R., Stead, L. F., \& Lancaster, T. (2004). Antidepressants for smoking cessation (Cochrane Rewiew). In Cochrane Library (Issue 2). Chichester, UK: John Wiley \& Sons. Hulscher, M. E. J. L., Van Drenth, B. B., Van der Wouden, J. C., Van de Lisdonk, E. H.. Mokkink, H.G.A. \& Grol, R.P.T.M. (1998), Implementatie van een preventief programma in de huisartsenpraktijk: Ervaringen van praktilkmedewerkerss (Effective implementation of prevention in general practice: Barriers and benefits experienced by care providers). Hort Butletin, 29,6-11.

Hunter, D. I. \& Fairfield, G. (1997). Managed care: disease management. British Medical Journal, $315,50-53$.

Imperilal Cancer Research Fund OXCHECK Study Group. (1995). Effectiveness of health checks conducted by nurses in primary care: Final results of the OXCHECK study. British Medical Journal, 310, 1099-1104.

Irvin, \. E., Bowers, C. A., Dunn, M. E., \& Wang, M. C. (1999). Efficacy of relapse prevention: A meta-analytic review. Journal of Consulting and Clinical Psychology, 67, 563-570.

Janz, N. K., \& Becker; M. (1984). The health belief model: A decade later. Health Education Quorterly, 11, 1-47.

Jones, E. E., \& Gerard, H. B. (1967). Foundations of social psychology. New York: John Wiley \& Sons. 
Kanfer, F. H., \& Gealick-Buys, L. (1991), Self-management methods. In F. H. Kanfer \&

A. P. Goldstein (Eds.), Helping people change: A textbook of methods (4th ed, pp. 305-360). New York: Pergamon.

Kanfer, F. H., \& Schefft, B. K. (1988). Guiding the process of theropeutic change. Champaign, IIInois: Research Press.

Kemper, H. C. G., Ooijendijk, W.T.M., \& Stiggelbout, M. (2000). Consensus over de Nederlandse norm voor gezond bewegen (Consensus with regard to the Dutch criterion for a healthy physical activity level). Tijdschrift voor Gezondheidswetenschappen, 78, 180-183.

Kenny, D.A., Kashy, D. A., \& Bolger, N. (1998). Data analysis in social psychology. In D. T. Gilbert, S. Fiske, T. \& G. Lindzey (Eds.), The handbook of social psychology (Vol. I, pp. 233-265). Boston: McGraw-Hill.

Ketola, E., Mäkelä, M., \& Klockars, M. (2001). Individualised multifactorial lifestyle intervention trial for high-risk cardiovascular patients in primary care. British Journal of General Proctice. $51.291-294$.

Ketola, E., Sipilä, R. \& Mäkelä, M. (2000). Effectiveness of individual lifestyle interventions in reducing cardiovascular disease and risk factors. Annols of Medicine, 32, 239-251.

Kettunen, T., Poskiparta, M., \& Liimatainen, L. (2000). Communicator styles of hospital patients during nurse-patient counseling. Patient Education and Counseling, 41, 161-180.

Kettunen "T., Poskiparta " M., Liimatainen, L., Sjögren, A., \& Karhila, P. (2001). Taciturn patients in health counseling at a hospital: Passive recipients or active participants? Qualitotive Health Research, 11, 399-422.

Kline, R. B. (1998). Principles and practice of structural equation madeling. New York: The Guilford Press.

KNMG. (2000). Artsen over voorrangszorg en leefstijladiviezen (Physicians on precedence in care and lifestyle advice). Medisch Contact, 55, 11168-1170.

Kok, G., Van den Borne, B., \& Mullen, P. D. (1997). Effectiveness of health education and health promotion: Meta-analyses of effect studies and determinants of effectiveness. Patient Education and Counseling, 30, 19-27.

Koremans, G. M., Derks, H. Tuinstra, A., Diederiks, M., \& Brug, I. (2000). A quick method to assess physical activity. Humanities Working Popers, 5, 3-13.

Kreuter, M.W., \& Strecher, V. J. (199.6). Do tailored behavior change messages enthance the effectiveness of health risk appraisal? Results from a randomized trial. Health Education Research, 11,97.105.

Kromhout, D. (1999). Primordial prevention of cardiovascular disease risk in The Netherlands. Preventive Medicine, 29, 5106-S110.

Krosse, J.A. J. (2001). Het maatschappelijk taboe op de beperking van ongezond gedrag (The social taboo with regard to restricting unhealthy behaviors). TSG / Tijdschrift voor Gezondheidswetenschoppen, 79, 267-268.

Kruijver, I. P. M., Kerkstra, A. Francke, A. L., Bensing, I. M., \& Van de Wiel, H. B. M. (2000). Evalluation of communication training programs in nursing care: $A$ rewiew of the literature. Patient Education and Counseling, 39, 129-145.

Laitakari, J. (1998), On the practical applicability of stage models to health promotion and health education. American Journal of Health Behavior, 22, 28-38. 
Laitakari, I., \& Millunpalo, S. (1998). How can physical activity be changed - Basic concepts and general principles in the promotion of health-related physical activity. Patient Education and Counseling 33. $547-559$.

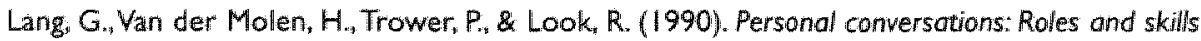
for counsellors. London: Routlledge.

Lasek, R. I. Barkley, W., Harper, D. L., Rosenthal, G. E. (1997). An evaluation of the impact of nonresponse bias on patient satisfaction surveys. Medical Care, 35, 646-652.

Law, M. \& Tang J. L. (1995). An analysis of the effectiveness of interventions intended to help people stop smoking. Archives of Internal Medicine; 155, 1933-1941.

Lear, S. A., Ignaszewski, A., Linden, W., Brozic, A., Kiess, M., Spinelli, J. J., Pritehard, P. H., \&. Frohlich J. I. (2003). The Extensive Lifestyle Management Intervention (ELMI) following cardiac rehabilitation trial. Europeon Heart Journal, 24, 1920-1927.

Like, R., \& Zyzanski, S. J. (I986). Patient requests in family practice:A focal point for clinical negotiations. Fomily Proctice, 3, 216.

Like, R., \& Zyzanski, S. J. (1987). Patient satisfaction with the clinical encounter: social psychological determinants. Social Science and Medicine, 24, 351-357.

Linder-Pelz, S. (1982). Toward a theory of patient satisfaction. Social Science and Medicine, 16, $577-582$.

Lindholm, L. H., Ekbom, T., Dash, C., Isacsson, A., \& Scherstén, B. (1996). Changes in cardiowascular risk factors by combined pharmacological and nompharmacological strategies: The main results of the CELL study. Journal of Internal Medicine, 240, 13-22.

Lindholm, L. H., Ekbom, T., Dash, C., Tibblin, G., \& Schersten, B., On behalf of the CELL Study Group. (1995). The impact of health care advice given in primary care on cardiowascular risk. British Medical Journal, 310, 1105-1109.

Lipsey, M.W. (1990). Design sensitivity: statistical power for experimental research. Newbury Park, California: Sage Publications.

Locke, E. A., Shaw K. N., Saari, L. M., \& Latham, G. P. (|98|). Goal setting and task performance: 1969-1980. Psychological Bulletin, 90, | 25-152.

Lomas, ]. (1998). Social capital and health: implications for public health and epidemiology. Social Science and Medicine, 47,1181-1188.

Mackinnon, D. P., Krull, J. L., \& Lockwood, C. M. (2000). Equivalence of the mediation, confounding and suppression effect. Prevention Science, 1, |73-|8|.

Maibach. E.W., \& Cotton. D. (1995). Moving people to behavior change:A staged social cognitive approach to message design. In E Maibach \& R. L. Parrott (Eds.). Designing heolth messages: Approoches from communication theory and public health practice (pp. 41-64). Thousand Oaks: Sage.

Marlatt, G.A., \& Gordon, J.R. (1985). Relapse prevention: Maintenance Strategies in the treatment of addictive behawiors. New York: Guilford Press.

Martin, M.W. (2001). Responsibility for health and blaming victims. Journal of Medical Humanities, $22,95-114$.

McAlister, F.A., Lawson, F. M. E., Teo, K. K., \& Armstrong, P.A. (2001). Randomised trials of secondary prevention programmes in coronary heart disease: systematic review. British Medical Journol, 323, 957-962.

McGuire, W. J. (1985). Attitudes and attitude change. In G. Lindzey \& E. Aronson (Eds.), Handbook of social psychology (3rd ed., pp. 258-294). New York: Random House. 
Mead, N., \& Bower, P. (2000). Patient-centredness: A conceptual framework and review of the empirical literature. Sociol Science and Medicine, 51, $1087-11110$.

Mead, N.. \& Bower, P. (2002). Patient-centred consultations and outcomes in primary care: a review of the literature. Potient Educotion and Counseling 48,51-61.

Meichenbaum, D. \& Turk, D. C. (1987). Facilitating treatment adherence:A practitioner's guidebook. New York: Plenum Press.

Michie, S., Miles, J., \& Weinman, J. (2003). Patient-centredness in chronic illness: What is it and does it matter? Patient Education and Counseling, 51, 197-206.

Miller, N. H., Hill, M., Kotcke, T., \& Ockene, I. S. (1997). The multilevel compliance challenge: Recommendations for a call to action: a statement for healthcare professionals. Circulation, 95, $1085-1090$.

Miller,W. R., \& Rollnick, S. (Eds.). (1991). Motivational interviewing: Preparing people to change addictive behowior. New York: Guilford Press.

Minkler, M. (1999). Personal responsibility for health? A review of the arguments and the evidence at century"s end. Health Education and Behovior, 26, $121-140$.

Mullen, P. D., Mains, D.A., \& Velez, R. (1992). A meta-analysis of controlled trials of cardiac patient education. Patient Education and Courseling, 19, 143-162.

Mullen, P. D., Simons-Morton, D. G., Ramirez, G., Frankowski, R. F, Green. L. W., \& Mains, D. A. (1997). A meta-analysis of trials evaluating patient education and counseling for three groups of preventive behaviors. Patient Education and Counseling, 32, 157-173.

Murchie, P., Campbell, N. C., Ritchie, L. D., Simpson, J. A., \& Thain, J. (2003). Secondary prevention clinics for coronary heart disease: four year follow up of a randomised controlled trial in primary care. British Medical Journol, 326, 84-89.

NHS Centre for Reviews and Dissemination University of York. (1998). Cardiac rehabilitation. Effective Health Care, $4,1-12$.

Nichals, D. (11997, 04 Aug 1997). SPSS Macro "mkappasc.sps / mkappasc.txt". Retrieved April 15th, 2003, from ftp://ftp.spss.com/pub/spss/statistics/nichols/macros/

Oldenburg, B., Hardcastle, D. M. \& Kok, G. (1997). Diffusion of innovations. In K. Glanz, F.M. Lewis \& B. K. Rimer (Eds.) "Health behowior and health education:Theory, research, and practice (2nd ed. Pp. 270-286). San Francisco: Jossey-Bass.

Oldenburg, B. F. Sallis, J. F., French, M. L., \& Owen, N. (1999). Health promotion research and the diffusion and institutionalization of interwentions. Heolth Education Reseorch, $14,121-130$.

Ong, L. M. L., De Haes, J. C. J. M., Hoos, A. M., \& Lammes, F. B. (1995). Doctor-patient communication: A review of the literature. Social Science and Medicine, 40, 903-918.

Ong. L. M. L., Visser, M. R. M., Lammes, F. B. \& De Haes, J. C. J. M. (2000). Doctor-patient communication and cancer patients' quality of life and satisfaction. Potient Education and Counseling, 41, 145-156.

Orbell, S., \& Sheeran, P. (2002). Changing health behaviours: The role of implementation intentions. In D. Rutter \& L. Quine (Eds.) Changing health behaviour: Intervention and reseorch with social cognition models (pp. 123-137). Buckingham: Open University Press.

Orlandi, M.A., Landers, C., Weston, R., \& Haley, N. (1990). Diffusion of thealth promotion innowations. In K. Glanz, M. F. Lewis \& B. K. Rimer (Eds.), Health behawior and heolth education: Theory, reseorch and practice (I rst ed., pp. 288-3 |3). San Francisco:Jossey-Bass. 
Parcel, G. S., Perry, C. L., \& Taylor, W. C. (1990). Beyond demonstration: Diffusion of health promotion innovations. In N. Bracht (Ed.), Heath promotion ot the community lewel (pp. 229 . 251) Newbury Park: Sage.

Parker, D., Manstead, A. S. R., \& Stradling, S. G. (1995). Extending the theory of planned behavlour" The role of personal norm. British journol of Social Psychology, 34.127-137.

Parrott, R. L. (1995). Motivation to attend to health messages. In E. Maibach \& R. L. Parrott (Eds.), Dessigning health messages: Approaches from communication theory and public health practice (Pp. 7.23). Thousand Oaks: Sage.

Pascoe, G.C. (1983). Patient satisfaction in primary health care: A literature review and analysis. Evaluation and Program Planning, 6, 185-210.

Peeperkorn, M. (2004, March 19th). Kamer: zorg afrekenen op prestaties (Chamber: judge. care on results). De Volkskront.

Perneger, T.' V., Kossovsky, M. P., Cathieni, F., Di Florio, V., \& Burnand, B. (2003). A randomized trial of four patient satisfaction questionnaires. Medical Care, 41, 1343-1352.

Petty, R. E., \& Cacioppo, I.T. (1986). Communication and persuasion: Central and peripheral routes to attitude change. New York: Springer.

Pieterse, M. E., Seydel, E. R., De Vries, H., Mudde, A. N., \& Kok, G. J. (200 h). Effectiveness of a minimal contact smoking cessation program for Dutch general practitioners: A randomized contralled trial. Preventive Medicine, $32,182-190$.

Pill, R., French, J., Harding, K., \& Stott, N. (1988). Invitation to attend a health check in a general practice setting: comparison of attenders and non-attenders. Journal of the Royal College of General Proctitioners, 38, 53-56.

Pill, R., \& Stott, N. (1988). Invitation to attend a health check in a generall practice setting: the views of a cohort of non-attenders. Journal of the Rayal College of General Practitioners, 38 , 57-60.

Polit, D. F." \& Hungler, B. P. (1995). Nursing Research. Principles and Methods (4ch ed.). Philadelphia: J.B. Lippincott Company.

Pope, V.T., \& Kline, W. B. (1999). The personal characteristics of effective counselors: What 10 experts think. Psychological Reports ${ }_{n} 84,1339-1344$.

Prochaska. J. O., DiClemente, C. C. (1984). The transthearetical appraach. Crassing traditional boundaries of theropy. Homewood, Illinois: Bow Jones/lrwin Homewood.

Prochaska, J. O., \& Velicer, W. F. (1997). The Transtheoretical Model of health behavior change. American journal of Health Promotion, 12, 38-48.

Pyörälä, K.. De Backer" G., Graham, I., Poole-Wilson, P., \& Wood, D. (1994). Prevention of col"onary heart disease in clinical practice. European Heart journal, 15,1300-1331.

Ram, P., Grol, R., Rethans, J. J, Schouten, B., Van der Vleuten, C., \& Kester, A. (1999). Assessment of general practitioners by video observation of communicative and medical performance in daily practice: Issues of validity relliability and feasibility. Medical Education, 33 , 447.45 .4

Rigotti, N. A., Munafo, M. R., Murphy, M. F. G., \& Stead, L. F. (2004). Interventions for smoking cessation in hospitalized patients (Cochrane Review). In The Cochrone Librory (Issue 1). Chichester: John Wiley \& Sons.

Rimer, B. K., Glanz, K., \& Rasband, G. (2001). Searching for evidence about health education and health behavior interventions. Heolth educotion and behavior, 28, $23 \|-248$. 
RIVM. (2002). Notionool Kompas Volksgezondheid (National Compass Public Heath). Retrieved April 15th, 2004, from http:/www.rivm.n//wrv/data/site_kompas/index.htm

RIVM. (2003). Heoth on course? The 2002 Dutch public heatth stotus and forecost report (No. 270551002). Bilthoven: National Institute for Public Health and the Environment (RIVM).

Roe, L., Hunt, P., Bradshaw, H., \& Rayner, M. (1997). Health promotion interventions to promote healthy eating in the general population - a rewiew. London: Health Education Authority.

Rogers, C. R. (1973). Client-centered therapy. Its current practice, implications and theory. London: Constable.

Rogers, E. M. (1983). Diffusion of innavations (3rd ed.). New York: Free Press.

Rogers, E. M. (1995). Diffusion of innowations (4th ed). New York: Free Presis.

Rogers, R. W., \& Prentice-Dunn, S. (1997). Protection Motivation Theory. In D. S. Gochman

(Ed.), Handboak of Health Behawior Research 1: Personal and social deteminants (pp. 113-132). New York: Plenum Press.

Ronda, G. (2003). The Dutch heart health community intervention "Hartslag Limburg". An evaluation. Maastricht University, Maastricht.

Ronda, G. Van Assema, P., \& Brug, J. (2001). Stages of change, psychological factors and awareness of physical activity levels in the Netherlands. Heath Promotion International, 16, 305-314.

Ronda, G., Van Assema. P., Candel, M., Ruland, E., Steenbakkers, M., Van Ree, J., \& Brug, J.

(2004). The Dutch heart health community intervention "Hartslag Limburg": Results of an effect study at individual level. Health Promotion International, 19,21-31.

Rose, G. (1992). Strategies of prevention: the individual and the population. In M. G. Marmot

\& P. Elliott (Eds.), Coronary heart disease epidemialogy: from aetiology to public health. Oxford: Oxford University Press.

Roter, D. (1989). Which facets of communication have strong effects on outcome: A meta-

analysis. In M. Stewart \& D. Roter (Eds.), Communicoting with medical patients (Pp. 183-196). Newbury Park: Sage.

Roter, D. L., \& Hall, 」. A. (1997). Patient-provider communication. In K. Glanz, F. M. Lewis \& B.

K. Rimer (Eds.), Health behavior and health education:Theary, research, and practice (2nd ed., pp. 206-226). San Francisco: Jossey-Bass.

Roth . D.. \& Crane-Ross. D. (2002). Impact of services, met needs, and service empowerment on consumer outcomes. Mental Health Services Research, 4.43-56.

Ruland, E., Harting, J., Van Limpt, P., Ronda, G., Van Assema, P., Van Ree, J., Gorgelts, T., Vermeer, F., \& Ament, A. (1999). "Hartslag Limburg": A united approach in preventive care. Communitybased prevention integrated with a high risk group opproach in general practices and in the haspital. A case summary in the framework of WHO's "Towards Unity for Heath" project Maastricht: Regional Public Health Institute Maastricht GGD-zzl.

Ruland, E., Van Raak, A., Spreeuwenberg, C., \& Van Ree, J. (Submitted). How to establish sustainable partnerships? Introducing the WIZSIC-model for sustained inter-organizational collaboration in new public health.

Russell, M. L. (1986). Behavioral counseling in medicine. Oxford: Oxford University press.

Schnabel, P. (2004, 24 maart 2004). Betere kansen voor goed werk. Paper presented at the New Health Promotion, Rotterdam.

Schwartz, 5. H., \& Howard, J.A. (1980). Explanations of the moderating effect of responsibility denial on the personal norm-behavior relationship. Social Psychology Quarterly, 43.441-446. 
Scott, T. B., Fuqua, D. R.s \& Newman, ]. L. (1986). Further evidence for unidimensionality of measures of counseling performance. Psychological Reparts, 58, 983-990.

Shaw, C., Abrams, K., \& Marteau, T. M. (1999). Psychological impact of predicting individuals' risks of illness: a systematic review. Sociol Science and Medicine, 49, 1571-1598.

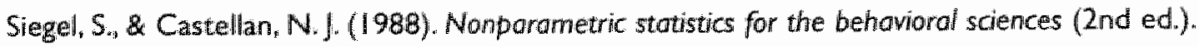
New York: McGraw-Hill.

Silagy, C., Lancaster, T., Stead, L., Mant, D. \& Fowler, G. (2004). Nicotine replacement therapy for smoking cessation (Cochrane Rewiew). In The Cochrone Librory (lssue 2). Chichester, UK: John Wiley \& Sons.

Silverman, J., Kurtz, S., \& Draper, J. (1998). Skitls for communicoting with patients. Abingdon: Radcliffe Medical Press.

Simons-Morton, D. G., Calfas, K. J. Oldenburg, B., \& Burton, N. W. (1998). Effects of interventions in heatth care settings on physical activity or cardiorespiratory fitness. Americon Journal of Preventive Medicine, 15,413-430.

Sinclair, R. R., Fleming, W. D., Radwinsky, R., Clupper, D. R., \& Clupper, J. H. (2002). Understanding patients" reactions to services: The role of personal service values in heart patient satisfaction and wellness. Journal of Applied Social Psychology, 32, 424-442.

Sitzia, \. (1999). How valid and reliable are patient satisfaction data? An analysis of 195 studies. International Journal for Quality in Heath Care, 11,319-328.

Sitzia J., \& Wood, N. (1997). Patient satisfaction: a review of issues and concepts. Sacial Science and Medicine, 45. 1829-1843.

Smit, G. N., \& Van der Mollen, H.T. (1996). Three methods for the assessment of communication skills. British Journal of Educational Psychology; 66, 543-555.

Steckler, A., Goodman, R. M., MeLeroy, K. R., Dawis, S., \& Koch, G. (1992). Measuring the diffusion of innovative health promotion programs. American Journal of Health Promotion, 6 , 214-224.

Steptoe, A., Doherty, S., Rink, E., Kerry, S., Kendrick, T., \& Hilton, S. (1999). Behavioural counselling in general practice for the promotion of healthy behaviour among adults at increased risk of coronary heart disease: randomised trial. British Medical Journad, 319, 943-948.

Stewart, M. (1995a). Effective physician-patient communication and health outcomes. Conodion Medical Association Journal, 152, 1423-1433.

Stewart, M. (1995b). Studies of health outcomes and patient-centered communication. In M. Stewart J. B. Brown, W.W.Weston, I. R. MeWhinney, C. L. McWilliam \& T. R. Freeman (Eds.), Patient-centered medicine. Tronsforming the clinical method (pp. 185-190). Thousand Oaks: Sage.

Stiles ,W. B. (1989). Evaluating medical interview process components. Null correlations with outcomes may be misleading. Medical Care, 27, 212-220.

Strasser, S., Aharony, L., \& Greenberger, D. (1993). The patient satisfaction process: moving toward a comprehensive model. Medicol Care Review, 50, 219-248.

Strecher, V. J., \& Kreuter, M.W. (1995). The psychosocial and behavioral impact of health risk appraisals. In R.T. Croyle (Ed.), Psychosacial effects of screening for disease prevention and detection (pp. 126-143). New York: Oxford University Press. 
Strecher, V. J., Seijts, G. H. Kok, G. J." Latham, G. P. Glasgow, R., DeVellis, B. Meertens, R. M., \& Bulger, D.W. (1995). Goal setting as a strategy for health behavior change. Hedth Educotion Quorterly, 22, 190-200.

Streiner, D. L., \& Norman, G. R. (1995). Health measurement scales. A practical guide to their development and use (2nd ed.). Oxford: Oxford University Press.

Tabachnick, B. G., \& Fidell, L. S. (2001). Using multivariate statistics (4th ed.). Boston: Allyn and Bacon.

Tang, J. L., Armitage, J. M., Lancaster, T., Sillagy, C. A.y Fowler, G. H., \& Neil, H. A.W. (1998). Systematic review of dietary intervention trials to lower blood total cholesterol in free-living subjects. British Medical journal, 316, 12/3-1220.

Tappin, D. M.. Lumsden, M.A., Mclntyre, D., Mckay, C., Gilmour, W. H., Webber, R., Cowan, S., Crawford, F. \& Currie F. (2000). A pilot study to establish a randomized trial methodology to test the efficacy of a behavioural intervention. Health Educotion Research, 15(4), 491.502.

Van Assema, P, Brug, J., Ronda, G. \& Steenhuis, 1. (2001), The relative validity of a short Dutch questionnaire as a means to categorise adults and adolescents to total and saturated fat intake. Journal of Human Nutrition and Dietetics, 14, 377-390.

Van Berkel, T. F. M., Boersma, H., De Baquer, D., Deckers, J.W., \& Wood, D. (1999). Registration and management of smoking behaviour in patients with coronary heart disease. The EUROASPIRE survey. European Heart Journal, 20, 1630-1637.

Van den Brink-Muinen, Aw, Verhaak, P. F. M., Bensing, J. M., Bahrs, O., Deveugele, M., Gask, L., Leiva, F., Mead, N., Messerli, V., Oppizzi, L., Peltenburg, M., \& Perez, A. (2000). Doctorpatient communication in different European health care systems: Relevance and performance from the patients' perspective. Fatient Education and Counseling, 39, 115-127.

Van der Burgt, M., \& Verhulst, F. (1996). Doen en blijven doen: Patiëntenwoorlichting in de paromedische praktijk (Implement and maintaim: Patient education in the paramedical practice). Houten: Bohn Stafleu Van Loghum.

Van Drenth, B. B., Hulscher, M. E. J. L., Van der Wouden, J. C., Mokkink, H. G. A., Van Weel, C., \& Grol, R.P.T.M. (1998). Relationship between practice organization and cardiovascular risk factor recording in general practice. Britisch journal of General Practice, 48 $1054-1058$.

Van Drenth, B. B., Hulscher, M. E. J. L., Van der Wouden, J. C., Van Weel, C., \& Grol, R. P.T. M. (1998). Practice guidelines for cardiovascular disease prevention in general practice In B. B. Van Drenth (Ed.), Organizing cordiovasculor preventive care in general practice (pp. 25-38). Amersfoort: Mediselect.

Van Elderen-van Kemenade, T., Maes, 5., \& Van den Broek, Y, (1994). Effects of a heaith education programme with telephone follow-up during cardiac rehabilitation. British Journol of Clinical Psychology, 33, 367-378.

Vordingsraad. (1991). Nader advies inzake de richtlijm m.b.t de vetconsumptie uit het odvies Richtlijnen goede woeding 1986 (Further advise regarding the recommendations with regard to the fot consumption in the advisory Guidelines on healthy nutrition 1986). Den Haag:Voedingsraad.

Wakefield, J. (1985). Direct observation. In V. R. Neufeld \& G. R. Norman (Eds.), Assessing clinical competence (Vol. 7. PP. 51-70). New York: Springer Publishing Company.

Ware, J. E., Snyder, M. K., Wright, W. R., \& Davies, A. R. (1983). Defining and measuring patient satisfaction with medical care. Evaluation and Program Planning, 6, 247-263.

Weiner, B. (1985). An attributional theory of achievement motivation and emotion. Psychological Review, 92, 548-573. 
Weingarten, M. A, Yaphe, J., Bumenthal, D. Oren, M., Margalit, A. (2001). A comparison of videotape and audiotape assessment of patient-centredness in familly physicians" consultations. Patient Education and Counseling 45, $107-\| 10$.

Weinstein, N. D. (1988). The precaution adoption process. Health Psychology, 7, 355-386.

Weinstein, N. D. Rothman, A. I. Sutton, S. R. (1998). Stage theories of health behavior: Conceptual and methodological issures. Health Psychology, 17,290-299.

WHO. (2003). Diet, nutrition and the prevention of chronic disease. Retrieved Apri\$ 15 th, 2004, from http:/www.who.int/hpr/NPH/docs/who fao_expert_report.pdf

Wiles, R. (1998). Patients' perceptions of their heart attack and recovery: the influence of epidemiological "evidence" and personal experience. Sacial Science and Medicine, 46, 1477-1486.

Williams, B., Coyle, J., \& Healy, D. (1998). The meaning of patient satisfaction: an explanation of thigh reported levels. Social Science and Medicine, 47, 1351-1359.

Williams, S. Weinman, J.\& \& Dale, J. (1998). Doctor-patient communication and patient satisfactioni: a review. Fomily Proctice, 15, 480-492.

Windsor, R. A., Baranowski, T. Clark, N., \& Cutter, G. (1994). Evaluation of health promotion health education and disease prevention programs (2nd ed.). Mountain View: Mayfield.

Witte, K. \& Allan, M. (2000). A meta-analysis of fear appeals: implications for effective public health campaigns. Health Education and Behavior, 27, 591-615.

Wood, D., De Backer, G., Faergeman, O." Graham, L., Mancia, G., \& Pyörälä, K., Together with members of the Task Force. (1998). Prevention of coronary heart disease in clinical practice. Summary of recommendations of the Second Joint Task Force of European and other Societies on Coronary Prevention. Journal of Hypertension, 16, 1407-1414.

Wood, D. A. Kinmonth, A. L." Davies, G.A., Yarwood, J., Thompson, S. G. Pyke, S. D. M., Kok, Y." Cramb, R., LeGuen, C., Marteau, T. M., \& Durrington, P. N. (1994). Randomised controlled trial evaluating cardiovascular screening and intervention in general practice: principal results of British family heart study. British Medical Journal, 308, 3॥3-320.

Wocllard, J., Burke, V., Beilin, L. J., Verheijden, M., \& Bulsara, M. K. (2003). Effects of a general practice-based intervention on diet, body mass index and blood lipids in patients at cardiovascular risk. Journal of Cardiovoscular Risk, 10, 1031 -1040.

Zastowny, T. R., Stratmann. W. C., Adams, E. H. \& Fox, M. L. (1995). Patient satisfaction and experience with health services and quality of care. Quality Mariggement in Health Core, 3. 50-61. 


\section{SUMMARY}

This thesis reports on the effect and process evaluations of the individual highrisk approach within the Hartslag Limburg cardiovascular prevention project. The main aim of the effect study, a randomized controlled trial, was to evaluate the effectiveness of the high-risk intervention in terms of three behavional risk factors: high fat consumption, smoking, and physical inactivity. The study took place in two research settings: the cardiology outpatient clinic of the University Hospital Maastricht and several general practices in the region. From these settings, around 2,750 patients with an elevared cardiovascular risk were included in the study. The process evaluation monitored whether the intervention as a whole was implemented as intended. With regard to one of the intervention components, individual lifestyle advice by a health advisor, the process evaluation also examined the applicability of the specially developed stage-matched counseling model, the quality of the counseling, the opinions of the patients, and the experiences of the health care providers involved. In addition, the process evaluation monitored the post-trial implementation of the health counseling component.

The Introduction (Chapter 1) provides the epidemiological rationale for starting the Hartslag Limburg project and briefly describes its two sub-projects: the community project and the high-risk project. The high-risk intervention was aimed at individuals with an elevated risk of developing cardiovascular disease (CVD). The method used in this intervention was three-fold: drawing up a complete cardiovascular risk profile for each patient, reviewing and optimizing the treatment of biomedical risk factors, and counseling on behavioral risk factors. This multiple-factor and multiple-component intervention strategy was assumed to be the most effective in reducing cardiovascular risk. The introduction also explains why Hartslag Limburg introduced the "health advisor" as a lifestyle counselor in the Dutch health care systen.

Chapter 2 presents the stage-matched health counseling model that was developed for the intervention. It was based on a combination of stage theories and motivational theories of behavior change. Methods of facilitating stage transition for behavior change were described for each of the six motivational stages of the model. Such a stage-matched approach is assumed to result in more tailored health communication, more targeted strategies for change, and thus more effective health counseling interventions. The health advisors regarded the basic framework of the model as a good guide for health counseling, but found it difficult to combine the general principles with both the specific counseling skills and the theory-based behavior change strategies. It was concluded that counseling in accordance with the model was rather difficult.

Chapter 3 reports on the quality assessment of the lifestyle advice by experts on health counseling and health behavior change. Sixty-four video-recorded health counseling sessions were independently evaluated by three experts with the help of an observation list. The overall quality of the counseling was assessed as not entirely sufficient. The interpretation of the experts' judgments 
was, however, complicated by the limited absolute interobserver agreement. Nevertheless, the relative agreement was sufficient to allow reliable comparisons between the various skills and the different health advisors. It was concluded. that the quality of the counseling had been promising, but that counseling on a healthy lifestyle is a difficult job that requires high levels of professional skills. In addition, the quality assessment method was found to be a useful tool for optimizing the intervention.

Chapter 4 describes the patients ${ }^{3}$ opinions about the new health counseling service. A questionnaire was developed to measure perceived quality, satisfaction, normative concerns, and, preliminary, behavior related outcomes. Patients generally reported rather high levels of quality and satisfaction, and considered the service a welcome addition to the existing health care facilities. Their reports also indicated that the lifestyle advice generated changes in health behavior related outcomes. It was concluded that the service was highly acceptable to patients, but that the health advisors should be careful not to induce less favorable normative concerns, such as experiencing life restraints and guilt.

Chapter 5 presents an exploratory path model analysis, using the cross-sectional data from chapter 4 to build a provisional causal framework. Quality aspects were included as independent variables, satisfaction and normative concerns as mediating variables, and changes in determinants and intention as outcome variables. The exploratory path analysis resulted in a model with an acceptable fit, from which several useful hypotheses could be derived. The first is that perceived quality seems highly important for the effectiveness of health counseling. Health advisors can improve the effects of their counseling efforts particularly if they succeed in making a professional impression and in optimizing their insight giving skills. Secondly, patient satisfaction seems indeed to be a vital mediator between counseling quality and counseling effects. Thirdly, high levels of information exchange, a respectfull attitude, and agreeing on actions that patients can easily perform may prevent the occurrence of undesirable sideeffects, such as life restraints or guilt. This is especially worthwhile since these troubling feelings do not seem to contribute to the desired health behavior related effects.

Chapter 6 and Chapter 7 describe the implementation of the intervention and present the behaviotal effects for the two respective research settings. At the cardiology outpatient clinic, the health counseling component of the intervention was the only one that could be implemented as planned. The individual lifestyle advice yielded short-term effects on fat consumption (substantial), smoking (small), and physical activity (marginal), which may contribute to the secondary prevention of CVD. Positive effects were also found on the intention to make healthy lifestyle changes, No long-term effects were found. Both the magnitude and the duration of the intervention effects may be further increased by additionally involving the cardiologists and by a more intense utilization of existing prevention facilities, such as cardiac rehabilitation programs and health behavior promoting services in the community. At the general practices, the health counseling component was also implemented as intended, while the 
other two intervention components were only partly implemented. The highrisk approach caused favorable short-term and long-term effects on fat consumption, but hardly any changes with regard to smoking, physical activity, and the intention to make heaithy lifestyle changes. Instead of further implementing the present multi-factorial health counseling intervention, it is proposed that smokers should be regularly approached by the general practitioner with the help of a minimal intervention strategy, and that nutrition and physical activity should be simultaneously addressed in a more intense and more comprehensive program that combines several prevention strategies.

Chapter 8 describes the post-trial episode, using Rogers' diffusion of innovations theory. Based on the positive process evaluation, funding was obtained to explore the opportunities for a further implementation of the health counseling component for another three years. Information was collected from minutes of meetings, informal conversations with the health advisors and the Hartslag project manager, and from short questionnaires for the cardiologists and general practitioners. The implementation efforts were found to be successful at the cardiology outpatient clinic, but unsuccessful at the general practices. The implementation of an innovative service may be facilitated by awoiding any posttrial interruption and by allocating the responsibility to one single "change agent". In addition, an innovative health care service that is perceived as not very complex and as compatible with current practice routines may be relatively easy to implement. The same holds for innovations that can be "re-invented" without much difficulty. The implementation process may be further supported by changes in the organization of care that create opportunities for, instead of competition with, an innovative health care service.

The Discussion (Chapter 9) summarizes the main results of the study as a whole. Next, it suggests that in cardiovascular prevention more attention may have to be paid to the aspects of risk perception and the way patients make use of this perception in deciding to adopt or to refrain from a healthier lifestyle. A similar suggestion is made for the resistance against behavioral changes that a considerable proportion of the high-risk patients seem to experience. The chapter then presents some methodological considerations about the study as a whole. Despite the limitations of the individual study parts, it concludes that the present combination of effect and process studies can be regarded as a satisfactory example of a theory-driven evaluation that was able to sensibly integrate multiple methodologies. Finally, some societal implications of the present findings are discussed. The intense, comprehensive and long-lasting cardiovascular prevention approaches that we recommended, require more funding than is at present available. In addition, they may be difficult to implement, and should include a normative perspective in their development, implementation, and evaluation, to ensure that they meet the patients' needs and are acceptable to them. Finally, to get such comprehensive cardiovascular prevention programs going, a more intensive collaboration between the various health care echelons seems a prerequisite. 



\section{SAMENVATTING}

Dit proefschrift beschrijft de ontwikkeling, de invoering en de evaluatie van de introductie van een nieuwe functionaris in de Nederlandse gezondheidszorg: een gezondheidsadviseur. Deze voerde individucle adviesgesprekken over een gezonde leefwijze. Het doel hiervan was mensen te motiveren tot gezond gedrag, om daarmee het, veelal verhoogde, risico van hart- en vaatziekten te verminderen en zodoende de individuele gezondheid te bevorderen en de kwaliteit van leven te verhogen.

De introductie (boofdstuk 1) laat zien dat hart-en vatziekten in Nederland veel voorkomen en zelfs de belangrijkste doodsoorzaak zijn. De provincie Limburg steekt wat dit betreft nog eens ongunstig af bij de rest van Nederland. Hart- en vaatziekten zelf en de factoren die bijdragen aan het ontstaan daarvan, komen in Limburg relatief veel voor. Dit was in 1998 aanleiding voor de start van Hartslag Limburg, een groot, regionaal project ter preventie van hart- en vaatziekten. Dit project speelde zich (en speelt zich nog steeds) af in Maastricht en vier omliggende gemeenten: Meerssen, Margraten, Valkenburg en Eijsden.

Hartslag Limburg bestond uit twee deelprojecten: het communityproject en het hoogrisicoproject. Het communityproject beoogde in de deelnemende gemeenten allerlei gezonde initiatieven tot stand te brengen, alle bewoners te stimuleren om daarvan gebruik te maken en het gezonde aanbod te handhaven door aan te sturen op een gezond gemeentebeleid. Dit communitydeel van Hartslag Limburg is elders uitgebreid beschreven. Het hoogrisicoproject richtte zich op personen met een verhoogd risico van een hart- of vaatziekte of met een al bestaande hartvaatziekte. Zij werden opgespoord via de poli cardiologie van het Academisch Ziekenhuis Maastricht (azM) en wia een aantal huisartsenpraktijken in de regio. In totaal werden circa 2750 hoogrisicopatiënten in het project betrokken. Van hen ontving de ene helft de gebruikelijke zorg, de andere helft kreeg speciale zorg, gericht op het verminderen van het risico van een (hernieuwde) hartaandoening. Dit hoogrisicodeel van Hartslag Limburg staat in dit proefschrift centraal.

De beste aanpak voor hoogrisicopatienten is dricledig. Het eerste onderded bestaat uit het in kaart brengen van alle factoren die bijdragen aan het risico van hart- en vaatziekten, of wel het opstellen van een compleet risicoprofiel. Daarbij gaat het enerzijds om biomedische factoren, zoals een hoge bloeddruk, een hoog cholesterolgehalte of suikerziekte, en anderzijds on gedragsmatige risicofactoren, zoals te veel vet eten, roken en te weinig lichaamsbeweging. Het tweede onderdeel vormt het evalueren van de behandeling van biomedische factoren, en het zonodig optimaliseren daarvan door bijstelling van de voorgeschreven geneesmiddelen. Het derde onderdeel is het voeren van adviesgesprekken over een gezonde leefwijze. Omdat in Nederland én de registratic van risicofactoren én de behandeling daarvan én de advisering over gezond gedrag te wensen over lieten, richte het hoogrisicoproject van Hartslag Limburg zich op het verbeteren van alle drie de componenten. Bovendien werd beoogd om meerdere risicofactoren tegelijk te beínvloeden omdat daarvan de grootste individucle gezondheidswinst te verwachten viel. 
Voor de adviesgesprekken over een gezonde leefwijze koos Hartslag Limburg voor de inzer van een 'gezondheidsadviseur', een nieuwe functionaris in de Nederlandse gezondheidszorg. De belangrijkste redenen hiervoor waren dat Nederlandse artsen in het algemeen weinig leefstiladviezen geven, er onvoldoende vardigheden en te weinig tijd voor hebben, en twijfelen aan de effectiviteit ervan. Bovendien paste de keuze voor een gezondheidsadviseur bij de trend in de Nederlandse gezondheidszorg om taken die niet strikt medisch zijn over te dragen an andere gezondheidswerkers. De gezondheidsadviseurs in Hartslag Limburg kregen de gelegenheid om met elke patiënt cen eerste, inventariserend gesprek van drie kwartier te voeren. Daarna konden nog vijf gesprekken volgen, elk van maximaal een half uur. De totale lengte van een adviestraject werd bepaald in samenspraak mer de patiënt.

Hartslag Limburg werd geflankeerd door meerdere wetenschappelijke onder. zoeken. Het huidige proefschrift doet verslag van de evaluatie van de effecten van het hoogrisicoproject op het niveau van gedrag. De hoofdvraag daarbij was: zijn mensen als gevolg van de drieledige hoogrisico-aanpak inderdaad minder vet gaan eten, gestopt met roken en meer gaan bewegen? Daarnaast rapporteert dit proefschrift over de gelijktijdig uitgevoerde procesevaluatie. Die bracht in kaart hoe getrouw de hoogrisico-aanpak in praktijk werd gebracht. Van een van de drie componenten, te weten de adviesgesprekken over een gezonde leefwijze, onderzocht de procesevaluatie bovendien de bruikbaarheid van het toegepaste gespreksmodel, de geleverde gesprekskwaliteit, de opinies van de patiënten en de ervaringen van de betrokken hulpverleners. Daarnaast volgde de procesevaluatie de woortzetting van de inzet van gezondheidsadviseurs in de zorg nadat de oorspronkelijke onderzoeksperiode was afgesloten.

Hoofdstuk 2 beschrijft het gespreksmodel dat speciaal voor de adviesgesprekken in het hoogrisicoproject van Hartslag Limburg was ontwikkeld en de ervaringen die de gezondheidsadviseurs daarmee opdeden. Het algemene uitgangspunt voor de gesprekswoering was het creëren van een goede samenwerkingsrelatic met de patiënt, waarin voldoende plaats was voor een patiëntgerichte benadering en een gezamenlijke besluitvorming. Op die manier werd rekening gehouden met het perspectief van de patiënt. Dat zou bijdragen aan beter afgestemde leefstijladviezen, sterker gemotiveerde patiënten, en een grotere mate van gedragsverandering. Het model beschreef verder een aantal algemene en specifiekc gespreksvaardigheden, alsmede de belangrijkste elementen van de opening en de afshiting van elk adviesgesprek.

De kern van het gespreksmodel was gebaseerd op theorieën die voorspellen dat mensen hun gedrag stapsgewijs veranderen, waarbij ze achtereenvolgens een aantal stadia doorlopen. In het gespreksmodel heetten deze stappen openstaan, begrijpen, willen, kumnen, doen en blijven doen. Elk van deze stappen kent eigen factoren die een gedragsverandering kunnen belemmeren. Om die beletsels weg te nemen, bieden cognitieve en motivationele theorieën van gedrag per stap weer bruikbare veranderingsmethoden. Het gespreksmodel vroeg de gezondheidsadviseurs om een patiënt in een van de zes stappen in te delen en hielp hen vervolgens om een voor die stap geschikte veranderingsstrategie te kie- 
zen. Op die manier bevorderde een gezondheidsadviseur her proces van stapsgewijze gedragsverandering, hetgeen uiteindelijk zou leiden tot een gezondere leefwijze.

Ter ondersteuning van hun boodschap konden de gezondheidsadviseurs bovendien foldermateriaali uitreiken en een telefonisch vervolggesprek regelen. Verder werden ze gestimuleerd om patienten te verwijzen naar gezondheidsbevorderende activiteiten of voorzieningen bij hen in de buurt. Ten slotte werden de gezondheidsadviseurs geacht regelmatig te overleggen met en te rapporteren aan de behandelend huisarts of cardioloog. Hiermee werd een wederzijdse bekrachtiging van ieders inspanning beoogd, om zo het risico van een hartvaatziekte maximaal te verminderen.

De gezondheidsadviseurs vonden het gespreksmodel een goede leidraad voor het voeren van de adviesgesprekken, maar hadden moeite met het tegelijkertijd in praktijk brengen van én de algemene uitgangspunten én de specifieke gespreksvaardigheden én de diverse theoriegestuurde veranderingsstrategieèn. Bovendien waren ze in eerste instantie geneigd om te focussen op veranderingen in gedrag in plaats van op de kleinere tussenstappen op de weg daar naartoe. Daarnaast vonden de gezondheidsadviseurs de stapsgewijze voorstelling van gedragsverandering een te sterke vereenvoudiging van de realiteit. De werkelijkheid is volgens hen weel complexer.

Hoofdstuk 3 bevat de beoordeling van de kwaliteit van de adviesgesprekken door experts op het gebied van gesprekswoering en gedragsverandering. Voor dit deelonderzoek nam elke gezondheidsadviseur over een periode van anderhalf jaar zestien gesprekken op video op. Elk gesprek werd beoordeeld door drie onafhankelijke beoordelaars aan de hand van een observatielijst. Over het geheel genomen vonden de experts de kwaliteit van de gesprekken net niet voldoende, maar wel bemoedigend, mede vanwege de ruim voldoende wijze waarop de gezondheidsadviseurs hun patiënten accepteerden én stimuleerden. De interpretatie van het oordeel van de experts werd bemoeilijkt doordat ze in absolute zin nogal van mening verschilden. Wel was het mogelijk om in relatieve zin onderscheid te maken tussen de manier waarop de verschillende gezondheidsadviseurs de diverse vaardigheden toepasten. Daarmee vormden de video's, samen met de kwaliteitsbeoordelingen, voor de gezondheidsadviseurs zelf een belangrijk leermiddel. Toch vertelden zij ook dat zij hun waardigheden slechts heel geleidelijk verder wisten te ontwikkelen. Geconcludeerd werd dat het voeren van adviesge. sprekken over een gezonde leefwijze een moeilijke taak is die een hoge mate van vakbekwaamheid wereist.

In hoofdstuk 4 komen de ervaringen van de patiënten aan de orde. Om hun mening te inventariseren kreeg elk van hen na het beëindigen van de adviesgesprekken een vragenlijst mee. Gemiddeld genomen waren de pariënten goed te spreken over de kwaliteit van zorg die de gezondheidsadviseurs boden. Ook voelden $z$ ij zich behoorlijk tevreden over de adviesgesprekken en het merendeel gaf aan zich meer verantwoordelijk te zijn gaan voelen voor hun gezondheid. Een groot deel zei positiever te zijn gaan denken over een gezonde leefwijze en vaster van plan te zijn om die ook in praktijk te brengen. Meer dan de helft van 
de patiénten zei zelfs al gezonde veranderingen te hebben doorgevoerd. In het algemeen vonden de patiênten de gezondheidsadviseur een waardevolle aanvulling op het bestaande aanbod van de gezond heidszorg. Toch gaf een aanzienlijk deel ook aan door de gesprekken meer vrijheidsbeperkingen en meer schuldgevoelens te ervaren. Dat laatst gold vooral voor rokers en voor mensen met een fors overgewicht. Hoewel het oordeel van patiënten in het algemeen dus positief was, bleck uit diverse reacties dat er tevens ruimte was voor verbetering van de adviesgesprekken.

190 Hoofdstuk 5 beschrifft een nadere analyse van de gegevens uit hoofdstuk 4 . Daarbij werd gezocht naar een verband tussen de waargenomen gesprekskwaliteit, de mate van tevredenheid, de ervaren morele gevolgen en de gerappor= teerde veranderingen ten aanzien van gezond gedrag. Omdat al deze aspecten op én moment gemeten werden, was het niet mogelijk conclusies te trekken wat betreft 'oorzaak en gevolg', maar wel om de navolgende veronderstellingen te formuleren. De kwaliteit van de gespreksvoering lijkt in hoge mate bij te dragen aan de effectiviteit van de adviesgesprekken. Gezondheidsadviseurs zouden met name een professionele indruk moeten maken en hun inzichtgevende vaardigheden optimaal dienen te benutten. Een grotere motivatie van patiënten voor een gezondere leefwijze treedt echter niet direct op, maar lijkt te verlopen via een gevoel van tevredenheid over de gesprekken en, in mindere mate, via een toegenomen verantwoordelijkheidsgevoel voor de eigen gezondheid. Gezondheidsadviseurs lijken te kunnen voorkomen dat patiënten zich beperkt gaan woelen in hun vrijheid of last krijgen wan een slecht geweten. Daartoe zouden zij een grote mate van respect moeten tonen, een maximale informatieuitwisseling moeten thastreven en, althans in cerste instantie, niet al te grote of moeilijke gedragsveranderingen met patiënten moeten overeenkomen. Dit is des te meer van belang, ondat de (belastende) morele gevolgen waarschijnlijk op generlei wijze bijdragen aan een gezondere leefwijze.

Hoofdstuh 6 schetst de invoering van de hoogrisico-aanpak op de poli cardiologie wan ther szM en doet verslag van de gedragseffecten. Omdar voorafgaand aan de interventie nier duidelijk was wie van de cardiologen an het onderzock zou deelnemen, was her organisatorisch niet mogelijk om hen actief bij de hoogrisico-aanpak te betrekken. Het risicoprofiel werd wel opgesteld, maar diende slechts als basismeting voor het onderzoek. De adviesgesprekken werden, als enige component, wel grotendeels wirgevoerd zoals tevoren de bedoeling was. Om de effecten daarvan op de vetconsumptie, her rookgedrag en de hoeveelheid lichaamsbeweging te meten, vulden de patiënten driemaal een vragenlijst in: bij aanvang van het onderzock, na vier maanden (korte termijn) en na anderhalf jaar (lange termijn). Op de korte termijn nam de vetinname aanzienlijk af, lag het percentage rokers iets lager, en nam de lichamelijke activiteit marginaal toe. Daarmast waren de patiènten sterker van plan om elk van de drie gedragingen in een gezonde richting te veranderen. Op de lange termijn werd echter geen enkel effect meer gevonden. Geconcludeerd werd dat de huidige anpak in principe werkzaam is, maar dat voor een effecrieve preventie van hart- en vatzickten grotere en langduriger gedragsveranderingen nodig zijn. Het zou daartoe aan- 
beveling verdienen om, naast het optimaliseren van de kwaliteit van de adviesgesprekken, de cardioloog actief in te schakelen om zo toch de nuttig geachte wederzijdse bekrachtiging te realiseren. Verder lijkt het zinvol on rokers al tijdens een ziekenhuisopname te benaderen en het bestaande zorgaanbod, zoals hartrevalidatieprogramma's en gezondheidsbevorderende voorzieningen in de regio, beter te benutten. Ten slotte lijkt een langduriger begeleiding geboden.

Hoofdstuk 7 laat zien hoe de invoering van de hoogrisico-aanpak in de huisartsenpraktijken verliep en tot welke gedragseffecten dit leidde. De huisartsen waren meer betrokken bij de hoogrisico-aanpak dan de cardiologen, al vormden beperkingen in tijd en interesse daartoe soms een belemmering. Dat het risicoprofiel niet, zoals de bedoeling was, elektronisch beschikbaar kwam, heeft het optimaliseren van de behandeling van biomedische risicofactoren waarschijnlijk bemoeilijkt. Ook hier werden de adviesgesprekken, als enige component, grotendeels uitgevoerd zoals tevoren werd beoogd. De effecten op gedrag werden met eenzelfde vragenlijst en op identieke tijdstippen gemeten als op de poli cardiologie. Op de korte termijn werd alleen een aanzienlijke daling van de vetconsumptie vastgesteld die op de lange termijn, zij her in minder mate, nog steeds aanwezig was. Bovendien bleken patiënten die bij aanvang van het onderzoek een fors overgewicht hadden, na anderhalf jaar vaker voldoende lichamelijk actief te zijn. Geen effect werd gevonden op roken, noch op het voornemen om zich op een van de drie gebieden gezonder te gaan gedragen. Geconcludeerd werd dat de huidige aanpak voornamelijk een gunstig effect heeft op één van de drie risicogedragingen. Omdat effecten op alle drie de gedragingen werden beoogd en voor het voorkomen van hart- en vaatziekten ook wenselijk zijn, is een brede invoering van de hoogrisico-aanpak in de huidige vorm niet gerechtvaardigd. In plaats daarvan kan de huisarts zelf rokers apart en met een zekere regelmaat benaderen met een al eerder effectief gebleken 'minimale interventiestrategie'. Voor vetconsumptie en lichamelijke activiteit lijkt een gezamenlijke aanpak zinvol, mits de adviesgesprekken worden aangevuld met andere gezondheidsbevorderende strategieën, zoals die warbij patiënten daadwerkelijk kennismaken met gezonde voeding of gezonde lichaamsbeweging. Verder zou de wederzijdse bekrachtiging van huisarts en gezondheidsadviseur nog beter uit de verf kunnen komen, en zouden bestaande gezondheidsbeworderende activiteiten en voorzieningen intensiever kunnen worden gebruikt.

Hoofdstuk 8 doet verslag van de pogingen de adviesgesprekken door de gezondheidsadviseurs voort te zetten na afloop van de oorspronkelijke onderzoeksperiode. Op basis van de positieve uitkomsten van de procesevaluatic stelde een grote Nederlandse zorgverzekeraar geld beschikbaar om gedurende drie jaar te experimenteren met de definitieve invoering van de nieuwe service. Als kader voor de beschrijving van dit proces werd een theorie gebruikt die voorspelt hoe vernieuwingen zich door de samenleving verspreiden. De benodigde informatie werd verkregen uit notulen van vergaderingen, een vragenljjst voor de huisartsen en de cardiologen, en informele gesprekken met de gezondheidsadviseurs en met de projectmanager van Hartslag Limburg. Op de poli cardiologie werd de invoering van de gezondheidsadviseurs een succes, in de 
huisartsenpraktijken niet. Dit kwam onder meer doordat er op de poli cardiologic een infrastructurur was ontstaan die het mogelijk maakte om de adviesgesprekken na afloop van het onderzoek direct voort te zetten, en er één - gemotiveerde-cardioloog verantwoordelijk was voor de verdere invoering. In de huisartsenpraktijken viel de infrastructuur na afloop van het onderzoek deels weg, waardoor de gezondheidsadviseurs hun werkzaamheden tijdelijk en/of gedeeltelijk moesten onderbreken. Verder moest met elke praktijk afzonderlijk onderhandeld worden over een mogelijk voortzetting. Daarnaast zagen de cardiologen de zorgvernieuwing als minder complex en beter inpasbaar in de huidige praktijk dan de huisartsen, en kon de functie van gezondheidsadviseur op de poli cardiologie veel gemakkelijker worden uitgebreid met aanvullende taken dan in de huisartsenpraktijken. Bovendien paste het nieuwe aanbod van adviesgesprekken over een gezonde leefwijze goed in de actuele ontwikkelingen in de poliklinische zorg, terwijl de gezondheidsadviseurs in de huisartsenpraktijken van de aanwezige ontwikkelingen aldaar juist concurrentie ondervonden. Geconcludeerd werd dat dit soort verspreidingsonderzoek na een eerste onderzoeksfase zinwol is om meer zicht te krijgen op factoren die beslissend zijn voor een verdere woorzetting van vernieuwingen in de zorg.

De algehele discussie (boofdstuk 9) vat allereerst de resultaten samen van het totale onderzoek. Vervolgens wordt gezocht naar mogelijke verklaringen voor de verschillen in effect van de hoogrisico-aanpak op de poli cardiologie en in de huisartsenpraktijken. Dat leidde tot de suggestie dat meer aandacht nodig is voor de manier waarop patiënten hun risico van een hartvaatziekte inschatten en hoe zij die inschatting vervolgens gebruiken om al dan niet hun gedrag te veranderen. Eenzelfde suggestie kon worden gedaan wat betreft de weerstand tegen gedragsverandering die een aanzienlijk deel van de patiënten leek te voelen. Het volgende deel van de discussie bespreekt de sterke en zwakke punten van het totale onderzoek. Ondanks de gesignaleerde tekortkomingen per deelonderzoek, vormt de huidige combinatie van een proces- en een effectevaluatie een goed woorbeeld van een theoretisch gefundeerd onderzoek dat diverse onderzoeksmethoden op een zinvolle wijze weet samen te brengen. Het laatste deel van de discussie beschrijft de maatschappelijke implicaties van de onderzoeksbevindingen. Om daadwerkelijk bij te dragen aan het voorkomen van harten vaatzickten zijn gezondheidsbevorderende programma's nodig die intensiever, uirgebreider en van langer duur zijn dan de hoogrisico-aanpak van Hartslag Limburg. Daarvoor zou meer geld ter beschikking moeten komen. Bij de ontwikkeling, uitwoering en evaluatie van dergelijke meeromvattende preventieprogramma's verdienen de mogelijke morele gevolgen ervan echter bij voortduring de aandacht. Alleen dan kan gewaarborgd worden dat die programma's aansluiten bij de behoeften van patiënten en ook in hun ogen acceptabel zijn. 


\section{MIJN DANK}

Allereerst dank voor mijn co-promotor en mijn promotor. Patricia, dit boekje lag er niet zonder jou. Veel dank voor je kritische blik, je niet aflatende vertrouwen, je voortdurende steun en alle, haast onverantwoorde vrijheid die je me gaf. Het was een feest om met je samen te werken. Nanne, jouw toegankelijkheid, scherpe vragen en nuttige suggesties vormden een dankbare bron van inspiratie. Fijn was verder dat toefje Amsterdams erin. Bedankt ook allebei voor de soms verhitte maar altijd vruchtbare discussies.

Dank is er ook voor Henk, mijn bereidwillige vraagbaak van buiten. Je deskundige hulp en je relariverende humor waren een meer dan welkome stimulans. Joho!

Dank is er voorts voor de sponsor van Hartslag Limburg, te weten de Nederlandse Hartstichting, en voor al diegenen met wie ik binnen Hartslag samenwerkte. Van hen noem ik speciaal de vier gezondheidsadviscurs: Kitty, Marita, Pia en Tjerkje. Respect had ik voor jullie doorzettingsvermogen en bijzonder geholpen was ik met jullie bereidheid om jullie ervaringen ruimhartig met mij te delen. Een aparte vermelding is er ook voor Erik. Dat jij er als projectcoördinator in slaagde al het verschillende onderzoeks- en praktijkpluimage in één team te laten samenwerken, mag een war wonder heten. En dan noem ik nog mijn aio-broeder Patrick. Met je gastvrijheid en je blijheid was je van begin tot eind een onmisbare wegwijzer en steunpilaar voor mij in Maastricht.

Dank heb ik verder voor eenieder die mij iets van het vele werk uit handen heeft genomen of die mij met raad en daad heeft gesteund, opgebeurd of afgeleid. Ik kon het allemaal goed gebruiken.

Mam, jii bedankt ondat je er altijd voor me was als ik je nodig had.

En ten slotte dan nog mijn twee nimfen: Gaby en Steven. Laat anderen her maar een ceremoniële functie noemen, voor mij waren jullie goud.

Bedankt! 



\section{CURRICULUM VITAE OF A LATE BLOOMER}

Janneke Harting was born in Born, a small village in the middle of the Dutch province of Limburg, on the 23rd of March 1959. Her being born there could in a way be seen as a coincidence, as her family had its roots elsewhere in the Netherlands. That was why Janneke's brother asked their mom anxiously if his newborn sister was going to speak the local dialect. Was it this concern that made the family decide to move up north and settle on the island of Texel?

As they arrived there, Janneke, by then four years old, immediately tried out the load-bearing capacity of the duckweed that, like an inviting "little green terrace", covered the pond in front of the new house. That was definitely why she was the first of the family to use the new shower. But was it also the reason why her dad immediately taught her to swim? In any case, the incident should at least have warned her about the dangets of becoming a researcher.

At the beginning of her educational career, Janneke showed no indication whatsoever of her later perfectionism. At primary school, for instance, her handwriting only became legible to others when she knew her parents were going to visit the school to have a look at their daughter's progress and might see her notebooks, and at secondary school, Janneke's curiosity mostly focused on out-of-school affairs. Out-of-school life became even more interesting as Janneke reached puberty, a state of life that, as a matter of fact, she never managed to leave completely behind. Nevertheless, she succeeded in getting her secondary school diploma (at the RSG college at Texel, 1977), with moderate grades though with eight out of ten for math. Was it her lively interest in "real life" that made Janneke feel studying at a university would be too academic? She was definitely more interested in learning about living persons, and opted for a physiotherapy program. But was this also the main reason why she moved to Amsterdam?

Anyhow, once she had setrled in that city, finding out about "real life" turned out to be much more attractive, although, to her parents relief, not for too long. After flourishing in the catering business for about two years, serving coffee to thirsty office workers, Janneke's brain desperately needed some new stimulation. Highly motivated this time, she got her physiotherapy degree with credit (Academie voor Gezondheidszorg Kennemerland, 1984). Moreover, she successfully applied for an attractive job at the Red Cross Hospital in Beverwijk (1986). A further cultivation of her growing interest in cardiovascular diseases and a healthy lifestyle (at that time mainly applicable to others) had to wait, however, as after several years she made a surprise move and became an editorial assistant at the Geneesmiddelenbulletin (the Dutch Drug Bulletin) in Utrecht (1993). For sure, this time the switch had not been instigated by any of the dimensions of "real life", however appealing these still were.

After two years, Janneke's intelligence once again urgently needed a new challenge. Was it just by chance that it was at that very time that the part-time Health Education and Promotion program started at Maastricht University in Limburg? Anyhow, after three joyful commuter years, which were fruitful 
in more than one sense of the word, Janneke obtained her Master's degree in Health Sciences with credit (1998). More importantly, after having explored "real life" for all these years, she finally discovered that the real life for her was doing research. And besides, her ten chill-prone fingers had made Janneke keen to live in the warmest part of the Netherlands again. That was a good thing, as her newly acquired $\mathrm{PhD}$ position at Maastricht University, which involved her in the Hartslag Limburg project (1998) and which was supposed to be parttime only, turned out to be at least a full-time job, so commuting was no longer 196 an option.

It was in this PhD project that some of Janneke's lifelines converged, including not just one, but many, many inviting "little green terraces", each turning out to be as impassible as the first. Thanks to her father's swimming lessons and her newly acquired reading glasses, she nevertheless managed to complete her thesis nearly on time. Luck was on her side, as she was straightaway able to continue her research career in a challenging post-doc position (Maastricht University, 2004). But was it purely by accident that the new project's name was "Forever Promising"?

Finally, to reassure her brother, even after living in Limburg for more than five year's, Janneke's pronunciation of Dutch still lacks any southern accent. Not a trace of coincidence this time - the local dialect is just too difficult. 